\title{
Hydraulic Research \\ in the United States
}

1954

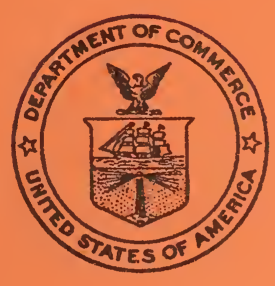

United States Department of Commerce

National Bureau of Standards

Miscellaneous Publication 210 


\section{Capacities of Plumbing Stacks in Buildings}

A study of the maximum load that can be brought from a horizontal branch into a stack down which water is being discharged from fixtures on higher floors. This phase of a projected complete investigation, intended to make drainage design more economical, is concentrated on the drainage stack and the building drain. The report describes tests to determine terminal velocities and terminal lengths in stacks as well as tests on stacks and drains. It analyzes stack conditions in a multistory building and suggests applications of the study's results.

Order NBS Building Materials and Structures Report 132, Capacities of Plumbing Stacks in Buildings, 28 pages. Price: 25 cents.

\section{Self-Siphonage of Fixture Traps}

An explanation of the extent to which trap-seal losses are influenced by such considerations as the diameter of the trap and the depth of trap seal, the diameter and slope of the fixture drain, the type of vent fitting used, and the rate of discharge of the fixture. The report shows the importance of standardizing fixture traps and the hydraulic characteristics of plumbing fixtures, such as lavatories, sinks, and trays; and it makes recommendations for use by code-writing authorities.

Order NBS Building Materials and Structures Report 126, Self-Siphonage of Fixture Traps, 32 pages. Price: 20 cents.

\section{Wet Venting of Plumbing Fixtures}

An account of extensive research and laboratory tests to determine the feasibility of using vented one- and two-story plumbing drainage systems. The conclusions reached regarding satisfactory operation limits for wet-vented fixtures are given in a form suitable for inclusion in plumbing codes. The report describes test procedures and explains results. Diagrams, tables, and graphs are included showing the trap-seal losses that occur under various conditions of wet venting and indicating the maximum permissible unvented lengths of fixture drain.

Order NBS Building Materials and Structures Report 119, Wet Venting of Plumbing Fixtures, 27 pages. Price: 25 cents.

\section{Stack Venting of Plumbing Fixtures}

A report describing tests involving use of pipes, traps, connections, and vents made of transparent plastics which make all flow phenomena visible. Similar tests were made with regular metal fittings to obtain comparative data and to permit correlation of results. The report discusses and interprets results, 


\section{Hydraulic Research in the United States}

1954

Edited by Helen K. Middleton

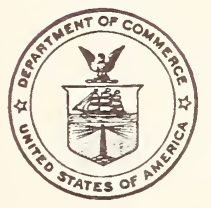

National Bureau of Standards Miscellaneous Publication 210 Issued June 2, 1954 



\section{FOREWORD}

The information contained in this publication was compiled from reports by the various hydraulic and hydrologic laboratories in the United States and Canada. The cooperation of these agencies is greatly appreciated.

Projects are numbered chronologically, and the number once assigned is repeated for identification purposes until a project is completed. Numbers commencing with 1813 refer to projects which are reported for the first time. All projects are in active state, unless otherwise noted under $(f)$.

It is emphasized that the National Bureau of Standards does not have in its files reports or detailed information regarding the research projects reported by other organizations. Such information may be obtained from the correspondent listed under (c) or immediately following the title of the organization reporting the work. It is of course understood that any laboratory submitting reports on its work will be willing to supply information to properly qualified inquirers.

A similar bulletin, "Hydraulic Research", compiled and published by the International Association for Hydraulic Research, contains information on hydraulic research being conducted in foreign countries. This bulletin is edited by Prof. J. Th. Thijsse, Director of the Hydraulic Laboratory at the Technical University of Delft, Netherlands, and Secretary of the International Association for Hydraulic Research. Copies may be obtained from the Secretary at $\$ 6.00$ each (postage included).

A bulletin entitled "Directory of Hydromechanics Research Projects in the United States Related to Naval Architecture and Marine Engineering" is prepared by the Hydrodynamics Committee of the Society of Naval Architects and Marine Engineers. Copies may be obtained by addressing the Secretary of the Society, Captain W. N. Landers, Society of Naval Architects and Marine Engineers, 29 West Thirty-ninth Street, New York 18, N. Y. 
Contents

Page

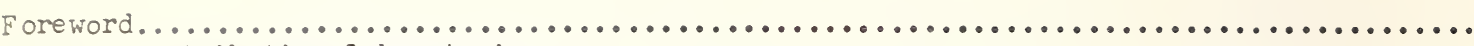

List of contributing laboratories.

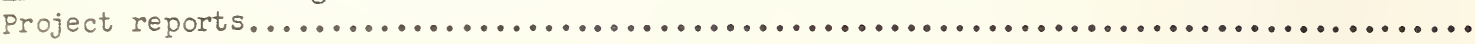

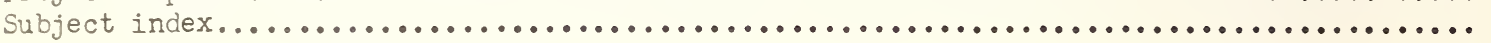

Key to Projects
(a) Number and title of project.
(b) Project conducted for.
(c) Correspondent.
(d) Nature of project.
(e) Description.
(f) Present status.
(g) Results.
(h) Publications. 
ARKANSAS, UNIVERSITY OF

College of Engineering, Fayettville, Ark.

Prof. George Branigan, Dean

BALDIIN-LIMA-HAMILTON CORPORATION, THE

Hydraulic Turbine Laboratory, Philadelphia 42, $\mathrm{Pa}$.

Mr. W. R. MacNamee, Manager, Hydraulic Turbine Department

Mr. C. H. Diehl, Supervisor of Laboratory

BEACH EROSION BOARD (see U.S. Government)

BONNEVILIE HYDRAULIC LABORATORY (see U. S. Government)

BROOKLYN, POLYTECHNIC INSTITUTE OF

99 Livingston Street, Brooklyn 2, N. Y.

Prof. Chilton A. Wright, Professor of Hydraulic and Sanitary Engineering

CALIFORNIA INSTITUTE OF TECHNOLOGY

Hydrodynamics Laboratory, Pasadena 4, Calif.

Dr. Robert T. Knapp, Director

CALIFORNIA, UNIVERSITY OF

College of Agriculture, Davis, Calif.

Prof. F. J. Veihmeyer, Directing Head, Department of Irrigation

CALIFORNIA, UNIVERSITY OF

College of Agriculture, Los Angeles 24, Calif.

Prof. M. R. Huberty, Chairman, Department of Irrigation and Soils

CALIFORNIA, UNIVERSITY OF

College of Engineering, Berkeley 4 , Calif.

Prof. J. W. Johnson, Fluid Mechanic s Laboratory

CALIFORNIA, UNIVERSITY OF

Department of Engineering, Los Angeles 24, Calif.

Prof. L. M. K. Boelter.

CALIFORNIA, UNIVERSITY OF SOUTHERN

Research Foundation for Cross-Connection Control, Los Angeles 7, Calif.

Dr. Robert E. Vivian, Director

CARNEGIE INSTITUTE OF TECHNOLOGY

Department of Civil Engineering, Pittsburgh 13, $\mathrm{Pa}$.

Prof. F. T. Mavis, Head

COLORADO A AND M COLLEGE

Department of Civil Engineering, Fort Collins, Colo.

Prof. Maurice L. Albertson, Head of Fluid Mechanics Research

COLORADO UNIVERSITY

Department of Civil Engineering, Boulder, Colo.

Mr. Narren Raeder, Head

COLUMBIA UNIVERSITY

Department of Civil Engineering, New York 27, New York

Fluid Mechanics Laboratory

CONNECTICUT, UNI VERSITY OF

Hydraulic Research Laboratory, Box U-37, Storrs, Conn.

Prof. Victor Scottron, Associate Professor of Civil Engineering 
CORNELL UNIVERSTTY

School of Civil Engineering, Ithaca, N. Y.

Dr. N. A. Christensen, Director

Prof. Andre L. Jorissen, Head, Department of Hydraulics and Hydraulic Engineering

DAVID TAYIOR MODEL BASIN (see U. S. Government)

GEORGIA INSTITUTE OF TECHNOLOGY

School of Civil Engineering, Atlanta, Ga.

Prof. C. E. Kindsvater

HARVARD UNIVERSTTY

Department of Mathematics, Div. of Applied Science, Cambridge 38, Mass.

IDAHO, UNIVERSITY OF

Engineering Experiment Station, Moscow, Idaho

Dean Allen S. Janssen, Director

ILLINOIS STATE WATERWAYS DIVISION

Departinent of Public Wrorks and Buildings, 201 hest Monroe St., Springfield, Ill. Mr. Thomas B. Casey, Ëngineer

IILINOIS STATE WATER SURVEY DIVISION

Engineering Subdivision, Box 232, Urbana, Ill.

Mr. H. E. Hudson, Jr., Head

Engineering Research Subdivision, Box 117, Peoria, Ill.

Dr. Max Suter, Head

ILIINOIS, UNIVERSITY OF

Department of Theoretical and Applied Mechanics, 214 Talbot Laboratory, Urbana, IIl.

Prof. F. B. Seely, Head

ILLINOIS, UNIVERSITY OF

Hydraulic Engineering Laboratory, Urbana, Ill.

Prof. J. J. Doland, Director of Hydraulic Engineering

IOWA INSTITUTE OF HYDRAULIC RESEARCH

State University of Iowa, Iowa City, Iowa

Dr. Hunter Rouse, Director

IONA, STATE UNIVERSITY OF (see Iowa Institute of Hydraulic Research)

JOHNS HOPKINS UNTVERSTTY, THE

Applied Physics Laboratory, Silver Spring, Md.

Mr. R. E. Gibson, Director

JOHNS HOPKINS UNIVERSTTY, THE

School of Engineering, Baltimore 18, Md.

Dr. John C. Geyer

LEEFEL AND COMPANY, THE JAMES

426 East Street, Springfield, Ohio

Mr. J. Robert Groff, President and General Manager

\section{LEHI HH UNIVERSTTY}

Fritz Engineering Laboratory, Bethlehem, $\mathrm{Pa}$.

Dr. N. J. Eney, Director 
MASSACHUSETTS INSTITUTE OF TECHNOLOGY

Department of Civil and Sanitary Engineering, Cambridge 39, Mass.

Dr. Arthur T. Ippen, Head, Hydrodynamics Laboratory

MASSACHUSETTS INSTITUTE OF TECHNOLOGY

Department of 'Mechanical Engineering, Cambridge 39, Mass.

Prof. C. R. Soderberg, Head

MASSACHUSETTS INST ITUTE OF TECHNOLOGY

Department of Naval Architecture and Marine Engineering, Cambridge 39, Mass.

Prof. F. M. Lewis, Director

MASSACHUSETTS, UNIVERSITY OF

Engineering Research Institute, Amherst, Mass.

Dean George A. Marston, Director

MICHIGAN, UNIVERSITY OF

Experimental Naval Tank, 326 west Engineering Building, Ann Arbor, Mich.

Prof. Louis A. Baier, Director

MICHICAN, UNIVERSTIY OF

Lake Hydraulics Laboratory, 320 west Engineering Building, Ann Arbor, Mich.

Prof. E. F. Brater

MINNESOTA, UNIVERSTTY OF (see St. Anthony Falls Hydraulic Laboratory)

MISSISSIPPI STATE COLLEGE

Engineering and Industrial Research Station, Box 1516, State College, Miss.

Dr. Harold Flinsch, Director

MISSOURI SCHOOL OF MINES AND METALLURGY

Department of Civil Engineering, Rolla, Mo.

Prof. Joe B. Butler, Chairman

NEWPORT NE SS SHIPBUILDING AND DRY DOCK COMPANY

Hydraulic Laboratory, Newport News, Va.

Mr. C. H. Hancock, Director

NEW YORK UNIVERSITY

Department of Chemical Engineering, Bronx 53, N. Y.

Prof. John Happel, Chairman

NEW YORK UNTVERSITY

Fluid Mechanics Laboratory, New York 53, N. Y.

Dr. Glen N. Cox, Director

NORTH CAROLINA, UNI VERSITY OF

North Carolina State College, Dept. of Engineering Research, Raleigh, N. C.

Prof. N. W. Connor, Director

The Technological Institute, Evanston, IIl.

Dr. Paul E. Klopsteg, Director of Research

NOTRE DAME, UNIVERSTTY OF

College of Engineering

Dr. Karl E. Schoenherr, Dean

Prof. Leslie A. Clayton, Hydraulics Laboratory 
PELTON WATER WHEEL COMPANY, THE

2929-19 Street, San Francisco 10, Calif.

Mr. I. M. White, Manager of Engineering

Mr. R. M. Bacchi, Development Engi neer

PENNSYIVANIA, STATE COLIEGE OF

Department of Civil Engineering, State College, Pa.

Dr. B. A. Whisler, Head

PENNSYLVANIA, STATE COLLEGE OF

Ordnance Research Iaboratory, P. O. Box 30, State College, Pa.

Dr. G. G. Quarles, Director

PENNSYLVANIA WATER AND POWER COMPANY

405 Fulton National Bank Building, Lancaster, $\mathrm{Pa}$.

Dr. S. K. Waldorf, Engineer of Research

PURDUE UNIVERSITY

School of Civil Engineering Mechanics, Lafayette, Ind.

Dr. R. B. Wiley, Head

RENSSELAER POLYTECHNIC INSTITUTE

Mechanical Engineering Department, Troy, N. Y.

Prof. Grant K. Palsgrove, Director Russell Sage Laboratory

RESEARCH FOUNDATION FOR CROSS-CONNECTION CONRROI (see University of Southern California)

ROCKY MOUNTAIN HYDRAULIC LABORATORY

Allenspark, Colo.

Prof. C. J. Posey, Director (winter address: State University of Iowa, Iowa City, Iowa)

RUTGERS UNIVERSITY

Department of Botany, New Brunstick, N. J.

Prof. M. F. Buell

ST. ANTHONY FALLS HYDRAULIC IABORATORY

Uni versity of Minnesota, Hennepin Island, Minneapolis 14 , Minn.

Dr. Lorenz G. Straub, Director

SCRIPPS INSTITUTE OF OCEANOGRAPHY

University of California, I.a Jolla, Calif.

S. MORGAN SMTTH COMPANY

Iincoln and Hartley Sts., York, Pennsylvamia

Mr. G. Dugan Johnson, Chief Hydraulic Engineer

Mr. Enmert M. Lowry, Jr., Hydraulic Laboratory Engineer

SOCIETY OF NAVAL ARCHITECTS AND MARINE ENGINEERS

29 West 39th Street, New York 18, N. Y.

Capt. W. N. Landers, Secretary

\section{STANFORD UNIVERSITY}

Department of Civil Engineering, Stanford, Calif.

Prof. John K. Vennard, Director, Hydraulic Laboratory

STEVENS INSTITUTE OF TECHNOLOGY

Experimental Towing Tank, 711 Hudson Street, Hoboken, N. J.

Dr. Kenneth S. M. Davidson, Director

TAYLOR MODEL BASIN (see U. S. Government) 
EENNESSEE, UNI JERSITY OF

Engineering Experiment Station, Knoxville 16, Tenn.

Dr. G. H. Hickox, Assoc. Director

IEXAS A AND M COLLEGE

Civil Engineering Department, College Station, Texas

Dr. S. R. Wright, Head

TEXAS, UNI VERSITY OF

Department of Civil Engineering, Austin 12, Texas

Dr. Wlalter L. Moore, Directing Head

JTAH STATE AGRICULTURAI COLIEGE

Engineering Experiment Station, Logan, Jtah

Dr.J.E. Christiansen, Dean, School of Engineering and Technology

WASHINGTON, STATE COLLEGE OF

Departinent of Civil Engineering and Division of Industrial Research, Pullman, Wash.

Prof. C. I. Barker, Hydraulic Engineer

WASHINGT ON, INIVERSITY OF

Department of Civil Engineering, Seattle 5, Whish.

Prof. R. B. Horn, Acting Director

WATERWAYS EXPERIMENT STATION (see U. S. Government)

NISCCNSIN, UNIVERSITY OF

Hydraulic and Sanitary Laboratory, Madison 6, hisc.

Prof. Arno T. Lenz

WORCESTER POLYTECHNIC INSTITUTE

Alden Hydraulic Laboratory, Worcester 2, Mass.

Prof. L. J. Hooper, Director

U. S. GOVERNMENT AGENCIES

DEPARTMENT OF AGRICULTURE

AGRICULTURAL RESEARCH SERVICE

Soil and water Conservation Research Branch, Beltsville, Md.

Dr. Robert M. Salter, Chief

DEPARTMENT OF AGRICULTURE

FOREST SERVICE

Califormia Forest and Range Experiment Station

P. 0. Box 245, Berkeley 1, Calif.

Mr. Stephen N. Wyckoff, Director

Intermountain Forest and Range Experiment Station

Ogden, Utah

Mr. Reed W. Bailey, Director

Northeastern Forest Experiment Station

Dr. Ralph W. Marquis, Director 
Pacific Northwest Forest and Range Experiment Station

423 U. S. Court House, Portland 5, Ore.

Mr. R. W. Cowlin, Director

Rocky Mountain Forest and Range Experiment Station

Fort Collins, Colo.

Mr. Raymond Price, Director

Southeastern Forest Experiment Station

P. O. Box 2570, Asheville, N. C.

Mr. E. L. Demmon, Director

DEPARTMENT OF THE ARMY

CORPS OF ENGINEERS

Beach Erosion Board

5201 Iittle Falls Road, N.W.

Whington $16, \mathrm{D} . \mathrm{C}$.

Colonel L. H. Hewitt, President

Bonneville Hydraulic Laboratory

628 Pittock Block, Portland, Ore.

The District Engineer

Jacksonville District

P. O. Box 4970

Jacksonville, Florida

The District Engineer

Los Angeles District

P. 0. Box 17277 Foy Station

Los Angeles 17, Calif.

The District Engineer

St. Paul District

1217 U. S. Post Office and Custom House

St. Paul 1, Minnesota

The District Engineer

Waterways Experiment Station

P. 0. Box 631, Vicksburg, Miss.

Director

\section{DEPARTMENT OF COMMERCE}

BUREAU OF PUBLIC ROADS

Hydraulics Branch, Washington 25, D. C.

Mr. Carl F. Izzard, Chief

NATIONAL BUREAU OF STANDARDS

National Hydraulic Laboratory

Washington $25, \mathrm{D}$. C.

WEATHER BUREAU

Hydrologic Services Division

hashington $25, \mathrm{D}$. C.

Mr. William E. Hiatt, Chief 
DEPARTMENT OF THE INTERIOR

GEOLOGICAL SURVEY

Whangton 25, D. C.

Mr. R. W. Davenport, Acting Chief Hydraulic Engineer

BUREAU OF RECLAMATION

Branch of Design and Construction

Denver Federal Center, Denver, Colo.

Mr. L. N. McClellan, Chief Engineer

DEPARTMENT OF THE NAVY

DAVID TAYLOR MODEL BASIN

Washington 7, D. C.

The Commanding officer and Director

NAVAL BOILER AND TURBINE LABORATORY

Philadelphia 12, Pennsylvania

The Commanding Officer and Director

NAVAI ENGINEERING EXPERTMENT STATION

Bureau of Ships, Washington 25, D. C.

The Commanding Officer and Director

NAVAL ORDNANGE TEST STATION

Pasadena Annex, 3202 E. Foothill Blvd.,

Pasadena 8, Calif.

The Commander

OFFICE OF NAVAL RESEARCH Washington $25, \mathrm{D} . \mathrm{C}$.

TENNESSEE VALLEY AUTHORITY

HYDRAULIC DATA BRANCH

Knoxville, Tenn.

Mr. Albert S. Fry, Chief

\section{CANADIAN IABORATORIES}

BRITISH COLUMBIA, UNIVERSITY OF

Hydraulics Laboratory

Prof.H.C. Gunning, Dean, Faculty of Applied Science

MCGILL UNIVERSITY

Department of Civil Engineering, Montreal 2, Que., Canada

Prof. R. E. Jamieson, Chairman, Dept. of Civil Engineering and Applied Mechanics

MONRREAL, ÉCOLE POLYTECHNIQUE DE

Hydraulics Laboratory, 1430 Rue Saint-Denis, Montreal 18, Canada

Prof. Raymond Boucher, Head, Department of Hydraulic Engineering

NATIONAL RESEARCH COUNCIL

Division of Mechanical Engineering, Montreal Road, Ottawa, Canada

Mr. J. H. Parkin, Director 


\section{QUEEN'S UNIVERSITY}

Faculty of Applied Science, Kingston, Ontario, Canada

Prof. D. S. Ellis, Dean, Faculty of Applied Science

TORONTO, UNTVERSITY OF

Prof. E. A. Allcut, Professor of Mechanical Engineering 
UNIVERSITY OF ARKANSAS, College of Engineering.

\section{(1813) UNDULATORY PROPULSION.}

(b) Vibrane Corporation, 30 Rockefeller Plaza, New York, New York.

(c) Prof.J.R. Bissett, Associate Director, Engineering Experiment Station, University of Arkansas, Fayetteville, Arkansas.

(d) Experimental; applied research.

(e) To test at least one propulsive device and one pumping device, to be furnished by sponsor, to determine the absolute and relative efficiency of each. To design and develop new models of both propulsive and pumping device of the "vibrane type", and to test against the inventor's standards and commercial mechanical development work as may be initially agreed upon.

(g) Project in preliminary stage.

THE BAIDWIN-IIMA-HAMIITON CORPORATION, Hydraulic Turbine Laboratory.

Inquiries concerning Projects Nos. 271, 1544, 1545, and 1814 should be addressed to Mr. C. H. Diehl, Hydraulic Turbine Laboratory, Baldwin-Lima-Hamilton Corporation, Philadelphia 42, Pa.

(271) ADJUSTABIE AND FIXED BLADE PROPELLER-TYPE HYDRAULIC TURBINE MODELS.

(b) Laboratory project.

(d) Experimental; applied research for design.

(e) To improve performance of present designs, and to extend the range of application of this type turbine. Propeller runners of various designs in combination with modified turbine settings are being methodically tested in the ll-inch cavitation flume. Efficiency, output, cavitation, runaway speed, hydraulic thrust, and hydraulic blade torque are measured.

(g) Results provide data for improvement of existing design and information for designs which extend the range of application.

(1544) ADJUSTABLE BLADE PROPELLER-TYPE HYDRAULIC TURBINE FOR THE DALLES PROJECT.

(b) Corps of Engineers, Portland, Oregon District.

(d) Experimental; applied research for design.

(e) A completely homologous model was tested to determine its performance over a wide range of operating conditions. Modifications of the design were made and are being tested in order to determine possible improvements of design.

(g) Results of the homologous tests indicate that all operating requirements for the prototype were generously exceeded.

(1545) ADJUSTABLE BLADE AXIAL FLOW PUMP FOR SIPHON SETTING.

(b) Laboratory project.

(d) Experimental; applied research.

(e) Several axial flow adjustable blade pump designs have been tested in several different designs of inflow and discharge chambers to determine the performance under various siphon conditions.

(g) Results of the above tests have indicated that this type of installation could be used advantage ously under siphon conditions. 
(1814) PUMP MODELS.

(b) Laboratory project.

(d) Experimental; applied research.

(e) A test flume is being installed in the Hydraulic Laboratory to test various types of pump models through a wide range of conditions of head and discharge, and the determination of cavitation limitations.

POLYTECHNIC INSTITUTE OF BROOKLYN.

Inquiries concerning Projects Nos. 1546 and 1547 should be addressed to Prof. M. W. Stewart, Polytechnic Institute of Brooklyn, 99 Livingston St., Brooklyn 2, N. Y.

(1546) DESIGN AND CONSTRUCTION OF A FLUID POLARISCOPE.

(b) Laboratory project.

(d) Applied research.

(e) Design and construction of a fluid polariscope, and the qualitative study of various fluid flow phenomena.

(f) Completed.

(h) "Study of fluid flow by means of fluid polariscope." Bachelor's Thesis, A. M. James. (Available on loan.)

(1547) DESIGN AND CONSTRUCTION OF A 6-INCH WATER TUNNEL.

(b) Laboratory project.

(d) Applied research.

(e) Design and construction of a 6-inch water tunnel to be used for various laboratory exercises as well as for fluid flow studies.

(f) Completed.

(h) "Design and construction of b-inch water tunnel." Bachelor's Thesis, S. Moskowitz. (Available on loan.)

\section{CALIFORNIA INSTITUTE OF TECHNOLOGY.}

Inquiries concerning Projects should be addressed to the following, all at Hydrodynamics Laboratory, California Institute of Technology, Pasadena 4 , Calif.

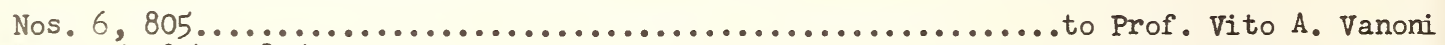

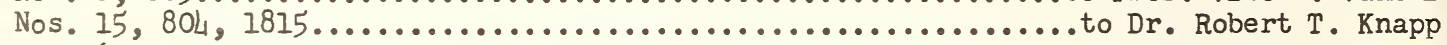

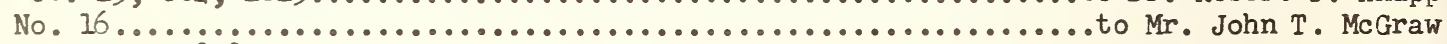

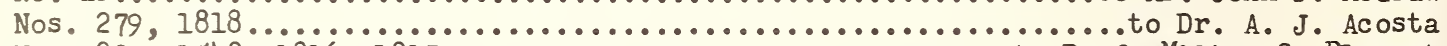

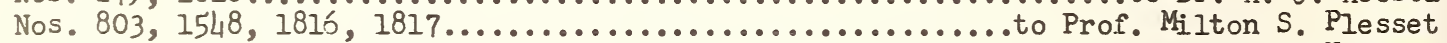

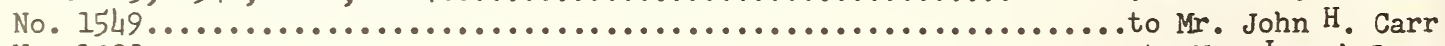

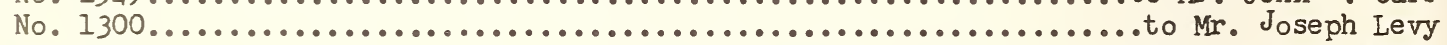

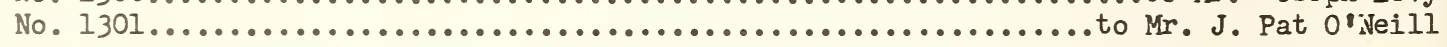

(6) MECHANICS OF SEDIMENT TRANSPORTATION.

(b) Laboratory project.

(d) Experimental and theoretical; basic research.

(e) To investigate the mechanics of transportation of sediment by flowing fluids including studies of the suspended load as well as the bed load phases of the problem.

(h) "A summary of sediment transportation mechanics." Proceedings of the Third Midwestern Conference in Fluid Mechanics, University of Minnesota, 1953. 
(15) STUDIES OF CAVITATION PHENOMENA.

(b) Office of Naval Research, Department of the Navy.

(d) Experimental; basic research.

(e) Details of fixed void type cavitation have been studied experimentally in the water tunnel. Special emphasis has been given to characteristics of the interface, dynamics of entrainment at downstream end of cavity, and behavior of entrained voids.

(h) "Present status of cavitation research." Robert T. Knapp, presented to the Heat Transfer and Fluid Mechanics Institute, Los Angeles, July 2, 1953.

(16) HYDRODYNAMTC FORCES ON SUBMERGED BODIES.

(b) Bureau of Ordnance, Department of the Navy.

(d) Experimental; basic research.

(e) Forces on bodies of different shapes and designs are measured in a water tunnel and the important steady state and damping force coefficients are thus obtained. These data are used to predict full-scale behavior.

(279) FLOW IN ROTATING CHANNELS.

(b) Office of Naval Research, Department of the Navy.

(d) Experimental and the oretical.

(e) Stuties on the internal and over-all flow behavior and hydrodynamic periormance of centrifugal pump impellers, volutes and axial flow pumps.

(h) "Three-dimensi onal interference effects of a finite number of blades in an axial turbomachine." H. N. Tyson, Jr., C.I.T. Hydrodynamics Laboratory Report No. E-19.1, Nov. 1952.

"An experimental study of axial flow pump cavitation." P. Guinard, T. Fuller, and A. J. Acosta, C.I.T. Hydrodynamics Laboratory Report No. E-19.3, Aug. 1953.

(803) DYNAMICS OF CAVITATION AND CAVITATION DAMAGE.

(b) Office of Naval Research, Department of the Navy.

(d) Theoretical and experimental; basic research.

(e) Dynamic behavior of cavitation bubbles; theoretical and experimental studies of cavitation damage.

(h) "Note on the dynamics of small vapor bubbles in liquids." S. A. 2wick, C.I.T. Hydrodynamics Laboratory Report No. 26-7, (in preparation). "Observations on cavitation bubble collapse." A. T. Ellis, C.I.T. Hydrodynamics Laboratory Report No. 21-12, Dec. 1952.

(804) THE EFFECT OF PHYSICAL CHARACTERISTICS OF LIQUID ON THE INCEPTION OF CAVTTATION.

(b) Office of Naval Research, Department of the Navy.

(d) Experimental; basic research.

(e) Scope of investigations has been extended to include the dynamic testing of treated samples under normal flow conditions. To date pressurized samples show significant apparent tensile strengths, but of somewhat lower magnitude than those determined by boiling point measurements. The results of these experiments, like all others in this particular research, appear to have inherent wide scatter. Thus, considerable additional work will be required before generalizations can be made.

(805) DIFFUSION IN TURBULENT FLOW.

(b) U. S. Air Force.

(d) Experimental.

(e) Studies were made of the diffusion of tracer droplets in a flow made turbulent by a grid. A water tunnel with a working section 12 inches by 12 inches has been built for continulng this work.

(g) Investigations are proceeding in the new low-turbulence water tunnel. 
(1300) BASIC WATER ENTRY STUDY.

(b) Office of Naval Research, Department of the Navy.

(d) Experimental; basic research.

(e) An investigation of the phenomena accompanying the entry into water of solids traveling at moderate speeds. The initial study covers the formation of the cavity, and the measurement of pressure within the cavity formed behind spheres entering the water verticall.

(1301) HYDRODYNANISS OF FREE-BOUNDARY FLOWS.

(b) Office of Naval Research and Bureau of Ordnance, Department of the Navy.

(d) Experimental and analytical; basic and applied research.

(e) A free-surface water tunnel is used in experimental and analytical studies of cavity and jet flows in two and three dimensions and planing surfaces, ventilated underwater surfaces and ventilated struts. Pressure surveys and measurements of drag, lift, cross force, and moment coefficients are compared with theory.

(g) Measurements have been made on a variety of bodies having attached open cavities. The "stagnation cup" has been investigated as a calibrating device for tunnels and towing facilities. Successful measurements have been made of force and moment coefficients for a variety of ventilated surfaces.

(h) "Evaluation of the integrals occurring in the cavity theory of Plesset and Shaffer." Byrne Perry, Hydrodynamics Laboratory Report No. 21-11, Dec. 1952.

(1548) SHECIAL PROBIEMS IN HYDRODYNAMICS.

(b) Office of Naval Research, Department of the Navy.

(d) Theoretical and experimental; basic research.

(e) Studies of cavitating and noncavitating flow.

(h) "On the flow of vapor between liquid surfaces." Narren Mathews, C.I.T. Hydrodynamics Laboratory Report No. 21-13, May, 1953.

\section{(1549) WAVE FORCES AND PRESSURES.}

(b) Bureau of Yards and Docks, Department of the Navy.

(d) Experimental and theoretical; applied research.

(e) The total force and pressure distribution due to water waves reflecting from and breakin on rigid bulkheads is to be investigated.

(g) Correlation between theory and experiment has been obtained for cases of waves reflected from plane barriers inclined between the angles of $10^{\circ}$ seaward and $30^{\circ}$ shoreward from the vertical.

(h) "Wave forces on plane barriers." Califormia Institute of Technology, Hydrodynamics Laboratory Report E-11.1, Oct. 1953.

(1815) THE CORRELATION OF THE MECHANICS OF CAVITATION IITH THAT OF PHYSICAL DAMAGE.

(b) Bureau of Ships, Department of the Navy.

(d) Experimental; basic research.

(e) Objective is on the basis of the present knowledge of the mechanics of the cavitation process to endeavor to clarify the mechanics of cavitation damage of solid surfaces. Two approaches are being used: (I) Study of damage on standard metal specimens subjected to cavitation in the water tunnel; (2) study of damage on samples of same material in the standard magnetostriction equipment.

(f) Auxiliary apparatus nearing completion and preliminary runs in process.

(1815) FORCE CHARACTERISTICS OF SUBMERGED HYDROFOIIS UNDER CAVITATING CONDITIONS.

(b) Bureau of Ships, Department of the Navy.

(d) Theoretical and experimental; basic research.

(e) Studies of hydrofoils.

(h) "A theory for hydrofoils of finite span." Y. T. Wh, C.I.T. Hydrodynamics Laboratory Report No. 26-8, May, 1953. 
(b) Office of Naval Research, Department of the Navy.

(d) Experimental and theoretical; basic research.

(e) Studies are being carried out on the effect of model size on incipient cavitation.

(h) "Incipient cavitation scaling experiments for hemispherical and 1.5-caliber ogive-nosed bodies. J. W. Holl and B. R. Parkin, a joint report by the Ordnance Research Laboratory, Pennsylvania State College and the Hydrodynamics Laboratory, California Institute of Technology, May 1953.

"Incipient cavitatjon and boundary layer interaction on a streamlined body." B. R. Parkin and R. W. Kermeen, C.I.T. Hydrodynamics Laboratory Report No. E-35.2, Dec. 1953. "Incipient cavitation and wake flow behind sharp-edged disks." $R$. W. Kermeen and B. R. Parkin, C.I.T. Hydrodynamics Laboratory Report No. E-35.3 (in preparation). "The mechanism of cavitation inception and the related scale effects problem." $R$. " $N$. Kermeen, J. T. McGraw and B. R. Parkin, (in press).

(1818) EXPERIMENTAL AXIAL FLO'N PUMP RESEARCH.

(b) Bureau of Ordnance, Department of the Navy.

(d) Experimental; basic research.

(e) Investigation of incipient cavitation phenomena at rotor blade tips with various tip clearances, tip vortex and secondary flow phenomena and over-all performance.

(h) "The axial flow pump test facility." T. W. Fuller and A. J. Acosta, C.I.T. Hydrodynamics Laboratory Report No. E-12.13.

UNIVERSITY OF CALIFORNIA, College of Agriculture, Department of Irrigation.

(19) THE EFIECT OF THE DEPTH OF WATER TABLE UPON THE ABILITY OF PLANTS TO EXTRACT WATER.

(b) California Agricultural Experiment Station.

(c) Dr. Robert M. Hagen, Department of Irrigation, University of California, Davis, Calif.

(d) Field and laboratory investigation; basic and applied research.

(e) Experiments have been performed to determine the upward rise of water in soils in contact with a free water surface. A study was made of the ability of some of the principal crops grown in the Delta region of California to obtain water supplies from various depths of water in peat soil.

(g) Information concerning the tolerance of different plants to saturated soil conditions will be secured.

(20) MOVEMENT OF WATER THROUGH SOILS.

(b) California Agricultural Experiment Station.

(c) Dr.F.J. Veihmeyer, Department of Irrigation, University of Califomia, Davis, Calif.

(d) Field and laboratory investigations; applied research.

(e) Plant-soil-water relation studies including loss of water by roots to dry soil, rooting habits of plants in relation to irrigation practices, methods for determining when irrigation is necessary (rate of plant growth, color of foliage, etc.) and the determination of water requirements of crops.

(g) The frequency of irrigation and amount of water required for various crops are being determined, taking into account numerous factors, such as soil structure and root systems of plants, which have a bearing on the results obtained.

(h) "Know how to water." R. M. Hagen, U. S. Golf Assoc. Jour. and Turf Management 5:26-30, 1953.

"Guides in cotton irrigation." Marvin Hoover and L. J. Booher, Calif. Agr. Exten. Service unnumbered leaflet, Oct. 1952.

"Production and quality of irrigated pasture mixtures as influenced by clipping frequency." M. L. Peterson and R. M. Hagan, Agron. Jour. 45:283-287, 1953.

"Soil moisture extraction by irrigated pasture mixtures as influenced by clipping frequency." R. M. Hagan and M. L. Peterson, Agron. Jour. 45:288-292, 1953. 
(2I) STUDY OF HYDRAULICS OF SPRINKIING SYSTEMS.

(b) California Agricultural Experiment Station.

(c) Prof. V.H. Scott, Department of Irrigation, University of California, Davis, Calif.

(d) Experimental; operation.

(e) Studies include water distribution and irrigation efficiency in orchards and field crops, characteristics of nozzle shapes and their effect on distribution patterns, cost analysis of sprinkler irrigation operation, and causes of aluminum pipe corrosion.

(g) Information is being secured which may lead to the design of new jets for more uniform distribution patterns. Several year's data will be secured on sprinkler irrigation efficiency of orchards.

(h) Mpressure control on individual sprinklers." C. N. Johnston, Agric. Engin. 34:332-333, 1953.

"Orchard sprinkler irrigation." A. H. Hendrickson and F. J. Veihmeyer, California Agric. $7: 3,12,1953$.

"Should I use sprinklers for irrigation of vegetable crops." P. A. Minges and I. J. Booher, California Agr. Exten. Service unmumbered leaflet, Oct. 1952.

(22) STUDY OF THERMODYNAMICS OF SOIL MOISTURE.

(b) California Agricultural Experiment Station.

(c) Dr. Robert M. Hagan, Department of Irrigation, University of California, Davis, Calif.

(d) Field and laboratory; basic research.

(e) Studies are being made on soil-moisture energy relations and soil temperature in relation to irrigation practices. A study of the ability of the aerial part of the plant to absorb water is being made.

(g) Results indicate the extent of "cold water" damage to rice and possible remedies, and the influence of irrigation water to temperature on plant growth. The conclusion that soil additives such as the numerous polyelectrolytes respecting water storage in soils seems open to question, has not been changed.

(h) "Available moisture capacities of soils as affected by additions of polyelectrolyte soil conditioners." D. B. Peters, R. M. Hagan and G. B. Bodman, Soil Sci. 75:467-471, 1953.

(23) HYDROLOGY OF IRRIGATION SUPPLIES IN CALIFORNIA.

(b) California Agricultural Experiment Station.

(c) Dr.F.J. Veihmeyer, Department of Irrigation, University of California, Davis, Calif.

(d) Experimental; applied research.

(e) Studies are being contimued on the effect of removing brush from range land by burning and other methods. Measurements are being made of rainfall, runoff, erosion and soil moisture on burned and unburned field plots and small watersheds located throughout the State on lands with widely different topography, soil, vegetation and rainfall patterns.

(g) Studies will be contimed pointing to the question of whether the elimination of brush, which usually is made up of species of plants which have no forage or commercial value, will save water and what effect their removal will have upon the amount of erosion which may occur. Results of experiments show that it is possible to clear brush land by burning resulting in the cleared areas growing up to grass, and that burning land does not result in the destruction of the roots of plants.

(h) "Use of water by native vegetation versus grasses and forbs on watersheds." F. J. Veihmeyer, Trans. Amer. Geophys. Uni on 34:201-212, 1953.

(24) MEASUREMENT OF IRRIGATION WATER AND IMPROVEMENT IN FARM IRRIGATION STRUCTURES.

(b) Califormia Agricultural Experiment Station.

(c) Prof. V. H. Scott, Department of Irrigation, University of California, Davis, Calif.

(d) Experimental; design.

(e) Studies of farm irrigation systems for the improvement of design and efficiency of irrigation equipment are being continued. Work on prefabricated asbestos and asphalt lining in small irrigation farm ditches is continuing. Methods of grading land for surface irrigation have been studied in detail. Such factors as land clearing, surveying staking, as well as the various pieces of earth moving equipment have been investigated. 
(g) Preliminary reports on various types of prefabricated linings in small irrigation farm ditches have been prepared and copies circulated to a number of commercial firms supplying materials for test. Information as to the best methods of grading land for surface imrigation is available for farmers and engineers and land leveling contractors.

(h) "Farm irrigation structures -- pipe turnouts." V. H. Scott and I. J. Booher, Calif. Agr. Exten. Service unnumbered leaflet, 1953.

"Grading land for surface irrigation." J. C. Marr. (In press.)

(25) PHYSICAL AND CHEMICAL FACTORS AFFECTING SOIL INFILTRATION RATES.

(b) California Agricultural Experiment Station.

(c) Dr. L. D. Doneen, Department of Irrigation, University of California, Davis, Calif.

(d) Field and laboratory; basic and applied research.

(e) Studies on the permeability of different soils are being contimed. Cultivation in relation to soil structure and soil compaction is being investigated. Research is contiming on factors affecting accumulation of salines in soil from irrigation water, the effect of quality of water on infiltration of water into soils, and treatment of imigation waters to increase water penetration into soils.

(g) As a result of studies on the quality of water for irrigation, a new method of calculating salinity of irrigation water has been devised. Analysis of an irrigation water may show a high concentration of salts, but only a small portion of them may be effective in accumulation of soluble salts in the soil. Under the current system of classification, many waters would be condemned for use in irrigation, but when solubility effects are considered, the se waters might be useful.

(h) "Compaction of irrigated soils by tractors." L. D. Doneen and D. W. Henderson, Agric. Engin. 34:94-5, 1953.

"Soil conditions affecting infiltration of water and root development of crop plants." I. D. Doneen and D. W. Henderson, Amer. Soc. Sugar Beet Tech. Proc. pp 214-223, 1952.

(1819) DRAINAGE IN RELATION TO IRRIGATION.

(b) California Agricultural Experiment Station.

(c) Dr. J.N. Luthin, Division of Irrigation, University of Calif ornia, Davis, Calif.

(d) Field and laboratory; basic and applied research.

(e) To improve drainage design through an increased understanding of the physics of the flow of water through saturated soils and by the development of methods of drainage investigation and design which will have wide application. Field work is in progress in several areas of the State. Observation wells have been located in selected sites, and drainage systems have been designed on indivicual farms to serve as demonstrations.

(g) Many areas of the State are affected by high water table conditions. In some areas salt concentration in the soil has resulted from poor drainage. Both the high water table and accumlated salt have caused a decrease in crop yield. Information concerning water table elevations, soil permeability and effectiveness of existing drains should alleviate the drainage problems in these areas.

(h) "An electrical resistance network for the solution of drainage problems." J. N. Luthin, Soil Sci. 75:259-274, 1953.

"Pressure distribution in layered soils during contimous water flow." $P . R$. Day and J. N. Luthin, Soil Sci. Proc. 17:87-91, 1953.

UNIVERSITY OF CALIFORNIA, College of Agriculture, Department of Irrigation and Soils.

Inquiries concerning Projects 26, 27, 1058, 1302, 1303, and 1820, should be addressed to Prof. M. R. Huberty, Chairman, Department of Irrigation and Soils, University of California, Los Angeles 24, California.

(26) DRAINAGE INVESTIGATIONS IN COACHELIA VALIEY, GALIFORNIA.

(b) Cooperative between the Coachella Valley County Water District, Coachella, Calif.; U. S. Salinity Laboratory, Riverside, California; U. S. Bureau of Reclamation, Boulder City, Nev.; and this laboratory. 
(d) Field investigations; applied research, and design.

(e) To develop and improve techniques for observing shallow ground water movement, for reclamation of saline and alkali soils, and for installation of drainage devices and systems.

(g) Techniques developed have been permitting the anticipation of the need for drainage before soil salinized and crops lost. Progress is being made towards the establishment of more rational design criteria.

(h) "Anticipating drainage and reclamation needs." A.F. Pillsbury, California (A popular surmary in press.) Preparation of a technical paper on the reclamttion experiments is being completed.

\section{(27) HYDROLOGY OF IRRIGATION WATER SUPPLIES IN CALIFORNIA.}

(b) Laboratory project, coordinated with similar work under Dr. F. J. Veihmeyer, Department of Irrigation, Iniversity of California, Davis, California. (Project 23, page 6.)

(d) Field experiments; applied research.

(e) To evaluate effects of watershed burning on munoff and erosion in southern California.

(g) Moderate increases in runoff and erosion indicated following denudation, but apparently not the result of any change in infiltration capacity of the soil.

(h) Results through $1951-52$ partially summarized by A. F. Pillsbury in a discussion of "Some effects of fire and ash on the infiltration capacity of soils." R. H. Burgy and V.H. Scott, Trans. Am. Geophys. Uni on 34:293-295. Apr. 1953.

(1058) SOIL PHYSICAL CONDITIONS IN RELATION TO IRRIGATION.

(b) Coordinated laboratory studies with field observations of water transfer in soils.

(d) Continuing laboratory and field studies; basic and applied research.

(e) Study of the soil properties and management practices which affect the flow of water into and through soils, the storage of water in soils and evaporation from soil.

(h) "Capillary conductivity values from moisture yield and tension measurements on soil columns." S. J. Richards and L. V. Weeks, Soil Science Soc. Am. Proc. 17:206-209.

(1302) OXNARD PLAIN IRRIGATION AND RECLAMATION INVESTIGATIONS.

(b) Laboratory project.

(d) Field investigations; applied research and design.

(e) Investigations of drainage conditions, drainage mechanics, and irrigation efficiency with view towards improving reclamation of this rather saline-high water table area.

(g) Survey of present conditions completed.

(1303) HYDRAULIC CHARACIERT STICS OF IRRIGATION DISTRIBUTION PIPE SYSTEMS.

(b) Laboratory project, cooperative with College of Engineering, University of California, Los Angeles 24 , Calif.

(d) Basic and applied research.

(e) (1) Analyses being made of a model of a semiclosed system. (2) A theory of surge amplification was developed. In a preliminary way, this theory was checked against model perfomnance by a step-by-step analytical solution of the theory. Later, a mathematical solution was accomplished through two stages of surge amplification by use of the mechanical differential analyzer, and the results were compared with model performance. At present, the mechanics of surge initiation is being studied.

(g) Since the last report, principal result has been the essential verification of the theory through more elaborate model instrumentation, and by utilization of the differential analyzer.

(h) "Hydraulic characteristics of pipe systems for irrigation enterprises." A. F. Pillsbury and E. H. Taylor, Agric. Engineering, (in press). "Unsteady flow in opentype pipe irrigation systems." E. H. Taylor, A. F. Pillsbury, T. O. Ellis, and G. A. Bekey, Proc. A.S.C.E., (in press). 
(1820) IMPROVEMENI OF THE PHYSICAL PROPERTIES OF SOILS IN ORNAMENTAL PLANTINGS.

(b) Laboratory project.

(d) Field and laboratory experiments; applied research.

(e) A study of the relationship between soil physical properties and plant growth, and to evaluate means of establishing and maintaining soils highly permeable to air and water.

(g) Experiments to date show that whole mixtures containing $85 \%$ sand withstood heavy compaction while retaining desirable infiltration rates, peat had the most pronounced effect on porosity of any of the admixtures. Of some ten wetting agents, none were effective in increasing infiltration rates into soils.

(h) "Infiltration rates." O.R. Lunt and M. R. Huberty, (in press).

UNIVERSITY OF CALIFORNIA, College of Engineering, Fluid Mechanics Laboratory.

Inquiries concerning Projects Nos. 35, 38, 39, 40, 41, 43, 46, 47, 280, 282, 529, 810, 811, 813, 1059 to 1062, incl., 1304 to 1307, incl., 1550 to 1557, incl., and 1821 to 1831, incl., should be addressed to Prof. J. W. Johnson, Department of Engineering, University of California, Berkeley 4, Calif.

(35) OSCILLATORY WAVES.

(b) Laboratory projects.

(d) Experimental.

(e) To obtain experimental information on the details of oscillatory waves in shallow water. Experiments are being conducted in a wave channel 60 feet long, 3 feet deep, and $I$ foot wide. Change in wave characteristics will be studied when the waves pass over various types of bottom discontimities and through various dampening devices.

(h) "Wave mump on sloping structures." Kenneth N. Grantham, Trans. Amer. Geophysical Union, Vol. 34, No. 5, pp 720-724, 1953.

(38) STRUCTURES EXPOSED TO WAVE ACTION.

(b) Laboratory and field research, Signal Oil and $\mathrm{G}_{a s}$ Co.

(e) To obtain experimental data for the design of offshore drilling structures. Present work involves measurement of forces exerted on both model and field structural elements subjected to wave action. Work is also being done on the pressure distribution around a model cylindrical caisson as a function of wave length depth and angular position. Data to be compared with theory.

(39) PHASE BEHAVIOR OF TWO-PHASE FLUIDS IN POROUS MEDIA.

(b) Laboratory project.

(d) Experimental and theoretical basic research; doctoral and masters theses.

(e) To determine the degree of departure from thermodynamic and phase equilibrium during flow of a multi-component fluid system through porous media under conditions of gas formation. Fluid saturation, pressure, and temperature di stribution determined during steady flow of the ethane-crystal oil system through a linear column of porous media. Experimental results to be compared with theoretical behavior based on assuming instantane ous equilibrium

(f) Suspended.

(g) $P-V-T$ and viscosity data have been determined for the ethane-crystal oil system at $95^{\circ} \mathrm{F}$ and $105^{\circ} \mathrm{F}$ for pressures up to 300 psia. Theoretical calculations for flow assuming equilibrium completed. Preliminary design of flow apparatus completed.

(40) FLOW CHARACTERISTICS OF GAS-SOLIDS MIXTURES.

(b) Laboratory project. Supported in part by Research Corporation.

(d) Experimental; basic and applied research, design. 
(e) The flow characteristics of a gas-solids mixtures ( $\mathrm{Al}_{2} \mathrm{O}_{3}$, SiO $\mathrm{Sitalyst}_{3}$ and air) are investigated in a $17 \mathrm{~mm}$. I. D. glass conduit for various gas llow and solids flow rates. Pressure drops across test sections are accurately measured for a series of air flow rates in which the solids to air ratio is varied from zero to 11.0 pounds of solids per pound of air. The solids are introduced into the flow system through a mixing nozzle fed by a slide valve controlled weighing tank, and have a size distribution varying from particles less than $10 \mathrm{mi}$ crons to particles greater than 220 micross. Investigation on the metering of solids-gas mixtures by nozzle and Venturi-tubes has been carried out and at present studies on heat transfer to flowing gas-solids mixtures are being carried on.

(g) Experimental data has been presented on the metering of gas-solids mixtures. Equipment for the study of the heat transfer characteristics of flowing mixtures has been set up and investigations started.

(h) The Venturi as a Meter for Gas-Solids Mixtures." L. Farbar, Transactions ASME, Vol. 75, No. 5, p. 943, July 1953.

(41) PRESSURE DROP ACCOMPANYING TWD-PHASE, TWD-COMPONENT FLOW IN PIPES.

(b) Laboratory project supported by Research Corporation.

(d) Experimental and theoretical, masters and doctoral theses.

(e) To determine the conditions governing transition under which the gas and/or liquid phases are flowing in viscous and/or turbulent motion or in slug flow for isothermal flow in horizontal and vertical pipes. Mixtures of air and various liquids are made to flow through tubes. Pressure drop and fluid distribution with consideration of flow stability are determined for a range of liquid and gas rates which may be controlled separately.

(g) Work completed on vertical flow for viscous liquid, turbulent gas flow and slug flow.

(h) Report in preparation.

\section{(43) A PITOT TUBE STANDARD FOR FIOW MEASUREMENT.}

(b) Cooperative with Turbine Pump Manufacturers Association.

(d) Experimental; applied research and development.

(e) The project is to design, construct, and calibrate a suitable Pitot tube for use with a standard code (to be developed) for application under a variety of field conditions.

(f) Temporarily suspended.

(g) Library study and correlation of existing information in progress.

(46) THE MEASUREMENI OF TURBULENI VELOCITY COMPONENTS BY THE METHOD OF ELECTROMAGEETIC INDUCTION.

(b) Laboratory project.

(d) Experimental and theoretical investigation; faculty research.

(f) Temporarily suspended.

(g) Velocity fluctuations are measured by determining the potentials induced in water cutting transversely across a steady magnetic field. An electrical probe consisting of two closely spaced fine wires is arranged to traverse the pipe cross section in the fluctuating potential gradient. The electrical impulses of the probe are amplified and measured by means of a thermal milliammeter.

(47) GRAVITY WAVES AND RELATED PHENOMENON.

(b) Office of Naval Research, Department of the Navy.

(d) Theoretical and laboratory investigation; basic research.

(e) To develop methods of forecasting wind waves and swell, surf conditions and beach changes; measurement of wave characteristics; and make laboratory investigations to provide experimental checks and other information. A wave channel, ripple tank, model basin, and other facilities are used in the laboratory investigations. 
(h) "have forces on piles: A diffraction theory." R. C. MacCamy and R. A. Fuchs, IER, University of Califormia, Berkeley, Report No. HE-116-334, Feb. 1952.

"Theory of surface waves produced by underwater explosions." R. A. Fuchs, IER, University of California, Berkeley, Report No. HE-116-335, June, 1952.

"Analysis of subsurface pressure records in constant depths and on sloping beaches." J. R. Morison, IER, University of Califormia, Berkeley, Report No. HE-116-336, May, 1952. "Prediction of linear effects from instrument records of wave motion." R. A. Fuchs, IER, University of California, Berkeley, Report No. HE-116-337, June, 1952.

"Sand transport by littoral currents." J. W. Johnson, IER, University of Califormia, Berkeley, Report No. HE-116-338, June, 1952.

"Telemetering of the Mark IX shore wave recorder output." F. E. Snodgrass, and W. W. Skiff, IER, University of California, Berkeley, Report No. HE-116-340, Aug. 1952.

"A means for remote control of the telemetering transmitter while it is transmitting."

F. E. Snodgrass and E. W. Skiff, IER, University of Califormia, Berkeley, Report No.

HE-116-34I, Aug. 1952 .

"Ocean wave measurements." F. E. Snodgrass, IER, University of Calif., Berkeley, Report No. HE-116-342, Aug. 1952.

"An electronic instrument for statistically analyzing ocean waves." E. W. Lund, IER, University of California, Berkeley, Report No. HE-116-343, Sept. 1952.

"The mechanics of deep-water, shallow-water, and breaking waves." J. R. Morison, and R. C. Crooke, IER, University of California, Berkeley, Report No. HE-116-344, Oct. 1952.

"The force distribution exerted by surface waves on piles." J.R. Morison, IER, University of California, Berkeley, Report HE-116-345, March, 1953.

"Ripple tank studies of the motion of surface gravity water waves." Osvald Sibul, University of California, IER, Berkeley, Report No. HE-116-346, Oct. 1952.

"Forms of equilibrium of coasts with a littoral drift." Per Bmun, IER, University of Califormia, Berkeley, Report No. HE-116-347, Feb. 1953.

"A model study of wave run-up on sloping structures." K. N. Granthem, IER, Unitersity of California, Berkeley, Report No. HE-116-348, Feb. 1953.

"Summary of wave data for San Francisco Bay and vicinity." J. W. Johnson, IER, University of California, Berkeley, Report No. HE-116-349, Feb. 1953.

"List of Reports, 301 to 350 inc." J. W. Johnson, IER, University of California,

Berkeley, Report No. HE-116-350.

"Ocean wave record analysis ordinate distribution and wave heights." R. R. Putz, IER, University of Calfformia, Berkeley, Report No. HE-116-351, May, 1953.

"The analysis of wave records as random processes." R. R. Putz, IER, University of

California, Berkeley, Report No. HE-116-352.

"Guam shore wave recorder installation: II." M. A. Hall and R. L. hiegel, IER, University of California, Berkeley, Report No. HE-116-354, July, 1953.

(280) SEDIMENT TRANSPORT.

(b) Laboratory project, U. S. Corps of Engineers.

(d) Experimental and theoretical.

(e) A study to determine the transport characteristics of the wash-load; the suspended-load theory in accordance with the findings of river measurements, and the effects of heavy sediment concentration near the bed in the transport characteristics and flows.

(g) The transport rate of wash-load was found to follow the bed-load function if the instantaneous bed composition is known. Only the bed composition as determined from the instantaneous condition of the channel has no lasting significance so far as the wash load is concerned.

The conventional suspended-load theory was revised by introducing higher derivative terms of the concentration gradient and the probability distributions of the turbulence characteristics. The improved suspended-load the ory appears to yield results comparable to those given by river measurements.

(h) "Can the rate of wash-load be predicted from the bed-load function?" H. A. Einstein and Ning Chien, AGTS Trans., Dec. 1953.

"Second approximation to the solution of the suspended-load theory." H. A. Einstein and Ning Chien, M.R.D. Sediment Series, Missouri River Division, U. S. Corps of Engineers, Omaha, Nebr. (in press). 
(282) EFFECT OF FLOW RATE ON RELATIVE PERMEABIIITY TO MULTIPHASE FLO'N IN POROUS MEDIA.

(b) Sponsored by American Petroleum Institute.

(c) Experimental; basic research.

(e) To determine whether or not there is a linear relationship between volume flux per unit area and potential gradient for each fluid phase when two immiscible fluids flow simultaneously through a porous material. Iso-octane and a brine of water and sodium iodide are made to flow through porous materials at constant volume rates. Brine saturation is determined by $\mathrm{x}$-ray absorption, and pressure drops in each phase are measured by means of semi-permeable membranes and electronic gages. Capillary pressure differences between phases is controlled by means of semi-permeable membranes.

(f) Completed.

(g) Results have indicated the possibility of rate sensitivity in the wetting phase saturation range exceeding immobile saturation and approximately 45 per cent saturation.

(h) Final project report under preparation. Several papers reporting details are proposed for future publication.

(529) LITTORAL SEDIMENT FLON ON A BEACH.

(b) Beach Erosion Board, Dept. of the Army, Washington, D. C.

(d) Field, laboratory, experimental and theoretical research.

(e) The mechanics of movement of sand in relatively deep water around the end of rocky promontories off the coast of southern California is being intensely investigated. The object of this work is to determine the source of sands on the beaches near Santa Barbara. Previous work had indicated considerable sand moved around various rocky promontories between Santa Barbara and the mouth of the nearest river, the Santa Ynez River, and the present investigation is designed to show how this sand moves.

(810) VERTICAL SHAFT PUMP SUCTION REQUIREMENTS.

(b) Peerless Pump Division of Food Machinery Corporation.

(d) Experimental; applied research.

(e) An experimental investigation of vortex formation and air entrainment in the suction sumps of typical vertical shaft pump suction sump arrangements. Model and prototype comparisons to determine the feasibility of model tests. Studies included sump geometries for minimum submergence with no air entrainnent and with negligible influence on pump performance. Special equipment was installed in the discharge lines from the pumps in order to measure the quantity of air being pumped in terms of the quantity of water. Visual observations were made regarding vortex formation and size under different conditions of geometry and submergence. Pump performance was determined as a function of sump geometry.

(f) Suspended.

(g) Model and prototype submergence and air entrainment results agree qualitatively. Optimum sump geometry for minimum submergence has been determined for rectangular plan form, end inflow sumps. Further work to be done to extend the range of investigated conditions.

(h) "Studies of submergence requirements of high specific speed pumps." H. W. Iversen. Trans. ASME, Vol. 75, No. 4, pp 635-642, May 1953.

(811) STUDY OF DETACHED SHOCK WAVES.

(f) Completed.

(h) "Developments in gas dynamics through the hydraulic analogy." E. V. Laitone, Riabouchinsky Anniversary Volume, Aerodynamic Institute of Koutchino, France, 1954 (to be published).

(813) FLUID RESISTANCE IN ACCELERATED MOTION.

(b) Laboratory project.

(d) Experimental; for graduate thesis.

(e) The fluid resistance of bodies subject to accelerated motion is being studied. Data have been obtained for flat circular disks moving through water with the plane of the disk perpendicular to the direction of motion. A drag coefficient has been developed in terms of a correlative modulus that includes the acceleration of the system. 
(1059) HEAT TRANSFER AND PRESSURE DROP IN COOLING TOWERS.

(b) Amer. Soc. of Heating and Ventilating Engineers; laboratory project.

(d) Experimental and analytical.

(e) To determine the heat transfer from water in contact with air in a mechanical draft, packed cooling tower as a function of water rate, air rate, water temperature and packing geometry. To determine the pressure drop as a function of the above-mentioned variables.

(g) Several results have been obtained and reported.

(1060) MASS TRANSFER TO RISING BUBBLES AND ON BUBBLE PLATES.

(b) Laboratory project.

(d) Experimental and analytical.

(e) A study of diffusion to bubbles and mass of bubbles.

(g) Some equipment has been completed; experimental research in progress on the mass transfer to single bubbles and to masses of bubbles on a $13^{\prime \prime}$ sieve plate.

(h) "Mass transfer in a rising bubble." G. Humphrey, Master of Science Thesis, June 1953.

(1304) VELOCITY DISTRIBUTION IN OPEN CHANNEL BENDS.

(b) Laboratory project.

(d) Theoretical and experimental.

(e) To describe and predict the cross-distribution of velocities in open channel bends.

(f) Completed.

(g) Values of the radial velocity gradient parameter $r / v d v / d r$, greater than 4 have been measured in a model channel bend. This is shown to require the existence of a bottom boundary layer associated with the cross components of the helical flow.

(1305) OPEN CHANNEL FLOW OF WATER-AIR MIXTURES.

(b) International Engineering Company.

(d) Experimental and theoretical.

(e) To predict the bulking of water by air in the discharge channels of impulse turbines under load rejection.

(f) Completed.

(h) "Open channel flow of water-air mixtures." H. A. Einstein and O. Sibul, The 1953 Heat Transfer and Fluid Mechanics Institute, Stanford University Press.

(1306) PARTICLE SEGREGATION IN AN AGGRADING STREAM.

(b) Corps of Engineers, Department of the Army.

(d) Experimental.

(f) Completed.

(g) It was found that equilibrium equations for sediment transport hold also for aggrading streams if the bed is defined by the composition of its surface layer. These relationships can be used for the individual grain sizes of mixtures with grains between 1.0 and $0.01 \mathrm{~mm}$ diameter over the entire range of sizes.

The bed material segregation was found to have a strong effect on the transport rate of various sediment sizes, especially on that of the fine particles.

(h) "Water jet pump for sediment circulation." Ning Chien, M.R.D. Sediment Series No. I, Missouri River Division, Corps of Engineers, Omaha, Nebr., 1952. "Transport of sediment mixtures with large ranges of grain sizes." H. A. Einstein and Ning Chien, M.R.D. Sediment Series No. 2 Missouri River Division, Corps of Engineers, Omaha, Nebr., 1953. 
(1307) DETERMINATION OF PRESSURE FLUCTUATIONS IN TURBULENCE IN LIQUID FLOW.

(b) Office of Naval Research, Department of the Navy.

(d) Experimental.

(e) Development of instruments and methods to measure pressure fluctuations in the free stream and at the flow boundaries.

(g) A Rutishauser pressure gage is tested for its applicability to the problem. The frequency response is measured and calculated for various measuring arrangements.

(1550) PRESSURE DROP ACROSS TAYLOR VORTICES.

(b) Laboratory project.

(d) Applied research.

(e) Measurements are being made of pressure drop across a one-pair system of Taylor vortices stabilized between two concentric rotating cylinders under conditions of super-imposed axial flow. Possible application to oil seal designs for roatating shafts.

(f) Discontinued.

(g) Results are not yet conclusive. So far no pressure drops have been observed which are sufficiently large to be of practical significance in bearing design.

(1551) STUDY OF VERTICAI GAS-LIQUID FLOW IN PIPES.

(b) Laboratory project.

(c) Experimental and theoretical; basic research.

(d) Collection of data and photographs of gas-liquid flow in glass tubes less than one inch diameter. Analytical work to help explain flow transitions.

(g) Apparatus designed.

(1552) EHFECT OF WAVE LENGTH ON PIPE FRICTION IN TRANSITION REGION FOR WAVED GLASS TUBES.

(b) Laboratory project.

(d) Experimental; basic research.

(e) Collection of one component pipe friction data on waved glass tubes to study effect of wavelength and amplitude on transition. Also to show rigid waved wall does not give exceptionally high friction factors.

(g) Early transition shown and correlated; little increase of friction.

(1553) HYDROFOIL INVESTIGATION.

(b) Laboratory project.

(d) Experimental and theoretical; applied research for a $\mathrm{Ph}$.D. dissertation.

(e) Hydrofoil theory in its present state does not accurately predict the effects of the free surface on a hydrofoil. The purpose of this thesis is to explain this discrepancy by exposing a very important physical restriction which has been overlooked in the mathematical theories of hydrofoils.

(f) Completed.

(g) On the upper surface of a hydrof oil moving with subcritical velocity (U less than gD) close to a free surface, pressure coefficients, $C_{p}=P-p / I / 2 U^{2}$, are equal to or less than the submergence number, gH/U2.

A correlation of hydrofoil test data gives some indication that a modified limiting pressure condition, $\mathrm{Cp}=\mathrm{A}+\mathrm{gH} / \mathrm{U}^{2}$, applies to hydrofolls operating at critical and supercritical velocities. The parameter A depends on the angle of attack and the profile shape of the hydrofoil.

(h) "Pressure limitation on the upper surface of a hydrofoil." John Ausman, a dissertation submitted in partial satisfaction of the requirements for the degree of Doctor of Philosophy in Mechanical Engineering in the Graduate Division of the University of California, Berkeley, Calif ornia, Aug. 1953. 
1554) SEA WATER RESEARCH.

(b) State of California.

(d) Experimental; design.

(e) Experimental investigation of three methods of distillation, one of which is that of solar distillation involving certain hydraulic problems. A second method being investigated is that of high vacuum distillation in which certain flow problems are important. The solar still consists of five units, each being $4^{3}$ wide $\times 50$ long. A unit consists of a shallow tray in which sea water stands to a depth varying from I/4" to I". The top is covered with a tent-shaped glass canopy which completely covers the tray. Solar energy coming through the glass heats the water and causes evaporation. Free convection of the water vapor thus formed causes condensation on the inside of the glass canopy. Water condensed is collected in troughs at the bottom of the sloping sides of the glass and flows by gravity toward one end of the unit. The five units differ from each other in constructional details and in bottom insulation. Performance of these units depends upon the circulation of air over the units as well as upon the intensity of solar radiation. Weather data related to air conditions and movements is being collected and performance of the units measured continuously.

(g) Preliminary results are contained in progress report dated Sept. 15, 1953. The low Temperature Difference system is described in the article, "Sea water as a source of fresh water." Everett D. Howe, Jour. Amer. Water Works Assn., Aug. 1952. Progress to date has been concerned chiefly with the assembly of apparatus which must contain a vacuum of approximately 29 " of mercury.

(1555) FORMATION OF A VAPOR PHASE FROM SUPERSATURATED LIQUIDS IN POROUS MEDIA.

(b) Laboratory project.

(d) Experimental; masters thesis.

(e) This is an attempt to see if a distributed gas phase may be evolved from a supersaturated liquid in a sample of porous sandstone by agitation with ultra-sonic irradiation. Present methods for determining capillary pressure-fluid saturation relations for porous materials required the introduction of a non-wetting fluid phase across the extemal surface of the material thus requiring excessively long times to establish each equilibrium state. The method under study, if proved feasible, would permit the establishment of true equilibrium states very rapidly.

(f) Suspended.

(1556) TRANSIENT BEHAVIOR OF FLUID SATURATION IN POROUS MEDIA DUE TO GRAVITY AND CAPILIARY FORCE FIELDS.

(b) Laboratory project.

(d) Experimental and theoretical; doctoral the sis.

(e) To develop fundamental information which may be used to formulate methods for analyzing petroleum reservoir behavior under gravity drainage and capillary retention. A theoretical solution has been obtained which predicts the change in liquid saturation as a function of time and space in a linear column of sand. If the solution is verified by experiment, it is then proposed to develop the necessary modifications for more complex systems.

(f) Completed.

(g) Darcy's law for flow under gravity and capillary pressure, combined with continuity, resulted in complex non-linear equations. A numerical method, employing punched cards, was devised to obtain a solution which described the saturation distribution history for a vertical sand column draining from an initially saturated condition. Reasonably good agreement between theory and experiment was obtained.

(h) "Gravity drainage of liquid from porous media." H. Rahme, Ph.D. Thesis, University of Calif ormia, Library, 1953. 
(1557) THERMAI CONDUCTIVITY OF POROUS MEDIA AS A FUNCTION OF FLUID SATURATION.

(b) Laboratory project.

(d) Experimental and theoretical; doctoral thesis.

(e) To obtain experimental confirmation of a theory of heat conduction in porous material which relates to the structure porosity of the material and the relative amounts of two different fluids contained in the pores. More complete information may show that parameters determined by heat flow may have possible application to interpretation of bore-hole measurements and certain other applications. Thermal conductivities to be correlated with electrical conductivities.

(g) Experimental work in progress.

(1821) TRANSIENT THRUST BEARING LOADS IN VERTICAL SHAFT PUMPS.

(b) Laboratory project.

(d) Experimental and developmental.

(e) An investigation to develop a thmist cell and to measure thrust time history of thrust bearing loading of vertical shaft pumps particularly during starting and stopping.

(f) Temporarily suspended.

(g) A thrust cell was developed and thrust time records obtained in a short column laboratory vertical turbine pump and on a vertical turbine pump in settings of 100 feet, 50 feet and close coupled. Transient thrust records within an accuracy of 100 pounds were obtained on two two-stage vertical turbine pumps with rated specific speeds of 2700 . Present results are limited to the systems investigated. Generalizations are expected from further investigation.

(h) Measurements of transient thrust loads in vertical turbine pumps." C. H. Ahrs, M. E. Thesis, 1953.

(1822) SHIP MOTION IN NON-UNIFORM AND SHORT-CRESTED WAVE SYSTEMS.

(b) David Taylor Model Basin, Department of the Navy.

(d) Theoretical and experimental.

(e) To make theoretical studies of ship motion in wave systems and to compare the results with experimental data.

(h) "A linear theory of ship motion in irregular waves." R. A. Fuchs and R. C. MacCamy, University of California, IER, Berkeley, Series 61, Issue 2, July, 1953.

"Laboratory studies of the motion of freely floating bodies in non-uniform and uniform long-crested waves." 0. Dibul, University of California, IER, Berkeley, Series 6I, Issue 1, July, 1953.

"Approximate solution to the problem of a freely floating cylinder in surface waves." R. C. MacCamy, University of California, IER, Series 61, Issue 3, oct. 1953.

(1823) THE MECHANICS OF BOTTOM SEDIMENI MOVEMENT WITH OSCIILATORY WAVES.

(b) Beach Erosion Board, Department of the Army.

(c) Experimental.

(d) To obtain experimental information on the criterion for initial and general movement of bottom sediment by wave action. Prototype conditions of the relative motion of water and bed were simulated by use of an oscillating plate in still water.

(h) "Stability of oscillatory laminar flow along a wall." Huon Li, IER, University of California, Series 72, Issue No. I, July, 1953.

"Sand movement mechanics in deep water." Madhav Manohar, IER, University of California, Series 72, Issue No. 2, Sept. 1953. 
(1824) BEHAVIOR OF AIR ABOVE MECHANICAL OCEAN WAVE MODEL.

(b) Laboratory project.

(d) Experimental; basic research.

(e) Measurement of velocity distributions in air above a mechanical model of long-and-shortcrested ocean waves as a function of wind velocity, wave height and wavelength. Drag forces as a function of distance from wave plane to a rigid ceiling determination.

(g) Prelimi nary model tested - being reinstalled.

(1825) WIND WAVES IN SHALLOW WATER.

(b) Beach Erosion Board, Department of the Army.

(d) Experimental.

(e) To obtain experimental information on the factors of wind velocity, wind duration, water depth, and bottom roughness as related to wave generation and wind tide produced in shallow water at limited extent. A glass-wall channel 70 feet long, 15 inches deep, and 12 inches wide has been constructed for this study.

(1826) INVESTIGATION OF UNSTEADY FLOW IN POROUS MEDIA BY MEANS OF A HELE-SHAW VISCOUS FLUID MODEL.

(b) Laboratory project.

(d) Experimental; basic research for doctoral thesis.

(e) A Hele-Shaw apparatus, consisting essentially of an oil flowing through two closelyspaced glass plates, was constructed as a model analogy of flow in porous media. Steady flow measurements were used to calibrate the model. Unsteady flows, including sudden releases of oil into and out of the channel and damping of solitary sine waves, were studied by means of motion pictures.

(f) Suspended.

(g) Sudden release flows were found to agree with earlier numerical solutions of unidirectional gas flow in porous media. The damping rate of sine waves was independent of both wave amplitude and period; whereas the damping distance was a function of the period but not of the amplitude.

(h) "Investigation of unsteady flow in porous media by means of a Hele-Shaw viscous fluid model." D. K. Todd, Doctoral Thesis, University of Califormia, Berkeley, Sept. 1953.

(1827) STUDY OF SHOCK REFLECTION AND CHANNEL BLOCKAGE BY THE HYDRAULIC ANALOGY.

(b) Laboratory study.

(d) Experimental; basic research.

(e) To study the behavior of shock reflection, channel blockage and wind-tunnel choking by the free-surface wave analogy. Cylinders and wedges are towed through still water in various channel widths.

(1828) BED-LOAD MEASUREMENT IN NATURAL STREAMS.

(b) Laboratory project.

(d) Field measurements and laboratory analyses, C. E. Thesis.

(e) Measurement of bed-load transport in Bear River, Utah, and comparison of the results with bed-load function.

(f) Completed.

(g) The measured sediment transport rates for the grain sizes smaller than $0.2 \mathrm{~mm}$ follow the generalized bed-load function fairly well. For the grain sizes larger than $0.2 \mathrm{~mm}$, the theoretical transport rates are larger than indicated by the measurements.

(h) "Sediment movement in Bear River, Utah." Calvin G. Clyde, C. E. Thesis, 1953.

(1829) STUDY OF INCLINED GAS-LIQUID FLOW IN TUBES.

(b) Laboratory project.

(d) Experimental and theoretical; basic research.

(e) Collection and correlation of data on several diameters of tubing at inclinations from horizontal to vertical.

(g) First tube of 1 inch diameter for air-water system being installed. 
(1830) MEASUREMENI OF THE DISTRIBUTION OF A GAS AND TWO LIQUIDS IN A POROUS MEDIUM BY X-RAY TECHNIQUES.

(b) Laboratory project.

(d) Experimental; applied research.

(e) Development of a calibration and measurement method for the distribution of three or more materials in a laboratory sample of sandstone.

(g) Apparatus tested.

(1831) SAIT WATER INTRUSION PROJECT.

(b) California State hater Resources Board.

(d) Experimental; applied research.

(e) Development of basic information on sea water intrusion methods for its control.

(f) Suspended.

(g) To prevent sea water intrusion the fresh water table must be held above sea level and some seaward leakage of fresh water will take place. Coastal injection wells cannot prevent intrusion unless they completely make up the local overdraft.

(h) "Basic parameters of salt water intrusion and the hydraulics of injection wells." Submitted to State Board of water Resources, Sacramento, California.

UNIVERSITY OF CALIFORNIA, College of Engineering.

(1832) PREDICTION OF MEAN DROP SIZE IN A SPRAY.

(b) Laboratory project.

(c) Prof. E. H. Taylor, Department of Engineering, Jniversity of California, Los Angeles 24, California.

(d) Basic and applied research for Ph.D. thesis by D. B. Harmon.

(f) Completed.

(g) A semi-empirical expression has been developed which fairly well coordinates the data of several experimenters for the prediction of drop size at high Reynolds mumbers. A single expression has been found which includes the effects of velocity, density of air and liquid, viscosity, surface tension and nozzle diameter.

UNIVERSITY OF CALIFORNIA, Scripps Institution of Oceanography •

See Scripps Institution of Oceanography, page 81.

UNIVERSITY OF SOUTHERN CALIFORNIA, Research Foundation for Cross-Connection Control.

(49) RESEARCH FOUNDATION FOR CROSS-CONNECTION CONTROL.

(b) Laboratory project.

(c) Dr. K. C. Reynolds, Supervisor, Research Foundation for Cross-Connection Control, Uni versity of Southern California, Los Angeles 7, California.

(d) Experimental research and field investigations; basic research.

(f) Laboratory being used intermittently for tests on backflow prevention devices and on water valves. 
CARNEGIE INSTITUTE OF TECHNOLOGY, Department of Civil Engineering.

Inquiries concerning Projects Nos. 1558 and 1833 to 1835, inclusive, addressed to Prof. F. T. Mavis, Carnegie Institute of Technology, Pittsburgh 13, Pennsylvania.

(1558) CONVERGING AND DIVERGING STREAMS.

(b) Laboratory project.

(d) Theoretical and experimental; for master's degree.

(e) For converging streams, the depth after the junction is a function of the common depth before the junction and the ratio of the flows in each branch.

(g) Depths after a junction are smaller than the common depth before the junction; it is possible for the downstream depth to drop below the critical depth.

(1833) ROUNDED ENTRANCES FOR CONDUITS.

(b) Laboratory project.

(d) Theoretical and experimental; for master's degree.

(e) Head-discharge curves were obtained for flow from a free surface into a short circular culvert. Entrances were square and rounded, and the outfall was free.

(f) Completed.

(h) "The effect of rounded entrances on a short circular conduit." Robert Iipp, M. S. Thesis, Carnegie Institute of Technology, 1953.

(1834) AIR-WATER FLOW.

(b) Laboratory project; J. Waldo Smith Fellowship of the American Society of Civil Engineers.

(d) Theoretical and experimental; for master's degree.

(e) An investigation to determine the amount of air that can be carried by flowing water. Experiments are conducted with free water jets and with air-water mixtures flowing in pipes at different slopes.

(1835) MORNING-GLORY SPILLIAYS.

(b) Laboratory project.

(d) Theoretical and experimental; for undergraduate thesis.

(e) The design of a morning-glory spillway without negative pressures and other undesirable hydraulic characteristics is being studied.

(g) Pressures are measured on models shaped by conventional design methods. Depths, and velocities in the nappe are also measured.

COLORADO A AND M COLIEGE, Department of Civil Engineering.

Inquiries concerning Projects Nos. 52, 822, 823, 828, 1073, 1075, 1313, 1314, 1565 to 1568, incl., 1570, and 1836 to 1838, inclusive, should be addressed to Prof. Maurice I. Albertson, Department of Civil Engineering, Colorado A and M College, Fort Collins, Colorado.

(52) HYDRAULIC SAND SEPARATOR.

(b) Laboratory project.

(d) Experimental; applied research.

(e) To obtain data for design of hydraulic models, and to supply means of separating sand and gravel where a narrow size range is desired.

(g) An apparatus designed and built classifies sand according to fall velocity by a contimuous flotation process. The process is purely dynamic in that sand is introduced directly into the flow. A check for duplication of results indicates that auplications within plus or minus one percent are obtained. Construction of a pilot apparatus is being completed to perform sand separation on a continuous basis of operation. Preliminary tests indicate satisfactory results. 


\section{(53) SAND TRAPS AND SLUICEWAYS.}

(b) Agricultural Research Service, Colorado Agricultural Experiment Station.

(c) Mr. R. I. Parshall, Agricultural Research Service, Colorado A and M College, Fort Collins, Colo.

(d) Experimental; applied research.

(e) To develop design data for sand tráps using vortex tubes, riffles, and deflectors alone, or in combination, and to perfect the design for sluiceways having a relatively flat grade which will effectively transport the bed load material from sand traps to a point of disposal. A vortex tube sand trap with outlet in the center of the canal has been designed and is being tested in the laboratory.

(g) Investigations, laboratory and field, of various designs of sand traps show that the vortex tube operated under favorable conditions has been successful. Field installations of large riffle-deflector, vortex-tube sand traps, have been efficient in removing the bed load. Based upon previous model studies and field experiences, a riffle-deflector, vortex-tube sand trap has been designed for the Kern County Land Company canal carrying 700 cfs. Final designs have been prepared for riffle-deflector, vortex-tube sand traps for three canals in Colombia and one in Peru. A vortex-tube sand trap of the new design is being designed for a canal in Colorado.

\section{(55) SNOW COURSE MEASUREMENIS AND FORECAST ANALYSIS.}

(b) Agricultural Research Service, Colorado Agricultural Experiment Station, Buraau of Reclamation, State Engineer of New Mexico, and State Engineer of Wyoming.

(c) Mr. H. J. Stockwell, Agricultural Research Service, Colorado A and M College, Fort Collins, Colorado.

(d) Field investigations; applied research.

(e) Systematic measurements of depths and water content of snow at high elevations in Colorado mountain areas for the purpose of forecasting the runoff of the principal rivers of the state in the interest of irrigation, power, domestic supplies, and other uses. The use of electrical resistance soil moisture units is being tested to determine a factor of soil moisture deficiency for water supply forecast purposes.

(g) Snow measurement data are correlated with runoff. Once the relationship is established, the snow measurement data are used to predict the runoff for the coming season.

(h) For 1953, Colorado Agricultural Experiment Station Ceneral Series Papers Nos. 532, 533, $534,536,537,538,540,541,542,545,546,547$. These are the monthly snow Survey reports for the Rio Grande, Colorado, and Platte-Arkansas Drainage Basin.

(287) PERFORMANCE OF WELI SCREENS.

(b) Colorado Agricultural Experiment Station, Agricultural Research Service, and various well screen manufacturers.

(c) Mr. C. H. Rohwer, Agricultural Research Service, Colorado A and M College, Fort Collins, Colo.

(d) Experimental; applied research.

(e) (1) Measurement of loss of head in different types of well screens for discharges suitable for each screen. (2) Determination of the size of opening in well screens, diameter of screen, thickness of gravel envelope, and size and gradation of sand or gravel for most effective control of flow of sands of different finenesses into the well with least loss of head. (3) Determination of the size of openings in well screens and diameter of screen for most efficient operation in natural sands and gravels of a given classification. An additional study is underway on the loss of head at interface of gravels of different sizes.

(g) A theoretical analysis based on the momentum, energy and continuity equations has been developed which checked very closely with tests made on idealized well screens. By this means a system has been established for determining a single coefficient which completely describes the hydraulic characteristics of any commercially-mamufactured well screen.

(h) "Hydraulic head loss at interface between porous media of different sizes." Frank N. Leatherwocd, M. S. Thesis, Colorado A and M College, 1952. 
20) THE STUDY OF SEEPAGE LOSSES FROM IRRIGATION CHANNELS.

(b) Agricultural Research Service, Bureau of Reclamation, Colorado Agricultural Experiment Station.

(c) Mr. C. H. Rohwer, Agricultural Rs search Service, Colorado A and M College, Fort Collins, Colo.

(d) Experimental and field investigation; applied research.

(e) To study the factors influencing seepage from irrigation channels and to perfect methods for making pre-investigations of seepage for the purpose of determining the seepage from existing canals, and predicting the seepage from proposed canals. Methods of measuring seepage will be evaluated to determine the limitations and advantages of each. The effect of depth to ground water on the seepage rate is also being investigated.

(h) "Progress report on the study of seepage losses from irrigation channels." A. R. Robinson and Carl Rohwer, April, 1953.

321) GROUND WATER FLUCTUATIONS AND THEIR RELATION TO PUMPING.

(b) Laboratory project.

(c) Mr. W. E. Code, Colorado A and M College, Fort Collins, Colorado.

(d) Field investigation; applied research.

(e) Measurements to the water table are made semi-annually in about 200 observation wells. These wells are located in the South Platie and Arkansas Valleys. As a measure of amount of pumping being done, data on electrical energy used for this purpose are also gathered.

(g) There is a loose relationship between water table fluctuation and power used. The relationship is masked by river water-supplies in districts under canals.

(h) Reports in Geological Survey Water Supply Papers.

322) DIFFUSION OF HEAT, VAPOR, AND MOMENTUR.

(b) Cooperative with office of Naval Research, Department of the Navy.

(d) Experimental; basic research.

(e) A controlled study in a wind tunnel of the fundamental principles describing the process of diffusion of vapor, heat and momentum from various surfaces. Eventually it is intended to use the fundamental information to aid in determining evaporation from free surfaces, land areas with various soil and crop covers, and plant surfaces, and heat and moisture losses from animals.

(g) A report is in preparation describins experimental results of evaporation measurements from a plane smooth boundary. One result of the data analysis is an apparent elimination of the effects of dry approach lengths upon the evaporation coefficient when the mean velocity in the Reynolds number is replaced by a shear velocity for the downstream end of the evaporation surface.

823) SCOUR IN A STILIING BASIN.

(b) Laboratory project.

(d) Experimental; for design and master's thesis.

(e) A laboratory study of the scour in a stilling basin as the energy in a jet of water is being dissipated.

(f) Inactive.

(g) Studies have been completed comparing the scour from a solid jet and that from a hollow jet valve. The variables considered were the depth of the pool, the fall velocity of the erodable material, the size of the jet, and the velocity of the jet. Results showed that the depth and rate of scour depended upon the depth of water in the stilling basin and the size of the bed material. As expected, the larger the bed material, the smaller was the degree of scour. As the depth of the water in the stiliing basin increased, the scour, likewise, increased to a maximum beyond which scour decreased as the depth increased.

(h) "Scour from jets." Doddiah Doddiah, Maurice L. Albertson, and Robert K. Thomas. Proceedings, International Assn. for Hydraulic Research, 1953. 
(828) INFLUENCE OF SHAPE ON THE FALL VELOCITY OF SEDIMENT PARTICLES.

(b) Laboratory project.

(d) Experimental; for design and masters' theses.

(e) A controlled study of the fall velocity of various typical sands and gravels obtained from stream beds throughout the western United States, from a wind-blown sand dune, from a rock crusher and from a glacial moraine. Small glass spheres were also used. The fall velocity was correlated with the shape of the particle and the Reynolds number of the flow. Special consideration was given to the problem of determining a shape factor of a particle which would be significant, and yet easily determined. Some of the gravel-sized particles were dropped in mineral oil to obtain data in the lower range of Reynolds number to compare with the data obtained from the small-sand sized particles.

(f) Inactive.

(g) A practical shape factor was found to correlate reasonably well considering the irregular and random shape of the particles involved. The shape factor is $c /-\sqrt{a b}$ where $a, b$, and $c$ respectively are the long intermediate and short perpendicular axes of the particle.

(h) "Influence of shape on the fall velocity of sedimentary particles." E. F. Schulz, R. H. Wilde and $M$. L. Albertson, Colorado $A$ and $M$ College report No. 53-10, 137 pages 1953.

"Effect of shape on the fall velocity of sand particles." E. F. Schulz, Master's Thesis, Colorado A and M College, 1953.

(1073) SEDIMENTATION STUDY USING A TURBULENCE TANK.

(f) Completed.

(h) "Temperature, seepage, and turbulence as factors affecting suspended sediment concentration." J. R. Barton and M. I. Albertson. Special report for the Bureau of Reclamation, June 1953.

(1075) HYDRAULICS OF DROP STRUCTURES.

(b) Laboratory project.

(d) Experimental; design and masters' theses.

(e) A series of fundamental experiments to obtain generalized design information for drop structures generally associated with irrigation and drainage canals. In an attempt to develop systematically a simple and yet economical drop structure, an initial two-dimensional study is being made in which the erosion is determined imnediately downstream from a drop structure made of a vertical cut-off wall. The variation of scour with time is being measured for various vertical drops, discharges, tailwater heights, and size ranges of bed material.

(f) Inactive.

(g) The depth of scour was influenced by the depth of water in the pool beneath the overfall, by the rate of discharge, and by the height of the drop. The rate of discharge was found to be the predominate factor in determining the resulting scour. The depth of scour continues to increase with a geometric progression of time. A critical depth of tailwater is reached at which either an increase or decrease in tailwater causes a decrease in scour depth.

(h) "Scour at the base of a free overfall." R. K. Thomas, Master's Thesis, Colorado $\mathrm{A}$ and $\mathrm{M}$ College, 1953.

(1076) INVESTIGATION OF THE ECONOIIICS AND PRACTICABILITY OF SPRINKIER IRRIGATION IN COLORADO.

(b) Laboratory project.

(c) Mr. W. E. Code, Colorado A and M College, Fort Collins, Colorado.

(d) Field investigation; applied research. 
(e) The work is principally that of interviewing users of sprinkler systems with a view of obtaining their viewpoint on their particular use and data on costs. Many of these users have been interviewed as many as 10 times over a period of 3 or 5 years. Frequently soil auger tests are made to determine penetration. In connection with this project a four-year comparison has just been completed between sprinkling and furrow irrigation on an apple orchard.

(f) Completed.

(g) It appears that no further attempt is being made in Colorado to irrigate orchards by sprinkler. There is a continuing substantial growth for pasture irrigation. Cost of operation is about the greatest cause for dissatisfaction.

(1313) HYDRAULTCS OF ALLUVIAL CHANNELS.

(b) Laboratory project and Omaha District, Corps of Engineers, Department of the Army.

(d) Experimental and theoretical; basic research and design; for masters' and doctors' theses.

(e) The long range objectives of the project are to determine the hydraulic characteristics (including the sedimentary aspects) of alluvial channels. Consideration will be given to steady and unsteady flow, uniform and non-uniform flow, transportation of bed load, suspended load, bed material load, and wash load.

An attempt is being made to correlate the resistance coefficient (for wide alluvial channels) with the discharge, the slope, the characteristics of the bed material, and the properties of the fluid using existing data from laboratory channels, natural rivers, and canals.

A laboratory study for the Corps of Engineers has been initiated in which sedimentladen water will be recirculated in the flume to study the formation of dunes on the bed and to determine the variation of the sediment transport and the resistance coefficient with these formations.

(g) Preliminary research has been completed on the development of meanders in alluvial material. For a single natural bed material and bed condition the discharge, the slope, and the time were varied. The results which were measured relative to time were: cross section shape, meander width, meander length, resistance coefficient, and size and concentration of total sediment load. Library research completed on roughness in alluvial channels -- results indicate a correlation between Chezy C, Reynolds mumber, and relative size of sediment.

(h) "Some aspects of roughness in alluvial channels." Said Malik Ali, Master's Thesis, $98 \mathrm{pp}$, Aug. 1953.

(13I4) LAKE HEFNER MODEL STUDY.

(b) Bureau of Ships, Department of the Navy, and the U. S. Geological Survey.

(d) Experimental; basic and applied research.

(e) An attempt is being made to reproduce in a model the wind structure above Lake $\mathrm{H}_{e f n e r}$ and the evaporation of water which took place from the lake as measured during intensive field investigations.

(g) The model has been constructed and certain phases of the testing have been performed. The preliminary results indicate that the model-prototype comparisons will yield considerable information which may be used in predicting prototype behavior from the results of model studies.

(1318) REYNOIDS NUMBER FOR FLOW THROUGH SANDS AND GRAVELS.

(b) Laboratory project.

(c) Prof. D. F. Peterson, Colorado A and M College, Fort Collins, Colo.

(d) Experimental; basic research for masters' and doctors' theses.

(e) The characteristics of porosity, particle shapes and size gradation of particles are not specifically considered in the usual equations of flow through porous materials. These fundamental characteristics are introduced into the equations of flow resulting in a standard Reynolds number.

(f) First phase completed. 
(g) Beginning with the Hagen-Poisseuille-equations the more fundamental media characteristics of porosity, particle shape, and characteristic pore length are introduced theoretically to give $\nabla=\left(2 g \rho d_{e}^{2} / c_{s} \mu\right)\left(n^{3} /(n-1)^{2}\right)(h / L)$,

where $V$ is the bulk velocity, $C_{s}$ is a particle shape factor, $d$ is an effective particle diameter, $\mathrm{n}$ is the porosity, $\mathrm{h}$ is the piezometric head, $\mathrm{L}$ is the length of flow and $\rho, g$, and $\mu$ are the fluid density, acceleration of gravity and viscosity respectively. Experimentation verified the theoretical effect of porosity and showed $C$ to vary from 350 for spherical particles to 680 for micaceous river sands. An ef lective diameter for graded sands of $\sum P / \sum(P / d)$ where $P$ is the percentage between any two sieve sizes and $d$ is the mean diameter between those sizes was shown to give correct results.

(h) "Reynolds number for flow through porous media." Fred W. Kiefer. A Master's thesis available from Colorado $\mathrm{A}$ and $\mathrm{M}$ College Library.

"Effect of porosity and particle size and shape on hydraulic conductivity of sands and gravels." Fred W. Kiefer and Dean F. Peterson, Jr. Submitted for publication to Applied Mechanics Division, American Society of Civil Engineers.

(1565) SEDIMENI CARRYING CAPACITY OF CLOSED CONDUITS.

(b) Cooperative with Armco Drainage and Metal Products, Inc., Middletown, Ohio, with additional support of Research Corporation.

(d) Experimental and theoretical; basic research.

(e) To determine the sediment carrying capacity of 12-inch diameter Helcor, corrugated and smooth pipe; flowing full. To develop design criterion for sediment carrying pipelines. Bank run sediments will be used with mean sizes of 0.1 to $0.5 \mathrm{~mm}$.

(1566) DIFFUSION OF GASES INTO AN AIR STREAM HAVING VARTOUS DEGREES OF STABIIITY.

(b) Air Force Cambridge Research Center, 230 Albany Street, Cambridge 39, Mass.

(d) Experimental and theoretical; basic research.

(e) By means of a horizontal, heated, metal plate placed in the floor of a wind tunnel, the effect of various artificially created lapse rates upon mean velocity profiles and turbulence structures is being investigated. Also the effect of lapse rates upon the diffusion of gases from a point source and a line source will be studied. In addition, simultaneous measurements of evaporation, boundary shear, and heat transfer will be conducted for a range of lapse rates.

(1567) BEHAVIOR OF SEAPIANE HULIS.

(b) Bureau of Aeronautics, Department of the Navy.

(d) Experimental.

(e) The behavior of seaplane hulls when towed at different angles to a wave train has never been studied experimentally. As a preliminary investigation, the motion of the models in an oblique sea will be studied by the use of photography.

(1568) BOUNDARY SHEAR IN OPEN CHANNEIS.

(b) Laboratory project.

(d) Experimental; for J. Waldo Smith Fellowsinip of the A.S.C.E.

(e) To supply experimental data on the shear distribution along the boundary of open channels. This information is needed in connection with the new theory conceived by E. N. Lane on the design of stable alluvial channels. The shear will be measured instead of calculated from other hydraulic measurements.

(g) The shear measuring device has been constructed and is now being calibrated.

(1559) USE OF COMBINED ELECTRICAL ANALOGY AND MEMBRANE ANALOGY TO INVESTIGATE UNCONEINED FLOW INTO WELLS.

(f) Completed.

(h) "Flow into a well by electric and membrane analogy•" C. H. Zee, D. F. Peterson, Jr., and R. O. Bock. Mechanics Division, American Society of Civil Engineers, Oct. 21, 1953. 
1570) DEVELOPMENT OF A CONSTANI FORCE BOTTOM FOR SEAPLANE HULLS.

(b) Bureau of Aeronautics, Department of the Navy.

(d) Experimental; developmental.

(e) To develop a shape of seaplane hull which will experience a constant acceleration upon impact. The procedure used is to determine the empirical corrections necessary to adapt the theoreticaliy icieal bottom contour to actual conditions. The tests are conducted by dropping vertically the two-dimensional hull contours into water. The acceleration-time history is measured by photographing the output from an electronic transducer on an oscilloscope screen. The water surface profile is photographed during impact to measure the "pile-up" of the water.

(f) Completed.

(h) "Development of the optimum bottom contour for seaplane hulls." E. F. Schulz, volorado A and $M$ College report. (Available from Navy Department, Bureau of Aeronautics.)

(1836) EFFECT OF CANAL WATER DEPTH AND DEPTH TO WATER TABLE ON SEEPAGE FROM AN IDEALI ZED CANAL.

(b) Laboratory project.

(c) Prof.D.F. Peterson, Jr., Colorado A and M College, Fort Collins, Colo.

(d) Experimental; master's thesis.

(e) A model study based on the dimensional analysis $Q / K B^{2}=F(B / y, B / L)$ where $Q$ is the seepage loss, $K$ is the permeability, $B$ is the canal breadth, $y$ is the depth of water in the canal and $I$ is the depth to the water table, is being conducted using a sand model. The first phase will be the case for a homogeneous medium of great depth.

(g) Apparatus has been constructed and testing started. Curves showing the functional relationship have been developed from data taken to date.

(1837) SEDIMENT LININGS FOR CANALS AND RESERVOIRS.

(b) U. S. Bureau of Reclamation.

(c) Mr. R. D. Dirmeyer, Jr., Civil Engineering Department, Colorado A and M College, Fort Collins, Colo.

(d) Experimental and fielci investigation; applied research.

(e) To develop a truly low-cost canal and reservoir lining method -- sediment linings. Briefly, sediment lining is a process involving the use of canal or reservoir water for the placement of an impervious filier or bincier into the pervious or unstable materials of the canal or reservoir bed.

(h) Monthly progress reports obtainable upon request.

(1838) BEHAVIOR OF MODEL SHIF HULLS IN AN OBIIQUE SEA.

(b) Office of Naval Research and David Taylor Model Basin, Bureau of Ships, Navy Department.

(c) Dr. M. L. Albertson, Head of Fluid Mechanics Research, Department of Civil Engineering, Colorado $A$ and $M$ College, Fort Collins, Colo.

(d) Experimental; applied research.

(e) This investigation will yield information regarding the magnitude of the amplitude response operators for the motions of heave, pitch and roll of a model when the model is towed at different angles to the wave front. Other information will be obtained relative to the problem of generating waves in a relatively wide basin, the amount of time required for the model to reach stability and the instrumentation necessary to obtain satisfactory data.

(1839) INVESTIGATION OF REGIME THEORY OF SELF FORMED CHANNELS.

(b) Cooperative with U. S. Geological Survey, Corps of Engineers, U. S. Army, and Bureau of Reclamation. 
(c) Dr. M. L. Albertson, Head of Fluid Mechanics Research, Department of Civil Engineering, Colorado A and M College, Fort Collins, Colorado.

(d) Field Investigations; applied research.

(e) The "regime the ory" of channel formation has been advanced by Blench and others. The purpose of this project is to investigate a mumber of different channels in different locations in the West to determine carefully and accurately the physical measurements of these channels, their discharge, their bed characteristics, and the nature and composition of the suspended sediment.

UNIVERSITY OF COLORADO, Hydraulics Laboratory Department of Civil Engineering.

Inquiries concerning Projects Nos. 1321, 1571, and 1572 should be addressed to Prof. harren DeLapp, University of Colorado, Boulder, Colo.

(1321) ENERGY LOSSES IN OPEN CHANNEL TRANSITIONS.

(b) Laboratory project.

(d) Experimental; for design and master's thesis.

(e) Work previously reported is being continued and extended to include studies of hydraulic jump in transitions.

(1571) FREE OVERFALL STUDIES.

(b) Laboratory project.

(d) Experimental; basic research for master's thesis.

(e) Studies are being made to determine the effects of slope and channel roughness on the water surface profiles in the vicinity of an outfall.

(f) Inactive.

(h) "A study of water surface profiles near a free overfall." Gunjit Singh. Master's Thesis, June, 1953.

(1572) HYDRAULIC JUMP AT JUNCTION OF STEEP AND MILD SIOPES.

(b) Laboratory project.

(d) Analytical; for design and master's thesis.

(e) Design charts have been developed for locating hydraulic jump at junction of $1: 3$, $1: 4$ and $1: 6$ slopes with horizontal apron.

(f) Completed.

(h) "Design criteria for hydraulic jump at junction of steep and milo slopes." A. A. Aljaberi. Master's Thesis, June, 1953.

COLUMBIA UNIVERSITY, Fluid Mechanics Laboratory, Department of Civil Engineering.

Inquiries concerning Projects Nos. 289, 1324, and 1840 should be addressed to $\mathrm{Mr}$. Richard Skalak, Department of Civil Engineering and Engineering Mechanics, Columbia University, New York 27, N. Y.

(62) HYDRAULIC STRUCTURES.

(b) Office of Naval Research, Department of the Navy.

(c) Mr.J.W. Delleur, Department of Civil Engineering and Engineering Mechanics, Columbia University, New York 27, New York.

(d) Experimental and theoretical; basic research.

(e) Experimental work is in progress for the study of boundary layer regimen in intake reaches of open channels. 
(g) Theory and experiments indicate an interaction of the boundary layer growth and the flow outside the boundary layer in an open channel near critical flow. The boundary layer develops more slowly than for comparable conditions for a flat plate in an infinite fluid.

(h) "An analysis of boundary layer growth in open conduits near critical regime." A. E. Craya and J. W. Delleur, Office of Naval Research Report, 1952.

899) SEPARATION PATTERNS IN THEIR RELATION TO IOCAL FOPM RESISTANCES.

(b) Laboratory project.

(d) Experimental.

(e) Experimental work has been completed for the case of abrupt expansion of a pipe including the effect of a spiral component of velocity artificially introduced just before the expansion.

(f) Suspended.

290) HYDRAULICS OF SHORT OUTLETS IN BODIES OF DAMS.

(b) Office of Naval Research, Department of the Navy.

(c) Mr. H. R. Henry, Department of Civil Engineering and Engineering Mechanics, Columbia University, New York 27, New York.

(d) Experimental and theoretical.

(e) Investigation of boundary layer development in outlet conduits. Pressure and velocity distributions are measured along the pipe and entrance section.

-324) LOSSES IN TWO-DIMENSIONAL JUNCTIONS.

(b) Office of Naval Research, Department of the Navy.

(d) Theoretical and experimental; basic research.

(e) A study of flow patterns at junctions in rectangular conduits which can be considered two-dimensional flow with particular attention to the influence of initial velocity distribution on the characteristics of the side jet.

(f) Suspended.

18L0) SURFACE CURVES OF SUPERCRITICAL FLOW ON A MILD SIOPE.

(b) Laboratory project.

(d) Experimental; master's thesis.

(e) Surface curves of a supercritical flow downstream of a sluice gate in a rectangular chamel set on a mild slope were measured for comparison with surface curves computed by the usual varied flow methods.

(f) Completed.

(g) It was found that to the surface curves, computed by the usual theory using a roughness determined experimentally for uniform flow, were shorter than the experimental curves. Results computed by considering the boundary layer development gave better agreement.

(h) Master's Thesis, G. M. Sicular, 1953.

UNIVERSITY OF CONNECTICUT, Hydraulic Research Laboratory, Department of Civil Engineering.

Inquiries concerning Projects Nos. 1574 to 1577, incl., should be addressed to Professor E. V. Gant, Box U-37, University of Connecticut, Storrs, Conn.

(1078) HYDROLOGIC FACTORS INFLUENCING RAINFALI-RUNOFF RELATIONSHIPS ON SMALI WATERSHEDS IN EASTERN CONNECTICUT.

(b) Laboratory project.

(c) Prof. K. C. Tippy, Box U-37, University of Connecticut, Storrs, Conn. 
(d) Field investigation; applied research.

(e) Rain gages are being installed on the $4.5 \mathrm{sq}$ mile watershed of the laboratory and on additional sites varying in size from 4 to 400 acres. Runoff weirs have been completed and installed with recording gages on the latter. Measurements are being taken.

(1079) STUDY OF WIND EFFECTS ON STRUCTURES.

(b) Laboratory project.

(c) Mr. A. L. Mirsky, Box U-37, University of Connecticut, Storrs, Conn.

(d) Experimental; applied research.

(e) A study of wind action and flow on the roofs of various types of buildings and structures is to be conclucted in a small wind tunnel.

(1080) STUDY OF HYDRAULIC DESIGN OF CURB INLETS.

(b) Laboratory project; State Highway Department.

(c) Prof. V. Scottron, Box U-37, University of Connecticut, Storrs, Conn.

(d) Experimental; for design.

(e) Involves the hydraulic and structural design of the curb inlet type of catch basin, with particular reference to the hydraulic efficiency of the grate now used by the State Highway Department. Half-scale models of highway gratings are under test.

(1574) VARIATION IN AMOUNT OF FROST HEAVE WITH DEPTH OF GROUND WATER TABLE.

(b) Laboratory project; State Highway Department.

(d) Experimental; applied research.

(e) Investigation is under way on a series of 12 test cells, 6 containing silt and 6 glacial till at depths from 2 l/2 to $6 \mathrm{ft}$. Observations taken on heave, depthtemperature variation, and water consumed from water table.

(1575) EFFECT OF WASHED CONCRETE SAND IN INCREASING CAPILIARY RISE AND FROST HEAVING IN ADJACENI SOII.

(b) Laboratory project; State Highway Department.

(d) Theoretical and experimental; applied research.

(e) Investigations are being made of the effect of washed concrete sand in raising the ground water table in adjacent silt or glacial till.

(1576) CAPILIARY POTENIAL OF VARTCUS MATERIALS.

(b) Laboratory project; State Highway Department.

(d) Theoretical; applied research.

(e) Preliminary studies are under way.

(1577) FILTER TESTS OF VARIOUS MATERI ALS.

(b) Laboratory project; State Highway Department.

(d) Experimental; applied research.

(e) A study of the stability of filters has begun.

CORNELI UNIVERSITY, School of Civil Engineering.

Inquiries concerning Projects Nos. 1327, 1328, 1841 to 1848, incl., should be adidressec to Professor Andre I. Jorissen, Head, Department of Hydraulics and Hydraulic Engineering, School of Civil Engineering, Lincoln Hall, Cornell University, Ithaca, N. Y. 
327) STUDY OF FLON-METERING DEVICES FOR LOW REYNOLDS NUMBERS.

(b) Builders-Providence, Inc., laboratory project.

(d) Experimental; development.

(e) To develop devices for measuring the rate of flow in pipelines, maintaining a constant coefficient of discharge at low Reynolds numbers.

(g) A new device, known as the Builders S. J. flow tube, has been developed.

(h) "Le debitmetre B.S.J. pour la mesure des debits de fluides aux faibles nombres de Reynolds." A. L. Jorissen, Revue universelle des Mines, Liege, Belgium, March, 1953. "A new flow-measuring device - the cylindrical nozzle with conical diffusor." A. L. Jorissen, J. M. Symons and S. L. Wise, Petroleum Processing, Dec. 1953.

1328) EFFECTS OF PIPE ROUGHNESS ON DISCHARGE COEFICIENT OF FLOW-METERING DEVICES.

(b) Builders-Providence, Inc., laboratory project.

(d) Theoretical and experimental; master's thesis.

(e) To investigate the relationship between pipe roughness and Venturi tube coefficient.

18L1) STUDY OF VENTURI TUBE CHARACTERISTICS.

(b) Builders-Providence, Inc., laboratory project.

(d) Experimental.

(e) Study of effect on Venturi tube coefficient of discharge of such factors as pressure taps locaticn, downstream throttling, mi smatch between inlet pipe and Venturi, etc.

1842) ANALYSIS OF VENIURI TUBE COEFFICIENTS.

(b) Research Committee on Fluid Meters, American Society of Mechamical Engineers.

(d) Analytical.

(e) Analysis of venturi tube coefficients to obtain data susceptible of being used in International Standards.

18L3) VENIURI TUBE AND NOZZLE CAIIBRATIONS.

(b) Builders-Providence, Inc.

(d) Experimental.

(e) The following have been calibrated: 2 venturi tubes 24 " $\times 12 "$, I Venturi tube $16 " \times 9.5 "$, and 1 Venturi nozzle 14" x 10".

(f) Completed.

(1844) 2L" FLOW CONTROLLER TEST.

(b) Builders-Providence, Inc.

(d) Experimental.

(e) Study of the behavior of a 24" flow controller under relatively high head. Determination of the coefficient of discharge and of the rate of leakage.

(f) Completed.

(1845) STUDY OF VENTURI TUBES AND REGISTERS.

(b) City of Miami, Miami, Fla.

(d) Experimental.

(e) Calibration of a $30 " \times 18 "$ and a $81 \times 4 "$ Simplex venturi tube. Determination of register accuracy.

(f) Completed. 


\section{(1846) TESTS OF FLANGED SILENT CHECK VALVES.}

(b) Williams Gauge Company, Pittsburgh, Pa.

(d) Experimental.

(e) Tests on 2", 4" and 8" check valves in both horizontal and vertical lines.

(f) Completed.

(1847) STUDY OF FLOAT-TYPE, VARIABLE AREA FLON METERS.

(b) Fischer and Porter Company, Hatboro, Pa., laboratory project.

(d) Theoretical and experimental.

(e) Comprehensive study of flow conditions, meter behavior and accuracy.

(1848) MODEL STUDY OF CORNELL UNIVERSTTY ROWING TANK.

(b) Department of Buildings and Grounds, Cornell University.

(d) Experimental.

(e) To conduct model study of flow conditions in new rowing tank being built by Cornell University in order to obtain smooth flow at desired velocity in useful portion of tank.

(1849) PUMP CAVITATION.

(b) Goulds Pumps, Inc., Seneca Falls, N. Y., laboratory project.

(c) Prof. Marvin Bogema, School of Civil Engineering, Lincoln Hall, Cornell University, Ithaca, N. Y.

(d) Experimental.

(e) Determination of required net positive suction head when pumping hot water. Equipment permits wide variation in water temperature and suction head.

(1850) A LABORATORY STUDY OF BEACH PROFILES AND BEACH STABILITY.

(b) Part of a project sponsored by the Office of Naval Research.

(c) Prof. Melville S. Priest, School of Civil Engineering, Iincoln Hall, Cornell University, Ithaca, N. Y.

(d) Experimental; basic research.

(e) This study was initiated for the purpose of acquiring some knowledge as to the influence of sand characteristics, wave characteristics, and initial beach slope upon beach profil and beach stability. The study was limited to normal wave incidence and initially plane beach slopes.

(f) Completed.

(g) Objective accomplished, see (e).

(h) A report has been submitted to the director of the project, of which this study was a part. Publication is not contemplated.

GEORGIA INSTITUTE OF TECHNOLOGY, School of Civil Engineering.

Inquiries concerning Projects Nos. 291, 1332, 1584 and 1851 to 1858, incl., should be addressed to Prof. C. E. Kindsvater, School of Engineering, Georgia Institute of Technol ogy, Atlanta, $\mathrm{Ga}$.

(291) FLOW OF WATER OVER HIGHWAY EMBANKMENTS.

(b) Laboratory project.

(d) Experimental; basic research.

(e) Tests on a 1:6-scale model of a typical highway embankment section have been completed. Preliminary tests on a $1: 12$-scale model are underway. Variables include roughness and shape of crown, slope and height of embankment. Data include discharge calibration, water-surface profiles, and tailwater levels corresponding to (1) free flow (2) incipier. submergence, (3) lower limit of surface flow, (4) upper limit of plunging flow, and (5) submerged flow.

(f) Temporarily suspended. 
(1331) THE DIFFUSION MECHANISM OF FOREIGN PARTICLES IN A FLUID.

(b) Laboratory project.

(c) M. R. Carstens, School of Civil Engineering, Georgia Institute of Technology, Atlanta, Georgia.

(d) Experimental; basic research.

(e) The diffusion of macroscopic foreign particles is being studied in a vertical diffusion chamber. The turbulence within the column is uniform. The turbulence amplitude and frequence are controlled. The diffusion characteristics of spherical glass beads are being studied in the water-filled column.

(1332) TRANQUIL FIOW THROUGH OPEN-CHANNEL CONSTRICTIONS.

(b) Water Resources Division, Surface Water Branch, U. S. Geological Survey.

(d) Experimental; basic research.

(e) Tests have been conducted on various forms of width-constrictions in level channels of various cross-sectional shapes. Flows were limited to the tranquil; boundary conditions considered were governed by highway bridge practice for single-opening waterways. The investigation was confined to an evaluation of the discharge characteristics of the constricted channel.

(f) Completed.

(g) A satisfactory analysis and computation procedure based on experimental coefficients was achieved.

(h) "Tranquil flow through open-channel constrictions." C. E. Kindsvater and R. W. Carter, Proceedings-Separate, A.S.C.E. (publication pending).

"Computation of peak discharge at contractions." C. E. Kindsvater, R. W. Carter and H. J. Tracy, U. S. Geological Survey Circular 284.

(1584) FLOW OF WATER OVER WEIRS AND SPILLWAYS.

(b) Water Resources Division, Surface Water Branch, U. S. Geological Survey.

(d) Library search, re-analysis, and correlation of published data, and original research.

(e) A comprehensive study of the discharge characteristics of practical forms of weirs and spillways. Initial phase includes the preparation of a bibliography and the collection of experimental data from all known sources. Objectives include the publication, in generalized form, of available empirical data and the preparation of a list of research problems.

(g) Bibliography includes 230 entries. Collection and analysis of data begun. A problem suggested by the bibliographic search was the subject of a master's thesis (Project 1852).

(1851) EFFICIENCY OF HYDRAULIC TURBINE DRAFT TUBES.

(b) S. Morgan Smith Company, York, $\mathrm{Pa}$.

(d) Experimental; for design.

(e) Transparent plastic models of several different draft-tube designs have been investigated. Draft-tube performance is evaluated on the basis of hydraulic efficiency. Test variables include a full range of artificially-produced discharge whirls and a limited variety of boundary modifications for each model.

(1852) DISCHARGE CHARACTERISTICS OF RECTANGULAR PIATE WEIRS IN RECTANGULAR CHANNELS.

(b) Laboratory project.

(d) Experimental and analytical; for master's thesis (James R. Wells).

(e) An investigation of the comprehensive discharge characteristics of the basic, sharpedged, rectangular-notch weir. An attempt to evaluate by empirical means the influence of geometric variables excluded by restrictions on the standard weir formulas. Tests conducted in 3-foot wide flume, covering a full range of notch widths, weir heights, and heads. Investigation limited to free flows of water at normal temperatures. 
(f) Research for one thesis completed. Additional tests will be made in a wider flume.

(h) Results of initial investigation submitted in Master's Thesis by James R. Wells (1954).

(1853) BACKWATER DUE TO WIDTH CONSTRICTIONS IN OPEN CHANNELS.

(b) Water Resources Division, Surface Water Branch, U. S. Geological Survey.

(d) Experimental; basic research.

(e) The increase in depth (backwater) caused by width constrictions in open channels was defined for various channel shapes, degrees of roughness and constriction geometries. Boundary conditions considered were governed by highway bridge practice for singleopening waterways.

(f) Completed.

(g) A satisfactory analysis and computation procedure based on experimental coefficients was achieved.

(h) Publication pending.

(1854) INFLUENCE OF BOUNDARY ROUGHNESS ON ABRUPT ENLARGEMENTS IN OPEN CHANNELS.

(b) Laboratory project, cooperative with the U. S. Geological Survey.

(d) Experimental and analytical; for master's thesis ( T. W. Fleetwood, Jr.).

(e) An experimental investigation of the influence of boundary roughness on the total energy loss due to abrupt width-enlargements in open channels. Various patterns of roughness distribution (transverse) in level channels of various cross-sectional shapes will be investigated. Tests will be conducted in a 3-foot wide flume. Flow conditions will be limited to the tranquil range. This is an extension of the work reported as Project 1853

(f) Experimental program to commence in first quarter, 1954.

(1855) TRANQUIL FLOW THROUGH SEVERAL OPENINGS IN AN OPEN-CHANNEL WIDTH CONSTRICTION.

(b) Whter Resources Division, Surface Water Branch, U. S. Geological Survey.

(d) Experimental; basic research.

(e) A preliminary objective will be to establish principles of flow division at a multiopening width constriction. A 14 -foot wide by 80 -foot long flume will be used in the experimental investigation. Channel shape, degree and pattern of boundary roughness and constriction geometries will be varied. Boundary conditions considered will be governed by highway bridge practice.

\section{(1855) DISCHARGE CHARACTERISTICS OF CULVERTS.}

(b) Whter Resources Division, Surface Water Branch, U. S. Geological Survey.

(d) Analysis and correlation of published data, plus original research as required.

(e) A study of the discharge characteristics of culverts. The study will be limited to culvert shapes which are common in modern highway practice. Criteria for distinguishing between full (pressure) flow and sluice (open-channel) flow based on length, roughness, bed slope and entrance geometry are sought.

(1857) REGIMES OF FLOW IN AN OPEN CHANNEL WITH A NON-RECTANGULAR CROSS SECTION.

(b) Laboratory project.

(d) Theoretical and experimental; basic research for master's thesis.

(e) A detailed analysis of the transition from subcritical flow to supercritical flow in an open channel with a non-rectangular cross section. The channel walls are parallel. In cross section, the bottom has a uniform slope. Velocity traverses and water surface elevation determinations are made upstream and downstream from a stationary finite gravity wave. Experiments have been performed with both the stationary breaking wave (hydraulic jump) and with the non-breaking wave.

(h) Research for one thesis is complete. 


\section{(1858) CLASSIFICATION OF FLOWS THROUGH HIGHWAY CULVERTS.}

(b) Laboratory project.

(d) Experimental; research for a master's thesis.

(e) The majority of possible flow conditions within a highway culvert were reproduced within a two-dimensional culvert. The flow profiles were then photographed. The flow conditions were then classified by position of the control section and each condition was then analyzed in regard to the limit of occurrence. From this qualitative study the effects of entrance streamlining; barrel slope, length, and roughness; and outlet submergence can be visualized.

(h) Research for one thesis completed.

HARVARD UNIVERSITY, Department of Mathematics.

(1335) MATHEMATICAI THEORY OF WAVES AND SHIP WAVE RESISTANCE.

(b) Office of Naval Research, Department of the Navy.

(c) Dr. Jack Kotik, 2 Divinity Avenue, Cambridge 38, Mass.

(d) Theoretical.

(e) Two new expressions for ship wave resistance have been derived and their advantages, from the point of view of computation, are being investigated. Asymptotic expansions at low Froude mumber have been obtained.

(h) "Surface waves of finite energy." J. Kampe de Feriet and J. Kotik, Journal of Rational Mechanics and Analysis, July, 1953.

"Note on the heat equation." G. Birkhoff and J. Kotik, to appear in the Proceedings of the American Mathematical Society.

UNIVERSITY OF IDAHO, Engineering Experiment Station.

Inquiries concerning Projects Nos. 547, 1091, and 1859, should be addressed to Prof. C. C. Warnick, and concerning Projects Nos. 1860, 1861, and 1862, to Prof. Victor I. Myers, College of Engineering, University of Idaho, Moscow, Idaho.

(547) STUDY OF PRINCIPLES, DEVELOPMENI AND USE OF HIGH ALTITUDE PRECIPITATION GAGES.

(b) Iaboratory project; cooperative with United States Army Engineers, Weather Bureau, Forest Service, Bureau of Reclamation, and Agricultural Research Service.

(d) Experimental; design and development.

(e) A series of wind tunnel tests have been made on movement of air around precipitation gages using sawcust to simulate snow. Qualitative catch studies on a model basis have also been made to develop proper windshielcing for several types of precipitation gages. Prototype gages and shields have been installed at remote mountain locations to check. field performance against the results obtained from wind tunnel tests.

(g) Photographic data and comparative catch data have revealed improved windshield designs that promise to give improved consistency in the measurement of precipitation in the form of snow. Tests of models in the wind tunnel have been very helpful in predicting structural performance of the prototype windshields. Results show definite variation in catch will result with different orifice diameters.

(h) "Developing and testing of new windshield for precipitation gages." T. B. Kerr, Idaho Engineer, Vol. 30 No. 4, pp 10-11, May, 1953.

"Experiments with windshields for precipitation gages." C. C. Warnick, Reprint No. 2, Engineering Experiment Station, from Trans. of the Amer. Geophys. Union, June, 1953. 
(1091) A STUDY OF CANAL IININGS FOR CONTROLIING SEEPAGE IOSSES.

(b) Laboratory project; cooperative with U. S. Bureau of Reclamation.

(d) Field investigation; applied operational research.

(e) A study was made of effectiveness and permanency of canal linings by installing short sections of lining in operating canals. Information was obtained on permeability of soil, seepage loss before lining, and seepage loss after lining.

(f) Completed.

(g) Three years of field study working with various types of prefabricated linings, concrete block linings, and earth linings gave information on methods of lining, seepage loss data, and performance of the linings.

(h) "Low-cost canal lining." V. G. King, Idaho Engineer, Vol. 30, No. 2, pp 8-9, Jan. 1953. "Prefabricated linings rated by seepage tests." C. C. harnick and R. J. Abbey, Reprint No. 1, Engineering Experiment Station, from western Construction, April, 1953. "A study of canal linings for controlling seepage losses." Progress Report No. 3, Engineering Experiment Station, University of Idaho, 48 pages, May, 1953.

(1859) A STUDY OF THE EFFECTIVENESS OF CANAL IININGS AND SOIL SEDIMENTS IN CONTROLIING SEEPAGE IOSSES.

(b) Laboratory project; cooperative with U. S. Bureau of Reclamation.

(d) Field investigation; basic and applied operational research.

(e) This study is a continuation of Project 1091 in which new exposed membrane linings are being studied. In addition, a study is being made of the effectiveness of soil sediments in preventing seepage. A survey is being made of the sediment carried in certain canals and an attempt made to determine the benefit of this sediment in preventing seepage loss.

(g) One summer of field testing has been completed, and laboratory analysis of soil and sediment samples is in progress.

(1860) APPLICATION OF ELECTRICAL RESISTANCE METHODS OF MEASURING SOIL MOISTURE IN IDAHO SOILS.

(b) Laboratory project; under investigation in the Agricultural Experiment Station.

(d) Experimental.

(e) To determine the accuracy of soil moisture blocks in measuring soil moisture in Idaho's arid soils. Preliminary work only.

(1861) THE IMPROVEMEMT AND DEVELOPMENT OF STREAM FLOW MEASURING DEVICES.

(b) Laboratory project; cooperative with Agricultural Research Service, being carried on under the Agricultural Experiment Station.

(d) Experimental; applied research.

(e) Study is being made in a laboratory flume and in field streams with full-size models of stage-measuring devices (primarily crest gages) under controlled conditions.

(g) Tests show excessive drawdown in standard crest gages at velocities exceeding 2 or 3 fps. In preliminary tests, one of the new gages shows promise of not having objectionable drawdown.

(1862) DETERMINATION OF ANNUAL RUNOFF FROM WATERSHED CHARACTERISTICS.

(b) Laboratory project; being carried on under the Agricultural Experiment Station.

(d) Experimental; applied research.

(e) To investigate statistically the correlation between various watershed characteristics and anmial runoff on gaged watersheds, for application to ungaged areas. Work is in progress evaluating watershed characteristics. 
IINOIS STATE WATERWAYS DIVISION, Springfield.

863) EROSION CONTROL, ILIINOIS SHORE OF IAKE MICHIGAN.

(b) State of Illinois.

(c) Mr. Thomas B. Casey, Chief Engineer, Division of Waterways, 201 W. Monroe Street, Springfield, Illinois.

(d) Field investigation; applied research.

(e) To obtain and correlate basic data on the several forces and factors involved in erosion processes along the Illinois Shore of Lake Michigan to the end that future efforts toward the prevention of erosion might be founded upon a more definite and factual basis with a consequent greater degree of assurance that the works will serve the intended purposes. The project was initiated in 1950 and is contiming. In of study are as follows: Observation of lake stages, wave height and period, wind direction and velocity, and barometric pressures at hilson Avenue Crib and hakegan Harbor; shoreline and offshore topography; sampling and analysis of beach and bottom materials; wave refraction studies; detailed studies of case histories of selected shore protection and harbor structures; periodic studies of selected recently constructed groin systems; detailed studies of effect of harbor structures upon littoral drift; measurements of littoral currents, including magnitude and direction; and determination of areal extent and depth of off shore sources of beach material for artificial replenishment.

(g) Results are incomplete.

(h) "Interim Report for Erosion Control, Illinois Shore of Lake Michigan". Division of haterways, Department of Public Works and Buildings, State of Illinois, 33 pages, 1952.

\section{ILITNOIS STATE WATER SURVEY DIVISION, Champaign.}

(551) RUNOFF FROM SMALI WATERSHEDS.

(b) Laboratory project, cooperative with U. S. Geological Survey.

(c) Mr. W. J. Roberts, Illinois State Water Survey, Box 232, Urbana, Ill.

(d) Field investigation; applied research, design.

(e) Measurements are being made of watershed rainfall and stream flow, of stage, discharge over the spillway, and mumicipal pumpage on five small water supply reservoirs in IIlinois.

(g) Twenty-three years of contimous measurements completed. Annual summaries 1946 to 1953 available for limited distribution.

(552) SEDIMENTATION OF ILIINOIS RESERVOIRS.

(b) Laboratory project, cooperative with Soil Conservation Service and Illinois Agricultural Experiment Station.

(c) Mr.J.B. Stall, Illinois State hater Survey Division, Box 232, Urbana, Illinois.

(d) Field investigation; applied research.

(e) For design of water supply reservoirs, measurements of sediment accumulation have been made on sixteen lakes in Illinois. Sediment samples are being analyzed and complete surveys of watershed soil type, slopes, land use, and conservation practices are being made.

(g) Results at Lake Decatur, Decatur, Ill., showed correlation between rate of sedimentation and land use on the watershed.

(h) Reports of Investigation Nos. 4, 7, 8, 9, 10, 12, 15, 16, and 18; sedimentation surveys of Spring Lake, Ridge Lake, Lake Chautauque, Carbondale Reservoir, Lake Bracken, west Frankfort Reservoir, Lake CaIhoun, Lake Springfield, and Lake Carthage, respectively. 


\section{(553) RADAR-RAINFALLL PROJECT.}

(b) Laboratory project, cooperative with Signal Corps, Department of the Army.

(c) Mr. G. E. Stout, IIlinois State Water Survey Division, Box 232, Jrbana, III.

(d) Field investigation; basic research.

(e) A radar installation is being used to track rain clouds, showing extent, movement, and intensity of each rain area. Two concentrated recording rain gage networks consisting of $2 L$ and 50 rain gages each yield rainfall data which are correlated with photographic records of the radar PPI scopes. Precipitation particle-size data are being collected in a volume of one-third cubic meter using high-speed photography. The se data will be correlated with radar echo-return. Twenty-one rain gages concentrated with 300 square feet are collecting data on the variability of precipitation within a very small area.

(g) Results indicate that radar is capable of matching an equivalent rain gage spacing of at least the gage each 150 square miles.

(h) Reports of Investigation 13 and 19, Illinois State Nater Survey.

\section{(555) EVAPORATION IN ILIINOIS.}

(b) Laboratory project.

(c) Mr. No J. Roberts, Illinois State Vater Survey Division, Box 232, Jrbana, Illinois.

(d) Field investigation; applied research.

(e) Measurements are being made of evaporation at three stations in northern, central, and southern Illinois. Vapor pressure gradients are obtained at Four-ifile Crib in Lake Michigan and at Jrbana. Evaporimeters constructed and installed adjacent to pans for year-round records.

(h) Report presented at Illinois State Academy of Science Meeting Macomb, IIl., May 8, 1953.

(561) GROUND WATER INVESTIGATION IN THE EAST ST. LOUIS AREA.

(b) Laboratory project.

(c) Mr. Jack Bruin, Illinois State Water Survey, Box 232, Jrbana, IIl.

(d) Field investigation; applied research.

(e) To evaluate the ground water resources of the American Bottom (E. St. Louis region). Ground water levels are measured continuously. Pumpage, river stage, and rainfall data are collected. Chemical quality of ground water is measured. Areas of infiltration are determined, and all data are correlated with consideration of local conditions. Statistical studies have been made of the service lives of muicipal wells.

(g) Average daily ground water pumpage in the area is between 100 and 110 million gallons. Since 1941 there has been no recession of ground water except in areas of highly concentrated pumpage. The data indicate the water-bearing formations are being recharged by water from the Mississippi River, local rainfall, and upland drainage.

(h) "Preliminary report on the ground water resources of the American Bottom." Report of investigation No. 17, Illinois State Water Survey, 1952.

(843) GROUND WATER RESOURCES IN JO DAVIESS, STEPHENSON, AND CARROLL COUNTIES.

(b) Laboratory project.

(c) Mr. H. F. Smith, Illinois State hater Survey Division, Box 232, Urbana, Ill.

(d) Field investization; applied research.

(e) To determine ground water resources of the area, water level contours of the sandstone aquifers, transmissibility and storage coefficients of the aquifers, quantity of water available were obtained.

(g) Data indicate that piezometric surface conforms generally with topography, with a 500foot drop in about $30 \mathrm{miles}$ with no apparent withdrawal. The sandstone aquifers are overlain with 100 to 300 feet and more of impervious limestone. 
(844) GROUND WATER RESOURCES IN CHAMFAIGN COUNTY.

(b) Laboratory project.

(c) Mr. H. F. Smith, Illinois State Nater Survey Division, Box 232, Urbana, Illinois.

(d) Field investigation; applied research.

(e) To determine ground water resources of the county, water level contours of two glacial aquifers. Pumping tests to determine transmissibility, rates of flow into heavily pumped areas.

(g) Data show little, if any, communication between two glacial aquifers. Wh thdrawal in heavily pumped area exceeds recharge by 30 percent.

(h) "Ground water resources in Champaign County." H. F. Smith, Report of Investigation No. 6 , Illinois State Water Survey Division. (Available on request.)

(1092) HYDROLOGIC CYCLE EVALUATION.

(b) Laboratory project; cooperative with the U. S. Geological Survey.

(c) Mr. H. E. Hudson, Jr., Illinois State inter Survey, Box 232, Urbana, Ill.

(d) Field investigation; applied research.

(e) Data from rain gage networks (gathered under Project 553) together with information from five stream-gaging stations and five ground water level recorders are being maintained. Data will be used in analyzing storm rainfall-runoff relationships on small watersheds and effect of munoff on water table. Analysis in progress.

(1336) DESIGN OF A 60FOOT TILTING FLUME.

(b) Laboratory project.

(c) Dr. G. H. Nelson, IIlinois State hater Survey, Box 232, Urbana, Ill.

(d) Experimental; design.

(e) Design of versatile flume for hydraulic laboratory.

(f) Design and fabrication complete, installation in progress.

(1337) DESIGN OF BUBBLER SYSTEM FOR MEASUREMENT OF WATER LEVELS IN WELIS.

(b) Laboratory project.

(c) Mr. G. H. Nelson, IIlinois State Water Survey, Box 232, Urbana, Ill.

(d) Experimental; applied research.

(e) The bubbler system or purge method of liquid level measurement was applied to measuring well levels. The theory of operation was advanced and checked by laboratory tests.

(f) Completed.

(g) Laboratory accuracy obtained to 0.020 feet. Field accuracy comparable to float operated recording devices.

(h) Report prepared for publication.

(1340) PHYSICAL PROPERTIES OF FLUIDS.

(b) Laboratory project.

(c) Mr. A. M. Buswell, Chief, Illinois State Water Survey Division, Box 232, Urbana, Ill.

(d) Experimental.

(e) To determine if any measurable changes in physical properties occur in fluids during flow.

(f) Completed.

(h) Report presented to Instrument Society of America, September, 1953.

(134I) CORROSION STUDY.

(b) Laboratory project.

(c) Dr. T. E. Larson, IIlinois State vater Survey Division, Box 232, Urbana, Ill.

(d) Experimental.

(e) A basic study of corrosion occurring at the steel electrodes under flow through a twenty foot plastic tower. 
(1342) STUDY OF CORROSION AND DEPOSITION RATES WITH DIFFERENT FLOW RATES.

(b) Laboratory project.

(c) Dr. T. E. Larson, Illinois State Water Survey Division, Box 232, Urbana, IIl.

(e) One-half inch pipes made of different materials are in service. Changes in the flow due to corrosion and at constant head are being measured.

(1864) FION THROUGH POROUS MEDIA.

(b) Mr. H. E. Hudson, Jr., Illinois State water Survey Division, Box 232, Urbana, Illinois.

(d) Basic research.

(e) Study of transition from viscous to turbulent flow in porous media.

(g) Data collection completed. Analysis in progress.

(1865) HYDRAULIC DESIGN OF DROP INLET SPILLWAY STRUCTURES FOR SMALL RESERVOIRS.

(b) Laboratory project.

(c) Mr. G. H. Nelson, Illinois State Water Survey, Box 232, Urbana, Ill.

(d) Experimental; applied research.

(e) The project will provide hydraulic criteria for the economic design of these structures. A field study of structures now in use is included.

\section{ILIINOIS STATE WATER SURVEY DIVISION, PeOria.}

Inquiries concerming Projects Nos. 556 to 560, incl., 845, 1335, and 1866, should be addressed to $D_{r}$. Max Suter, Engineering Research Subdivision, Illinois State water Survey Division, Box 717, Peoria, Ill.

\section{(556) PERMEABIIITY OF GRADED SAND MIXTURES.}

(b) Laboratory project.

(d) Experimental; basic research.

(e) The permeabilities of known mixtures of graded sand are measured to determine functional changes.

(g) Sand mixtures containing 60 to 70 percent of fine material in 40 to 30 percent of coarser from 2 adjoining sieves of the $\sqrt{2}$ series have less permeability than the material of the fine screen alone.

(557) TURBULENT FLOW THROUGH GRANULAR MEDIA.

(b) Laboratory project.

(d) Experimental; basic research.

(e) Critical flow is determined to define conditions under which turbulent flow occurs outside of well screens.

(g) In flow through granular media, the Reynolds mumber cannot be calculated from ordinary formulas. By assuming a critical Reynolds mumber as existing at the determined critical flow conditions, the corresponding pore size can be calculated. This has been done in preliminary tests, but further work is needed to get a correlation with screen analysis.

(558) STUDY OF CAUSES AND PREVENIION OF SAND BOILS.

(b) Laboratory project.

(d) Field investigation; basic research.

(e) Sand boils occurring during floods in levied districts are mapped, classified, and sampled. Also sampled are river and nearby well waters.

(g) From chemical analyses and temperature measurements it was found that the water flowing in typical sand boils (those free from pipe connections towards the river) is different from the river water and similar to well water in neighboring wells. Such sand boils can be stopped from flowing by damming them up to a level that is below that of the river stage. They are not caused by leaks through the levee. 
(559) ARTIFICIAL RECHARGE OF GROUND WATER.

(b) Laboratory project.

(d) Experimental laboratory and field investigation; basic research.

(e) Experimental pilot plant consists of river intake, control tower with chlorination and measuring devices, gravel pit with bottom 10 feet below river pool stage, sides and bottom covered with sand.

(g) Pit now in operation for third winter. In second winter silting reduced inflow to one-third in seven months. Algea growth can give this reduction in four days. Model shows that doubling the size of the pit gives less than double inflow. This relation is being studied experimentally and analytically.

(560) GROUND WATER INVESTIGATION IN THE PEORIA, ILIINOIS, DISTRICT.

(b) Laboratory project.

(d) Field investigation; basic research.

(e) To determine the ground water resources of the district, inventory of wells was made, including construction and logs of wells. Ground water levels are measured contimously, pumpage data collected, river stages and rainfall recorded, chemical analyses for changes in composition of ground water are made, areas of infiltration are determined, and all data are correlated with consideration of local ground conditions.

(g) So far conservation measures have shown more effect than artificial recharge.

(845) EXTENSION OF THEIS' NON-EQUTIIBRIUM THEORY FOR VARIABLE FLOW.

(b) Office project.

(d) Theoretical; basic research.

(e) Development of formulas that could be used for conditions of variable flow.

(g) Formulas developed for most important types of variable flow, but the series obtained have not been calculated for wide ranges.

(1335) GROUND WATER INVESTIGATION IN THE CHICAGO AREA.

(b) Laboratory project.

(d) Field study on variations of natural resources. Investigation of artesian well field with wells 1200 to 2200 feet deep, locally heavily pumped. Study of ground water level recession, interferences, transmissibilities, effect of additional demands.

(g) Results determine recession and give good data for future prediction. Collection of data continued.

(1866) GROUND WATER FORMULAS.

(b) Office project.

(d) Theoretical.

(e) Compilation of all published groundwater the ories and formulas and a comparative evaluation of their range of usefulness.

(h) Report in preparation.

UNI VERSITY OF ILLINOIS, Fluid Mechanics and Hydraulics Laboratory, Department of Theoretical and Applied Mechanics.

Inquiries concerning Projects Nos. 1343 and 1589 should be addressed to Prof. W. M. Lansford, Department of Theoretical and Applied Mechanics, 214 Talbot Laboratory, University of Illinois, Urbana, IIl.

(1343) VELOCITY DISTRIBUTION STUDY IN A FLOOD-PLAIN CHANNEL.

(b) Laboratory project. 
(d) Basic research.

(e) Data has been collected on quantities of flow varying from 1.59 c.f.s. to 11.5 c.f.s. in a flood plain channel, 160+ feet long. The cross-section of the channel consists of a I'x I' main channel with a sloped flood plain on each side.

(f) Data being analyzed.

(1589) OPEN CHANNEL METER.

(b) Laboratory project.

(d) Experimental and analytical.

(e) Data is being collected on a meter which may be built in a sewer leading from a man hole after the sewer has been in service. The models tested were constructed of artists clay in a 6-inch lucite pipe and in a 6-inch $\times$ 6-inch lucite open channel.

UNIVERSITY OF ILIINOIS, Hydraulic Engineering Laboratory, Department of Civil Engineering.

Inquiries concerning Projects Nos. 554, 1590, and 1591 should be addressed to Prof. J. J. Doland, University of Illinois, Urbana, III.

(564) HYDROLOGY OF URBAN AREAS.

(b) Laboratory project, cooperative with IIlinois State Water Survey Division and U. S. Geological Survey.

(d) Experimental, theoretical, and field investigation; applied research and design.

(e) Fourteen recording rain gages, one evaporation station including recording dew-point device, one radar station, and two recording stream gaging stations are installed for observation of rainfall and munof for an area of about eight square miles. Analytical investigation includes frequency analysis of rainfall intensity, area-depth relationship for stcrms, ground-water depletion study, unit hydrograph analysis and consumptive use determination. New type of evaporimeter has been developed and check studies are being made.

(1590) FREQUENCY STUDY OF HYDROLOGIC DATA.

(b) Laboratory project, cooperative with the Illinois Division of Highways and U. S. Bureau of Public Roads.

(d) Theoretical investigation; basic and applied research.

(e) To develop sound principles and practical procedures for the frequency analysis of hydrologic data. A comprehensive survey was made of available literature and theories in the fiela under investigation. Various existing statistical methods of hydrologic analysis were reviewed and an investigation on the suitability and deficiencies of data to be used in the analysis were made. The analyses of precipitation data for Chicago, Illinois, Seattle, Washington and Los Angeles, California were taken as sample cases.

(f) Completed.

(g) Two new procedures of frequency analysis were developed. Procedures for the preparation of hydrologic data were recommended.

(h) Thirteen preliminary reports were produced. A final report entitled, "Frequency analysis of hydrologic data." Ven Te Chow, Technical Bulletin No. 44, University of Illinois Engineering Experiment Station. 
(1591) DETERMINATION OF WATERWAY AREAS.

(b) Laboratory project, cooperative with Illinois Division of Highways.

(d) Theoretical and field investigation; applied research and design.

(e) To determine the amount of water which will reach highway openings, such as bridges and culverts and provide a simple but scientific procedure for use of engineers in establishing the economical and adequate size of opening. Methods of investigation include a survey of existing structures, library study of literature, analyses of pertinent climatological and physical factors relating to the hydrologic and hydraulic features of the problem. The following studies were completed in 1953: (1) Compilation of formulas for waterway area determination, (2) historical review of engineering studies of the subject under consideration, (3) preparation of a bibliography of related lj.terature that have been studied, (4) analyses of waterway area problems at Florence and Petersburg, Illinois, and (5) nation-ride survey of waterway area design practice in state highway departments.

(h) Two preliminary reports and two field reports were produced.

IOWA INSTIMUTE OF HYDRAULIC RESEARCH, State University of Iowa.

Inquiries concerning Projects should be addressed to the following, all at State University of Iowa, Iowa City, Iowa:

Nos. $56,1593,2869,1870 \ldots \ldots \ldots \ldots \ldots \ldots \ldots \ldots \ldots \ldots \ldots \ldots$ to Prof. J. W. Howe.

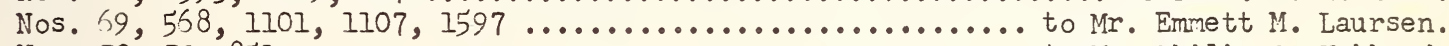

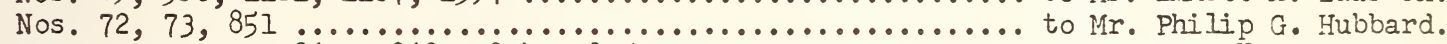
Nos. $302,1102,1867,1868,1874,1875 \ldots \ldots \ldots \ldots \ldots \ldots \ldots \ldots$ to Dr. Hunter Rouse. Nos. $79,81,298,1104,1344,1595,1872 \ldots \ldots \ldots \ldots \ldots \ldots \ldots$ to Dr. John S. McNown.

(66) HYDROLOGIC STUDIES, RALSTON CREEK WATERSHED.

(b) Cooperative with Department of Agriculture and Geological Survey.

(d) Field investigation; applied research and master's thesis.

(e) Study being made of relation between rainfall and munoff over a small area. Discharge from a 3-square-mile area measured by U. S. Geological Survey; rainfall records at five automatic recording stations collected by Soil Conservation Service. Continuous records since 1924 of precipitation, runoff, ground-rater levels, and vegetal cover.

(g) Yearly records available for examination at Iowa Institute of Hydraulic Research.

(h) Reports prepared annually since 1924 available in files at the Iowa Institute of Hydraulic Research.

(67) COOPERATIVE SURFACE-WATER INVESTIGATIONS IN IOWA.

(b) Cooperative with Geological Survey.

(c) Mr. V. R. Bennion, Iowa Institute of Hydraulic Research, Iowa City, Iowa.

(d) Field investigation; collection of basic stream-flow data.

(e) Stream-flow and sediment measuring stations maintained throughout the State of Iowa cooperatively on a continuous basis. Records collected by standard methods of U. S. Geological Survey.

(g) Records of stream flow and sediment discharge computed yearly.

(h) Records contained in water-Supply Papers available throush offices of the Geological Survey.

(う8) HYDROLOGIC STUDIES, RAPID CREEK WATERSHED.

(b) Cooperative with Department of Agriculture and Geological Survey.

(c) Mr. V. R. Benni on, Iowa Institute of Hydraulic Research, Iowa City, Iowa.

(d) Field investigation; applied research and master's thesis. 
(e) Study being made of relation between rainfall and runoff over a small area. Discharge from a 25-square-mile area measured and flood runoff on main sub-basins determined by U. S. Geological Survey; rainfall records at four automatic recording stations collected by U. S. Weather Bureau. Contimuous records since $194 I$ of precipitation, runoff, and ground-water levels.

(g) Rainfall records published in weather Bureau Climatological Bulletins and surface runoff and ground-water levels published in Geological Survey water-Supply Papers.

\section{(69) RELATION OF SEDIMENT CHARACTERISTICS TO BED EROSION.}

(b) Cooperative with Office of Naval Research, Department of the Navy.

(d) Experimental; for doctor's thesis.

(e) To evaluate general relations between geometric and kinematic parameters of flow and mean size and grading of bed sediments for an arbitrary condition of scour. Experiments conducted in glass-walled flume 15 feet long, 3 feet deep, 1-1/2 feet wide with a twodimensional horizontal jet. Selected geometrical proportions kept constant during all runs, the variables being the rate of flow, the mean diameter and standard deviation of the sediment, and time and depth of scour.

(g) Determination of the transport capacity of the flow as a function of the scour hole size, the sediment size and the jet velocity permitted the establishment of a relationship between the extent of scour relative to a limiting extent as a function of a time parameter wt/a divided by a flow parameter $V / \sqrt{2 \Delta y / p}$. The limiting extent of scour was found to be a function of the flow parameter and the ratio of the jet velocity to the fall velocity of the sediment $\nabla / w$. The equipment has been modified for the continuation of the study to include the effect of the grading of the bed sediments.

(h) "Observations on the nature of scour." E. M. Laursen, Proceedings of the Fifth Hydraulics Conference, Bulletin 34, State University of Iowa Studies in Engineering, 1953.

(72) ELECTRICAL ANALOGY OF THREE-DIMENSIONAL FLOW.

(b) Cooperative with Office of Naval Research, Department of the Navy.

(d) Experimental; basic research.

(e) During the year, constant-pressure transitions computed with the aid of a free-streamline theory were tested.

(f) Inactive.

(73) MEASUREMENT OF TURBULENCE IN FLOWING WATER.

(b) Laboratory and field project.

(d) Experimental development.

(e) To develop practical instruments for the field measurement of turbulence in flowing water. Instruments under study include a rigidly mounted unit for shallow water over a considerable velocity range, a unit to be suspended on a cable for deep water, and a tape recorder for evaluation of means and root-mean-squares of three velocity components. Measurements utilizing the dissipation of heat by forced convection are under way.

(g) Work will contimue on analyzing methods.

(h) Report to Waterways Experimental Station on earlier phase of project has been made, but no publication to date.

\section{(79) CAVITATION.}

(b) Cooperative with Office of Naval Research, Department of the Navy.

(d) Experimental and theoretical; basic research and graduate theses.

(e) Basic information is sought on cavitation for systematically varied boundary conditions. Tests are conducted in two variable-pressure water tunnels and a special cavitation tank. Studies have been conducted on high-velocity submerged jets, using underwater noise as a criterion, to determine cavitation parameters. Tests have been nade to evaluate the relati onship between the cavitati on index and temperature, relative velocity, and nozzle geometry. Determination is being made of the effect of relative spacing upon the pressure distribution around a grid of equipment cylinders mounted perpendicular to a steady, unform, two-dimensional flow. Pressure distributions have been measured in the water tunnel for two-dimensional flow at Reynolds numbers above the boundary-layer critical. Previous measurements of the pressure distribution around various rounded, ellipsoidal, and conical head forms have been extended to various angles of yaw. 
(h) "Drag tests on cylinders arranged in a straight grid." Clark Glen DeHaven, M. S. Thesis, State University of Iowa, June, 1953.

(81) MATHEMATICAL ANALYSIS OF PRESSURE DISTRIBUTION.

(b) Cooperative with Office of Naval Research, Department of the Navy.

(d) The oretical; basic research.

(e) Methods of applying irrotational-flow theory to problems of hydraulic design have been used to obtain information on specific problems. The pressure distributions around faired boundary forms were obtained mathematically, assuming that viscous effects are negligible. Both exact and approximate methods were used, and wherever possible the results have been compared with experimental measurements determined in other studies. An inverse form of the relaxation method has been used for analysis of flows with curved boundaries. Representative problems in progress or recently completed are flow over a high weir, transformation of a gravity wave in an open-channel transition, and efflux from a two-dimensional conduit (see 1593).

(h) "Applications of the relaxation technique in fluid mechanics." John S. McNown, En-Yun Hsu, and Chia-Shun Yih, Proceedings Sep. No. 223, ASCE, July, 1953.

(298) FALL VELOCITY OF SEDIMENT.

(b) Laboratory project.

(d) Experimental; basic research and master's theses.

(e) The effect of a cylindrical boundary and the particle shape on the fall velocity of individual particles, and the effects on concentration on the rate of settlement of sediment samples have been investigated. Various reports on these studies have been prepared.

(f) Inactive.

(302) SEDIMENT SIZE ANALYSIS BY MEANS OF PRESSURE DIFFERENTIALS IN STRATIFIED SUSPENSION.

(b) Laboratory project.

(d) Experimental; doctoral dissertation.

(e) To develop a technique for rapid size-frequency determination by measurement of pressure differentials during relative motion between sediment and suspending liquid. Sample is introduced at top of a water-filled tube containing a previous piston which can be displaced along axis of tube. Piezometers at top of tube and just above piston permit differential pressure, and hence immersed weight of suspended sediment, to be recorded during traverse of tube by piston. Instrumentation has been completed.

(f) Inactive.

(h) "An instrument for the rapid size-frequency analysis of sediment samples." D. W. Appel, Proceedings Fifth Hydraulics Conference, Bulletin 34, State University of Iowa Studies in Engineering, 1953.

"An instrument for rapid-size frequency analysis of sediment." David W. Appel, Ph. D. Dissertation, State University of Iowa, August, 1953.

(568) SCOUR AT BRIDGE PIERS AND ABUTMENTS.

(b) Cooperative with Iowa State Highway Commission and U. S. Bureau of Public of Public Roads.

(d) Experimental; applied research.

(e) To investigate the effects of pier and abutment geometry, sediment properties, and stream-flow characteristics on the rate and pattern of scour, to the end of providing safe design criteria. 
(g) Initial phase, the study of pier and abutment geometry has been inactive for the past year. The second phase, the study of the effect of stream-flow characteristics, and the third phase, the study of sediment characteristics, are almost complete. If the bed-load movement is general and the flow sub-critical, the investigation shows that neither the velocity of flow nor the sediment size has any appreciable effect on the equilibrium depth of scour. The depth of flow, however, has an effect on the scour depth at equilibrium. Because of the limited range of the laboratory experiments this effect cannot be well established. Electrical measuring and recording equipment have now been installed at a chosen bridge site to determine the depth of erosion at a centrally located pier during floods. Results will be correlated with laboratory studies to provide information relative to the necessary depth of footings for bridge piers.

(h) "Observations on the nature of scour." E. M. Laursen, Proceedings Fifth Hydraulics Conference, Bulletin 34, State University of Iowa Studies in Engineering, 1953. "A generalized model study of scour around bridge piers and abutments." E. M. Laursen and A. Toch, Minnesota International Hydraulies Convention, 1953.

\section{(851) A CONSTANT-TEMPERATURE HOT-IIIRE ANEMOMETER FOR THE MEASUREMENT OF TURBULENCE IN AIR.}

(b) Cooperative with Office of Naval Research, Department of the Navy.

(d) Experimental; instrument design.

(e) The anemometer was designed to measure fundamental properties of turbulence in a lowvelocity air tunnel, with special emphasis on simple operation techniques and high sensitivity at low frequencies. The aims were accomplished by utilizing carefully designed electronic control circuits and maintenance of the wire temperature at a constant level, above that of the air stream.

(g) Improvements have been made which led to greater stability and a more nearly linear response to the magni.tude of the velocity. Complete new design now available. During the year, a complete two-channel system with linear velocity vs. output-voltage characteristic was constmuted for the David Taylor Model Basin.

(854) BOUNDARY-LAYER DETELOPMENT ON SMOOTH AND ROUGH SURFACES.

(b) Cooperative with Office of Naval Research, Department of the Navy.

(c) Dr. Francis Hama, Iowa Institute of Hydraulic Research, Iowa City, Iowa.

(d) Experimental and theoretical basic research.

(e) Following completion of velocity and turbulence measurements on surfaces artificially roughened by wire screen varying from 1 to 30 mesh, investigation will be extended to surfaces with natural roughness.

\section{(1201) MOVEMENT OF SEDTIENT IN HIGHWAY DRAINAGE SYSTEMS.}

(b) Cooperatitre with Iowa State Highway Comnission and U. S. Bureau of Public Roads.

(d) Experimental; for basic research and graduate theses.

(e) A study of the movement of sediment in pipes, including the pattern of sand transport and the accompanying hydraulic energy losses for quasi-uniform flow in a circular conduit. Both full-pipe and free-surface flows have been studied.

(f) Complete except for final report.

(g) Relationships adequate for design established for the energy loss, the blockage, and the limiting condition of residual deposition as a function of the discharge, the sediment load, the pipe size, and the sediment size. Experiments now include pit-run sand and slag.

(h) "The transportation of sand in pipes." J.P. Craven, and H. H. Ambrose, Proceedings Fifth Hydraulics Conference, Bulletin 34, State University of Iowa Studies in Engineering, 1953.

"Transportation of sand in a pipe." H. R. Vallentine, Master's Thesis, State University of Iowa, June, 1953. 
(1102) HISTORY OF HYDRAULICS.

(b) Institute project.

(d) Library research.

(e) To trace the historical development of the important theories of hydraulics, covering the fundamental ideas of the science, the critical periods of development, and the contribution of personalities of major importance to this development.

(g) Twelve of projected fifteen chapters completed by Dr. Rouse through facilities of Neyrpic library during 1952-53 Fulbright Scholarship at Grenoble. Publication planned as bilingual supplement to La Houille Blanche in 1954.

(1104) ACCELERATED MOTION OF A SPHERE.

(b) Laboratory project.

(d) Experimental; basic research and doctor's thesis.

(e) The force components on an accelerated sphere in a fluid medium have been studied by experimental means. An investigation is also being made of the acceleration of a sphere falling freely from rest. The project is intended to provide information concerning the diffusion characteristics of suspended sediment.

(1107) TRANSPORTATION OF SEDIMENT AS SUSPENDED AND TOTAL LOAD.

(b) Cooperative with Office of Naval Research, Department of the Navy.

(d) Experimental; basic research.

(e) To determine the suspended and total load as a function of hydraulic and sediment parameters. A recirculating flume 3 feet wide, 15 inches deep, 100 feet long, and of variable slope (see Proj. 569, 1950) has been in operation for several years. Distribution of sediment, as well as total load, are measured. Effect of sedinent transport on velocity distribution, energy loss, and other hydraulic characteristics will also be evaluated.

(1344) CALCULATION OF FREE-ST REAMLINE FLOWS.

(b) Laboratory project; cooperative with the Office of Naval Research.

(d) Theoretical; applied research.

(e) Calculations have been made of various two-dimensional flows using the classical Helmholtz-Kirchhoff method. Manifold flow with free and constricted lateral efflux, curved inlets and pier profiles, and the deflection and division of jets by symmetrically and unsymmetrically placed vanes are being computed. The intenled applications are to the design of pipe and lock manifolds, the selection of appropriate profiles for inlets and the upstream portion of streamlined piers, and the more precise definition of the behavior of Pelton-wheel buckets.

(f) Essentially completed.

(g) Concordance in bulk characteristics found between results calculated for two-dimensional flow and those measured indicates the usefulness of the computed results.

(h) "Free-streamline analyses of transition flow and jet deflection." Edited by J. S. McNown and C.-S. Yih, Bulletin 35, State University of Iowa Studies in Engineering, 1953.

(1345) DESIGN OF HIGHWAY FILIS FOR SAFE OVERTOPPING BY FIOOD WATERS.

(b) Cooperative with Iowa Highway Research Council.

(c) Prof. C. J. Posey, State University of Iowa, Iowa City, Iowa.

(d) Experimental; applied research pertaining to design.

(e) Full-scale embankments built according to principles developed in model tests are now being tested.

(g) Flume tests show that fine material can be protected by graded layers of crushed-rock or gravel meeting requi rements of Terzaghi-Vicksburg criteria. By binding the top layer tightly in wire sausages, it is not necessary to carry the filter up to uneconomical sizes.

(h) "Some basic requirements for protection against erosion." C. J. Posey, Proceedings of Minnesota International Hydraulics Convention, 1953. 
(1593) PRESSURE CONDITIONS AT THE OUTLET OF A PIPE.

(b) Laboratory project.

(d) Experimental; basic investigation for master's thesis.

(e) Location of the line of piezometric head just upstream from the outlet of a pipe in relation to the Froude number.

(g) Head line slopes toward a point in the outlet section which varies in location from above the top to below the center of the pipe, depending on the Froude number. Negative pressures exist in the flow several diameters from the outlet.

(1594) UNSTEADY PHENOMENA IN FLUID FLOW AND IN HEAT TRANSFER.

(b) Laboratory project.

(c) Dr. Chia-Shun Yih, Iowa Institute of Hydraulic Research, Iowa City, Iowa.

(d) Theoretical.

(e) To study certain unsteady phenomena in fluid flow and in heat transfer. Unsteady boundary conditions and internal heat sources are treated by a technique similar to the Duhamel principle of heat conduction. This technique is applicable to a wide variety of problems in the field of lubrication.

(g) Results for unsteady fluid flow and heat transfer between concentric cylinders have been obtained.

(1595) MODEL STUDY FOR STEAM POWER PLANT, WILL COUNPY, ILLINOIS.

(b) Public Service Company of Northern Illinois.

(d) Experimental; for investigation of design.

(e) Flow conditions in Chicago Sanitary and Ship Canal with diversion for condenser cooling water up to 100 percent of canal flow are being studied in relation to effect on large traffic. Recirculation of heated water due to gravity-current formation is being checked. Continued study is in prospect.

(g) Vaned outlet transition reduced velocity of return flow to canal. Investigation indicated recirculation of heated water will be considerable.

(h) Initial report submitted to sponsor.

(1597) A STUDY OF THE EF FICIENCY OF SAND TRAPS.

(b) U. S. Bureau of Public Roads and Iowa State Highway Commission.

(d) Experimental; for master's thesis.

(e) A study of the effects on the efficiency of sand traps of the geometry of the trap and the ratio of velocity of flow to settling velocity of particles. Various trap proportions, sand sizes, and rates of both sediment and water transport have been varied.

(g) Efficiency of trap shown to be a function of relative trap dimensions and ratio of conduit velocity to fall velocity of sediment. Experiments continuing to check tentative relationships.

(h) "Efficiency of short sand traps." Rasin Z. Etiman, M. S. Thesis, State University of Iowa, February, 1953.

(1598) A STUDY OF THE EFFECT OF IIP ANGLE ON FLOW UNDER A TAINTER GATE.

(b) Laboratory project.

(c) Prof. D. E. Metzler, State University of Iowa, Iowa City, Iowa.

(d) Experimental; for master's thesis.

(e) Experimental data was obtained on a model Tainter gate in a horizontal channel. The results, presented in three dimensionless diagrams, show the discharge coefficient as a function of the ratios of headwater elevation to gate radius, tailwater elevation to gate radius, gate opening to gate radius, and trunnion height to gate radius. 
(1867) MODEL STUDY OF LAKE GEODE DAM SPILLWAY.

(b) Stanley Engineering Company, Muscatine, Iowa.

(d) Experimental; for rectification of design.

(e) Chute spillway as constructed included assymetrical inlet weir, transition from rectangular to trapezoidal section and horizontal curve in alignment.

(f) Complete.

(g) Superelevation of bottom in curve and strategically placed walls corrected flow in spillway.

(h) Report submitted to sponsor.

(1868) MODEL STUDY OF IAKE GEODE DAM SPILLWAY.

(b) Iowa State Conservation Commission.

(d) Experimental, investigation of design.

(e) Design includes assynetrical weir at inlet of chute and horizontal curve in alignment.

(1869) AERATION DEMAND OF A STANDARD SHARP-CRESTED WEIR.

(b) Laboratory project.

(d) Experimental; basic; master's thesis.

(e) Air is fed to space under weir nappe in quantity necessary to keep this space at atmospheric pressure. Quantity of air required in relation to several factors is being investigated.

(1870) EFFECT OF SHAPE OF VERTICAL DRAFT TUBES ON THEIR EFFICIENCY.

(b) Laboratory project.

(d) Experimental; master's thesis.

(e) Comparative study of conical, Prasil, White, and Moody draft-tube efficiency under identical conditions.

(1871) CAVITATING FLOW AROUND HYDROFOIIS.

(b) David Taylor Model Basin, Department of the Navy.

(c) Mr. David W. Appel, Iowa Institute of Hydraulic Research, Iowa City, Iowa.

(d) Experimental project.

(e) To provide information on the effect of cavitation on the characteristics of twodimensional hydrofoils at various angles of attack. Hydrof oils of the NACA 66-series and EPH-series of various thickness and camber are to be tested in a variable-pressure water tunnel having a closed-throat test section 6 by 24 inches. Model hydrofoils supported at one end and spanning the width of the water tunnel will be tested to determine the lift, drag, and pitching moment at various angles of attack and with various degrees of cavitation. The requirements for a water-tunnel balance are being studied in preparation for design and construction. Tests scheduled to begin during surmer of 1954 .

(1872) STUDY OF VORTEX RINGS.

(b) Laboratory project.

(d) Experimental and theoretical basic research.

(e) Studies have been made of vortex rings formed in air by means of a spring-driven piston in an open-ended cylinder. A hot-wire anemometer was used in measurements of velocity distribution and velocity of ring travel. Qualitative observations were also made in both air and water of two types of vortices, the one moving as a vortex and the other as a mass of fluid.

(h) "An exploratory study of vortex rings." A. K. Johnston, M. S. Thesis, State University of Iowa, June, 1953. 
(1873) STABIIITY OF LAMINAR PARALIEL FIOWS WITH A FREE SURFACE.

(b) Laboratory project.

(c) Dr. C.-S. Yih, Iowa Institute of Hydraulic Research, Iowa City, Iowa.

(d) Theoretical and basic.

(e) Series solutions of the Sommerfeld-orr equation have been obtained. From the boundary conditions a secular equation in determinant form can be obtained, which yields the relation between Reynolds member and wave number for neutral stability. The problem for single-layer flow with a free surface nearly completed.

(1874) DIFFUSION OF TURBULENCE ON STEEP SLOPES.

(b) Laboratory project.

(d) Experimental; basic research for master's thesis.

(e) Extension of Project (1100) to include effects of side walls and piers on the disturbance of the free surface on spillways.

(1875) CHARACTERISTICS OF STABLE EDDIES.

(b) Laboratory project.

(d) Experimental; basic research for master's the sis.

(e) Distributions of velocity, pressure, and turbulence will be measured in an air tunnel throughout the vicinity of separation zones produced by abrupt changes in flow section, to the end of establishing the primary eddy characteristics as functions of the boundary geometry.

THE JOHNS HOPKINS UNIVERSITY, Applied Physics Laboratory.

(1876) ANALYSIS OF DYNAMIC OPERATION OF HYDRAULIC (FORCE) AMPLIFIER TRANSFER VALVES.

(b) Bureau of Ordnance, Department of the Navy.

(d) Theoretical and experimental; basic development and research.

(e) Theoretical and experimental project designed to develop a set of linearized differential equations to describe the operation of the single and double nozzle type, hydraulic force amplifier, transfer valves.

(g) Comparison of theoretical and experimental data just beginning.

(h) Report on experimental data and preliminary non-linear equations complete - APL/JHU, TG No. 198.

(1877) ANALYSIS OF STATIC AND DYNAMIC OPERATING CHARACTERISTICS OF HYDRAULIC SERVO MECHANISMS.

(b) Bureau of ordnance, Department of the Navy.

(d) Theoretical and experimental; basic development and research.

(e) Phase (1); static operating characteristics of closed-loop servo mechanisms. Phase (2); dynamic operating characteristics of closed-loop servo mechanisms, including effects of complex mechanical loads.

(f) Phase one; nearly complete. Phase two; proceeding.

(g) Phase (1); some specific recommendations have been derived for system and component design. Phase (2); with the use of analogue computers, the non-linear differential equations of the servo mechanism have been solved. These equations include effect of oil compressibility and complex mechanical loads. Excellent agreement has been obtained between experimental and theoretical results. Analysis is in process to develop a technique to linearize equations and solve for servo transfer characteristics and stability problems without the aid of analogue computers.

(h) Phase (1); Bumblebee Report No. CM-717 completed. Phase (2); Report in preparation. 
THE JOHNS HOPKINS UNIVERSITY, School of Engineering.

Inquiries concerning Projects Nos. 855, 856, and 111 ll should be addressed to Dr. John C. Geyer, The Johns Hopkins University, Baltimore 18, Md.

(855) HYDRAULIC BEHAVIOR OF STORM SEWER INLETS.

(b) Baltimore City, Baltimore County, and the Maryland State Roads Commission.

(d) Experimental, basic research, and design.

(e) Model tests of curb, gutter, deflector and combination inlets of various designs for inflow changes with street dimensions of grade, crown and roughness. Attempt has been made to design a "best" inlet for given street conditions.

(g) Structural tests of a new-type highly efficient cast steel grate with longitudinal bars only show this grate to have adequate strength. Field calibration tests confirm previous model tests which show this grate to have 18 to 30 per cent greater capacity than grates in present use.

(h) "Flow into Curb-openings with Deflectors." W. H. Ii, B. C. Goodell, and J. C. Geyer, to be published in Journal of Sewage and Industrial Wastes.

"Flow into Depressed Combination Inlets." To be published in Journal of Sewage and Industrial wastes.

"Storm Water Inlets." To be published shortly by Sanitary Engineering Department, The Johns Hopkins University, Baltimore, Md.

(856) HYDROLOGY OF STORM DRAINAGE SYSTEMS IN URBAN AREAS.

(b) Baltimore City, Baltimore County, and the Maryland State Roads Commission.

(d) Field Investigation, basic research and design.

(e) Study of rainfall and runoff relationships as affected by types and patterns of ground surface, length and degree of slope, shape of watershed, pattern of drainage ways. At present, runoff from 6 urban areas ranging in size from 30 to 400 acres are gaged by stage measurement only, pending final field installations of a newly developed flow meter. Two recording systems which simultaneously record rainfall on and runoff from 14 inlet areas provide good opportunity for detailed study. About 3 years of rainfall records now exist for a rain gage network of 10 recording gages covering an area of about 50 square miles.

(g) The most significant results of the analyses made to date are: (I) that the time between the peak rainfall rate and the peak flow into inlets in the gaged areas averages about 2 minutes, and in some instances as little as 30 seconds, and (2) that runoff coefficients, calculated back from the rational method used in the actual design of the sewer, appear to be considerably higher than had been anticipated. Further analyses are under way.

(IIII) DEVELOPMENT OF A FIOT GAGE FOR STORM SEWER DISCHARGES.

(b) Baltimore City, Baltimore County, and the Maryland State Roads Commission.

(d) Experimental; applied research.

(e) The development of gages for measuring both depth and velocity of the debris-laden, shooting flow commonly found in storm sewers. The search is for a method generally adaptable to existing storm sewers that does not require extensive alterations of the sewer channel.

(g) A "Pigmy" type cup (Price) current meter in a special mount to give shielding against debris has remained in satisfactory operation with a few exceptions throughout one summer thunder storm season. Velocity and depth of flow are recorded alternately on a single chart.

THE JAMES IEFFEL AND COMPANY.

(1878) TUREINE DEVELOPMENT.

(b) Laboratory project. 
(c) Mr. J. Robert Groff, The James Leffel and Company, 426 East Street, Springfield, Ohio.

(d) Experimental, basic and applied research, design, operation and development.

(e) Additional design, development and testing of low specific speed Francis range of

turbine runners, and model testing of turbines and suitable inlet and discharge approache for same.

Experiments and testing nearly completed and will be continued to completion on thrust bearings of various kinds for hydraulic turbines.

Testing of Impulse model wheels progressing and will be continued. Further tests will be made on propeller type turbines including inlet and discharge approaches.

Certain testing is contemplated in connection with model settings for installations of a commercial nature. Tests duplicating field conditions and determining by prototype performance the expected results to be obtained in the actual field installation.

\section{IEHIGH UNIVERSITY, Fritz Engineering Laboratory.}

Inquiries concerning Projects Nos. 90, 1113, 1602, and 1603, should be addressed to Prof. M. B. McPherson, Department of Civil Engineering and Mechanics, Lehigh University, Bethlehem, $\mathrm{Pa}$.

(90) STUDIES OF PRESSURE VARIATIONS CAUSED BY BOUNDARY MISAIIGNMENT IN THEIR RELATION TO CAVITATION IN HYDRAULIC STRUCTURES.

(b) A.S.C.E. Subcomittee on Cavitation and the Lehigh Institute of Research.

(d) Experimental; basic research; master's thesis.

(e) Determination of pressure variation as a function of approach velocity and head, and magnitude of misalignment. Study of pressure distribution along one surface of both a rectangular open channel and a closed conduit in which a transverse step of variable height has been placed, with the object of defining misalignment tolerances for hydraulic structures.

(f) Reactivated in 1953, with the objective of extending the scope of application.

(g) Studies of open and closed conduits to date have yielded distinct relationships between difference in piezometric head, velocity head and height of misalignment.

(1113) A STUDY OF SHARP-CRESTED CIRCULAR WEIRS.

(b) Laboratory project.

(d) Experimental; undergraduate thesis.

(e) Study of the effects of variations in head, approach depths and diameter. Weirs are circular in plan, radial in approach.

(f) Experimental work being extended in 1953-54.

(h) Report for publication to be prepared.

(1602) PRESSURE DISTRIBUTION IN CONDUIT BENDS.

(b) Laboratory project.

(d) Experimental; applied research, for professional degree thesis, undergraduate and graduate special problem.

(e) An investigation of minimum pressure has been made for bends of both rectangular and circular cross-section, with varying degrees of curvature. The flow characteristics of 90-degree pipe "elbow meters" or "flow bends" have been studied. By locating piezometer taps at the station of maximum differential more reliable results and independence from the effects of adjacent piping have been obtained. Paper being prepared for possible publication. The flow characteristics of duct bends of rectangular crosssection are now being investigated using air. Former tests with water were consistent and conclusive.

(h) "The Calibration and Accuracy of Elbow Meters." Donald C. Taylor, undergraduate special problem, March, 1953. 
(1603) BUTTERFLY VALVE STUDY.

(b) C.D.C. Controls Services, Inc., Hatboro, Pa.

(d) Experimental; applied research; master's thesis.

(e) Fundamental butterfly valve characteristics are being investigated. Detalls presently are confidential but results eventually will be submitted for publication.

(g) The first of three phases of investigation was completed in 1953.

(1879) SHAWILLE DAM MODEL INVESTICATION.

(b) Gilbert Associates.

(c) $\mathrm{Mr}$. A. W. Reid, Gilbert Associates, Reading, $\mathrm{Pa}$.

(d) Experimental; design.

(e) Two-dimensional study of a proposed condensing-water intake dam with flashboards.

(f) Completed.

(g) Scouring effect with differential flashboard release was major consideration.

(h) Model tests for Shawville Dam." Report No. 1427, A. W. Reid, Jan. 6, 1953.

(1880) OPEN CHANNEL OUTLET MANIFOLD.

(b) Gilbert Associates.

(c) Mr. A. W. Reid, Gilbert Associates, Reading, Pa.

(d) Experimental; design.

(e) Objective was to check design of a manifold for the end of an eight-foot condensing water outlet conduit. Efflux velocity of existing outlet had to be reduced.

(f) Completed.

(g) Modification of original design produced a reasonably low, uniformly distributed eff lux velocity.

(h) "Model tests for condensing water outlet structure - Front St. Station, Erie, Penna." Report No. 山29, A. W. Reid, May 8, 1953.

MASSACHUSETTS INSTITUTE OF TECHNOLOGY, Department of Civil and Sanitary Engineering, Hydrodynami cs Laboratory.

Inquiries concerning Projects Nos. 307, 577 to 580, incl., 1354, 1355, 1608 to 1612, incl., and 1881, should be addressed to Dr. Arthur T. Ippen, Prof. of Hydraulics, Hydrodynamics Laboratory, Massachusetts Institute of Technology, Cambridge 39, Massachusetts.

(307) STABILITY OF FIOW STRATIFIED DUE TO DENSITY DI?FERENCES.

(b) Laboratory project.

(d) Theoretical and experimental; graduate research.

(e) (1) Theoretical and experimental investigations have been made on steady-state uniform density current flows including determination of velocity distributions, resistance laws and interfacial stability. (2) Investigation of the characteristics of stratified flow through a sluice gate.

(g) Resistance laws for uniform subsurface flows have been obtained. Theoretical velocity distribution for laminar flow agrees with experimental observations and various criteria for interfacial mixing have been investigated. Experimental work now in progress on phase 2. Object is to determine conditions under which lighter liquid is drawn through sluice gate when a two-layer system exists upstream of the gate. Both steady and unsteady state flow conditions are being investigated.

(577) CHARACTERISTICS OF SOLITARY WAVES.

(b) Office of Naval Research, Department of the Navy.

(d) Experimental; basic research. 
(e) (1) Experimental investigation of solitary wave characteristics in a horizontal channel. Measurements of attenuation for various bottom roughnesses. (2) Investigation of amplitude change, profile deformation and breaking characteristics of the solitary wave on a sloping beach.

(g) Phase $I$ of the program is essentially complete. Wave celerity, shape internal velocities, and smooth-bottom attenuation have been measured and compared with various analytical results. Measurements of amplitude attemuation for different bottom roughnesses have been obtained.

In phase 2, the complete history of solitary waves propagating from a region of constant depth onto a smooth beach of constant slope is being recorded for several slopes.

Breaking data are being compared with available theories.

(h) "The solitary wave--its celerity, profile, internal velocities and amplitude attenuation in a horizontal smooth channel." J.W. Dailey, and S. C. Stephen, Jr., Coastal Engineering, Cambridge, Mass., Oct. 1952.

(578) TURBULENCE MEASUREMENTS WITH A PITOT TUBE-PRESSURE CELL COMBINATION.

(b) Office of Naval Research, Department of the Navy.

(d) Experimental; development of instrumentation.

(e) Studies of turbulence characteristics in open channel flow.

(g) A turbulence-measuring instrument consisting of a Pitot tube and an electric capacitance pressure cell is employed for turbulence investigations in an open channel. Autocorrelation curves from an oscillograph record of the turbulent fluctuations have been obtained using a mechanical correlator. Analysis showed a very low resonance frequency to be present in the record. Accordingly, a new gage having a higher frequency response has been designed and constructed. Preliminary tests indicate a resonance frequency higher than $250 \mathrm{cps}$. Turbulence records from this gage are being correlated by means of a digital computer.

(579) INVESTIGATION OF FLUTD FRICTION IN UNSTEADY MOTION.

(b) Office of Naval Research, Department of the Navy.

(d) Experimental; basic research and development of instrumentation.

(e) Investigation of the influence of unsteady motion on the flow in conduits and past submerged bodies in a specially developed water tunnel.

(g) High frequency response electronic cells were developed for direct measurement of transient pressure differentials. These cells were employed in experiments to determine loss of head in a one-inch pipe during unsteady flows with accelerations up to $40 \mathrm{ft} /$ $\mathrm{sec} / \mathrm{sec}$. A servo-mechanism has been developed to regulate the pressures governing the acceleration rates.

The first phase of experimental work in which head losses were measured at various acceleration rates has been completed. Experiments on the second phase are concerned with the measurement of losses for unsteady flow through orifices of various orifice-topipe diameter ratios. Both accelerating and decelerating flows will be used for these studies.

(h) "The unsteady flow water tunnel at the Massachusetts Institute of Technology." ASME Spring Meeting, April, 1953, Paper No. 53-S-31.

"Head loss coefficients for unsteady flow through orifices." W. L. Hankey, Jr., M. S. Thesis, 1953.

"Redesign of a water tunnel pressure-control system." W. H. Seaver, M. S. Thesis, 1953. "Resistance coefficients for accelerated flow through orifices." J. W. Daily, and W. I. Hankey, Jr., Technical Report No. 10, M.I.T. Hydrodynamics Laboratory, Oct. 1953.

(580) FUNDAMENTAL RESEARCH ON METHODS OF AIR DISPERSION IN AERATION PROCESSES.

(b) Federal Security Agency, U. S. Public Health Service.

(d) Experimental; basic research.

(e) Study of the mechanics of oxygen absorption by water with the purpose of increasing the efficiency of aeration processes. 
(g) Both air and oxygen are systematically dispersed by means of diffusor nozzles through water deaerated to low concentrations of axygen. Bubble size, frequency and concentration are varied in a vertical lucite test column of 5-1/2 in. diameter. The rate of oxygen absorption by the water is recorded contimously by a polarographic instrument, and values of the absorption coefficients are obtained in relation to the above variables. Additional tests are to determine mixing coefficients and associated turbulence induced by the bubble motion.

(h) "Contimuous measurement of dissolved oxygen with dropping mercury and rotating platinum electrodes." A. T. Ippen, and C. E. Carver, Jr. Conference on Instrumentation in Water, Sewage and Industrial Waste Treatment, Manhattan College, May, 1953.

"Basic factors of oxygen transfer in aeration systems." A. I. Ippen, and C. E. Carver, Jr., 26th Annual Meeting Federation of Sewage and Industrial Wastes Association, Miami, Florida, Oct. 1953.

1354) THE MOTION OF DISCRETE PARTICLES ALONG THE BED OF A TURBULENT STREAM.

(b) Laboratory project.

(d) Experimental; graduate research.

(e) To establish a more rational basis for the analysis of some of the complex bed-load phenomena. By use of discrete particles on beds of varying roughness the variables entering the experimental analysis are reduced to distinct sediment and stream characteristics for which analytical concepts can be postulated.

(g) An analytical expression for incipient particle motion has been obtained in terms of the physical characteristics of the sediment, bed and hydrodynamic forces on the particle. Additional experiments to widen the range of the tests are proposed.

(h) "The motion of discrete particles along the bed of turbulent stream." A. T. Ippen, and R. P. Verma, Proceedings, Minnesota International Hydraulics Convention, Sept. 1953.

1355) CAVITATION INCEPIION FOR STEADY MOTION.

(b) Office of Naval Research, Department of the Navy.

(d) Experimental; basic research.

(e) Cavitation inception for steady motion is to be studied for systematic variations in boundary layer development and in the turbulence level for the zone of minimum pressure.

(g) A closed-jet water tunnel with a rectangular test section has been developed for these studies. The working section is arranged so that the boundary layer growth is controlled by a systematic change of its shape. Provision is also made for control of turbulence level, pressure intensity and air content.

A photographic technique for detecting the inception of cavitation and the location of the initial cavities with respect to the boundary is also being developed.

(h) "A water tunnel for the study of Reynolds mumber effects on cavitation inception." J. D. Harms, M. S. Thesis, Sept. 1953.

1608) FLOW CHARACTERT STICS OF SWING AND BALI CHECK VAIVES.

(b) Atomic Energy Commission.

(d) Experimental; development.

(e) Hydraulic characteristics of the components of a heat exchange circuit are to be determined. Components include check valves, transitions, expansion joints and filters.

(g) Test circuit consists of an 8 -inch pipe approximately 60 feet long with associated pressure measuring and flow metering equipment. Comprehensive tests have been completed on the head loss characteristics of various types of check and stop valves. Special attention is devoted to the behavior of check valves under sudden flow reversal and also to the stability of check valves under various forward flow conditions.

(h) "Water tests of eight-inch check and stop valves." A. T. Gifford; R. E. Nece; and R. E. DuBois, Technical Report No. 5, M.I.T., Hydrodynamics Laboratory, Aug. 1953. 
(1609) EXPERIMENTAL STUDY OF THE SORTING OF BEACH SEDIMENTS BY WAVE ACTION.

(b) Beach Erosion Board, U. S. Army Corps of Engineers.

(d) Experimental; basic research.

(e) Quantitative study of the sorting action and selective transport of beach material by shallow water waves moving on a gramular beach.

(g) Equipment to be used consists of a wave channel together with a piston type wave generating mechanism. The wave generator is controlled by a hydraulic servo mechanism which permits contimuous variation of both wave amplitude and frequency during operati Beaches consist of graded materials of selected sizes and variable physical properties The results of the sediment transport and sorting studies are to be related systematically to the various wave characteristics such as shape, celerity, frequency and internal velocities.

(1610) WATER TABLE EXPERIMENTS FOR THE STUDY OF BLAST EFFECT ON STRUCTURES.

(b) U. S. Air Force.

(d) Experimental; basic research.

(e) Investigation of water table techniques as a means of simulating and providing basic information for supplementing available shock tube and wind tunnel data.

(g) A water table with a total surface area of $50 \mathrm{ft}^{2}$ having a glass bottom is used for these studies. Moving shock waves of variable intensity are created by a surge generator. As the shock impinges on various obstacles, the depth-time relationships at designated points are obtained by various photographic and electrical methods. An electronic water-level indicator which operates on a capacitance principle with a single coated probe is used for these studies. The instrument provides a continuous depth-time relationship on a recording oscillograph.

A method has been proposed for the transfer of water-table data to analogous shock tube aerodynamic information. Pressure loadings around various obstacles are being compared with shock tube results.

(h) "Water table experiments on transient shock wave diffraction." Part I. D. R. Harleman, and 0.A. Boedtker, Technical Report No. 12, M.I.T. Hydrodynamics Laboratory Aug. 1953.

(1611) DIRECT DRAG MEASUREMENTS ON BAFFLE PIERS.

(b) Laboratory project.

(d) Experimental; basic research for master's thesis.

(e) Investigation of the effect of baffle piers on the stabilization and energy dissipatior associated with hydraulic jumps.

(g) Direct measurements of drag exerted on baffle piers by flow is made possible by the use of an isolated plate in the floor of a glass-walled flume. Small displacements of the plate, to which the piers are attached, are measured by electronic methods and related to drag force. Major variables are initial Froude number, depth and position of the jump with respect to the piers.

(h) "The direct measurement of forces on baffle piers in the hydraulic jump." D. T. Higgins, M. S. Thesis, 1953.

"Effect of baffle piers on the hydraulic jump." J. B. Newman, and F. A. LaBoon, M. S. Thesis, 1953 .

(1612) CORPLETE CHARACTERISTICS OF A $10 "$ KAPLAN TURBINE AND A 12 " ADJUSTABIE BLADE PROPELIOR PUMP.

(b) Laboratory project.

(d) Experimental; research for master's thesis.

(e) Study of pump and turbine characteristics for a wide range of operating conditions including energy dissipation and flow reversal.

(g) The test circuit provided by the S. Morgan Smith Company consists of an adjustable blade pump, a Kaplan turbine, draft tube pressure tank, Venturi meter, and dynamometers Power is supplied by $40 \mathrm{KW}$ DC motor generator set.

Complete characteristic curves for the Kaplan turbine have been obtained for two blade angles at various gate positions.

(h) "The complete characteristics of a Kaplan turbomachine." E. N. Rein, M. S. Thesis, 195 
(1881) WAVE FORCES ON OFF SHORE STRUCTURES.

(b) Humble $0 i l$ and Refining Company.

(d) Experimental; basic research.

(e) Objective is the determination, by means of model tests, of the design forces to be expected on off shore structures subjected to shallow water wave action.

(g) Experimental equipment includes a 100-ft wave tank, an oscillatory wave generator of variable amplitude and frequency and a force balance for measuring dynamic forces caused by the wave motion. Tests on various sizes of vertical cylinders are being made to determine scale effect. Comparison of model tests with field data is planned.

MASSACHUSETTS INSTITUTE OF TECHNOLOGY, Department of Mechanical Engineering.

Inquiries concerning Projects should be addressed to the following, all at Massachusetts Institute of Technology, Cambridge 39, Mass.

Nos. 1359, 1616, 1885 to 1889, incl................... to Prof. A. H. Shapiro.

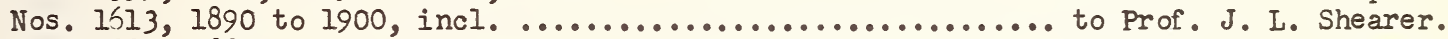

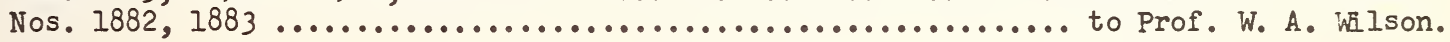

(880) RECOVERY FACTORS AND HEAT-TRANSFER COEFFICIENTS FOR SUPERSONIC FLOW OF AIR IN A TUBE.

(b) Office of Naval Research, Department of the Navy.

(c) Prof. Joseph Kaye, Massachusetts Institute of Technology, Cambridge 39, Mass.

(d) Experimental and theoretical; basic research for M.S. and D.Sc. degrees.

(e) To measure reliable heat-transfer coefficients for supersonic flow of air in a tube.

(g) Publications summarize results obtained to date.

(h) "Measurements of friction coefficients for supersonic flow of air in the entrance region of a tube with and without heat transfer." J. Kaye and T. Y. Toong.

Measurements of friction coefficients, recovery factors, and heat transfer coefficients for supersonic flow of air in a pipe." J. Kaye, J.H. Keenan, W. H. McAdams.

Measurement of recovery factors and friction coefficients for supersonic flow of air in a tube." J. Kaye, J. H. Keenan, and R. H. Shoulberg.

"Measurement of recovery factors and friction coefficients f or supersonic flow of air in a tube." J. Kaye, J. H. Ke enan, K. K. Klingensmith, G. M. Ketchum and T. Y. Toong. (part I). (part II) J. Kaye, T. Y. Toong, and R. H. Shoulberg.

"Survey of Iriction cofficients, recovery factors, and heat-transfer coeficients for supersonic flow." J. Kaye.

(1118) RESEARCH ON CASCADES OF AIRFOILS (IOW-SPEED CASCADE, THREE-DIMENSIONAL FLOW).

(b) General Electric Company and Westinghouse Electric Corp.

(c) Mr. Jan V. Zika, Room 31-267 Massachusetts Institute of Technology, Cambridge 39, Mass.

(d) Experimental and theoretical; applied research.

(e) Investigation of three-dimensional flow effects on performance of two-dimensional decelerating cascades; influence of leakage flow at the tips of compressor blades; effect of relative motion between the wall and the airfoil tips; methods of control of secondary circulation in order to increase loading of compressor blading; determination of stream lines of turbulent flow through blade passages; and evaluation of losses, particularly of those due to secondary flow.

(g) Numerical methods for determination of secondary velocities, total losses. Qualitative results of above topics. 
(h) "Design of a cascade test rig." R. S. Sproule, M. S. Thesis, 1947.

"Characteristics of a compression cascade." T. W. Graff, M. S. Thesis, 1950.

"Some exact solutions of the flow through annular cascade actuator discs." S. I. Bragg and W. R. Hawthorne, Jour. Aero. Sci., Vol. 17, No. 7, 1950.

"A theory of struts in boundary layers." W. R. Hawthorne, Gas Turbine Laboratory

Memorandum, 1951.

"The flow of air through a cascade." D. C. Prince, Sc. D. Thesis, 1951.

"Secondary circulation in fluid flow." W. R. Hawthorne, Proc. Royal Soc. A., Vol. 206, 1951.

"Three-dimensional flow in a cascade." N. Van Le, Sc. D. Thesis, 1952.

"The effects of a moving wall on secondary flow in a cascade." F. R. Toline, and R. H. Watson, M. S. Thesis, 1953.

(1359) EFFECT OF HEATING ON THE TRANSITION OF LAMINAR BOUNDARY IAYERS IN WATER.

(b) Office of Naval Research, Department of the Navy.

(d) Experimental; applied research; doctoral thesis.

(e) The theory of the stability of laminar boundary layers indicates that in water the stability is increased if the wall past which the layer flows is heated. Experiments are being conducted near a tube entry to test this theory.

(f) Contimuing.

(g) Whth water containing a normal amount of air in solution, no significant effect of heating was observed. The experiments are being continued with deaerated water.

(h) "The effect of heating on boundary layer transition for liquid flow in a tube." $R$. Siegel, and A. H. Shapiro, Report submitted to ONR under Contract N5-ori-07871, 1953 (also in preparation as ASME paper).

(1374) SHEAR FLOW IN BENDS.

(b) Office of Naval Research, Department of the Navy.

(c) Mr. Raymond Moore, Room 31-257, Massachusetts Institute of Technology, Cambridge 39, Mass.

(d) Experimental and theoretical; applied research and development.

(e) To investigate the three-dimensional behavior of a viscous fluid flowing through a channel which changes the direction of the stream and to use results of this investigation to explain the various flow patterns observed in turbomachines. The flow distribution in a rectangular cross section duct with a $90^{\circ}$ bend was determined and a physical understanding of the phenomena at work was gained. A single-stage, axial test compressor has been built and the flow distribution through the machine will be determined. It is hopec that a better understanding of flow behavi or in a turbo-machine will make possible more accurate design.

(h) "Shear flow in bends." Hans Eichenberger, S. M. Thesis, Jan. 1950.

"Shear flow in bends." Hans Eichenberger, M. E. and Sc. D. Thesis, Jan., 1952.

\section{(1613) DYNAMIC CHARACIERISTICS OF VALVE-CONTROLIED HYDRAUIC SERVOMOTORS.}

(b) Cooperative with Bureau of Ordnance, Department of the Navy.

(d) Applied research.

(e) A servomotor consisting of a valve-controlled ram connected to a mass plus viscous friction load is analyzed on the basis of its response to small changes of valve position and external load force. The approach is sufficiently general to enable one to deal effectively with systems in which fluid compressibility is an important factor. At the same time, this approach is helpful in working with simpler systems. A functiona] block diagram is employed to delineate symbolically the significance of each system char acteristic.

(g) Although the performance of a number of systems studied experimentally does depart a little from that predicted by linearized analysis, this departure is due to effects such as dry friction and additional component lags which were ignored in the linearized analysis. The linearized analysis has proven to be an excellent design tool.

(h) "Dynamic characteristics of valve-controlled hydraulic servomotors." J. I. Shearer, Paper No. 53-A-147, presented at the Anmual Meeting of the A.S.M.E., Nov. 30 - Dec. 4, 1953, in New York City. Reprints available from A.S.M.E. Order Dept. 
(1616) PERFORMANCE OF DIFFUSERS FOR A STREAM OF AIR CONTAINING ENIRAINED LIQUID DROPLETS.

(b) Office of Naval Research, Department of the Navy.

(d) Experimental and theoretical; applied research; for master's thesis.

(e) A stream of air containing liquid droplets is decelerated in a diffuser. Theoretically the momentum of the liquid may be transferred to the air and thereby increase the pressure rise which would otherwi se be attained.

Theoretical work has been done to compute the pressure rise attainable. Experiments have been carried out to determine the pressure distribution and efficiency as functions of water-air ratio and inlet Mach Number.

(f) Suspended.

(h) "Experimental and theoretical investigation of subsonic air diffusers with entrained liquid droplets." E. G. Feher, S. M. Thesis, 1953.

(1882) INVESTIGATION OF FIOW OF FLUIDIZED SOLIDS.

(b) Laboratory project - under Grant-in-Aid from M. W. Kellogg.

(d) Analytical and experimental.

(e) To produce several regimes of fluidized solid flow under controlled conditions and to rationalize the observed behavior.

(g) An apparatus capable of establishing steady state flow in a vertical test section has been developed. Iight, medium and dense phase flows have been observed.

(1883) INVESTIGATION OF "REGENERATIVE TURBINE" PUMPS.

(b) Laboratory project; under Grant-in-Aid from Worthington Corporation.

(d) Analytical and experimental.

(e) The rationalization of the performance characteristics of "friction" pumps and the determination of the relationship between these characteristics and the design parameters.

(g) A satisfactory theoretical model has been devised and shown to be adequate to account for the performance of at least one commercial unit.

(h) "Development of an analysis of a regenerative pump." J.A. Oelrich, M. E. Thesis.

(1884) INVESTIGATION OF CYCLONE DUST SEPARATOR.

(b) Jabez Burns and Sons, Inc., New York, N. Y.

(c) Professor Joseph H. Kennan, Massachusetts Institute of Technology, Cambridge 39, Mass.

(d) Experimental; applied research; master's thesis.

(e) Experimental studies have been made of the boundary-layer flow patterns in a cyclone with a small ratio of inlet area to diameter squared. Measurements of dust separating efficiency have been made over a range of inlet velocities and with certain variations in the geometry of the separating chamber. Planning to extend measurements over a range of ratios of inlet area to diameter squared.

(g) Some understanding of boundary-layer flow patterns. Insensitiveness of separating efficiency to changes in velocity or end geometry under the conditions studied.

(h) "Secondary flow in a cyclone separator." R. A. Shuart and A. B. Magnus, Bachelor's Thesis, 1952.

"Secondary flow in a cyclone separator." R. A. Shuart, Master's Thesis, 1953.

(1885) FLOW OF AIR CONTAINING SUSPENDED WATER SPRAYS IN PIPES.

(b) Office of Naval Research, Department of the Navy.

(d) Theoretical; applied research; engineer's thesis.

(e) A number of simple flow examples of air-water mixtures were investigated and results presented in convenient reference form for engineering use. The problems comprise:

(1) The one-dimensional trajectory of droplets accelerated in a gas stream, (2) The variation of stream properties during the droplet acceleration, and (3) The variation of stream properties due to wall friction when water is present in the stream.

(f) Completed.

(g) Graphs, tables, and formulas give results for problems stated above.

(h) "One-dimensional analysis of steady-flow air-water mixtures in pipes." M. Booth, Thesis for Degree of Naval Engineer, 1953. 
(1886) SAMPIING OF WATER CONTENT OF SPRAY-LADEN AIR STREAM.

(b) Office of Naval Research, Department of the Navy.

(d) Experimental; applied research; engineer's thesis.

(e) Object of investigation was to develop a sampling technique for measuring the waterair ratio of a high-speed, spray-laden air stream. Experiments have been conducted with several probe designs.

(h) "A sampling technique for the measurement of the water-air ratio of a high speed sprayladen air stream." R. E. Kosiba, and F.H. E. Vose, Thesis for degree of Naval Engineer, 1953.

(1887) THE COEFFICIENT OF DISCHARGE OF FUUNDED-ENTRANCE FLOWMETERS.

(b) Laboratory project.

(d) Theoretical.

(e) The details of the potential and boundary layer flows for a rounded-entrance flowmeter are worked out in sufficient detail to permit determination of the discharge cœfficient.

(f) Completed.

(g) The analytical curve of flow coefficient vs. Reynolds number is in excellent agreement with the measured curve.

(h) Paper in preparation.

(1888) THEORY OF IAMINAR FLOW IN THE ENTRY OF A PIPE.

(b) Office of Naval Research, Department of the Navy.

(d) Theoretical; basic research; doctoral thesis.

(e) The development of the boundary layer at the inlet of a pipe in laminar flow has been studied the oretically, with the object of determining the boundary layer thickness and the friction coefficient.

(f) Completed.

(g) A complete theory has been worked out. It is in excellent agreement with experiment.

(h) "Friction factor in the inlet length of smooth tubes." A. H. Shapiro, R. Siegel, and S. J. Kline. Paper in preparation for publication.

(1889) TOTAI PRESSURE MEASUREMENTS IN A STREAM CONTAINING ENTRAINED WATER PARTICLES.

(b) Office of Naval Research, Department of the Navy.

(d) Experimental and theoretical; basic research; doctoral thesis.

(e) Studies (analytical and experimental) are being made to determine methods of measuring the total pressure of an air stream containing entrained liquid particles.

(g) Several designs of total pressure probe have been devised and tested, and several appear to be capable of yielding accurate measurements of total pressure.

(1890) STATIC AND DYNAMIC CHARACTERISTICS OF PRESSURIZED AIR BEARINGS.

(b) Laboratory project.

(d) Basic and applied research.

(e) In order to gain a better understanding of the behaviour of pressurized bearings having no extemal flow resistances, basic studies have been made of the flow between closely spaced flat plates. The results of this basic work are being applied to the design of a pressurized air bearing which is to be used in an experimental investigation of dynamic characteristics of this type of bearing.

(g) Non-dimensionalized graphs have been obtained showing the pressure distribution for various flow configurations between parallel and non-parallel flat plates.

(h) S. M. Thesis, S. K. Grinnell, (in preparation). 


\section{1) DYNAMIC CHARACTERISTICS OF PRESSURIZED IIQUID BEARINGS.}

(b) Laboratory project.

(d) Applied research.

(e) Analytical and experimental techniques are employed to study the dynamic performance of pressurized liquid bearings. Electronic analogue studies are planned to augment the experimental work and provide useful design data for bearings of this kind.

(g) Incomplete.

(h) S. M. Thesis, Max Luming (in preparation).

892) STUDY OF FLOW IN A POPPET VALVE.

(b) Laboratory project.

(d) Basic and applied research.

(e) A large scale model is to be used to study the characteristics of the flow through a poppet valve. Of particular interest is the change from orifice-type flow to laminar flow at small valve openings.

(g) Incomplete.

893) DYNAMIC CHARACTERISTICS OF PRESSURE CONTROL SYSTEMS.

(b) Laboratory project.

(d) Applied research and design.

(e) Analytical and electronic analogue investigation of a typical pressure controlled system. Experimental study of a specific system.

(f) Suspended.

(g) The results of the analysis show what factors are important in the design of a stable system of this type and the experimental work done to date agrees reasonably well with the analytical work.

(h) "On the dynamics of pressure controlled hydraulic systems." Prof. G. Reethof. Paper submitted for presentation at a meeting of the ASME.

1894) EXPERIMENTAL STUDY OF THE PROCESSES OF CHARGING AND DISCHARGING CONSTANT VOLUME CONTAINERS WITH AIR.

(b) Laboratory project.

(d) Basic research.

(e) A thorough experimental study was made to determine the average value of the polytropic coefficient obtained during the charging and discharging of constant volume tanks at various rates and with various initial and final pressures with the tanks standing in still air.

(f) Completed.

(g) It was found that the value of the polytropic coefficient is primarily effected by the value of a single dimensionless parameter which is basically a measure of the rate of charge or discharge for a tank having a given surface area.

(h) "A study of the processes of charging and discharging constant volume tanks with air." F. D. Skinner and C. K. Wagner, S. B. thesis, Mechanical Engineering. M.I.T. Library will furnish quotation on microfilm or photocopy upon request.

1895) EFFECTS OF FLUID MASS AND COMPRESSIBILITY ON CONIROL VALVE STROKING FORCES.

(b) Bureau of Ordnance, Department of the Navy.

(d) Basic research.

(e) A fundamental investigation has been made into the nature of the dynamic flow forces. encountered in valves when the mass of the fluid in the connecting passages is significant.

(g) A thorough analysis reveals that the mass of the fluid in the passages of a valve-controlled hydraulic system can have an important influence on the dynamic forces exerted by the fluid on the moving member of the control valve. Experimental results were inconclusive because of insufficient instrumentation and the compromising effects of fluid compressibility. Further work is in progress. 
(h) "Stability of flow control valves." George Friedensohn, S. M. Thesis, Mechanical Engineering, M.I.T. Iibrary will furni sh quotation on microfilm or photocopy upon request.

(1896) FUNDAMENTAL STUDY OF THE DESIGN OF PNEUMATIC CONTROL SYSTEMS.

(b) Bureau of Ordnance, Department of the Navy.

(d) Applied research and design.

(e) A comprehensive design study is being made on a typical valve-controlled-ram-plus-load system. The approach is made in the most general manner possible so that the results may be applied to a wide variety of pneumatic systems. Since the characteristics of some of the system components are not or have not been thoroughly known, part of the effort is being expended on the supervision of bachelors' and masters' theses and Dynamic Analysis and Control Laboratory projects aimed at gaining a better understandin of these components.

(g) Incomplete.

(h) Sc. D. Thesis, J. L. Shearer (in preparation).

(1897) NEW VALVE CONFIGURATIONS FOR USE IN HYDRAULIC AND PNEUMATIC CONTROL SYSTEMS.

(b) Bureau of Ordnance, Department of the Navy.

(d) Applied research; design and development.

(e) A new method of construction employing a hole, slot, and plug technique has been used in the development of high performance control valves for hydraulic and pneumatic systems. The new construction is considerably simpler and easier to mamufacture than conventional spool-type control valves having the same precision of control.

(f) Completed.

(g) Control valves of this kind have been built and used in a mumber of successful hydraulic and pneumatic control systems.

(h) "Contributions to hydraulic control - 6, new valve configurations for high-performance hydraulic and pneumatic systems." Dr. S.-Y. Lee, Paper No. 53-A-139, presented at the Anmual Meeting of the A.S.M.E., Nov. 30-Dec. 4, 1953, in New York City. Reprints available from A.S.M.E. Order Department.

(1898) A MINIATURE VALVE ACTUATOR - HYDRAULIC AND PNEUMATIC CONTROL SYSTEMS.

(b) Bureau of Ordnance, Department of the Navy.

(d) Design and development.

(e) A miniature valve-controlled hydraulic servomotor employing an electro-mechanical torque motor and mechanical feedback has been developed to stroke precision control valves with simplicity, reliability and speed of response as major objectives in the design.

(f) Completed.

(g) A single unit has been operated successfully for a limited period of time. It is capable of delivering an output motion of .050 inch with an available force of $50 \mathrm{lb}$. when operating with hydraulic oil supplied at $2000 \mathrm{psi}$.

(h) Research memorandum prepared by $\mathrm{Dr}$. S. $-\mathrm{Y}$. Lee is to be released by the Dynamic Analysis and Control Laboratory, M.I.T., 77 Massachusetts Avenue, Cambridge 39, Massachusetts. Available on request from D.A.C.I., M.I.T.

(1899) STUDY OF PNEUMATIC CONTROL SYSTEMS ULTH RANDOM INPUT SIGNAL TECHNIQUES.

(b) Bureau of Ordnance, Department of the Navy.

(d) Basic and applied research.

(e) The dynamic performance of pneumatic control systems is being studied by statistical methods (analytical and experimental) using random input signals as system disturbances

(g) Instrumentation has been developed to monitor system performance and preliminary electronic analogue studies have been made.

(h) Sc. D. Thesis, T. P. Goodman (in preparation). 
1900) PRESSURE-FIOW CHARACTERISTICS OF PNEUMATIC VALVES.

(b) Bureau of Ordnance, Department of the Navy.

(d) Applied research.

(e) Flow versus pressure curves at various valve openings have been obtained analytically for various 3-way valve configurations and experimental curves are being obtained for a number of real valves.

(g) The experimental curves obtained to date agree qualitatively with the analytical ones but it has been found that the effects of external leakage are quite strong in a "closed-center" valve at small openings.

:1901) VANED DIFFUSERS FOR CENTRIFUGAL COMPRESSORS.

(b) General Electric Company, Fitchburg, Mass.

(c) Mr. Charles R. Faulders, Research Assistant, Room 31-268 Massachusetts Institute of Technology, Cambridge 39, Mass.

(d) Theoretical and experimental; applied research; for doctoral thesis.

(e) To determine nature of flow in conventional type of diffuser; in particular, to locate the major sources of loss and the way in which these losses are affected by diffuser geometry, and to consider possible design procedures for designing a diffuser of maximum efficiency when used with standard type of impeller.

(g) Efficiencies, static pressure contour plots and blade pressure and velocity distributions have been obtained. Wall boundary layer flow, and effect thereof on performance, has been determined. Design methods for improving performance have been developed in part.

(1902) DESIGN AND DEVEIOPMENT OF RADIAL INFIOW EXPANSION TURBINE.

(b) U. S. Air Force.

(c) Mr. George L. Mayne, Bldg. 31-267, Massachusetts Institute of Technology, Cambridge 39, Mass.

(d) Experimental; design and development.

(e) The project has to do with the development of a small turbine to be used in the production of liquid oxygen. The working substance is received at $160 \mathrm{psi}$ and $263^{\circ}$ Rankine and is discharged at $20 \mathrm{psi}$ and $163^{\circ}$ Rankine. The first portion of the project was for a master's degree and is now being completed as a research project.

(f) The project is in the development stage, eliminating all difficulties encountered through specifications.

(g) The significant results are more in the form of difficulties in obtaining bearings to function properly at speeds in the order of 100,000 RPM.

(h) "Design and development of a radial inflow expansion turbine." Richard S. Semple, M. S. Thesis, August 1953, Gas Turbine Laboratory.

"Design of radial inflow refrigeration turbine." Bjorn M. Olson, M. S. Thesis, May 1952, Gas Turbine Laboratory.

(1903) ROTATING STALI IN ANNULAR CASCADES.

(b) National Advisory Comittee for Aeronautics.

(c) Mr. Jack R. Webb, Room 31-268, Massachusetts Institute of Technology, Cambridge 39, Mass.

(d) Experimental and theoretical investigation; basic research.

(e) Investigation of nature of rotating stall in fluid machinery. Study of the interdependence of this stall and blade vibration.

(g) Apparatus in design stage.

MASSACHUSETTS INSTITUTE OF TECHNOLOGY, Department of Naval Architecture and Marine Engineering.

(1904) TEST OF A SERIES OF CONTROLLABIE PITCH PROPELIERS.

(b) David Taylor Model Basin, Department of the Navy. 
(c) Prof.F.M. Lewis, Director, Department of Naval Architecture and Marine Engineering, Massachusetts Institute of Technology, Cambridge 39, Mass.

(d) For design.

(e) It is desired to have available for design purposes the characteristics of a set of controllable pitch propellers.

(h) Publication on completion.

UNIVERSITY OF MASSACHUSETTS, Department of Civil Engineering.

(1905) DETERMINATION OF LIFT COEFICIENTS OF CYIINDERS PLANTNG IN TROUGHS.

(b) Laboratory project.

(c) Dean George A. Marston, Director of Engineering Research Institute, University of Massachusetts, Amherst, Mass.

(d) Master's Thesis.

(e) Iift forces on cylinders planing in a trough and on plane water surfaces are being determined by means of a beam and SR-L gage arrangement.

UNI VERSITY OF MICHICAN, Experimental Naval Tank.

Inquiries concerning Projects Nos. 585, 1127, 1128, 1378, and 1906, should be addressed to Prof. L. A. Baier, 325 West Engineering Building, University of Michigan, Ann Arbor, Mich.

(585) RESISTANCE OF BARGE TOWS.

(b) Corps of Engineers, Department of the Army.

(d) Experimental; design.

(e) To determine resistance of several formations of certain barge types relative to nonrestricted straight channels and to selected channels restricted in width and depth. Each run will consist of movement of one model formation, at one draft and one depth of water for a given channel condition through a range of velocities sufficient to define a curve of functions of resistance versus velocity.

(1127) TRANSOM IMMERSION ON HIGH-SPEED MOTORBOATS.

(b) Laboratory project.

(d) Research; design.

(e) Tests are being conducted to determine the most efficient transom immersion for various high speed hull forms.

(1128) COIMERCIAL VESSELS, 150 to 250 FEET IN LENGTH.

(b) Fairbanks, Morse and Company.

(d) Experimental; design.

(e) A large family of hull forms is being tested in order to provide design data for the future design of commercial vessels, 150 to 250 feet in lergth.

(1378) VIBRATION ELIMINATION.

(b) Laboratory project.

(d) Experimental.

(e) Design and testing of fins fitted to both single and multiple screw mulls in way of propeller aperture in order to eliminate fantail vibration.

(h) Paper - Proceedings, Third Midwestern Conference on Fluid Mechanics, University of Minnesota. 
(1906) FORM DESIGN, GREAT LAKES CARRIERS.

(b) Bradley Transportation Iine.

(d) Experimental.

(e) Design and testing of four types of hull forms suitable for large cargo carriers on the Great Lakes, including self-propelled tests.

(f) $90 \%$ complete.

UNIVERSITY OF MICHIGAN, Lake Hydraulics Laboratory.

(1630) MODEL STUDY OF OFF-SHORE DRILIING PLATFORM.

(b) Bethlehem Steel Co.

(c) Mr. J.E. Steele, Chief of Design, Shipbuilding Division, Bethlehem Steel Co., Beaumont, Texas.

(d) Experimental; applied research.

(e) To study the effect of wave action on a pile-supported structure.

(f) Completed.

(g) The desired design information was obtained.

(h) "Model study of an of fshore drilling structure." E. F. Brater and L. C. Maugh, Tech. Report No. 6, 1953.

MISSISSIPPI STATE COLIEGE, Engineering and Industrial Research Station.

Inquiries concerning Projects Nos. 4, 1631, and 1907 should be addressed to Dr. Harold Flinsch, Box 1516, State College, Miss.

(4) THE EFFECT OF WIND ON WAVES.

(b) Laboratory project.

(d) Experimental, the oretical, and field investigation; basic research.

(e) Measurement of wave characteristics in wind-wave tunnel in laboratory; measurement of wind and waves in field (Gulf of Mexico and Atlantic Ocean); theoretical analysis.

(g) Off-shore wave height measurements in Gulf of Mexico, with recording apparatus.

(h) Report in preparation.

(1631) THE EFFECT OF WAVES ON BEACHES.

(b) Laboratory project.

(d) Experimental, theoretical, and field investigation; basic research.

(e) Beach material and contour measurements, under natural and laboratory conditions.

(g) A the ory of the development of beach contours under wave action has been discovered.

(h) "The effect of waves on a sand beach." International Association for Hydraulic Research, Minneapolis, Minn., Sept. 2, 1953.

"The development of a sand beach by deep-water waves." Fourth Conference on Coastal Engineering, Chicago, Illinois, Oct. 30, 1953. Further reports in preparation.

(1907) THE STABILITY OF SHIPS UNDER WAVE ACTION.

(b) Laboratory project.

(d) Experimental, theoretical, and field investigation; basic research.

(e) Wave tank measurements on a variety of ship models, field measurements on available boats and ships, and theoretical analysis of the results obtained.

(g) Equipment is complete for roll, pitch, and yaw measurements in wave tank. 
MISSOURI SCHOOL OF MINES AND METALLURGY, Department of Civil Engineering.

Inquiries concerning Projects Nos. 1908 and 1909 should be addressed to Prof. E. W. Carlton, Missouri School of Mines and Metallurgy, Rolla, Missouri.

(1908) HYDROLOGICAL CHARACTERISTICS OF SMALL DRAINAGE AREAS.

(b) Laboratory project.

(d) Analytical; basic research for master's thesis.

(e) Actual and computed runoffs, as well as other hydrological characteristics, were compared for several drainage areas. An attempt was made to correlate actual and theoretical values.

(f) Suspended.

(g) Study indicated that the hydrological characteristics of small drainage areas can be correlated.

(h) "Hydrology of small drainage areas." J. K. Searcy, Master's Thesis, Missouri School of Mines and Metallurgy, 1952. (Available on loan).

(1909) AFFECT OF SOIL MOSITURE ON RUNOFF.

(b) Laboratory project.

(d) Experimental; basic research for master's thesis.

(e) Using electrical resistance blocks, soil moisture percentages at several points in a small drainage area were obtained. Corresponding runoff was obtained by means of a recording gage.

(f) Suspended.

(g) Study indicated a relationship exists between runoff and a soil moisture index.

(h) "Runoff and soil moisture." J.W. Clark, Master's Thesis, Missouri School of Mines and Metallurgy, 1953. (Available on loan).

NEWFORT NEWS SHIPBUILDING AND DRY DOCK COMPANY.

Inquiries concerning Projects Nos. 123, 124, 896, 901, 1132, 1133, 1134, 1136, and 1634 , should be addressed to Mr. C. H. Hancock, Hydraulic Laboratory, Newport News Shipbuilding and Dry Dock Company, Newport News, Virginia.

(123) HYDRAULIC TURBINE TESTS.

(b) Laboratory project.

(d) Experimental; for design data.

(e) Scale model turbines, using either Francis or propeller type runners, are tested for power and efficiency at various speeds.

(124) METER CALIBRATION TESTS.

(b) Laboratory project.

(d) Experimental.

(e) To establish calibration curve for determining correction for various rates of flow. Meters are tested at various heads and rates of flow by weighing tank method. Time is recorded electrically by chronograph.

(896) VANE MONENT TESTS ON ADJUSTABLE BLADE RUNNERS.

(b) Laboratory project.

(d) Experimental; for design data.

(e) Tests are to determine vane moment diagrams. The turbine load is applied by an electrical dynamometer and the gate openings are controlled by a governor. The blades adjust automatically and the blade moment is measured by a spring dynamometer. 
(901) SHIP MODEL RESISTANCE TESTS.

(b) Laboratory project.

(d) Experimental; for design data.

(e) Scale ship models are towed to determine the effective horsepower, bare hull, required by the ship. Because of their small size, several models may be towed in a short period of time thus allowing much preliminary work to be done on the choice of lines. The final lines are checked by the David Taylor Model Basin. To eliminate a large portion of this preliminary testing, a schedule of systematic models was arranged in which the beam-draft ratio, the displacement-length ratio, and the prismatic coefficient are varied over a wide range. Towing of this set of models is continuing and when completed will provide design data for a standard offset series covering a wide range.

(1132) HYDRAULIC PUMP TESTS.

(b) Laboratory project.

(d) Experimental; for design data.

(e) Scale model pumps, centrifugal and propeller types, are tested at constant speeds for head developed, power consumption, and efficiency at various rates of discharge. Cavitation tests are sometimes conducted by lowering the suction head to a point where the developed head and efficiency break down.

(1133) CAVITATION TESTS OF HYDRAULIC TURBINE MODELS.

(b) Laboratory project.

(d) Experimental; for design data.

(e) Scale model turbines are tested on cavitation stand to determine sigma at which cavitation starts.

(1134) CAVITATION TESTS ON MODEL SHIP PROPELLERS.

(b) Laboratory project.

(d) Experimental; for design data.

(e) A water tunnel with a 42 -inch test section is under construction. An electric dynamometer has been built to measure the propeller torque and thrust. Propellers up to 8-inch diameter will be tested and a suction head approaching 33 feet will be available.

(1136) WAVE TESTS ON SHIP MODELS.

(b) Laboratory project.

(d) Experimental; for design data.

(e) Ship models are tested with scaled waves to determine the speed reduction in waves for the pull required for various still water speeds. Pitching periods and angles are determined from light trace photographs.

(1634) RESEARCH AND TEST OF MAIN INJECTION SCOOPS AND OVERBOARD DISCHARGE.

(b) Bureau of Ships, Department of the Navy.

(d) Experimental.

(e) To determine the principal criteria governing the flow in ship circulating systems and to obtain some design data on the various circulating system components. Model components are tested separately in a water channel. Dynamic similarity is enhanced by modeling the boundary layer thickness and shape to scale. Stagnation, secondary flow, etc. are observed through transparent plastic models. 
NEW YORK UNIVERSITY, Department of Chemical Engineering.

Inquiries concerning Projects Nos. 590, 1138, 1635, 1910, and 1911 should be addressed to Prof. John Happel, Department of Chemical Engineering, New York University, Bronx 53, N. Y.

(590) PRESSURE DROP DUE TO FLUID FLOW THROUGH ASSEMBLAGES OF SPHERES.

(b) Texas Company, laboratory project.

(d) Experimental and theoretical; for two doctoral theses.

(e) Rigid assemblages of uniform spheres of various fractional void volumes in cubical assemblages were constructed, and the effect on pressure drop of passing a viscous Iiquid through these assemblages was measured. A theoretical approach to the effect of fractional void volume on pressure drop by means of the Stokes-Navier equations and the method of reflections is being derived.

(f) Experimental work completed; theoretical active.

(g) Completed results for viscous flow indicate that assemblage approach velocities calculated from pressure drop data do not approach Stokes Law at a void volume fraction of $100 \%$.

(h) "Fluid flow through assemblages of spheres." John Happel and Norman Epstein, presented at the 1953 Christmas Symposium of the American Chemical Society, Ann Arbor, Mich.

(1138) EFFECT OF VARIATION OF SOLID TO FLUID DENSITY RATIO ON FLUIDIZATION CHARACTERISTICS.

(b) Laboratory project.

(d) Experimental; for one doctoral and one master's thesis.

(e) Screened particles of very light solid substances were fluidized in a 2-inch glass tube and the fluidization characteristics observed. The primary objective will be the determination of the optimum ratio of solid to gas density for smooth fluidization.

(g) Preliminary results indicate that the range of smooth fluidization and slugging zones can be graphically correlated on a single plot.

(1635) A CRITICAI STUDY OF THE PRIME VARTABLES IN A FLUIDIZED BED.

(b) Texas Company, laboratory project.

(d) Experimental; for doctoral the sis.

(e) The parabolic flow pattern was converted to a uniform flow pattern by means of a properly constructed bed screen support, and the velocity profile was measured with a pitot tube. The effect of flow pattern and height of colum to diameter ratio on the variables in a fluidized bed together with the results of Projects (590), (1379) and (1910) will be used to separate and determine the effect of the various variables present on fluidization tendencies and pressure drop.

(1910) THE STEADY MOTION OF A SPHERE AND A VISCOUS FLUID IN A CIRCULAR CYLINDRICAL TUBE.

(b) Laboratory project.

(d) Theoretical for master's thesis.

(e) The Stokes-Navier equations, neglecting initial terms, were solved in order to determine the effect of the cylinder wall on the velocity distribution and pressure drop when a fluid with a parabolic velocity distribution moves past a sphere.

(f) Completed.

(g) It has been demonstrated that a sphere falling in a fluid at a given velocity does not experience the same resistance as that caused by fluid moving with the same axial velocity past a stationary sphere. Also, the pressure drop caused by the presence of a sphere is not simply equivalent to the buoyant force exerted on it. The mathematical results are in agreement with the experimental results of project No. 590.

(h) "The steady motion of a sphere and a viscous fluid in a circular cylindrical tube." John HappeI and B. J. Byrne, presented at the 1953 Christmas Symposium of the American Chemical Society, Ann Arbor, Mich. 
(1911) STEADY STATE VISCOUS FLOW IN A CUBICAL ASSEMBLAGES OF SPHERES.

(b) Texas Company, laboratory project.

(d) Theoretical, for doctoral thesis.

(e) With the assumptions of incompressible flow and an infinite cylinder, the StokesNavier equations will be solved using spherical harmonics with cubical boundaries to give theoretical expressions for a void volume function, velocity distribution and pressure drop.

NEW YORK UNIVERSITY, Fluid Mechanics Laboratory.

(1912) DISCHARGE CHARACTERISTICS OF A SIDE WEIR.

(b) Laboratory project.

(c) Prof. A. H. Griswold, New York University, New York 53, New York.

(d) This is an applied research project in which a theoretical analysis is to be checked experimentally.

(e) Because of the wide divergence between the results that can be obtained using generally accepted equations, a theoretical and experimental study of the discharge characteristics of a sharp-crested side weir is underway. It is planned to vary the width, length and height of crest.

UNIVERSITY OF NORTH CAROLINA, North Carolina State College of Agriculture and Engineering.

(593) DYNAMIC SIMILARITY OF SMALI HYDRAULIC MODELS.

(b) Laboratory project.

(c) Prof. L. W. Iong, Department of Engineering Mechanics, North Carolina State College, Raleigh, N. C.

(d) Experimental and theoretical; basic research.

(e) To make a theoretical study of dynamic similarity of small hydraulic models and at large scale ratios.

(h) To be published by the Department of Engineering Research, North Carolina State College.

(1636) RAINFALL INTENSITY DURATIONFFREUENCY CURVES FOR NORTH CAROLINA.

(b) Laboratory project.

(c) Prof. Charles Smallwood, Jr., Civil Engineering Department, North Carolina State College, Raleigh, N. C.

(d) Experimental; applied research.

(e) The collection and analysis of data pertaining to intensity, durability, and frequency of rainfall in North Carolina.

(h) To be published by the Department of Engineering Research, North Carolina State College. 
NORTHIESTERN UNIVERSITY, The Technological Institute.

Inquiries concerning Projects Nos. 905, 906, and 1141 should be addressed to Prof. D. A. Dahlstrom, Projects Nos. 326 and 1637 to Prof. W. S. Hamilton, and Projects Nos. 127 and 904 to Prof. M. B. Gamet, Northwestern Technological Institute, Evanston, III.

(127) RELIEF FROM WATER HAMMER BY MECHANICAL-PNEUMATIC SURGE SUPPRESSORS.

(b) Laboratory project.

(d) Experimental; for design.

(e) To determine extent to which surge pressures in pipe lines may be relieved by a preloaded, gas-filled, compression chamber in which the gas is separated from the liquid in the pipes by a stainless steel bellows.

(f) Inactive, to be continued.

(g) Work has shown this type of unit to be free from fatigue failure and capable of protecting pipe systems from severe shock. Field tests are now being conducted.

(326) CAVITATION DAMAGES UNDER CONTROLIED CONDITIONS.

(b) Laboratory project.

(d) Experimental; basic research; for theses and staff papers.

(e) The pressure in a vertical column of liquid is caused to fluctuate by a motor-operated piston and bellows arrangement, thereby forming and releasing a cavity at the top of the column. The amount of damage to various materials will be related to size of cavity and proximity of material to point of cavity collapse.

(g) Pits have been caused in brass, lucite, and mortar. An elastic-tube strain gage has been constructed for pressure measurements. Tests on mortar samples have begun.

(904) BULK MODULUS OF PETROLEUM PRODUCTS, INCLUDING CRUDE OIIS AND GASOLINE.

(b) Laboratory project.

(d) Experimental; basic research for design.

(e) Tests have been conducted on three crude oils, one gasoline, and on distilled water at temperatures from $60^{\circ} \mathrm{F}$. to $130^{\circ} \mathrm{F}$. and at pressures ranging from 0 to $1500 \mathrm{psig}$.

(f) Inactive; to be continued.

(g) Tests indicate high modulus with low temperatures and rapidly increasing modulus at low pressures after which leveling off takes place with nearly constant modulus above $1000 \mathrm{ps}$

(905) THE IIQUID-SOIID CYCLONE.

(b) Laboratory project.

(d) Experimental and field investigations; basic and applied research, for design and operation.

(e) Application of centrifugal fields as obtained in the liquid-solid cyclone to the rapid classification, separation, and desliming of coal and minerals.

(f) Completed.

(g) Experimental and field investigations on theory and operation of the liquid-solid cyclone have been completed, making it possible to design equipment for any capacity and efficiency desired.

(906) SEPARATION OF FINE-SIZED CLOSE GRAVITY SOLIDS BY CENTRIFUGAL FORCE AS OBTAINED IN THE LIQUID-SOLID CYCLONE.

(b) Laboratory project.

(d) Theoretical and experimental; basic and applied research for design and operation.

(e) Separation of close gravity solids by liquids and the application of centrifugal fields as obtained in the liquid-solid cyclone is being investigated.

(f) Field studies contiming.

(g) Economical separation and recovery of materials differing by as little as 0.01 in specific gravity and as small as 100 mesh in size have been obtained. Industrial installations perform in accordance with laboratory predictions. 
(1山I) HIGH SPEED SEPARATION OF CLOSE SPECIFIC GRAVITY LIQUIDS IN THE CYCLONE.

(b) Laboratory project.

(d) Theoretical and experimental; basic and applied research for design and operation.

(e) Rapid separation of close specific gravity liquids by use of centrifugal fields as obtained in the cyclone is being investigated. Tests indicate that recovery of either liquid phase will be a function of feed and overflow diameters, cyclone included angle, pressure drop across cyclone, volume split between overflow and underflow, specific gravity difference between liquid phases, free composition and interfacial tension between liquids. Iiquid-liquid separation work will be especially important for liquidliquid extraction applications.

(f) Inactive, to be continued.

(g) It has been proven that separation of the two liquid phases can be obtained at a probable cost and simplicity far surpassing that experienced in most liquid-liquid extraction applications to date. Correlations have been obtained for recovery of the various liquid phases as a function of volume split, feed composition and pressure drop across the cyclone.

(1637) SPRAY FORMATION.

(b) Bureau of Aeronautics, Department of the Navy.

(d) Theoretical and experimental; for design.

(e) The effects of different variables in causing a jet of water to break up into spray are being investigated.

(g) The literature has been reviewed and a preliminary report prepared for the sponsor. Little is known about the effect of initial turbulence in the stream, and this phase is to be studied experimentally using a jet issuing from a large tank of still water.

UNI VERSITY OF NOTRE DAME, College of Engineering.

(1640) STABILITY OF TOTED SHIPS.

(b) Office of Naval Research, Department of the Navy.

(c) Dr. A. G. Strandhagen, Department of Engineering Mechanics, University of Notre Dame, Notre Dame, Ind.

(d) Theoretical.

(e) Most of all of the hydrodynamic forces and moment experienced by a trailing ship have been evaluated analytically.

(h) Report in preparation.

(1913) DESIGN OF OPEN CHANNELS.

(b) Laboratory project.

(c) Dr. Steponas Kolupaila, Department of Civil Engineering, University of Notre Dame, Notre Dame, Ind.

(d) Applied research and design.

(e) A convenient determination of the size of open channels under various conditions.

(f) Completed.

(g) A nomogram developed.

(h) Report in preparation. 
OREGON STATE COLIEGE, Department of Civil Engineering.

(918) RELATION BETWEEN RAINFALI AND RUNOFF FROM SMALL WATERSHED IN WESTERN OREGON.

(b) Laboratory project.

(c) Mr. W. C. Westgarth, Oregon State College, Corvallis, Oregon.

(d) Field investigation; basic research.

(e) Watershed $7.34 \mathrm{sq}$ mi partly wooded, partly farmed; automatic recording rain gages and flow recording gages on loan from weather Bureau and U. S. Geological Survey. Planned as a 10-year project, 4 years completed.

(1383) MODEL STUDIES OF TAPERED INLETS FOR BOX CULVERTS ON STEEP GRADES.

(b) Cooperative with Oregon State Highway Department and Bureau of Public Roads.

(c) Mr. Roy H. Shoemaker, Jr., Oregon State College, Corvallis, Oregon.

(d) Experimental; design.

(e) Scale models of inlets tested with culvert on steep grades to improve discharge characteristics of box culverts.

(f) Completed.

(g) Simple modification to existing culvert design permits culvert to flow full under low head.

(h) "Model studies of tapered inlets for box culverts." Roy H. Shoemaker, Jr. and Leslie A. Clayton, Highway Research Board Research Report No. 15-B. "Culvert Hydraulics" (check for publication date with HRB).

(1654) MODEL INVESTIGATION OF FISH LADDERS IN BOX CULVERTS.

(b) Cooperative with Oregon State Highway Department and Bureau of Public Roads.

(c) Mr. Roy H. Shoemaker, Jr., Oregon State College, Corvallis, Oregon.

(d) Experimental; design.

(e) Scale model of box culvert with fish ladder baffles installed to determine discharge characteristics of culvert for variable baffle height and spacing.

(1914) MODEL STUDIES OF INLET DESIGNS FOR PIPE CULVERTS ON STEEP GRADES.

(b) Cooperative with Oregon State Highway Department.

(c) Mr. Malcolm H. Karr, Oregon State College, Corvallis, Oregon.

(d) Experimental; design.

(e) Scale models of inlets tested with culvert on steep grades to determine flow and priming characteristics of pipe culverts.

(g) Simple modification to existing culverts permits culvert to flow full under low head.

PELTON WATER WHEEL COMPANY.

Inquiries concerning Projects Nos. 1146, 1656, 1915, and 1915, should be addressed to Mr. R. M. Bacchi, Pelton Water Wheel Company, 2929 19th Street, San Francisco 10, Calif.

(1146) HEAD EFFECT ON IMPULSE TURBINE MODEL TESTING.

(b) Laboratory project; sponsored by the Mountain Laboratory Group.

(d) Experimental; applied research.

(e) To establish model law for testing impulse turbines under various operating pressures. Tests are being made under heads of 100 to $2000 \mathrm{ft}$. The effect of housing size and shape is under study.

(g) Most of the high head testing has been completed. 
(1656) FOUR NOZZLE VERTICAL SHAFT IMPULSE TURBINE MODEL EFFICIENCY AND HORSEPOWER TESTS.

(b) Laboratory project.

(d) Experimental; applied research.

(e) A I -7/8 inch P.D. Wheel impulse turbine has been built with a vertical shaft, fournozzle arrangement to study the effect of bucket size and shape on this configuration.

(f) Completed.

(1915) BUCKET SHAPE TESTING.

(b) Laboratory project.

(d) Experimental; applied research.

(e) A new bucket shape is being tested to determine its characteristics.

(1916) SPHERICAL VALVE TEST.

(b) Laboratory project.

(d) Experimental; applied research.

(e) A new type spherical valve has been designed, and has been thoroughly tested for its flow and torque characteristics.

(f) Completed.

PENNSYLVANIA STATE COLIEGE, Department of Civil Engineering.

Inquiries concerning Projects No. 1917 to 1920, incl., should be addressed to Prof. Sam Shulits, Civil Engineering Department, The Pennsylvania State University, State College, Pennsylvania.

(1917) BED LOAD FORMULAS.

(b) Laboratory project, supported by Research Cooperation.

(d) Analytical; applied research.

(e) Examination and analytical comparison of existing bed load formulas and their theoretical and experimental bases, to determine whether the formalas can be synthesized into one or a reduced number.

(1918) DESIGN OF STILIING BASINS.

(b) Laboratory project, supported by Research Cooperation.

(d) Experimental; applied research.

(e) Procurement of experimental data for investigation of rational basis of design of stilling basins, to reduce dependence on model studies. Glass-walled flume, I foot wide, 15 to 20 feet long in test section, is being built.

(1919) DOTNSTREAM DISTURBANCE OF ORIFICE METERS.

(b) Laboratory project.

(d) Experimental; applied research; master's thesis.

(e) Determination of minimum distance downstream from an orifice meter various disturbances may be placed without altering meter reliability. A gate valve will be installed at varying distances downstream from orifices of varying diameters in a 2-inch pipe.

(1920) EQUATION OF RIVER-BED PROFILES.

(b) Laboratory project, supported by Research Cooperation.

(d) Analytical; basic research.

(e) Quantitative examination to probe whether a rational equation of river-bed profiles is attainable. 
PENNSYLVANIA STATE COLLEGE, Ordnance Research Laboratory.

Inquiries concerming Projects Nos. 328, 605, 1150, 1151, 1152, 1388, and 1389 should be addressed to $D_{r}$. J. M. Robertson; Projects Nos. 920, 921 and 1387 to Mr. B. W. McCormick; and Project No. 1386 to Mr. J.W. Holl; Ordnance Research Laboratory, P. 0. Box 30, State College, $\mathrm{Pa}$.

(328) FLOW PAST SLOTS IN SURFACES.

(b) Laboratory project.

(d) Experimental; applied research.

(e) Studies were made on the pressure and flow conditions near slots in surfaces, as affected by relative boundary layer thickness and contour of slot corners.

(f) Inactive.

(g) The boundary layer thickness, slot width in the direction of flow, and rounding of downstream edge were found to govern the magnitude of the pressure dip following the slot.

(605) FUNDAMENTALS OF SURFACE CAVITATION.

(b) Navy Bureau of Ordnance (Contract Nord 7958), Department of the Navy.

(d) Experimental; basic research.

(e) A laboratory-size eggbeater apparatus is used in which the noise inception point is correlated with the composition and nature of the liquid and the surface of the propeller.

(920) ELECTROMAGNETIC ANALOGY FOR PROPELLERS.

(f) Completed and in use as a design tool.

(921) PROPELIERS FOR OPERATION IN SYMMETRIC WAKES.

(b) Bureau of Ordnance (Contract NOrd 7958), Department of the Navy.

(d) Theoretical and experimental; applied research.

(e) The problem is the design of optimum-efficiency and cavitation-free propellers for operation behind bodies of revolution. It is being attacked through consideration of the physics of propeller action. Design methods resulting from the theory are being tested by experiment on an 8-inch diameter model torpedo in the 48-inch Water Tunnel.

(g) Several tests have been made with the first research propellers. Other propellers are being fabricated and designed.

(h) "An observation on the vortex system of dual-rotation propellers." J. J. Eisenhuth and B. W. McCormick, Jourmal of the Aeronautical Sciences, Vol. 20, No. 6, June, 1953, p 435.

(1150) HYDRODYNAMIC PERFORMANCE OF L8-INCH WATER TUNNEL.

(b) Bureau of Ordnance (Contract Nord 7958), Department of the Navy.

(d) Experimental; applied research.

(e) Velocity distributions and pressures are being measured in all portions of the 48-inch hater Tunnel at velocities up to $80 \mathrm{fps}$.

(g) Approaching completion.

(I151) DESIGN AND CONSTRUCTION OF I2-INCH WATER TUNNEL.

(b) Bureau of Ordnance (Contract Nord 7958 and NOrd (f) 1445), Department of the Navy.

(d) Design.

(e) Tunnel is planned for general supplementary research; interchangeable working sections have been designed. One circular closed jet 12" diameter, one circular open jet 12" diameter, one 4 l/2 inch $x 20$ inch rectangular closed; maximum design velocity 70 fps.

(g) Tunnel shell and two working sections erected. Tunnel has been run, but requires some proofing. 
(1152) DESIGN AND CONSTRUCTION OF 48-INCH AIR TUNNEL.

(b) Bureau of Ordnance (Contract NOrd 7958 and NOrd (f) 1445), Department of the Navy.

(d) Design.

(e) Closed circuit tunnel planned for supplementary research; working section 48 -inch octagon, 16 feet long; maximum design velocity including honeycomb and screens, $200 \mathrm{fps}$.

(g) Construction is complete, tunnel has been run but still needs honeycomb and screens.

(1386) CAVTTATION STUDIES.

(b) Navy Bureau of Ordnance (Contract Nord 7958), Department of the Navy.

(c) Mr. J. W. Holl, ordnance Research Laboratory, P. O. Box 30, State College, Pennsylvania.

(d) Experimental; basic research.

(e) Cavitation inception as noted visually and acoustically on body noses is being correlated with the size, water velocity and temperature.

(h) "Incipient-cavitation scaling experiments for hemi spherical and 1.5-caliber ogive-nosed bodies." Joint Report with California Institute of Technology Hydrodynamics Laboratory, by B. R. Parkin and J. W. Holl, ORL External Report, Serial No. Nord 7958-264, May 15, 1953. (Available by request via Section Reba, Bureau of Ordnance, Navy Department).

(1387) STUDY OF TIP VORTEX CAVITATION.

(b) Office of Naval Research, Department of the Navy.

(d) Experimental; basic research.

(e) Attempt to predict the minimum pressure in the trailing vortex system behind a wing.

(1388) TURBULENT BOUNDARY LAYERS.

(b) Laboratory project supported by Office of Naval Research.

(d) Experimental; basic research.

(f) Major activity suspended.

(g) A new empirical method for calculating two-dimensional, turbulent, boundary-layer flows in adverse pressure gradients has been developed by correlating existing data for a wide variety of flows. Division of the boundary layer into inner and outer turbulent regions has made possible an analysis which does not depend upon the assumption of a single parameter family of profiles. Experimental measurements were made in a conical diffuser with various entrance conditions.

(h) "A new analysis of Nikuradse's experiments on turbulent flow in smooth pipes." Donald Ross, Proceedings of the Third Midwestern Conference on Fluid Mechanics, 1953, pp 651-667.

"Evaluation of the momentum integral equation for turbulent boundary layers." Donald Ross, Journal of the Aeronautical Sciences, Vol. 20, No. 7, July, 1953, p 502. "A study of incompressible turbulent boundary layers." Donald Ross, Ph.D. Thesis, Harvard University, June, 1953. (Loan copies available). "Investigation of the growth of an axisymmetric turbulent boundary layer in an adverse pressure gradient." Earl M. Uram, M.S. Thesis, The Pennsylvania State College, June, 1953. (Loan copies available).

(1389) REDUCTION OF STRUT WAKE.

(b) Bureau of Ordnance (Contract Nord 7958), Department of the Navy.

(d) Theoretical and experimental; applied research.

(e) The model torpedo supporting strut in the 48-inch water Tunnel exerts an asymmetric effect on the velocity distribution at the plane of the propeller. A method of filling in the wake flux deficiency by an external pumping apparatus has been tried to alleviate this condition.

(f) Inactive but plan to reactivate.

(g) It was found possible to reduce the stmat wake by filling; however, this did not eliminate the interference of the strut on the boundary layer of the body. 
PENNSYLVANIA WATER AND POWER COMPANY.

Inquiries concerning Projects Nos. 1154, 1156, 1157, and 1921 should be addressed to Dr. S. K. Waldorf, Pennsylvania Wher and Power Company, 405 Fulton Bank Building, Lancaster, $\mathrm{Pa}$.

\section{(1154) MEASUREMENT OF WATER VELOCITIES WLTH ULTRASONICS.}

(b) Laboratory project.

(d) Experimental; applied research.

(e) To develop an improved method of measuring large quantities of water, particularly the discharge of Iarge hydroelectric units having short intake conduits with large rectangular cross sections. The development is being made using a turbine intake 25 feet by 16 feet in cross section. An ultrasonic transcucer rod is placed at each of two parallel opposite walls of the rectangular duct in which water velocity is to be measured. The transducers are displaced from each other along the principal axis of flow. The phase angle between the transmitted and received ultrasonic signals is a measure of the water velocity.

(g) Water velocities up to ten feet per second have been measured with an error of onehalf percent in the laboratory with a rectangular duct five inches by nine inches.

\section{(1156) AIR BUBBLER SYSTEM TO MAINTAIN OPEN CHANNEL IN SHEET ICE.}

(b) Laboratory project.

(d) Field investigation; applied research.

(e) Three experimental 1000-foot and one 1500-foot lengths of galvanized steel pipe, with holes at intervals for discharging compressed air, are laid on the reservoir bottom perpendicular to the dam. The warmer water caused to rise with the bubbles maintains an open channel in the reservoir sheet ice. The pipes are widely spaced to avoid interaction and are placed so that open channels will direct the movement of pack ice over the dam at selected gates. If successful, a system of such pipes extended farth upstream is expected to reduce the possibility of ice jams.

(g) Results are encouraging, but not conclusive because of recent mild winters. Experiments with flexible tubing revealed some inherent difficulties with tubing which have not been overcome.

(h) "Experimental use of air bubbler system at safe harbor to maintain open channel in ice cover on pond." P. M. Hess, Mimutes of Hydraulic Power Committee, Edison Electric Institute, pp 70-71a, May 1-2, 1950.

"Air bubbler system maintains open channel in ice sheet." P. M. Hess, Electrical World, Vol. 139, No. 10, pp 106 and 108, March 9, 1953.

(1157) SEDIMENTATION IN RESERVOIR OF SAFE HARBOR HYDROELECTRIC STATION.

(b) Laboratory project.

(d) Field investigation; applied research.

(e) if th a U. S. D-43 sampler, suspended sediment in the Susquehanna River is measured at the head of the Safe Harbor Reservoir. The suspended sediment in the discharge of the reservoir is measured at the station discharge and dam overflow by special means applicable to turbulent water. The rate of silting in the reservoir is measured periodically by fathometer soundings.

(g) Suspended sediment has been measured for flows of 4,000 to 450,000 cfs. Recorded extremes of flow of the Susquehama are 2,000 and almost $900,000 \mathrm{cfs}$.

(1158) FOREWARNING OF FRAZIL ICE FORMATION.

(b) Laboratory project.

(d) Experimental; applied research.

(e) By means of a resistance thermometer and strip chart recorder, the temperature of the Susquehanna River is measured within $0.001^{\circ} \mathrm{C}$ at Safe Harbor and Holtwood hydroelectric stations for the prediction of frazil ice formation. The equipment also records river water temperature at times other than the frazil ice season, but with a less sensitive instrument range. 
(f) Completed.

(g) A cooling rate in excess of $0.01^{\circ} \mathrm{C}$ per hour to the freezing point of the river water is followed by the formation of frazil ice rather than sheet ice.

(h) "Combatting frazil ice in hydroelectric stations." K. J. Granbois, American Institute of Electrical Engineers Transactions, Vol. 72, Part III, pp 111-116, April, 1953.

(1921) VISIBILITY THROUGH SUSQUEHANNA RIVER WATER.

(b) Laboratory project.

(d) Field investigation; applied research.

(e) Anticipating the use of photography and closed-circuit television for the inspection of underwater structures at Holtwood, the maximum visibility in the River was determined with a Secchi disc which was 6 inches in diameter and painted white.

(f) Completed.

(g) The visibility was not more than about 2 l/2 feet under the most favorable conditions, which demonstrated that special optical means would be required at Holtwood for satisfactory visual underwater examinations.

PURDUE UNIVERSITY, School of Civil Engineering and Engineering Mechanics.

(1391) INVESTIGATION OF THE FUNDAMENAL THEORIES OF SEDTMENTATION IN A TANK.

(b) Federal Security Agency, Public Health Service, and National Institutes of Health.

(c) Prof. Don E. Bloodgood, Purdue University, Lafayette, Ind.

(d) Experimental; for design and masters' theses.

(e) Observing the sedimentation rate of finely divided solids suspended in water moving at various velocities. The effect of variation in depth and width and length of channel eventually will be observed. The sediment used in the first series of tests was finely ground coal. The sediment currently being investigated for a new series of tests is a diatomaceous silica.

(f) Active after a one year lapse.

RENSSELAER POLYTECHNIC INSTITUTE, Mechanical and Hydraulic Laboratory.

(1660) HIGH SPEED HYDRAUITC COMPONENIS.

(b) Frankford Arsenal, Ordnance Corps, Department of the Army.

(c) Assoc. Prof. Frederick J. Bordt, Mechanical Engineering Department, Rensselaer Polytechnic Institute, Troy, N. Y.

(d) Experimental; applied research, development.

(e) Investigation and development of a 24,000 RPM hydraulic torque conversion system including control to be used for traversing and elevating high speed guns. The system with a constant speed and power input is to have a variable torque and speed output.

ROCKY MOUNTAIN HYDRAULIC LABORATORY.

(1922) TESTS OF RIP-RAP PROTECTION FOR DOWNSTREAM SLOPES OF HIGHWAY EMBANKMENTS SUBJECT TO OVERFLOW.

(b) Laboratory project.

(c) Prof.C.J. Posey, Allenspark, Colo., (winter address; Engineering Building, State University of Iowa, Iowa City, Iowa.) 
(d) Experimental; design.

(e) Study of permissible head of overflow for various slopes and rip-rap gradings, and for wire "sausage" construction.

(f) Active during summers.

(g) "Sausage" construction greatly increases erosion resistance.

RUTGERS UNIVERSTTY, Department of Botany.

(1662) PINE REGION HYDROLOGICAL RESEARCH PROJECT.

(b) Cooperative with Groundwater Division of the U. S. Geological Survey, New Jersey Department of Conservation and Economic Development, and United States Forest Service.

(c) Mr. Henry C. Barksdale, U. S. Geological Survey, P. O. Building, Trenton, New Jersey.

(d) Field investigation; basic research.

(e) Study of water relations of two watersheds, one of which will be burned according to recently developed silvicultural practices, and the other will be left to natural forest succession.

ST. ANHONY FALLS HYDRAULIC LABORATORY, University of Minnesota.

Inquiries concerning Projects Nos. 100, 104, 924, 1155, 1397, 1663, 1665, 1668, 1669, 1671,1672 , and 1923 to 1928, incl., should be addressed to Dr. Lorenz G. Straub, Director, St. Anthony Falls Hydraulic Laboratory, Hennepin Island, Minneapolis IL, Minnesota.

Inquiries concerning Projects Nos. 111, 1168, and 1398, which are conducted in cooperation with the Agricultural Research Service, should be addressed to Dr. Robert M. Salter, Chief, Soil and Water Conservation Research Branch, Agricultural Research Service, Plant Industry Station, Beltsville, Md.

Inquiries concerning Projects Nos. 194, 412, 985, 1206, and 1977, which are conducted in cooperation with the Corps of Engineers, should be addressed to the District Engineer, Corps of Engineers, Department of the Army, St. Paul District, St. Paul, Minnesota. (These projects are listed on pages 121 and 122.

(100) AIR ENTRAINMENT RESEARCH.

(b) Office of Naval Research, Department of the Navy.

(d) Theoretical and experimental; basic and applied research.

(e) Detailed study of the self-aeration of high velocity open-channel flows. Velocity distributions and air concentration distributions in the flows are being obtained with specially developed electrical instruments. Control and variation of flows afforded by laboratory channel built for purpose. Present phase concerns observation of flows when fully aerated.

(h) "Experimental studies of air entrainment in open channel flow." Lorenz G. Straub and Owen P. Lamb, Proceedings, Minnesota International Hydraulics Convention, Sept. 1953, pp. $425-437$.

(IO) FLOW DIVERSION RESEARCH.

(b) Office of Naval Research, Department of the Navy.

(d) Theoretical and experimental; basic and applied research and design.

(e) Detailed study of flow processes in bends with main emphasis on guide vane bends. Two-dimensional and secondary effects are to be separated so that the performance of a given bend geometry can be predicted.

(f) Completed. 
(g) It has been shown that secondary flows have only a small influence upon the twodimensional deflection in a guide vane bend, but increase the two-dimensional loss many fold. The relation of the secondary flow to the increased loss has been shown and formulas which check the experimental data reasonably well have been deduced. A result of practical importance is that a guide vane system of minimum loss can be obtained using thin plate vanes by selecting a two dimensional cascade of such vanes having a small head-loss coefficient and using vanes of large chord length.

(h) "Secondary flows in guide vane bends with some notes on the primary two-dimensional flow." Edward Silberman, St. Anthony Falls Hydraulic Laboratory Project Report No. 36, Jan. 1953.

"Importance of secondary flow in guide vane bends." Edward Silberman, Proc. of the Third Midwesterm Conference on Fluid Mechanics, June, 1953, pp 669-686. (Also available as St. Anthony Falls Hydraulic Laboratory Technical Paper No. 14, Series B, Jan. 1953.)

(924) FREE-JET WATER TUNNEL STUDIES.

(b) Office of Naval Research, Department of the Navy.

(d) Experimental; applied research and design.

(e) The characteristics of the free-jet type of water tunnel, including the effect of the test stream boundary conditions on steady state cavity phenomena which are modeled within the stream, are being studied in the new 10-inch free-jet water tunnel.

(h) "Description of a 10-inch free-jet water tunnel." Charles Christopherson, St. Anthony Falls Hydraulic Laboratory Project Report No. 35, Jan. 1953.

(1165) RIPPLE FORMATION AND ITS RELATION TO BED-LOAD MOVEMENT.

(b) Laboratory project.

(d) Theoretical and experimental; for doctor's thesis.

(e) A basic research to investigate the phenomenon of ripple formation of an alluvial stream. Criterion for ripple formation has been established by experiments. Frictional resistance of an alluvial channel based on analysis has been established by using data from various sources.

(f) Completed.

(h) "Ripple formation and its relation to bed-load movement." Hsin-Kuan Liu. Doctor's Thesis, University of Minnesota, June, 1953.

(1663) MODEL STUDY OF BOX CANYON POWER PROJECT.

(b) Harza Engineering Co., Inc., Chicago, IIl.

(d) Experimental; design.

(e) Model study to examine flow in main channel and appurtenant works for various flow conditions, study of spillway operation, and spillway calibration.

(f) Completed.

(h) Report in preparation.

(1665) LOW VELOCITY WIND INSTRUMENTATION.

(b) Army Ordnance Corps and Signal Corps.

(d) Literature search leading to applied design recommendations.

(e) Survey of basic nature and limitations of existing systems adaptable for precision measurement of low velocity winds.

(f) Survey completed with further development work expected.

(h) "Low-velocity wind instruments." John F. Ripken, St. Anthony Falls Hydraulic Laboratory Project Report No. 40. 
(1668) FLUID FLOW IN ROUGH TRIANGULAR CHANNELS.

(b) Laboratory project.

(d) Experimental; master's thesis.

(e) Bulk flow in a small, rough triangular channel is studied to determine the effect of such factors as roughness characteristics and Reynolds number on the Darcy friction factor and on Manning 's "n." Strip type roughness elements whose spacing can be varied are used and the control angle of the channel cross section can be varied.

(f) Completed.

(g) In general, the friction factor is shown to be very similar to that for pipes with similar type roughness elements over the range of Reynolds numbers investigated (500 to 10,000 using hydraulic radius as length parameter). Manning 's " $n$ " proves to be nearly constant over this range for each type of roughness.

(h) "Fluid flow in rough triangular channels." H. C. Nelson, Master's Thesis, University of Minnesota, March, 1953.

(1669) EXPERIMENTAL INVESTIGATION OF BASIC EQUIPMENT AND METHODS ASSOCIATED WTTH IABORATORY WAVE STUDIES.

(b) David Taylor Model Basin, Department of the Navy.

(d) Experimental; basic and applied research.

(e) The investigation of equipment and methods associated with laboratory surface-wave studies. Three items are proposed for study, namely, absorbers, filters, and generators.

(g) A brief sumary of literature and a translation of several foreign papers have been prepared in the form of project reports. Experimental studies have largely been restricted to absorbers although some data were obtained on filters. Several types of permeable absorbers have been developed with good absorption characteristics.

(h) Two project reports pertaining to available literature have been prepared but are not available for distribution.

\section{(1671) CAITTATION TESTING IN WATER TUNNELS.}

(b) David Taylor Model Basin, Department of the Navy.

(d) Experimental; basic and applied research.

(e) An experimental study to determine if there is a measurable pressure at which cavitation occurs which is a better indication of the cavitation susceptibility. This is the vapor pressure. The objective is to use this measured pressure rather than the vapor pressure in defining the cavitation index.

(1672) SLOTTED-WALL TEST SECTION FOR WATER TUNNELS.

(b) David Taylor Model Basin, Department of the Navy.

(d) Experimental; design.

(e) Studies will be made of a new type of test section for a water tunnel intended to combine the constant-pressure characteristics of a closed jet with the negligible wall interference effects obtained in an open-jet test section. This takes the form of an open-jet with an inner slotted liner wall.

(1923) DRAG OF AN ACCELERATED SPHERE.

(b) Laboratory project.

(d) Experimental; master's thesis.

(e) Smooth spheres of various materials ranging in diameter from $21 / 2$ to 6 inches are dropped through water a distance of 18 feet in one of the laboratory's volumetric measuring tanks ( 30 by 70 feet in plan). Accelerations are determined from a positiontime graph recorded on a rotating drum.

(g) Measured apparent drag is being separated into added mass effect and surface drag. 
1924) FLOW STUDIES IN LARGE TEST CHANNEL.

(b) Laboratory project.

(d) Experimental.

(e) Objective of the study is to develop uniform flow distribution for both subcritical and supercritical flow in an existing test channel.

(g) The channel in question is equipped with a tunnel-type entrance in which are located a flow-control baffle and a sluice gate. The function of the flow-control baffle is to regulate the discharge and produce a unform velocity distribution. As the head acting on the baffle is constant, variations in discharge are effected by varying the effective opening of the baffle. Solidity ratios of 80 to $95 \%$ are necessary. As a result of the high solidity ratio an unstable flow developed. Stability has been achieved by addition of a special honeycomb immediately downstream of the baffle.

(1925) EFFECT OF INLET DESIGN ON CULVERT CAPACITY.

(b) Bureau of Public Roads and Minnesota State Highway Department.

(d) Experimental; applied research.

(e) Tests were on a 4 -inch diameter culvert 35 feet long fitted with either a square-edged or rounded inlet. Head-discharge relationships and behavior curves were measured for various slopes.

(f) Completed.

(g) Experiments showed that in general a considerable head-advantage was gained by using a rounded inlet. Project report being completed.

(h) "Importance of inlet design on culvert capacity." Lorenz G. Straub, Alvin G. Anderson, and Charles E. Bowers, St. Anthony Falls Hydraulic Laboratory Tech. Paper No. 13, Series B, Aug. 1953.

(1926) STUDY OF HYDROELECTRIC TURBINE SETTING.

(b) Northern States Power Company, Minneapolis, Minnesota.

(d) Experimental; design.

(e) Test of hydroelectric turbine model to determine methods or construction for the improvement of flow into the propeller turbines installed in the reconstruction project at the Lower Dam Hydroelectric Plant at St. Anthony Falls.

(1927) ULTRASONIC AND OTHER VISCOSITY MEASUREMENTS.

(b) Laboratory project.

(d) Experimental; basic research.

(e) Investigation of Newtonian and non-Newtonian liquids, mixtures, and suspensions using commercial ultrasonic viscosimeter in conjunction with conventional apparatus (rotating, cylinder, capillary).

(1928) DEPRESSED TEMPERATURE SEDIMENT STUDIES.

(b) Missouri River Division, Corps of Engineers.

(d) Basic research; analytical and experimental.

(e) An investigation of the effect of temperature changes on the suspended load of natural streams. The experimental program includes measuring in a flume the amount and size distribution of sediment carried in suspension by water whose temperature is held constant at several levels between freezing and well above room temperature.

(1929) DRAIN TILE JUNCTION LOSSES.

(b) Minnesota Agricultural Experiment Station in cooperation with the Agricultural Research Service, U. S. Department of Agriculture and the St. Anthony Falls Hydraulic Laboratory.

(c) Prof. Philip W. Manson, University of Minnesota, St. Paul Campus, St. Paul, Minnesota.

(d) Experimental; applied research for design.

(e) The junction losses in drain tile flowing $f u l l$ will be determined for laterals of different sizes entering mains of different sizes at various angles. 


\section{(111) CIOSED CONDUTT SPILITAY.}

(b) Agricultural Research Service, U. S. Department of Agriculture, in cooperation with the Minnesota Agricultural Experiment Station and the St. Anthony $F$ alls Hydraulic Laboratory.

(d) Experimental; applied research for development and design.

(e) Tests have been made on three different sizes of Lucite pipe set on slopes ranging from 2.5\% to $30 \%$ to verify the similarity relationships. Information on discharges, pressures, and flow conditions has been obtalned. Future studies will be on the effect of different types of inlets on the flow conditions and hydraulic losses.

(g) Theory has been developed and verified. Generalized methods for analysis and reporting results have been developed. Pipe culverts laid on steep slopes will flow completely full even though the outlet discharges freely. Entrained air did not invalidate the Froude model law.

(h) "Hydraulics of closed conduit spillways. Part I, Theory and its application." Fred W. Blaisdell, St. Anthony Falls Hydraulic Laboratory Tech. Paper No. 12, Series B, Jan. 1952. Available from the St. Anthony Falls Hydraulic Laboratory at 50 per copy. "Hydraulic fundamentals of closed conduit spillways." Fred W. Blai sdell. ProceedingsSeparate No.

(Publication pending.)

(1168) A STUDY OF CANTILEVERED OUTLETS.

(b) Agricultural Research Service, U. S. Department of Agriculture, in cooperation with the Minnesota Agricultural Experiment Station and the St. Anthony Falls Hydraulic Laboratory.

(d) Experimental; applied research for design.

(e) Pipe outlet conduits for small spillways are frequently cantilevered beyond the toe of the earth dam. Attempts will be made to determine quantitatively the size of the scour hole to be expected under various field conditions.

(f) Suspended.

(1397) PERFORATED PLATE EMTRANCE TO A FLOW-THROUGH SEDIMENTATION BASIN.

(b) Laboratory project.

(d) Experimental; for master's thesis.

(e) To determine the effect of perforated plate entrances upon sedimentation in a flowthrough type basin.

(f) Completed.

(g) Three entrances, each with a different size perforation, were studied. The number and pattern of the holes were the same in all three entrances. Sediment retention and flow-through efficiency were measured for various discharges. The highest sediment retention occurred when using the plate with the lowest solidity ratio. Using a sediment consisting of discrete particles, the retention was higher than that obtained when entrances of a type normally employed in sectimentation basins were used.

(h) "Study of a perforated-plate type entrance to a flow-through sedimentation basin." John J. Casey, Master's Thesis, University of Minnesota, Sept. 1953.

\section{(1398) STRAIGHT DROP SPIIIWAY.}

(b) Agricultural Research Service, U. S. Department of Agriculture, in cooperation with the Minnesota Agricultural Experiment Station and the St. Anthony Falls Hydraulic Laboratory.

(d) Experimental; applied research for development and design.

(e) Spillway is used as a grade control structure in ditches and streams. Study will result in general design rules for the spillway and outlet. Outlet will have floor blocks and an end sill. Movable sand beds are used to evaluate the outlet performance.

(g) Ninimum basin length is equal to distance at whlch upper nappe strikes basin floor plus 2.55 times the critical depth of flow. Floor blocks $0.8 \mathrm{~d}$ high by $0.4 \mathrm{~d}$ wide. Flaring triangular hingwalls are used. Approach channel design affects basin ferformance. Longer stilling basins are required with high tailwater levels because the nappe floats.

(h) Report in preparation. 
SCRIPPS INSTITUTION OF OCEANOGRAPHY, University of California.

Inquiries concerning Projects Nos. 1930 and 1931 should be addressed to Mr. WLIlard N. Bascom and Projects Nos. 1932 to 1934, incl., should be addressed to Dr. John D. Isaacs, University of California, Scripps Institution of Oceanography, La Jolla, Calif.

(1930) BOTTOM CURRENTS AND SAND MOTION.

(b) Office of Naval Research, Department of the Navy.

(d) Experimental; field investigation.

(e) Project involves the measurement of bottom currents in estuaries and on the inshore ocean bottom and the examination of sand motion caused by the se currents.

(g) A better understanding of the complex mechanisms by which sand grains migrate is slowly developing.

(h) "Characteristics of natural beaches." Proc. Lth Conf. on Coastal Engineering, Chicago, 1953.

"Beach face slope." Trans. Amer. Geophys. Union, Dec. 1951.

(1931) DEEP-SEA INSTRUMENT STATION.

(b) Office of Naval Research, Department of the Navy.

(d) Field investigation; applied research.

(e) A means of easily and cheaply obtaining a fixed point in the deep ocean has been developed.

(g) A fixed recording meter (waves, currents, temperature) can be mounted on this deepsea instrument station.

(1932) HIGH-SPEED, MAXIMUM-DEPTH CABLE DEPRESSORS.

(b) Office of Naval Research, Department of the Navy.

(d) Experimental; design.

(e) Study and analysis of hydrodynamic and gravity loads of homogeneous cable depressors with respect to efficiency and speed of tow. Relation of potential depth-seeking characteristics with the physical limitations of towing cables and towing cable instrumentation.

(1933) OCEAN SWELI RESONATING SYSTEM.

(b) Office of Naval Research, Department of the Navy.

(d) Experimental; applied research.

(e) A pipe with proper diameter, length, and entrance conditions to resonate to ocean swell of a specific period with the purpose of lifting a quantity of salt water above mean sea level.

(1934) FREE-INSTRUIENT DESIGN.

(b) Laboratory project.

(d) Experimental.

(e) General study of free-floating, submersible oceanographic instruments at various depths. One of the design requirements is that the instruments remain at the desired depth a predetermined length of time, another that they contain some means of easy location after their return to the surface.

(1935) BEACH AND NEARSHORE PROCESSES.

(b) Beach Erosion Board, Office of Naval Research, and Institute of Marine Resources of the University of California.

(c) Mr. Douglas L. Inman, Uni versity of California, Scripps Institution of oceanography.

(d) Field investigation; basic research.

(e) Study of the mechanics of sand transport under the influence of waves and currents. The project includes 1) measurement of orbital velocities associated with waves near shore, 2) studies of the formation of ripples, 3) accurate measurement of cut and fill at selected depths, and 4) development and improvement of equipment and techniques for underwater studies. 
(h) "Currents in the surf zone." Douglas L. Inman and William H. Quinn, Coastal Engineering, chapter III, pp 24-36, 1952, SIO Contribution, New Series, No. 560.

"Areal and seasonal variations in beach and nearshore sediments at La Jolla, California." Douglas I. Inman. Beach Erosion Board Tech. Memo. No 39, SIO Contribution, New Series, No. 638 .

\section{(1936) GRAVTTY WAVES AND RELATED PHENOMENA.}

(b) Office of Naval Research, Air Force, and Beach Erosion Board.

(c) Dr. Walter H. Munk, University of California, Scripps Institution of Oceanography, La Jolla, Calif.

(d) Basic research.

(e) The probability distribution of slopes has been measured by means of photographs of sun's glitter on the water. Results have been interpreted in terms of the behavior of the wave spectrum at high frequencies. Theoretical studies of wave refraction are being conducted. Instruments are being developed for measuring waves of periods from two minutes to two hours at various depths up to 500 feet. A shore-based long-period wave recorder is in contimuous operation. Waves of periods exceeding ordinary tides are beins studied by means of tide records from which the principal tidal constituents have been removed by a highly selective mathematical "filter." The diffusion of tides into permeable rock has been theoretically investigated.

(h) "Wave intensity along a refracted ray." W. H. Munk and Robert S. Arthur, National Bureau of Standards Circular 251, SIO Contribution, New Series, No. 618.

"Small tsunami waves reaching Califormia from Japanese earthquake of 4 March, 1952." W. H. Munk, Bulletin of the Seismological Society of America, Vol. 43, No. 3, July, 1953, SIO Contribution New Series No. 641.

(1937) WIND STRESS ON WATER.

(b) U. J. Air Force.

(c) Dr. Wm. G. Van Dorn, Uni versity of California, Scripps Institution of Oceanography, La Jolla, Calif.

(d) Basic research.

(e) The set-up over a 200-meter model yacht basin was measured to an accuracy of \pm 0.1 millimeter. In addition, measurements of bottom stress were conducted by means of a stress disk buried in the sand bottom.

(f) Completed.

(g) The wind stress is proportional to the mean square wind speed. The proportionality constant varies seemingly abruptly from a lower value at low wind speeds to a higher value at high wind speeds. The effect of detergent added to the water surface is to annul the additional set-up at high wind speeds. The results are quite similar to those obtained by Keulegan in the experimental closed flume.

\section{S. MORGAN SMTTH COMPANY.}

Inquiries concerning Projects Nos. 1938 to 1942, incl., should be addressed to Mr. Emmert M. Lowry, Jr., S. Morgan Smith Company, York, Pa.

(1938) HYDRAULIC TURBINE TESTS.

(b) Laboratory project.

(d) Experimental; applied research.

(e) To improve the performance and to extend the ranges of application, homologous models of Smith-Kaplan, Francis, and Impulse turbines are tested for power and efficiency at various speeds and heads.

(g) Results are being used for prototype designs. 


\section{(1939) CAVITATION TESTS.}

(b) Laboratory project.

(d) Experimental; applied research.

(e) Homologous models of Smith-Kaplan and Francis turbines are tested for critical sigma values.

(g) Results are being used for prototype designs.

(1940) HYDRAULIC PUMP TESTS.

(b) Laboratory project.

(d) Experimental; applied research.

(e) Homologous models of adjustable-bladed axial and mixed-flow pumps are tested for efficiency, power and cavitation under various operating conditions.

(g) Results used for prototype designs.

(19LI) VALVE TESTS.

(b) Laboratory project.

(d) Experimental; applied research.

(e) Scale model valves are tested for coefficients of discharge and operating characteristics.

(g) Results are used in prototype designs.

(1942) PITOT TUBE CAIIBRATION TESTS.

(b) Laboratory project.

(d) Experimental; applied research.

(e) To establish coefficients for pitot tubes used in velocity measurements.

(f) Completed.

(g) Results were used to more accurately evaluate and correlate experimental results.

THE SOCIETY OF NAVAL ARCHITECTS AND MARINE ENGINEERS.

(895) THE COMPIIATION OF RESISTANCE AND PROPULSION DATA.

(b) Office of Naval Research, Department of the Navy.

(c) Capt. W. N. Landers, Secretary, The Society of Naval Architects and Marine Engineers, 29 hest 39 th Street, New York 18, N. Y.

(d) The compilation of ship model resistance data, propeller data and self-propulsion data presently available at the various model basins and in designing offices, and the presentation of these data in a readily usable form.

(e) A study and correlation of existing data on the wave-making resistance of ship hull models which have been tested by the several towing tanks of this country and abroad. An analysis of the se data after correlation to determine systematically the influence of differences of hull form and propeller characteristics on wave-making resistance.

(g) A standard form entitled "Model resistance and expanded resistance data" sheets has been developed to record model data and test results and for the expansion of the model test results to ship size. Explanatory notes defining the various dimensions, ratios and coefficients used on the data sheets have beer compiled. An index listing all models in the compilation has been completed. Model resistance and expanded resistance data sheets covering 150 models have been completed. Propeller data forms and self-propulsion data forms have been prepared.

(h) "Model resistance and expanded resistance data sheets with explanatory notes." For models $1-150 \$ 10.00$ per set of 50 to members. $\$ 11.00$ per set to nonmembers

Explanatory notes sent with each order for model sheets.

Single sheets can be ordered at $\$ 1.00$ per sheet.

Bulletin No. I-I4, Index to model and expanded resistance data sheets, No. I-150, $\$ 1.00$ per copy. 
STANFORD UNIVERSITY, Hydraulic Laboratory.

Inquiries concerning Projects Nos. 627, 628, 1171 , and 1172 should be addressed to Prof. John K. Vennard, and Projects Nos. 1943 to 19L6, incl., to Prof. Ray K. Iinsley, Stanf ord University, Stanf ord, Calif ornia.

(627) STUDY OF TURBULENT BOUNDARY LAYERS.

(b) Laboratory project.

(d) Experimental; $\mathrm{Ph} . \mathrm{D}$. thesis.

(e) Study of the zone of boundary layer transition in smooth pipes of various diameters.

(g) Engineer theses by S. M. Barnes and C. T. Chen completed. Work now continuing under Karl Brenkert, $\mathrm{J}_{\mathrm{r}}$. as $\mathrm{Ph}$. D. project.

(628) EFFECT OF SHAPE OF PARTICLE ON SETTLING VELOCITY.

(f) Inactive.

(1171) STUDY OF MANIFOLD PORTS.

(b) Laboratory project.

(d) Experimental; engineer thesis.

(e) Measurement and interpretation of pressure variation near outlet ports in manifold pipes and obtaining hydraulic coefficients for various flow geometries.

(f) Experimental work completed; thesis being written.

(h) Discussion of "Mechanics of manifold flow. John S. McNown, A.S.C.E. Proceedings 1953. Discussion by John K. Vennard and Darrhl I. Dentoni.

(1172) PERMEAMETER WALL EFFECT.

(f) Inactive.

(1943) DEVELOPMENT OF IMPROVED STREAM FLOW ROUTING ANALOGUE.

(b) U. S. Weather Bureau.

(d) Experimental; applied research.

(e) Using a Beckman analog computer equations of the type $S=a I^{X}+b 0^{z}=X^{n} 0^{m}$ are being tested to determine if they are superior to the ordinary Muskingum type equation. Special components for introducing the inflow current and for raising the necessary numbers to powers are being designed.

(g) It appears that a more satisfactory equation can be found if adequate components for the high speed computation can be derived.

(1944) STUDY OF METHODS OF ESTIMATING RESERTOIR EVAPORATION.

(b) U. S. Weather Bureau.

(d) Experimental; applied research.

(e) In an experiment comparable to the Lake Hefner studies, the energy-balance concept, the mass transfer concept, and various types of evaporation pans will be compared with a water budget developed for Felt Lake on the Stanf ord campus.

(1945) ESTTMATING RATNFALI INTENSITY FROM TOPOGRAPHIC PARAMETERS.

(b) U. S. Bureau of Public Roads.

(d) Theoretical; basic research.

(e) An attempt is being made to correlate rainfall intensity at approximately 125 northerm Califormia stations with topographic parameters. Presently, the study is concentrating on the one hour, two-year frequency intensity. 
46) SYNTHESIS OF HYDROGRAPH FOR SMALI AREAS.

(b) Laboratory.

(d) Theoretical and field investigation; basic research, doctoral dissertation.

(e) An attempt is being made to develop practical methods of computing the hydrograph of munoff from small areas for the design of small drainage stmuctures. Several small basins on the Stanford campus will be instrumented to provide date.

EVENS INSTITUIE OF TECHNOLOGY, Experimental Towing Tank.

SCELLANEOUS PROJECTS.

The Experimental Towing Tank carries out an extensive research program of a classified nature for the Bureau of Ships, Bureau of Ordnance, Office of Naval Research, and the Bureau of Aeronautics, Department of the Navy. A large mumber of projects involving commercial vessels of many different designs for private clients are also undertaken for the determination of effective horsepower, the resistance, directional stability of barges, the determination of shaft horsepower for river towoats and comparable vessels, resistances under sailing conditions of sailing yachts, and the hydrodynamic characteristics of flying boats and seaplane floats.

\section{L0) PLANING SURFACES.}

(b) Office of Naval Research, Department of the Navy.

(c) Prof. B. V. Korvin-Kroukovsky, Experimental Towing Tank, Stevens Institute of Technology, 711 Hudson St., Hoboken, N. J.

(d) Theoretical and experimental; basic research.

(e) A continuous, related research study directed towards the investigation of the fundamental factors affecting the hydrodynamic performance of planing surfaces for application to seaplane and planing type surface craft. Also to investigate the wake shape and spray formations associated with planing surfaces.

(g) Investigations will extend from elementary planing surfaces of several deadrises, through surfaces with steps of Vee planform; and combinations of forebody with an afterbody planing in its wake.

(h) Twelve reports on the results of research conducted under the subject contract have been prepared and published. Four reports are presently in preparation. Two are theoretical, dealing with loads, pressures and wake of planing surfaces; two are experimental and empirical dealing with low speed planing characteristics and two-step planing of seaplane hulls.

173) THE DEVELOPMENT OF A TEST TECHNIQUE FOR THE DETERMINATION OF SHIP MODEL RESISTANCE IN HEAD SEAS.

(b) Laboratory.

(c) Mr. Randolph Ashton, Experimental Towing Tank, Stevens Institute of Technology, 711 Hudson St., Hoboken, N. J.

(d) Experimental and developmental.

(e) Resistance tests in waves of ship models (commercial vessels and fast power boats) so that models are as free as possible to respond to oncoming waves-in particular, to heave, pitch and surge fore and aft.

(f) Completed.

(g) A method has been developed, termed the "gravity weight method", with extremely little friction in the system and no towbar, springs, or dashpot damping. It is currently being used for obtaining model resistance in head seas.

(h) Note No. 175 describing the method has been given informal distribution and is available to interested parties. 
(1405) IMPACT IOADS ON THE JR2F-I FOR BOW LANDING CONDITIONS.

(b) Bureau of Aeronautics, Department of the Navy.

(c) Mr. Wifred C. Hugli, Jr., Experimental Towing Tank, Stevens Institute of Technology, 711 Hudson St., Hoboken, N. J.

(d) Experimental; applied research for design.

(e) A 1/16-scale dynamic model of the XJR2F-I was catapulted at various bow-down attitudes and impact accelerations were recorded.

(f) Completed.

(g) The test results indicated that the $K_{2}$ factor, employed in the ANC-3 seaplane impact load specification, did not vary with ${ }^{2}$ center of pressure position.

(h) "An experimental investigation of the eccentric impact loads on a free-flight model of the XJR2F-1 Amphibian during bow landing in smooth water." Samuel Leshnover, ETT Report No. 463, Dec. 1952.

(1406) TURBULENCE STIMULATION OF PIANING SURFACE MODELS.

(b) National Advisory Comittee for Aeronautics.

(c) Professor B. V. Korvin-Kroukovsky, Experimental Towing Tank, Stevens Institute of Technology, 711 Hudson Street, Hoboken, N. J.

(d) Experimental and theoretical.

(e) Previous experimental and analytical material on the subject is being reviewed. Experiments are being made to test out theories.

(f) Completed.

(山07) SEATDRTHINESS OF SHIPS.

(b) Society of Naval Architects and Marine Engineers.

(c) Professor B. V. Korvin-Kroukovsky, Experimental Towing Tank, Stevens Institute of Technology, 711 Hudson St., Hoboken, N. J.

(d) Experimental; basic research.

(e) To determine the vertical forces and pitching moments acting on a restrained ship model moving against head seas. This project supplements the project on seaworthiness model tests conducted at David Taylor Model Basin and Massachusetts Institute of Technology.

(g) Preliminary tests of a model in waves of one length and height are completed and the experimental data are ready for analysis. The remaining tests are to be conducted after analysis of the preliminary data.

(1408) HYDRODYNAMIC COEFFICIENTS OF AN AIRSHIP.

(b) Bureau of Aeronautics, Department of the Navy.

(c) John B. Drisko, Experimental Towing Tank, Stevens Institute of Technology, 71 I Hudson, St., Hoboken, N. J.

(d) Experimental.

(e) Experimental determination, utilizing the rotating arm, of the static and hydrodynamic coefficients of a conventional airship form. Static (straight-line) values have been determined by wind-tunnel tests, and the principal reason for curvilinear tests is to determine the rotary (damping) coefficients.

(f) Virtually complete.

(h) Report in preparation.

(1409) BENDING MOMENT OF SHIPS IN WAVES.

(b) Society of Naval Architects and Marine Engineers.

(c) Mr. Edward V. Lewis, Experimental Towing Tank, Stevens Institute of Technology, 711 Hudson St., Hoboken, N. J.

(d) Experimental method to check calculations.

(e) Stress measurement s of jointed model to determine external bending moment underway in waves, for comparison with calculated bending moment in "stationary" wave.

(f) First phase completed; project continuing.

(g) Preliminary report completed and submitted to the Hull Structure Committee of the spon 
(h) Report to be published by sponsor in the near future.

110) SELF-PROPELIED TESTING.

(b) Laboratory.

(c) Mr. E. V. Lewis.

(d) Experimental; developmental research.

(e) To determine if successful self-propelled testing can be conducted using models of less than 12-foot length and to determine causes of scale effect in propulsion factors.

(g) Open water tests have been completed on three different sized models of a propeller designed by the Netherlands Model Basin for the Victory type cargo ship. A 9-foot hull model of the Victory ship has been tested self-propelled and a 7-1/2 foot model will be tested shortly. This work is being carried out in cooperation with the Netherlands Model Basin who are testing models $9-\mathrm{ft}$. long and above.

(h) First part dealing with tests on the M.S. SAN FRANCISCO and related studies was published in the form of a paper "Self-Propulsion Tests with Small Models," by Messrs. Allan B. Murray, B. V. Korvin-Kroukovsky and Edward V. Lewis, Transactions, Society of Naval Architects and Marine Engineers, 1951.

(山11) PROPELLER MEASURING APPARATUS。

(b) The Society of Naval Architects and Marine Engineers.

(c) Mr. Allan B. Murray, Experimental Towing Tank, Stevens Institute of Technology, 711 Hudson St., Hoboken, N. J.

(d) Design and construction.

(e) Apparatus to assist in the carrying out of open water tests of ship propeller models by providing a means of accurate measurement of the models.

(f) Completed.

(g) Instrument has been giving very satisfactory results in measuring model propellers of $2-1 / 2$ to $5-1 / 2$ inches in diameter. Blade section offsets can be read to $0.001-0.002$ inches.

(h) Report published in the october 1953 Bulletin, Society of Naval Architects and Marine Engineers. (Also available as ETT Note No. 245, Aug. 1953.)

(山12) DESIGN AND CONSTRUCTION OF PROPELIER BOAT.

(b) The Society of Naval Architects and Marine Engineers.

(c) Mr. Allan B. Murray, Experimental Towing Tank, Stevens Institute of Technology, 711 Hudson St., Hoboken, N. J.

(d) Design and construction.

(e) Apparatus to enable the carrying out of open-water tests of ship propeller models.

(f) Completed.

(g) Equipment has been used with satisfactory results.

(h) Report published in the October 1953 Bulletin, Society of Naval Architects and Marine Engineers. (Also available as ETT Technical Memorandum No. 105.)

(山13) AN INVESTIGATION OF SHIP RESISTANCE USING STATISTICAL METHODS.

(b) Office of Naval Research, Department of the Navy.

(c) Mr. Milton Morrison, Experimental Towing Tank, Stevens Institute of Technology, 711 Hudson St., Hoboken, N. J.

(d) Applied research.

(e) Forty-two displacement hulls (reduced to a common 400 foot LBP) have been selected to investigate the effects of shape and hull parameters on resistance. The statistical techniques will involve the application of regression analysis.

(f) Completed.

(g) A statistical evaluation of the importance of the various hull parameters chosen has been made.

(h) Report in preparation. 
(1680) COMPUTATION OF WAVE RESISTANCE OF SHIPS.

(b) Society of Naval Architects and Marine Engineers and Office of Naval Research, Department of the Navy.

(c) Professor B. V. Korvin-Kroukovsky, Experimental Towing Tank, Stevens Institute of Technology, 711 Hudson St., Hoboken, N. J.

(d) Theoretical; applied research.

(e) To verify the applicability of methods and tables developed by $R$. Guilloton to the calculation of wave-making resistance of ships of practical shape. To verify validity of certain second order corrections.

(g) The preliminary stage of work under SNAME sponsorship has been completed. The work on ships of a practical form under sponsorship of ONR and DTMB is well advanced. The use of second order corrections was found significant in the case of ships of simple form, and appears to be necessary for ships of practical form, in some sections of which the sides at Lif are not vertical but have a large slope. The development of the method of these corrections is now in progress.

(h) "Preliminary application of Guilloton's method to the calculation of ship wave profile and wavemaking resistance." B. V. Korvin-Kroukovsky and hinnifred R. Jacobs, ETT Report No. 478 .

"Report on voyage to Europe for the purpose of reviewing the status of the theory of ship wavemaking." B. V. Korvin-Kroukovsky, ETT Report No. 504 .

"Discussions with Dr. R. Guilloton in Paris during the period from May 18 to May 26, 1953, including translation of informal notes written by Dr. Guilloton." B. V. KorvinKroukovsky, ETT Note No. 229.

(1681) TO EVALUATE RESISTANCE AND MOTION IN STILL WATER AND IN WAVES WITH BULB VARIATIONS FROM O\% TO ABOUT 13\% OF THE IMMERSED MIDSHIP AREA.

(b) U. S. Maritime Administration.

(c) Mr. Edward V. Lewis, Experimental Towing Tank, Stevens Institute of Technology, 711 Hudson St., Hoboken, N. J.

(d) Experimental; model testing.

(e) Resistances of various models being measured in smooth water and in head seas. Bow accelerations and bow pitching being measured in head seas.

(f) Completed.

(g) The effect of bulbous bow size and resistance and motion has been evaluated.

(h) Report has been submitted to the sponsor who contemplates publication in the near future

(1947) THE DETERMINATION OF RESISTANCE AND AMPLITUDES OF PITCH AND HEAVE OF A MERCHANT SHIP MODEL IN WAVES.

(b) International Conference on Ship Hydrodynamics, Committee on Seakeeping Qualities.

(c) Mr. Edward V. Lewis, Experimental Towing Tank, Stevens Institute of Technology, 711 Hudson St., Hoboken, N. J.

(d) Experimental; model testing.

(e) Resistance of David Taylor Model Basin Series 60 ship model is being measured in smooth water and in waves of various lengths; amplitudes of pitch and heave are being determined by analysis of moving picture records.

(g) Results to be forwarded to the sponsor for analysis and comparison with results from other model basins.

(h) Report may be published by sponsor after completion of analysis and comparison.

(1948) SYSTEMATIC INVESTIGATION OF THE TURNING CHARACTERISTICS OF A SHIP MODEL FITTED WITH VARIOUS COMBINATIONS OF APPENDAGES.

(b) Bureau of Ships, Department of the Navy.

(c) Mr. Edward V. Lewis, Experimental Towing Tank, Stevens Institute of Technology, 711 Hudson St., Hoboken, N. J.

(d) Experimental; applied research.

(e) To obtain data on the influence of appendages on the turning characteristics of a surface ship; the appendages under consideration are skegs and bilge keels, with rudders and propellers of different sizes.

(g) Tests have been completed on a number of appendage combinations. Field of usefulness of free turning and rotating arm tests is being ascertained.

(h) Progress report in preparation; to be submitted to sponsor. 
JNIVERSTTY OF TENNESSEE, Engineering Experiment Station.

(944) HYDRAULIC FRICTION.

(b) Office of Naval Research, Department of the Navy.

(c) Dr. Harry H. Ambrose, Associate Professor of Civil Engineering, University of Tennessee, Knoxville, Tennessee.

(d) Experimental; basic research.

(e) A long term investigation to determine the relationship between roughness of pipe surface and frictional resistance in the transition range between smooth and rough turbulent flow. Tests are being made on a four-inch lucite pipe which is roughened by the insertion of sleeves.

(h) "An investigation of a depression-type roughness." Dr. H. H. Ambrose, presented at American Towing Tank Conference, Boston, May 5, 1953.

(1949) A STUDY OF IAMINAR FIOW PHENOMENA UTILIZING A DOUBLY REFRACTIVE LIQUID.

(b) Office of Naval Research, Departinent of the Navy.

(c) Prof. F.N. Peebles, Department of Chemical Engineering, University of Tennessee, Knoxville, Tennessee.

(d) Experimental; basic research.

(e) To investigate in detail the methods of preparing and determining the properties of doubly refractive liquids; to investigate the quantitative interpretation of simple laminar flow stress patterns. Equipment is being assembled.

(1950) MECHANICS OF GAS BUBBLE MOTION.

(b) Laboratory project.

(c) Prof.F.N. Peebles, Department of Chemical Engineering, University of Tennessee, Knoxville, Tennessee.

(d) Experimental; basic research.

(e) Investigation of motion of gas bubbles and bubble streams in liquids with specific interest in determining the velocity and drag as functions of bubble size and physical properties of the liquid.

(h) "Studies in the motion of gas bubbles in liquids." F. N. Peebles and H. J. Garber, Chemical Engineering Progress, Vol. 49, pp 88-97, 1953.

(1951) A STUDY OF SWIRIING FLOW WITHIN SPHERICAL AND CYIINDRICAL VESSELS.

(b) Carbide and Carbon Chemicals Division for Oak Ridge National Laboratory.

(c) Prof. H. J. Garber, Department of Chemical Engineering, Uni versity of Tennessee, Knoxville, Tennessee.

(d) Theoretical and experimental basic research, doctoral thesis.

(e) Analytical investigation of velocity and pressure distribution in swirling flow within a sphere, and the dissipation of swirling motion in a cylindrical tube. Experimental verification of results using transparent models.

(g) The velocity and pressure distribution within the central portion of the sphere were found to follow the well-known free vortex theory. Strong secondary motion was found to exist on the sphere walls. Analytical solutions for the extent of secondary flow were developed.

(h) "Nature of liquid flow within a spherical container." H. J. Garber and F. N. Peebles, U. S. Atomic Energy Commission, AECU-1824, 43 pages, 1951.

TEXAS A AND M COLLEGE, Civil Engineering Department.

(1952) PIPE CULVERT MODEL TESTS.

(b) Texas Concrete Pipe Mamufactures Association, through Texas A and M Research Foundation. 
(c) R. E. Schiller, Jr., Civil Engineering Department, Texas A and M College, College Station, Texas.

(d) Experimental; applied research.

(e) Tests were run to determine the effect of inlet conditions on flow through 5 inch diameter circular pipe models operating under free outfall conditions.

(f) Completed.

(g) The test results reveal the effect of the following types of inlets on flow through circular pipes; projecting inlet concrete, flush inlet concrete, beveled inlet concrete, projecting inlet corrugated metal, flush inlet corrugated metal, beveled inlet corrugatec metal. Design procedures making use of nomographs have been worked out.

(h) A report submitted to Texas Concrete Pipe Manufactures Association and to the American Concrete Pipe Association for possible publication in Concrete Pipe News.

UNIVERSITY OF TEXAS, Department of Civil Engineering.

Inquiries concerning Projects Nos. 948, and 1683 to 1685, incl., should be addressed to Dr. Whlter L. Moore, Department of Civil Engineering, Uni versity of Texas, Austin, Texas.

(948) DIFFUSION OF A TWO-DIMENSIONAL SUBMERGED JET.

(b) National Science Foundation.

(d) Experimental.

(e) An experimental study of the effect of the relative distance to a solid boundary on the diffusion of a two-dimensional subrerged jet. The velocity field in a two-dimensional air jet will be measured with a parallel plane boundary at various distances from the jet axis. A spreading coefficient will be determined as a function of distance along the axis, and a systematic study made of its variation with the location of the parallel boundary. A limited investigation is anticipated of the effect of a plane boundary normal to the jet axis at various relative distances.

(g) Equipment is under construction for the above study. A related investigation was reported in last year's report. (See National Bureau of Standards Misc. Pub. 208.)

(1583) THE EQUTVALENT PIPE CONCEPT IN RELATION TO THE GENERAL RESISTANCE DIAGRAM.

(b) Laboratory project.

(d) Theoretical.

(e) An analytical study to clarify the conditions for the validity of the equivalent pipe concept and to modify the parameters of the conventional resistance diagram making it more convenient for problems with branching pipes, pipes in series, and pipe networks.

(g) Some of the previous concepts have been changed and more evaluation of the proposed method is required.

(1684) FLOW PATTERNS ASSOCIATED WITH THE VENTILATION OF A IARGE AREA.

(b) Laboratory project.

(d) Experimental; applied research.

(e) The flow patterns associated with a conventional plan for the ventilation of a large area will be studied by visual observations in a model of a portion of a large underground garage. Water will be used as the fluid and colored dye to trace the flow pattems. The effectiveness of alternative flow patterns will be investigated.

(g) The model has been completed and ventilation patterns recorded by photographing the movement of a front of dyed fluid sweeping through the area. Additional observation and analysis remains to be done.

(1685) THE INFLUENCE OF ENTRANCE CONDITIONS ON THE FLOW IN SPILLWAYS.

(b) Texas Board of Whter Engineers.

(d) Experimental. 
(e) Tests are being made on some typical spillways to investigate the effect of entrance conditions on the flow in the spillway and channel. Examples of good and bad conditions will be reported for the benefit of interested engineers.

(g) Tests on a model with sharply curved entrance channel indicated that flow conditions were improved by the gradual introduction of a cross slope in the bottom. Although a definite improvement resulted from the introduction of cross slope according to values determined by a simple approximate calculation, further improvement resulted from trial adjustments in the model.

'AH STATE AGRICULTURAL COLIEGE, Agricultural Experiment Station.

151) LINING OF IRRIGATION CANALS AND DITCHES. (Under Project No. 1966.)

See U.S. Department of Agriculture, Agricultural Research Servise, Soil and Water Conservation Research Branch, page 106.

359) DRAINAGE OF IRRIGATED LANDS.

(b) Laboratory project.

(c) Dr. O. W. Israelsen, Irrigation Department, Utah State Agricultural College, Logan, Utah.

(d) Field studies; applied research and masters theses.

(e) The major purposes are to find low cost, effective methods of drainage of arid-region waterlogged saline and alkali lands. Work has been concentrated on five Utah areas and one area in Canada in need of drainage; (1) the 10,000-acre area in Cache County, (2) the 1,000-acre area in Salt Lake County, designated respectively the Lewiston and the Draper areas, (3) the Delta area in Millard County, (4) the Logan-Cache County Airport area overlying an artesian aquifer, and (5) Utah County water-logged lands near Springville and Salem.

(g) Use of piezometers for low cost development of ground water flow patterns has been helpful in all areas. Pumping from sand formations having permeabilities as low as $3 \times 10^{-5}$ feet per second shows a measurable influence in lowering the ground water table. Project to be enlarged with special reference to regional aspects of research.

(h) "Drainage of the Logan-Hyde Park-Benson Area, Utah." Gordon H. Flammer, Thesis, Utah State Agricultural College, Logan, Utah, 1953.

"Drainage of land overlying an artesian aquifer Logan-Cache Airport." John Paul Riley, Thesis, Utah State Agricultural College, Logan, Utah, 1953.

"Drainage in the Lewiston Area, Utah." 0. W. Israelsen, Utah Agricultural Experiment Station Special Report No. 9, Logan, Utah, Nov. 1953.

Report concerning recent experiments and needs for drainage in the Logan-Hyde ParkBenson area will be published early in 1954.

1189) METHODS OF CONTROL AND DISTRIBUTION OF WATER.

(b) Laboratory project; BPIS and AE, U. S. Dept. of Agriculture.

(c) Dr. Vaughn E. Hansen, Irrigation, Dept., Box 70, Utah State Agricultural College, Logan, Utah.

(d) Experimental, field and laboratory; basic and applied research.

(e) Not only existing but proposed and new methods are being tested to determine their feasibility and applicability for the control and distribution of irrigated water.

(h) "Irrigation, fertilization, and soil management of crops in rotation." Sterling $A$. Taylor, Vaughn E. Hansen, and Jay L. Haddock. Anmual Progress Report, Utah Agricultural Experiment Station, Logan, Utah, 1952.

"Hydraulic tests on barrel valves for use as irrigation outlets to concrete pipe lines." Journal of Soil and water Conservation, Vol. 8, No. 4, July, 1953, p 167-168. "Determination of flow from gated pipe." Prepared for Joumal, American Society of Agricultural Engineers, Oct. 1953. 
(1190) DISTRIBUTION OF WATER FROM PERFORATED PIPE.

(b) Laboratory project; BPIS and AE, U. S. Dept. of Agriculture.

(c) Dr. Vaughn E. Hansen, Irrigation Dept., Box 70, Utah State Agricultural College, Logan, Utah.

(d) Experimental; applied research.

(e) The effect of wind on the distribution pattern from perforated pipe is being studied to provide design data and to determine the limitations of this type of distribution for irrigation purposes.

(1191) DETERMTNATION OF THE DISCHARGE FROM HORIZONTAL PIPE BY THE COORDINATE METHOD. See Utah State Agricultural College, Engineering Experiment Station, page 93.

(1192) FIOW THROUGH FIEXIBLE NON-ELASTIC PIPE.

(b) Cooperative with Agricultural Research Service, Soil and Water Conservation Research Branch and Irrigation Department of the Utah State Agricultural College.

(c) Dr. Vaughn E. Hansen, Irrigation Dept., Box 70, Utah State Agricultural College, Logan, Utah.

(d) Experimental and theoretical; applied research, master's thesis.

(e) A light-weight, flexible, non-elastic pipe has recently been developed to convey water. As very little is known regarding the hydraulic properties of this material they are being studied.

(f) Inactive.

(I415) PERMEABILITY AND STABIIITY OF SOIL AND SOIL MATERIAI. (Under Project No. 1966.)

See U. S. Department of Agriculture, Agricultural Research Service, Soil and Water Conservation Research Branch, page 103.

(1686) CONSUMPTIVE USE OF WATER AND IRRIGATION REQUIREMENTS.

(b) Laboratory project, cooperating with Agricultural Research Service, U. S. Geological Survey and Utah State Engineer.

(c) Dr. D. K. Fuhriman, Irrigation Dept., Utah State Agricultural College, Iogan, Utah.

(d) Field investigation; applied research.

(e) To obtain basic information regarding consumptive use of water by agricultural crops, pastures, and native vegetation; and to study methods of measurement of consumptive use of water.

(g) Results being obtained are used currently in administration of the surface and underground waters of Utah.

(h) "Consumptive water use and requirements in the Colorado River Area of Utah." WhIlis C. Barrett and C.H. Milligan. Special Report No. 8, Utah Agricultural Experiment Statior 1953.

"Consumptive use of water by major farm crops in the Milford District of Utah." Glen H. Calder, M. S. Thesis, Utah State Agricultural College, 1953.

"Consumptive use of water studies provide basis for division of the waters of the Colorado River." D. K. Fuhriman and W. D. Criddle. Farm and Home Science 13:86, 1953.

(1715) CONSUMPTIVE USE OF WATER AND IRRIGATION REQUIREMENTS IN THE BONNEVILLE BASIN OF UTAH. (Under Project No. 1966.)

See U. S. Department of Agriculture, Agricultural Research Service, Soil and Water Conservation Research Branch, page 103.

(1953) SOIL MOISTURE DEPLETION PATTERNS IN THE ROOT ZONE.

(b) Cooperative with Utah Engineering Experiment Station and the BPIS and AE, U. S. Department of Agriculture.

(c) Dr. Vaughn E. Hansen, Irrigation Department, Utah State Agricultural College, Logan, Ut 
(d) Experimental and theoretical; applied research, master's thesis.

(e) To determine soil moisture depletion rates within different portions of root zone during the growing season.

To determine the variation in the consumptive use during the growing season of the crop.

(f) Experimental work completed.

(h) Thesis by Uttamrao A. Patil in process of preparation.

954) EFFECTIVENESS OF EVAPORATION FROM GROUND AND FOLIAGE IN REDUCING SOIL MOISTURE DEPLETION.

(b) Cooperative with Utah Engineering Experiment Station and the BPIS and AE, U. S. Department of Agriculture.

(c) Dr. Vaughn E. Hansen, Irrigation Department, Utah State Agricultural College, Logan, Otah.

(d) Experimental and theoretical; applied research, master's thesis.

(e) The notion is generally prevalent that evaporation from the ground and follage is not effective in reducing soil moisture depletion. An average of 0.5 inch is generally considered lost to plant use by evaporation following a storm or imigation. Observation indicated that evaporation losses tended to reduce soil moisture depletion. The experiment was designed to test the effectiveness by applying to a growing crop each day the estimated consumptive use by use of sprinklers.

(f) Experimental work completed.

(h) Thesis by Val Wynn in process of preparation.

1955) A STUDY OF FARM IRRIGATION EQUIPMENT AS RELATED TO OPERATION CHARACTERISTICS, COSTS, IABOR REQUIREMENTS AND TIME STUDIES INVOLVING IRRIGATION SCHEDULES AND SYSTEM CAPACITIES.

(b) Laboratory project, cooperative with Reynolds Metals Company.

(c) Dr. D. K. Fuhriman, Irrigation Dept., Utah State Agricultural College, Logan, Utah.

(d) Field investigation; applied research.

(e) To evaluate irrigation equipment being used in the field and to develop criteria for the use of various types of equipment.

TAH STATE AGRICULTURAL COLIEGE, Engineering Experiment Station.

(359) DRAINAGE OF IRRIGATED IANDS.

See Utah State Agricultural College, Agricultural Experiment Station, page 91.

(950) AN INVESTIGATION OF FRICTION IOSSES IN ALUMINUM TUBING AND COUPLINGS.

(b) Cooperative with Aluminum Company of America.

(c) Dean J. E. Christiansen, Engineering Experiment Station, Utah State Agricultural College, Logan, Utah.

(d) Experimental; applied research and master's thesis.

(e) To determine friction loss in alumi mum tubing and losses at commercial couplings. Additional studies being made on alumi num irrigation pipe with deflection angles at couplings.

(f) Experimental work completed.

(h) Thesis by Lyman S. hillardson in preparation.

1191) DETERMINATION OF THE DISCHARGE FROM HORIZONTAL PIPE BY THE COORDINATE METHOD.

(b) Cooperative with BPIS and AE, U. S. Dept. of Agriculture, and with the Utah Agricultural Experiment Station.

(c) Dr. Vaughn E. Hansen, Irrigation Department, Utah State Agricultural College, Logan, Utah.

(d) Experimental and theoretical; applied research, master's thesis. 
(e) To determine the coefficient of discharge for the flow from a horizontal pipe as determined by the coordinate method. This coefficient has been assumed to be one, which is definitely not the case in the majority of problems encountered in the field. The tests were conducted so that the method may be applied with confidence to the measurements of water.

(f) Additional field work completed summer 1953. Additional field work needed before publication of results.

(g) The discharge from a horizontal pipe is measured by the coordinate method. The result might be in considerable error unless the appropriate discharge coefficient is applied to the equation. The results of this study can be used with a fair degree of accuracy in predicting the actual discharge, however, further field studies will be made in orde: to further evaluate the method for field application.

(1687) INFIITRATION IN FURROW IRRIGATION AS EFFECTED BY FURROW SHAPE, SIZE OF STREAM, AND MOISTURE LEVEL IN THE SOIL.

(b) Cooperative with BPIS and AE, U. S. Dept. of Agriculture, and with the Utah Agricultura Experiment Station.

(c) Dr. Vaughn E. Hansen, Imrigation Department, Utah State Agricultural College, Logan, Ut

(d) Experimental; basic research.

(e) (1) To determine the effect of size of stream, shape of furrow, and moisture level in $t$ soil at the beginning of an irrigation upon the maximum infiltration rate of Greenville loam soil. (2) To test the following hypothesis; (a) size of stream (Q) has no effect o the maximum infiltration rate of a $V$-shaped furrow but the rate increases as the furrow departs from a $\nabla$-shape; (b) shape of furrow and width-depth ratio are directly related to the infiltration rate; (c) the asymtotic rate of infiltration is independent of the moisture level at a six inch depth below the furrow; (a) the infiltration is reduced as time of season (days) advances. (3) An attempt will be made to establish the quantitative relationship of the three factors to the asymtotic rate of infiltration.

(f) Experimental work completed.

(h) Thesis by Charles T. Bourns in preparation.

(1953) SOIL MOISTURE DEPLETION PATTERNS IN THE ROOT ZONE.

See Utah State Agricultural College, Agricultural Experiment Station, page 92.

(1954) EFFECTIVENESS OF EVAPORATION FROM GROUND AND FOLIAGE IN REDUCING SOIL MOISTURE DEPLETIO See Utah State Agricultural College, Agricultural Experiment Station, page 93.

(1956) INVESTIGATION OF FRICTION LOSSES IN FITTINGS AND VALVES FOR PORTABLE SPRINKLER IRRIGATION EQUIPMENT.

(b) Irrigation Equipment Company and Laboratory Project.

(c) Mr. A. Alvin Bishop, Irrigation Department, Utah State Agricultural College, Logan, Uta

(d) Experimental, design research for master's the sis.

(e) To obtain head loss factors for fittings and valves used in portable sprinkler irrigati systems and to compare hydraulic performance of valves partially closed with valves ful opened.

STATE COLIEGE OF WASHINGTON, Department of Civil Engineering and Division of Industrial Researc

(1689) STUDY OF FLUID FLOW IN PIPE NET WORKS.

(b) Laboratory project.

(c) Prof. Charles L. Barker, Hydraulic Engineer, Hydraulic Laboratory, Washington State College, Pullman, Washington. 
(d) Experimental.

(e) Using the McIlroy flow network analyzer the following studies are to be made: (1) Effect of eliminating small pipes in a distribution system in the Handy Cross analysis, (2) effect of combining loads in a network, and (3) the effect of pipe roughness on pumping costs on network flow.

(1690) PLACEMENT OF AIR VENTS IN IRRIGATION PIPELINES.

(b) Concrete Products Association of Washington.

(c) Mr. John A. Roberson, Hydraulic Laboratory, Washington State College, Pullman, Washington.

(d) Experimental; applied research for design.

(e) The minimum distance that an air vent is to be placed from the inlet of a pipeline (where air enters the pipeline) is a function of the rise velocity of the air bubbles, the velocity of water in the pipe, and physical characteristics of the structure. An attempt will be made to determine the rise velocity of bubbles as a function of bubble size, and Reynolds number.

(1691) PRESSURE RELIEF STRUCTURE.

(b) Concrete Products Association of Washington.

(c) Mr. John A. Roberson, Hydraulic Laboratory, Washington State College, Pullman, Washington.

(d) Theoretical and experimental; for design.

(e) Former research has shown that air releases from small vents in imigation pipelines may generate water hammer. An air dome used in conjunction with the small vent pipe will reduce the magnitude of pressure generation. Design dimensions of the air dome are being evaluated as a function of vent size, pressure reduction desired, size of main pipe, length of main pipe.

(1957) DRAIN TIIE IN DISPOSAL FIEIDS.

(b) Laboratory project.

(c) Mr. Paul F. Ruff, Hydraulic Laboratory, Wasinington State College, Pullman, Washington.

(d) Development.

(e) Investigation of drain tile lengths specified in various parts of the U.S.A.

(1958) OROGRAPHIC PRECIPITATION.

(b) Laboratory project.

(c) Mr. John A. Roberson, Hydraulic Laboratory, Washington State College, Pullman, Washington.

(d) The oretical.

(e) It is known that frontal type storms produce greater precipitation in the higher elevations than in the lower elevations. This variation is being studied to determine whether definite percentage relationships exists between stations of different elevations for all storms of the same type.

UNIVERSITY OF WASHINGTON, Department of Civil Engineering.

Inquiries concerning Projects should be addressed to the following, all at the University of Weshington, Seattle 5, Wishington.

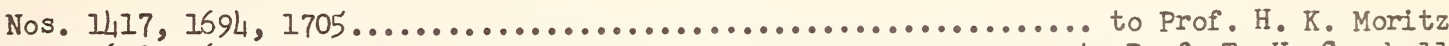

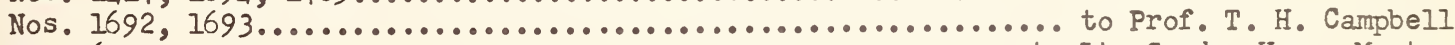

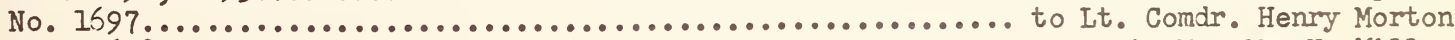

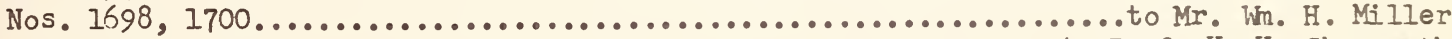

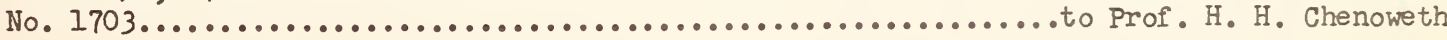


(1417) STATIC HEAD REQUIRED TO PRODUCE A FULI FIOWING CONDUIT.

(f) Suspended.

(1418) PRESSURE MEASUREMENTS FOLLOWING ABRUPT EXPANSION.

(f) Suspended.

(1692) SHORT RANGE FORECASTS OF SNOW-MEIT RUNOFF IN COLUMBIA RIVER BASIN.

(b) Bonneville Power Administration, cooperative with the Geological Survey, Tacoma, Wash.

(d) Theoretical; applied research, for doctor's thesis.

(e) To develop a procedure whereby increased flow from snow melt can be forecast for periods of five to ten days from weather bureau records or from forecasts of weather in the Columbia River Basin.

(1693) SHORT RANGE FORECASTS OF RUNOFF FROM PRECIPITATION IN COLUMBIA RIVER BASIN.

(b) Bonneville Power Administration, cooperative with the Geological Survey, Tacoma, Whash.

(d) Theoretical; applied research.

(e) To develop a practicable procedure for estimating the flow of streams in the columbia River Basin for periods of flve to ten days in advance during periods of rainfall.

(1694) REDUCTION OF PRESSURE FROM HIGH TO IOW PRESSURE HEADER WITHOUT CAVITATION BY TANGENTIAL NOZZLES.

(f) Completed.

(1697) A COMPARATIVE STUDY OF JETS FROM DIFFERENT TYPES OF FIRE NOZZLES.

(f) Completed.

(g) Master's The sis.

(1698) INVESTIGATION OF GRADUALIY VARIED FLOW IN CIRCULAR CONDUTTS PARTLY FULI.

(f) Completed.

(h) Unpublished report in Library of Hydraulics Laboratory.

(1700) A STUDY OF SEWER OUTFALIS.

(f) Suspended.

(1703) HYDRAULIC FACTORS AFFEGTING DESIGN OF SALMONOID REARING PONDS.

(f) Suspended.

(1704) FRICTION IN PIPES WITH CONTROLLED ARTIFICIAL ROUGHNESS.

(b) Laboratory project.

(c) Dr. Joseph Kent, Department of Civil Engineering, University of hashington, Seattle, hish.

(d) Experimental; basic research.

(e) An experimental investigation of the effect upon the friction factor characteristics of controlled and varying roughness caused by numerous screws projecting various distances into the pipe wall.

(1705) A HYDROGRAPHIC SUMMARY OF THE STREAMS IN THE STATE OF WASHINGTON.

(b) State of Whington, Department of Fisheries.

(d) Field investigation, operation.

(e) Comparative hydrographic study of streams in the State on basis of high year, low year, and mean year. 
UNIVERSITY OF WISCONSIN, Hydraulic Laboratory.

Inquiries concerming Projects Nos.956, 957, 958, and 1181 should be addressed to Dr. J. R. Villemonte, and Projects Nos. 959, 山20, and 1707 to 1710, incl., to Dr. Armo T. Lenz, Hydraulic Laboratory, University of sconsin, Madison 6, his.

(956) HEAD IOSSES IN FIOW OF LTQUIDS IN PIPES UNDER HIGH LINE PRESSURES.

(b) Cooperative with Ladish Company, Cudahy, Wh.

(d) Experimental; for master's and doctoral theses.

(e) A circulating system of 2-inch seamless steel pipe with oil flowing contains a 20-foot section in which energy losses are measured by latest type strain gages. Inne pressures vary from 100 to 2000 psi and show the effect of high line pressure on the friction factor for both laminar and turbulent flow.

(g) Tests have been completed on $1 / 4,1 / 2,1$ and 2-inch seamless steel tubes over a Reynolds' number range of 50 to 150,000. The relation between the friction factor $f$ and Reynolds' number is consistent, provided the temperature and pressure effects on fluid properties are known.

(h) "Energy loss in liquid flow in straight pipes under high pressure." J. G. Slater, Ph. D. Thesis, August, 1952. (Available on loan.)

"Energy loss in liquid flow in straight pipes under high pressure." H. J. Day, M. S. Thesis, June, 1953. (Available on loan.)

(957) THE THERMODYNAMICS OF IIQUIDS.

(b) Laboratory project.

(d) Experimental; for doctoral, master's and bachelor theses.

(e) The effects of temperature $\left(35-130^{\circ} \mathrm{F}\right)$ and pressure $(0-2200 \mathrm{psig})$ on the viscosity of a wide variety of liquids are being observed by use of a new type falling-ball viscosimeter.

(f) Inactive.

(g) Tests have been completed on five oils ranging in atmospheric viscosity at $100^{\circ} \mathrm{F}$ from 0.00004 to 0.0015 slugs per ft sec. A general correlation equation has been developed.

(h) "The effect of temperature and pressure on the viscosity of petroleum oils." $\nabla$. N. Gunaji and J. R. Villemonte, Proceedings 3rd Midwest Conference on Fluid Mechanics, University of Minnesota, 1953, Univ. of 项s. Engr. Experiment Station Reprint No. 210.

(958) HEAD LOSSES IN FLOW OF IIQUIDS IN WELING PIPE FITTINGS AND VALVES.

(b) Cooperative with Ladish Company, Cudahy, hỉs.

(d) Experimental; for master's and doctoral theses.

(e) Head loss observations have been completed on a select group of 4 -inch welding pipe fittings and a series of constriction type gate valves. Head loss observations are in progress on a select group of 2 -inch and 1/2-inch pipe fittings, the latter being tested in both laminar and turbulent flow ranges.

(g) Coefficients $K$, in equation $H=K \nabla^{2} / 2 g$, are as follows for the fittings and valves already tested:

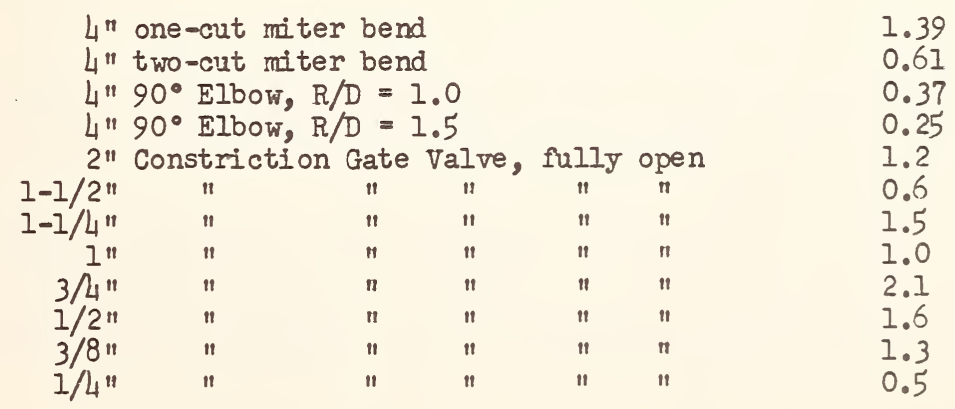


(h) "Energy loss in liquid flow in gate valves." W. J. Tudor, M. S. Thesis, June, 1953. (Available on loan.)

(959) HYDROLOGIC INVESTIGATION OF LAKE MENDOTA DRAINAGE BASIN.

(b) Part of a larger project entitled Morigin and quantities of algal fertilizers tributary to Lake Mendota." Cooperative study sponsored by University of hisconsin.

(d) Field investigation; applied research for M. S. thesis.

(e) Seven stream gaging stations have been installed to measure tributary inflow to Lake Mendota and Yahara River outflow. Precipitation records are being obtained from fourteen recording rain gages. M. S. thesis by C. I. Iderstad (1953) was concerned with methods of separation of surface runoff and groundwater flow, channel storage, unit hydrographs, and infiltration for basins of 7.7, 45 and 82 sq. mi. areas.

(g) Three M. S. and six B. S. the ses completed. (Available on loan.)

(1181) VORTEX FLOW FROM HORIZONTAL THIN-PLATE ORIFICES.

(b) Cooperative with Mr. J. C. Stevens, Portland, Ore.

(d) Theoretical and experimental; for doctoral and master's theses.

(e) Existing fundamental considerations are being studied and a new practical approach has been developed. Initial vorticity can be completely controlled, and measurements of head, discharge, and surface profile can be made. Orifice diameters will vary from 3 to 12 inches.

(g) Tests have been completed on a 4-inch dianeter sharp-edged orifice. The functional relation between head and vorticity and standard orifice discharge coefficient has been determined experimentally and represented as a three-dimensional plot. Vortex flow with free radial approach produced standard discharge coefficients for the orifices tested. Tests on a 6-inch dia orifice are now in progress.

(420) FORECASTIMG SNOWEIT RUNOFF, BIG EAO PLEINE RIVER, WISCONSIN.

(b) Wisconsin Valley Hydrologic Research Project.

(d) Experimental for Ph. D. thesis.

(e) Using readily available U. S. Geological Survey and weather Bureau records a method was developed for forecasting the time distribution of spring runoff volume caused by snowmelt.

(f) Suspended.

(g) A method was developed for determination of melt potential from convection, condensation, and radiation. From this potential, using a snowmelt unit hydrograph, correlation was obtained with actual runoff corrected for precipitation during the snowmelt period.

(h) "Forecasting the rate of snowmelt runoff." J. Harold Zoller, Ph. D. Thesis, Aug. 1953. (Available on loan.)

Two Ph. D. theses completed. Papers in preparation.

(1707) PROBLEMS OF SCOUR AT BRIDGE AND CULVEFR OPENINGS.

(b) Consolidated's Civic Foundation, Inc.

(d) Experimental; for M. S. and B. S. theses.

(e) Hydraulic model studies are in progress to determine methods of estimating probable scour pattern for a proposed structure having certain physical site characteristics and conditions of flow. Remedial methods will also be studied so scour at existing structures will be recuced or eliminated.

(g) Causes of scour at one location have been correlated with topography and water levels. Safe limits of reservoir drawdown at downstream dam and temporary remedial measures have been determined. More permanent remedial measures are now being studied.

(h) Model-prototype correlation for scour at Buckhorn Bridge." W. A. Hunt, M. S. Thesis. Model tests of scour at Buckhorn Bridge." G. R. Steiner and J. W. Williams, B. S. Thesis completed. (Available on loan.) 
708) MODEL STUDIES OF DRAFT TUBES FOR HYDRAULIC TURBINES.

(b) Allis Chalmers Mfg. Co.

(d) Experimental; for M. S. thesis.

(e) Elbow and horseshoe type draft tube models of lucite ( 4 -inch throat diameter) were tested with inlet velocity vectors controlled by guide vanes set at various angles set from +30 to $-30 \mathrm{deg}$.

(f) Inactive.

(g) Tests showed the draft tube efficiency was materially greater for zero angle of guide vanes than any other angle. Non-uniform flow distribution in the draft tube accounted for the efficiency loss at large vane angles. The center pier also reduced efficiencies.

(h) Model tests of turbine draft tubes." J. M. Jordaan, M. S. Thesis completed. (Available on loan.)

1709) CALIBRATION OF V-NOTCH WEIRS AT ENDS OF CULVERTS.

(b) Wisconsin Culvert Co.

(d) Experimental; for B. S. thesis.

(e) A $90^{\circ} \nabla$-Notch weir was installed at the end of a 30-inch corrugated steel culvert and calibrated for flows up to and above the top of the weir plate.

(f) Completed.

(g) Mathematical interpretation of the flows as the summation of $V$-Notch and rectangular weir flows was made and coefficients determined to express the total flow as a function of the he ad above the bottom of the $\nabla$-Notch.

(h) "Calibration of $\nabla$-Notch weirs at ends of culvert pipes." M. W. Busby and L. R. Hafeman, B. S. Thesis, June, 1953. (Available on loan.)

1710) CALIBRATION OF NEW DESIGN OF HEAD SPILLWAY.

(b) Laboratory project in cooperation with Agricultural Research Service.

(d) Experimental; for B. S. the sis.

(e) Hydraulic model studies have been made to detemine discharge coefficients for a 6inch lucite head flume used for soil erosion control. This flume has sloping sides to confine the earth fill, but no flaring head walls.

(f) Completed.

(g) Various length, width, and depth ratios were studied for various heads. Head discharge curves were plotted. After completion of the student thesis project the data was checked by A.R.S. personnel working under the direction of Mr. N. E. Minshall. This group then determined the effect of location of dyke positions on discharge coefficients for a conventional type head spillway with right angle head walls.

(h) "Model test of head spillway." R. K. Bastian, E. G. Olson and F. L. Plautz, B. S. thesis, June, 1953. (Avallable on loan.)

NORCESTER POLYTECHNIC INSTITUTE, AIden Hydraulic Laboratory.

Inquiries concerning Projects Nos. 961, 1712, 1713, and 1959 to 1963, incl., should be addressed to Prof. I. J. Hooper, Alden Hydraulic Laboratory, Worcester Polytechnic Institute, Wrcester 2, Mass.

(961) VALVE TESTS.

(b) Chapman valve Company.

(d) Experimental; for design.

(e) Head Loss measurements for various discharges are made on a $24^{11}$ disc type check valve. Closure time and pressure changes are determined photographically for various flows up to 45 efs.

(f) Work in progress. 
(1712) CROMBY MOVEABLE BED MODEL.

(b) Philadelphia Electric Company.

(d) Experimental; for design.

(e) A distorted model ( $1: 15$ vertical scale, 1:45 horizontal scale) was constructed of a section of the Schuylkill River including provision for heating water pumped through the condensers. Studies were made of re-circulation of hot water discharged from condensers.

(1713) LITTLETON HYDROELECTRIC DEVELOPMENT.

(b) Connecticut River Power Company.

(d) Experimental; for design.

(e) A 1:60 model was constructed of the chute spillway and section of the Connecticut River to study flow conditions in the chute and in the river adjacent to the chute.

(f) Completed.

(h) Report in preparation.

(1959) IITTLETON HYDROELECTRIC DEVELOPMENT.

(b) Connecticut River Power Company.

(d) Experimental; for design.

(e) A 1:48 model was constructed of one-half of one penstock intake and transition to circular penstock section. A transparent lucite sheet was used at the center line to allow observation of flow throughout length of model. Tests were made to study flow conditions at various sections of the model.

(f) Completed.

(h) Report in preparation.

(1960) A. J. WILEY HYDROELECTRIC DEVELOPMENI.

(b) Ebasco Services Inc.

(d) Experimental; for design.

(e) A 1:50 model of the spillway, stilling basin and river bed immediately up and down stream was constructed in the 5 foot wide, glass-sided flume. Preliminary tests were made to permit photographs and some measurements of flow over spillway and through diversion chutes.

(f) Inactive - work may be continued.

(1961) HOGBACK DAM WATER SUPPLY DEVELOPMENI.

(b) The Water Bureau, Hartford, Conn.

(d) Experimental; for design.

(e) A 1:50 model of the dam, spillway diversion tunnel, Mill Brook diversion and adjacent river topography was constructed to study flow conditions for diversion and flood flows. Water surface profiles in diversion tunnel and spillway channel have been determined.

(1962) TRUFANT PUMP.

(b) Russell A. Trufant.

(d) Experimental; for design.

(e) A turbine type pump was installed in the 8 foot wide flume with a calibrated venturi meter in series. Performance tests were mun with various turbine blades.

(f) Completed.

(1963) FOXBORO METER.

(b) Foxboro Company.

(d) Experimental; for design.

(e) An experimental type of flow meter was tested to determine operating characteristics.

(f) Completed. 
U. S. DEPARTMENT OF AGRICULTURE, AGRICULTURAL RESEARCH SERVICE, Soil and water Conservation Research Branch.

Inquiries concerning Projects Nos. 11l, 150-153, incl., 386-390, incl., 393-397, incl., $658,1168,1189,1190,1415,1429-1437$, incl., 1439-1443, incl., 1445-1456, inc1., and 1715-1723, incl., previously reported by Soil Conservation Service, and Projects Nos. 26, 394-397, incl., 1194 and 1714, previously reported by Bureau of Plant Industry, Soils and Agricultural Engineering, should be addressed to Dr. Robert M. Salter, Chief, Soil and Water Conservation Research Branch, Agricultural Research Service, Plant Industry Station, Beltsville, Maryland.

(53) SAND TRAPS AND SLUICEWAYS.

See Colorado A and M College, page 20.

(55) SNOW COURSE MEASUREMENTS AND FORECAST ANALYSIS.

See Colorado A and M College, page 20.

(150) HYDROLOGIC EXPERTMENT STATIONS.

(b) Soil and Water Conservation Research Branch, Agricultural Research Service and State Experiment Stations of Ohio, Texas, Nebraska and Michigan.

In addition, measurements of rainfall, runoff rates and amounts, from farm watersheds, are being made by this branch in cooperation with State Agricultural Experiment Stations in Illinois, Wi sconsin, Oklahoma, New Jersey, Delaware, Maryland, New York, Pennsylvania, Iowa, Massachusetts, Vermont, Virginia and Maine.

(d) Experimental, field and laboratory; for design and general information in planning farms for soil and water conservation.

(e) Rainfall and runoff are measured on watersheds ranging from 1 to 5,000 acres. In addition to rainfall and runoff measurements, studies are made on small Government-operated areas of evapo-transpiration, moisture storage, moisture transmission through the soil, hydrologic effect of physiography, tillage, and ground surface conditions, vegetal covers and soils and geology, and the effect of conservation farming on runoff and erosion, as well as the characteristics of flood runoff from agricultural watersheds.

(g) Conservation practices have appreciably reduced peak rates of runoff for all storms for areas as large as 300 acres. Runoff volume is appreciably reduced for some storms. Data comparing areas larger than 300 acres under conservation with similar untreated areas are not available due to the difficulty of finding comparable treated and untreated areas.

(h) North Appalachian Experimental Watershed, Coshocton, Ohio.

"Water use by crops." L. L. Harrold and F. R. Dreibelblis, Soil science society of America, Proceedings 17:70-74. 1953.

Central Great Plains Experimental Watersheds, Hastings, Nebraska.

"Runoff from conservation and non-conservation watersheds." John A. Allis, Agricultural Engineering 31:766-768, illus. 1953.

Blacklands Experimental Watershed, Waco, Texas.

"Runoff from conservation and non-conservation watersheds." Ralph W. Baird, submitted at Amer. Society of Agricultural Engineering Meeting, Pittsburgh, Penna. June 17, 1953. In process of publication in ASAE Journal. Michigan Hydrologic Research Station, East Lansing, Michigan.

"Soil temperature compari sons under varying covers." George A Crabb, Jr. and James L. Smith. Invitational paper presented at the annual meeting of the U. S. Highway Research Board of the National Research Council in January, 1953.

"Insolation: A primary factor in evaporation from a free-water surface in Michigan." George A. Crabb, Jr. Quarterly Bulletin of Michigan Agricultural Experiment Station, Vol. 35, pp 186-192. 1952.

"Comparative analysis of hydrographs from similar storms on a watershed under timbered and clean-cut conditions." J. L. Smith and George A. Crabb, Jr. Quarterly Bulletin of Michigan Agricultural Experiment Station. Vol. 35, pp 489-502. 1953. 
(152) (153) THE HYDRAULICS AND STABILITY OF CONSERVATION CHANNELS.

(b) Cooperative with Oklahoma Agricultural Experiment Station.

(d) Experimental; for design.

(e) Measured flows up to $150 \mathrm{cfs}$ are passed through outdoor test channels of various crosssections up to 40 feet in width with slopes up to 10 percent. Measurements of hydraulic elements and scour rates are made for flows of different velocities and for various channel linings. The purpose is to obtain ( 1 ) effects of linings, vegetal and nonvegetal, on the water carrying capacity and other hydraulic characteristics of channels used in soil and water conservation operations; and (2) protective characteristics of various types of linings, vegetal and non-vegetal.

(287) PERFORMANCE TESTS OF WELL SCREENS.

See Colorado $\mathrm{A}$ and $\mathrm{M}$ College, page 20.

(820) THE STUDY OF SEEPAGE IOSSES FROM IRRIGATION CHANNELS.

See Colorado $\mathrm{A}$ and $\mathrm{M}$ College, page 21.

(1191) DETERMINATION OF THE DISCHARGE FROM HORIZONTAL PIPE BI THE COORDINATE METHOD.

See Utah State Agricultural College, Engineering Experiment Station, page 92.

(1192) FIOW THROUGH FLEXIBLE NON-ELASTIC PIPE.

See Utah State Agricultural College, Agricultural Experiment Station, page 92.

(1722) RUNFF CHARACTERISTICS OF AGRICULTURAL AREAS IN NORTH CENTRAL OKLAHOMA.

(b) Cooperative with Oklahoma Agricultural Experiment Station.

(d) Experimental; for design.

(e) Rainfall and runoff are measured on three watersheds ranging from 15 to 210 acres. The highway culverts through which the watersheds discharge are used as rate measuring devices. The purpose is two-fold. First, information is obtained for planning farms for soil and water conservation and second, the technique of using existing highway drainage structures for runoff measurement is being developed.

(g) Rating characteristics have been determined for the weir sills installed in the culverts for measuring low flows. Runoff rates and amounts have been compiled for the period of the study. Rating characteristics are being determined for culverts subjected to limited tailwater control.

(1723) THE HYDRAULICS OF CONSERVATION STRUCTURES.

(b) Cooperative with Oklahoma Agricultural Experiment Station.

(d) Experimental; for design.

(e) Tests are made on full size conservation structures built under field conditions at the Stillwater Outdoor Hydraulic Laboratory. Flows up to 175 cfs are available for the testing. Experiments have been mun on a chute with stilling basin and on a pipe outlet spilliway.

(1964) DESIGN AND MAINTENANCE OF WATER CONTROL FACIIITIES.

(b) Soil and water Conservation Research Branch, Agricultural Research Service, Florida Agricultural Experiment Station and Central and Southern Florida Flood Control District.

(d) Experimental and field investigations. Applied research for design and development of water control facilities in southern and central Florida. 
(e) To determine the most efficient type layout and design of water control installations, and the maintenance practices required to provide the drainage and irrigation needs of crops under subtropical conditions. A variety of measures have been employed for the reclamation of swamp lands in Florida since their development with different degrees of success. Some involving excessive drainage were actually detrimental to the soils. Past and present studies show that it is essential to construct and maintain water control systems that will conserve water supplies, and to carry the level of the ground water as high as is safe for crops to reduce burning and subsidence of the organic soils. Field surveys and experimental station studies are being carried out to determine the most effective and economical measures to employ to provide the necessary agricultural water requirements.

(g) Iong-time subsidence studies have shown that the loss of organic soils in the Everglades is directly related to the depth of water table and that the life of the se soils can be prolonged by holding higher water tables. The age of the Everglades soil has been determined as 5,000 years by the "Carbon 14" method. Cost efficiency studies have been made on large drainage district pumping stations adjacent to Lake Okeechobee, as well as tests on different types of farm size pumps. Values of Kutter's and Manning's " $n$ " have been established on typical ditches and the effect of vegetative growth on raising the values of "n" determined. Economical herbicidal treatments have been developed for ditch maintenance.

(h) "Aromatic solvents for the control of the submersed water Naiad, Najas guadelupensis (Spreng.) Morog., in South Florida." Charles C. Seale, J. W. Randolph and J. C. Stephens. Florida Agricultural Experiment Station Journal, Series No. 76, Weeds. Vol. I, No. 4, July, 1952 .

"Herbicidal tests for control of Para Grass on ditch banks in the Everglades region of Florida." WLIliam H. Speir and J. C. Stephens. Florida Agricultural Experiment Station Journal, Series No. 96, heeds. Vol. II, No. I, January, 1953.

(1965) SURFACE AND SUB-SURFACE HYDROLOGIC STUDIES IN CENTRAL AND SOUTH FIORIDA.

(b) Soil and hater Conservation Research Branch, Agricultural Research Service, Florida Agricultural Experiment Station and Central and Southern Florida Flood Control District.

(d) Experimental and field investigations; basic and applied research to determine water requirements of crops as influenced by the hydrological environment.

(e) To measure, record, and analyze surface and subsurface hydrologic and related phenomena for establishing criteria to be used in the development and operation of agricultural water control systems in Central and Southern Florida.

Rainfall and evaporation records are obtained over Central and Southern Florida in cooperation with other agencies. These records are compiled and analyzed to aid in the design of drainage and imigation requirements. Transpiration and water consumption by plants has been studied at the Everglades Experimental Station during recent years and a limited amount of data for some specific crops at given water table depths are available. A few runoff records for natural drainage areas in Florida have been made, and for the past two years detailed hydrologic records of rainfall, evaporation and runoff have been obtained on the Indian River Farms Drainage District, near Vero Beach, Florida. Reconnaissance ground water surveys have been made in the Everglades area and at a few scattered places in the rest of Central and South Florida. A hydrologic plot was set up at the Everglades Experiment Station in 1951, and at the Plantation Field Laboratory at Ft. Lauderdale in 1953. These installations include rain gauges for obtaining rainfall, standard evaporation pans and land tanks for establishing relation of evaporation from standard pans to evaporation from large land tanks, anemometers for wind motion, and instruments with shelters for measuring temperatures. Sunken tanks are installed for a study of the tolerance to flooding, and the normal rate of water use by various crops.

(1966) SOIL AND WATER MANAGEMENT STUDIE'S, INCLUDING DRAINAGE AND IRRIGATION.

Work on this project conducted in the states as listed. (Project numbers indicated appeared in Miscellaneous Publication 208, 1953.)

Alabama-1714, 1744; Arizona-658, 1429; Arkansas; Califormia-26, 389, 390, 1194, 14451451, incl., 1717-1720, incl.; Colorado $-53,55,287,820,1430$, 1431 ; Florida-395, 396, 397; Georgia; Idaho-1553, 1455, 1456, 1716; IIIinois; Indiana-394; Iowa; Kansas-1432; 
Maine; Maryland; Missouri; Mississippi; Nebraska-1433, 山34; Nevada-1435; New Jersey; New York; North Carolina; Ohio; Oregon-387, 1452; Pennsylvania; South Carolina; South Dakota-1436, 山37; Texas-386, 1439-1442, incl., 1721; Utah-151, 388, 1189-1192, incl., 1415, 1715, 1454; Virginia; Weshington-393; Wisconsin; Wyoming-1443.

(b) In cooperation with State Agricultural Experiment Stations and other agencies throughout the United States. Hydraulic measurements are necessary for determining the effects of land management practices on runoff, soil moisture and erosion. Research is contimually being carried on to improve these hydraulic measurements, since few data are available on measurement of silt and trash laden flows from small agricultural areas. Since the type of studies conducted at different locations within the many states are similar except for variations in soils, climate and cropping, they are being consolidated under a single heading. This research is not considered as hydraulic research, but much of the data secured will be of interest to those in the field of hydraulics.

(d) Field and laboratory investigations; basic and applied research for design purposes.

(e) To determine the (I) effects of different land use and farming practices upon surface runoff, soil losses and groundwater supply and movement; (2) soil characteristics that are basically related to soil and moisture conservation principles as a basis for designing conservation practices; (3) relation of water munof and soil erosion to the topography and other physiographic conditions of the drainage area, and to climatological conditions; (4) design of effective and economical structures and cultural practices for erosion control, water disposal and moisture conservation; (5) requirements for control of surface water and ground water where agricultural production is prevented or limited by excess or deficiency of moisture; (6) practical methods and means of installing and maintaining land drainage improvements in the East and west; (7) water requirements for irrigation, both in the West and East; ( 8 ) best sources of irrigation water and how it may be most economically stored and applied to the land; $(9)$ best techniques for measuring and evaluating the infiltration rates and permeability characteristics of soils throughout the United States and to determine the magnitude of change that may result from changes in management and varying soil treatments; and (10) principles underlying the flow of water into and through soils.

(g) Rainfall, muoff and erosion data from land in different crops and receiving different cultural and fertilizer treatments in many locations, are being tabulated on standard forms for early analysis.

(h) "A method for determining the stability of soil structure based upon air and water permeability measurements." R. C. Reeve. Soil Science Society of America, Proceedings 17:32L. 1953.

"Equipment for subsampling and packing fragmented soil samples for air and water permeability tests." R. C. Reeve and R. H. Brooks. Soil Science Society of America, Proceedings $17: 324$. 1953 .

"A comparison of the effects of exchangeable sodium and potassium upon the physical conditions of soils." R. C. Reeve, C. A. Bower, R. H. Brooks and F. B. Gschwend. Soil Science Society of America, Proceedings. Submitted for publication Soil Sci. Soc. Amer. Proc., November, 1953.

"Dependability of surface munoff supplies in the ridges and valleys region of virginia." M. H. Kirkpatrick, Jr. Soil Conservation Service Tech. Pub. 113. April, 1953.

"Rainfall and munoff characteristics on a small watershed in the southern Piedmont." J. R. Carreker and A. P. Barnett. Soil Conservation Service Tech. Pub. 114. August, 1953. "Evaluation of gully control structures in southeastern usconsin." N. E. Minshall. September, 1953.

"The silting of Caonillas Reservoir, Puerto Rico." John J. Noll. Soil Conservation Service Tech. Pub. 119. October, 1953.

"Drainage investigation in irrigated areas of Imperial Valley, Califormia, 1941-51, a 10-year sumary." W. W. Donnan, G. B. Bradshaw and H. F. Blaney. Soil Conservation Service Tech. Pub. 120. September, 1953.

"Changes in drainage properties of a muck soil as a result of drainage practices." H. A. Jongedyk, R. B. Hickok and I. D. Mayer. Scheduled for publication Soil Sci. Soc. Amer. Proc. Vol. 18, No. 1, January, 1954.

"Kudzu in rotation with corm and small grain." T. L. Copley and Luke A. Forrest. Department of Agronomy. North Carolina State College Research Report No. 5, Aug. 1953. 
MRunoff from permanent pastures in Pennsylvania." R. R. Robinson and R. B. Alderfer. Agron. Journal 44:459-462. September, 1952.

"Soil fertility levels of grassland in some datry sections of the Northeast." R. R. Robinson, Leo J. Gotnoir, Jr., C. H. Moran, E. R. Purvis, W. A. Mitcheltree, H. G. Allbritten, Irene H. Stuckey and Milton Solomon. Agron. Journal 45:371-376. Aug. 1953. Frost penetration into soils as influenced by depth of snow, vegetative cover and air temperatures." Claude E. Bay, George W. hunnecke and Orville E. Hays. Transactions, American Geophysical Union. Vol. 33, No. 4, 6 pp, illus. August, 1952.

"Strip cropping reduces soil loss." Orville E. Hays. What's New in Farm Science, Part II. 68th Annual Report, Agr. Exp. Sta., Univ. of hisconsin, 2 pp. July, 1952. "Improving soil structure for erosion control and crop production: The soil additives." R. W. Pearson and V.C. Jami son. Jour. Soll and Water Conservation 8:130-135. 1953. "A 20-year appraisal of engineering practices in soil and water conservation." Dwight D. Smith. Agricultural Engineering, Vol. 53, No.9, 4 pp, 8 illus. Sept. 1952. "Compaction as a factor in soil conservation." G. R. Free. Soil Sci.Soc. Amer. Proc. $2: 165.1953$.

"Weter consumption by plants as influenced by soil fertility." R. J. Hanks and C. B. Tanner. Agron. Journal, Vol. 44:98-100. 1952.

"Leaching of potassium as influenced by frequency of application and source of mitrogen." R. W. Pearson. Agron. Journal 44:305-307. 1952.

"Report of Subcomittee of permeability and infiltration." L. A. Richards. Soil Science Society of America, Proceedings 16:85-88. 1952.

"Some thermodynamic properties of soil moisture." J.S. Robins. Soil Science 74: No. 2, $127-139.1952$.

"Slope length and conservation in central Texas." R. M. Smith. Texas Agr. Exp. Sta. Research Report 267. 1953.

"Movement of ammonia mitrogen and phosphorus in an alkaline irrigated soil." A. I. Dow, C. D. Moodie and C. O. Stanberry. Agron. Journal 45:353-356. 1953.

"Peculiarities of eastern Whishington soils and how to handle them." F. G. Viets, Jr. Proceedings 48th Annual Meeting Wash. State Horticultural Association, pp 112-114. 1952.

"The relationship of moisture and macroporosity to the hardness of Lloyd Clay." Agron. Journal 34. 1952.

"Irrigation practice as it affects fertilizer requirements, quality and yield of sugar beets." D. Boyd Archibald and Jay L. Haddock. Proceedings 7th General Meeting Amer. Society of Sugar Beet Technologists. 1952.

"Unconfined ground water flow to multiple wells." Vaughn E. Hansen. Proc. Separate No. W2, Proceedings American Society Civil Engineers, Vol. 78. August, 1952. "Complicated well problems solved by the membrane analogy." Vaughn E. Hansen. Trans actions American Geophysical Union, Vol. 33. December, 1952.

"Hydraulic tests on barrel valves for use as irrigation outlets to concrete pipe lines." Vaughn E. Hansen. Journal Soil and Water Conservation, Vol. 8, No. 4, pp 167-168. July, 1953.

"Nultiple tensiometer for determining the vertical component of the hydraulic gradient in soil." L. A. Richards. Proceedings Soil Sci. Society of America. 1953.

"Laboratory evaluation of desert soils for irrigation." V. S. Aronovici. Transactions, American Geophysical Union, Vol. 33, No. 1, pp 49-52, illus. February, 1952.

"Consumptive use of water - definitions, methods and research data." Harry F. Blaney. Transactions, American Society of Civil Engineers, Vol. 117, pp 949-973, illus. 1952. "Some factors involved in ground water repleni shment." E. S. Bliss and C. E. Johnson. Transactions, American Geophysical Union, Vol. 33, No. 4, pp 547-558. 1952.

"Drainage investigation methods for irrigated areas in western United States." W. W. Donnan and G. B. Bradshaw. Technical Bulletin No. 1065, pp 45. 1952.

The effect of surface head on infiltration rates based on the performance of ring infiltrometers and ponds." Dean C. Muckel. Transactions, American Geophysical Union, Vol. 34, No. 2. April, 1953.

"Tentative sprinkler irrigation guide for lower coastal plains of Alabama." July, 1953. 
U. S. DEPARTMENT OF AGRICULTURE, AGRICULTURAL RESEARCH SERVICE, St. Anthony Falls Hydraulic Laboratory.

Reports on Projects Nos. 111, 1168, and 1398 conducted by the Soll and Water Conservation Research Branch at the St. Anthony Falls Hydraulic Laboratory are listed under St. Anthony Falls Hydraulic Laboratory, Univ. of Minn., Minneapolis, Minn.

U. S. DEPARTMENT OF AGRICULTURE, FOREST SERVICE, California Forest and Range Experiment Station.

Inquiries concerming Projects Nos. 261 and 1186 should be addressed to Mr. Stephen N. Wyckoff, California Forest and Range Experiment Station, P. 0. Box 245, Berkeley 1, Calif.

(26I) WATERSHED MANAGEMENT RESEARCH, CAIIFORNIA.

(b) Laboratory project.

(d) Experimental; field investigation; basic and applied research.

(e) Purposes are: (I) to study the disposition of rainfall as influenced by watershed conditions, including vegetation, soils, geology, and topography; and (2) to develop methods of watershed management, including the treatment of areas denuded by fire, to assure maximum yield of usable water, and satisfactory regulation of flood runoff and erosion. Major work center is the San Dimas Experimental Forest in the San Gabriel Mountains of southern California. Rainfall, runoff, and erosion are measured on two main drainage areas, on ten large and seven small watersheds within these areas, and on twenty-one experimental plots. Twelve of these plots are equipped to obtain detailed information on the disposition of rainfall from grass, mature brush, and a 26-year-old pine plantation, and 26 large lysimeters furnish comparisons of the use of water by various species of shrubs, one species of pine, and a bunch grass association. Climatic data are obtained from several meteorological stations. Studies to improve wild land vegetation for better stability of mountain soils are in progress in Los Angeles River watershed and at Pasadena in cooperation with the California Institute of Technology. During 1953, five plots were established in Los Angeles River watershed to measure the rate of surface movement of materials (soil, rock, and organic matter) on slopes varying from 30 to 120 percent representing typical soil and vegetative conditions. Studies of runoff and erosion as influenced by fire and the revegetation of large burned areas are in progress elsewhere in California.

(g) Studies to improve the accuracy of rainfall measurement in mountainous country conducted over a period of years on the San Dimas Experimental Forest, were summarized for publication in a U.S.D.A. Tech. Bulletin entitled "Rainfall Sampling in Rugged Terrain." The results show that within the area studied, rainfall was sampled more accurately with rain gages tilted and oriented according to watershed slopes than with gages placed vertically. The effect of low rainfall during the winter of $1952-53$ on streamflow in the San Gabriel Mountains of southerm California is indicated by records from Monroe Canyon. During the hydrologic year Oct. 1, 1952-Sept. 30, 1953 precipitation totaled 15.88 in. or 54.4\% of the 18-year mean of 29.22 in. During the same period streamflow amounted to .32 surface in. or only $8.4 \%$ of the 18-year mean of 3.81 surface in. Soil moi sture records from lysimeters and plots on the San Dimas Forest show that California scrub oak uses less water than Coulter pine during the winter season. A study of the influence of forest floors on water yield from ponderosa pine stands in California showed that floors $3 / 4$ in. deep controlled evaporation (from the floor and the soil) and surface runoff nearly as well as floors of greater depths and much better than floors of lesser depths.

(h) "Shock resistant lucite graduate." E. I. Hamilton, I. F. Reimann, and I. A. Andrews, California Forest and Range Experiment Station Misc. Paper No. 9.

"A guide to the San Dimas Experiment Forest." J. D. Sinclair and E. I. Hamilton, California Forest and Range Experiment Station Misc. Paper No. 11.

"Indicators of erosion on watershed land in Califomia." C. H. Gleason, Trans. A.G.U. $34(3): 419-426.1953$.

"Control of evaporation from rain gages by oil." E. I. Hamilton and L. A. Andrews. Bull. Amer. Meteor. Soc. 34(5): 202-204. 1953.

"Vegetation and watershed management." E. A. Colman, Ronald Press Co., New York, Nov. 1953. 
(1186) FLOOD CONTROL SURVEY RESEARCH, CALIFORNIA AND WESTERN OREGON.

(b) Laboratory project.

(d) Experimental, field investigation; statistical studies in applied research.

(e) To furnish a physical base for evaluation of flood control measures as they affect flood and sediment damages. Emphasis is on the determination of the influence of "land use" on frequency flood peaks, anmual and seasonal yields of water, and sediment production from whole watersheds.

(g) Average ammual suspended sediment discharge from 29 watersheds in western oregon was related by regression analysis to average watershed values to two streamflow variables, two topographic variables, two soil variables, four land-use variables and one channel bank variable. The results were used (I) to construct a map of the sediment producing potential of lands in western Oregon under average land use conditions; (2) to estimate how the actual production of sediment would differ from the potential with deviations of land use from average; and (3) to distribute present sediment production to the three major source areas: forest land, agricultural land, and chamel banks of the main river. Double-mass plotting of inflow and sedimentation of Gibraltar Reservoir, Santa Ynez watershed, Califormia, showed that sedimentation and peak inflow increased markedly following the wildfires of 1932 and 1933, then decreased as the watershed recovered from the fires. No change in the total annual inflow was detected using the same method.

(h) "Suspended sediment discharge as related to streamflow, topography, soil, and land use." H. W. Anderson, submitted to Amer. Geophys. Union for publication. August, 1953. "Detecting hydrologic effects of changes in watershed condition." H. W. Anderson, submitted to Amer. Geophys. Uni on for publication. September, 1953.

"How will you have your water?" H. W. Anderson, Jour. Forestry 50(2):135, 1952.

U. S. DEPARTMENT OF AGRICULTURE, FOREST SERVICE, Intermountain Forest and Range Experiment Station.

Inquiries concerning Projects Nos. 652 to 655, incl., should be addressed to the Director, Intermountain Forest and Range Experiment Station, Ogden, Utah.

(652) SOIL RELATIONS (IN WATERSHED MANAGEMENI AND PROTECTION).

(b) Branch of Research, Forest Service, U. S. Department of Agriculture.

(d) Experimental and field investigation; basic and applied research.

(e) Tests on plots and small watersheds of the effects of forest, brush, and herbaceous plant cover in natural, depleted, and restored condition on the infiltration, storage, fertility, biology and stability of forest and range land soils; to determine land use practices for stabilizing eroding watershed soils and for maintaining soil stability under the impact of grazing, logging, and other wild land uses. Studies are under way on coarse, gramitic soils of southwest Idaho; various soils on steep slopes of Wasatch Mountains in northern Utah; and on heavy limestone soils on the Wasatch Plateau in central Utah.

(g) Initiated study of effects of methods cutting and logging virgin ponderosa pine in Boise Basin Experimental Forest near Idaho City, Idaho. Sediment catchment dams and observation plots installed on first of two replicate sets of 9 watersheds.

Second replication of 9 catchment dams to be installed in 1954. Prepared draft of report on 36 years of munoff and sediment records from two subalpine watersheds at Great Basin Research $C_{e}$ nter near Ephraim, Utah and Initiated new phase of this long term experiment by intensive seeding and contour trenching one of the depleted watersheds.

(h) "Effects of trampling disturbance on watershed condition, runoff, and erosion" by P. E. Packer; Jour. Forestry Vol. 51(1):28-31, January, 1953.

(653) WATER RELATIONS (IN WATERSHED MANAGEMENT AND PROTECTION).

(b) Branch of Research, Forest Service, U. S. Department of Agriculture.

(d) Experimental and field investigation; basic and applied research. 
(e) Tests on watersheds of the effects of forest, brush, and herbaceous plant cover, and of mechanical soil stabilization structures, on munoff characteristics of mountain watersheds; to determine land use treatments required for flood control and for maximum yields of usable streamflow.

(g) Formally established the Davis County Experimental Watershed (28,000 acres) within the Wasatch National Forest near Farmington, Utah. Brought up to date the calculation of daily streamflow records from 14 experimental watersheds, involving from 7 to 15 years of records per station.

(h) "Guide to Davis County Experimental Watershed." R. B. Marston; Mimeo. Illus. Report, Intermountain Forest and Range Experiment Station, Ogden, Utah, 1953.

\section{(654) PLANT RELATIONS (IN WATERSHED MANAGENENT AND PROTECTION).}

(b) Branch of Research, Forest Service, U. S. Department of Agriculture.

(d) Experimental and field investigation; basic and applied research.

(e) Tests on plots and watersheds of the effects of forest, brush, and herbaceous cover on interception and evapo-transpiration losses; to determine the kind of plant cover required for producing maximum yields of useful munoff from watersheds. Principal effort now limited to study of evapo-transpiration loss from herbaceous cover on Wasatch Mountains, northern Utah.

(g) Initiated plot study of effect of herbaceous plant cover on rainfall interception, overland flow, soil erosion, evapo-transpiration, and water available for streamflow and made 15-year inventory of plant cover on two experimental watersheds in cooperation with the University of Utah at the Davis County Experimental Watershed near Farmington, Utah.

(h) "Evapo-transpiration and other water losses on some aspen forest sites in Utah in relation to water available for streamflow." A. R. Croft and L. V. Monninger, Amer. Geophys. Union, Tol. 34:563-574, 1953.

\section{(555) CLTMATIC RELATIONS (IN WATERSHED MANAGEMENT AND PROTECTION).}

(b) Branch of Research, Forest Service, U. S. Department of Agriculture.

(d) Experimental and field investigation; basic and applied research.

(e) Measurements and studies of climatic factors including precipitation, temperature, wind, etc., that have a bearing on the hydrologic behavior of forest and range watershed areas at the Boise Research Center near Idaho City, Idaho; Wasatch Research Center, Farmington, Utah, and Great Basin Research Center, near Ephraim, Utah.

U. S. DEPARTMENI OF AGRICULTURE, FOREST SERVICE, Northeastern Forest Experiment Station.

Inquiries concerning projects Nos.656, 966, and 1187, should be addressed to Dr. Ralph W. Marquis, Director, Northeastern Forest Experiment Station, 102 Motors Avenue, Upper Darby, $\mathrm{Pa}$.

(656) FOREST INFLUENCES INVESTIGATION (WATERSHED MANAGEMENT).

(b) Laboratory project; cooperative with the Pennsylvania Department of Forests and Waters and U. S. Geological Survey.

(d) Field investigation; basic and applied research.

(e) Studies have been started on the Delaware-Iehigh Experimental Forest, Monroe County, $\mathrm{Pa}$., to determine the water econony for a watershed covered with scrub oak. Afterwards, the cover will be converted by planting and fire protection to a commercially valuable type, and the effect on water relations will be measured. Installations have been established to evaluate all components of a water balance equation for the watershed.

(g) Rainfall interception, after correction for stemflow, by scrub oak bears a linear relation to amount of rain for individual storms. The relation is as follows: $I=0.043 \mathrm{P}+0.010$ where, $I=$ interception loss corrected for stemflow $P=$ total rainfall per storm.

Rainfall interception by a high forest of mixed hardwoods and conifers with a dense understory of rhododendron follows the relation: $I=0.138 \mathrm{P}+0.019$.

Average daily evapo-transpirational water losses appear to be related to the logarithm of the average daily saturation deficit. 
(h) "A method for approximating the water content of soils." Nedavia Bethlahmy, Amer. Geophys. Uni on Trans., 33: 699-706, 1952.

"Estimating summer evapo-transpiration losses in a Pennsylvania scrub oak forest." Nedavia Bethlahmy, Soil Sci. Soc. Amer., Proc. 17: 295-297, 1953.

"Report No. 2 forest and water research project." Penna. Dept. of Forests and Waters, 1953.

(966) FOREST INFLUENCES INVESTIGATION (WNTERSHED MANAGEMENT).

(b) Laboratory project.

(d) Fleld investigation; basic and applied research.

(e) Studies have been started on the Pocono Experimental Forest, Wayne County, $\mathrm{Pa}$., to determine effects of forest management practices and logging operations upon the quantity and quality of water yielded by a small watershed. Installations have been established to measure precipitation, streamflow and rainfall interception.

(1187) FROST STUDIES IN THE NORTHEASTERN UNITED STATES.

(b) Laboratory project.

(d) Field investigation; applied research.

(e) To determine the effect of land use and condition upon type and depth of frost formation. Periodic observations of frost type and depth, snow depth, and water content are made upon a large mumber of plots in New England, New York, and northern Pennsylvania, selected to sample a variety of land uses and conditions within certain land use classes. A system of 186 plots were established and observations made thereon during the winters 1950-51 and 1951-52. Data are now being analyzed.

(1188) FOREST INFLUENCES INVESTIGATION (WATERSHED MANAGEMENT)。

(b) Laboratory project.

(d) Field investigation; basic and applied research.

(e) Studies have been started on the Fernow Experimental Forest, Tucker County, W. Va., to determine the effect of different levels of cutting practices and different logging methods upon water quantity and quality. Five watersheds have been equipped with streamgaging stations and raingages. No logging will be done on these watersheds during calibration period. Measurements are now being made on areas adjacent to the gaged watersheds to determine erosion rates on logging roads as influenced by length and steepness of grade and various erosion control measures.

(h) "A method of measuring increase in soil depth and water-storage capacity due to forest management." George R. Trimble, Jr., Northeastern Forest Experiment Station, Paper 47, 1952.

"Forestry (in west Virginia)." Sidney Weitzman, W. Va. Watershed Development Conf. Proc. 1950: 31-37, 1952.

"Soil erosion on logging roads." George R. Trimble, Jr., and Sidney Weitzman, Soil Sci. Soc. Amer. Proc. 17 (2), 152-154, April, 1953.

U. S. DEPARTMENT OF AGRICUITURE, FOREST SERVICE, Pacific Northwest Forest and Range Experiment Station.

(969) EFFECT OF IOGGING AND OTHER FOREST OPERATIONS ON STREAM FIOW.

(b) Experiment Station project.

(c) Mr. R. W. Cowlin, Director, Pacific Northwest Forest and Range Experiment Station, 423 U. S. Court House, Portland 5, Ore.

(d) Field investigation; basic research.

(e) H. J. Andrews Experimental Forest (formerly Blue River Experimental Forest), in the McKenzie River drainage of west central Oregon. Streamflow from three small experimental watersheds in virgin Douglas-fir has been measured for one year by means of trapezoidal flume stream gages. Observations are beginning of a pretreatment calibration which will be carried on for 5 years or more. Planned treatments will test effect of two systems of timber cutting on water yield and erosion. 
U. S. DEPARTMENT OF AGRICULTURE, FOREST SERVICE, Rocky Mountain Forest and Range Experiment Station.

\section{(376) FOREST INFLUENCES RESEARCH, MANITOU EXPERIMENTAL FOREST.}

(b) Laboratory project.

(c) Dr. L. D. Love, Research Center Leader, Front Range Research Center, Room 221 Forestry Bldg., Fort Collins, Colo.

(e) Studies of the influence of grazing, timber cutting, and revegetation of depleted watershed lands upon water supplies, and upon erosion and sedimentation, to solve problems in watershed management for the forest and range covered watershed lands of the Rocky Mountain Front Range.

(g) The recording of rainfall, runoff, and erosion from plots and watersheds representing different complexes of soil, vegetation, and treatment has been continued in conformance with the long-term nature of the study.

(h) "Does research pay?" 1952 Anmual Report Rocky Mountain Forest and Range Experiment Station. March, 1953.

"hiatershed management experiments in the Colorado Front Range." L. D. Love, Jour. of Soil and hater Conservation, 8:213-218, Illus. 1953.

(377) FOREST INFLUENCES RESEARCH, FRASER EXPERDMENTAL FOREST.

(b) Laboratory project.

(c) Mr. B. C. Goodell, Research Center Leader, Continental Divide Research Center, Room 221 Forestry Building, Fort Collins, Colorado.

(d) Field investigation; applied research.

(e) To determine influence of lodgepole pine and spruce-fir forests and of the management of these forests for wood products on factors associated with the yield of water, largely from stored snow. The purpose is to solve problems in the management of forested watersheds of the high altitude zone of the Rocky Mountains for maximum yields of usable water.

(g) The correlation between anmal precipitation and annual streamflow is apparently improved if the water year is taken as the period between August 1 and July 31 instead of the more commonly taken period starting october 1 . This is explained by the effect of late summer rains on the soil moisture present prior to snow melt during the following spring. Erosion from a 7l4-acre watershed covered with virgin vegetation, mostly pine and sprucefir forest, but containing 13 miles of logging road produced a sediment deposit of 105 tons in a debris basin.

(h) 1952 Annual Report, Rocky Mountain Forest and Range Experiment Station, Fort Collins, Colorado. March, 1953.

(657) FOREST INFLUENCES INVESTICATIONS AND WATERSHED MANAGEMENT, SIERRA ANCHA RESEARCH CENTER.

(b) Laboratory project.

(c) Mr. H. C. Fletcher, Research Center Leader, Sierra Ancha Research Center, Arizona State College, Tempe, Arizona.

(d) Experimental; basic and applied research.

(e) The purpose is: (1) To study the disposition of rainfall as influenced by watershed vegetation, and (2) to determine the influence of various types and densities of natural vegetation as well as vegetation modified by cultural treatment such as grazing and timber harvest, on streamflow, water uses, water losses, and erosion and sediment yields. At Sierra Ancha Experimental Watersheds in central Arizona rainfall, runoff, and erosion are measured on three watersheds in the pine-fir vegetation types at high elevation, on two watersheds in the ponderosa-chaparral type and four watersheds in the grasslandchaparral type at intermediate elevation, and on nine small watersheds in the semidesert chaparral type at low elevations. hiter use by different types of plants in different soils is studied on 11 large lysimeters. 
(g) The four Natural Drainage Watersheds on which the effect on water yields of protection from grazing is being studied are unique in that the gaging stations are tied into bedrock and all subsurface and surface runoff is measured. These watersheds were fenced and grazing use eliminated in 1934. In 1939 one watershed was opened to moderate grazing ( 40 percent utilization of the perennial grass) and one watershed was opened to heavy grazing in 1942 ( 80 percent utilization). Quadrat and transect measurements on the four watersheds indicate: (1) the grass density essentially doubled during the pretreatment period and was fairly uniform among the watersheds in 1942; (2) grass density decreased on the heavily grazed watershed compared to the moderately grazed watershed and the watersheds protected from grazing; and (3) climatic variations caused wide fluctuations in grass density on all watersheds. Results summarized to date indicate no significant difference in adjusted mean water yields from watersheds protected from grazing compared to grazed watersheds.

Preliminary results of a continuing study of the effect of timber stand density on rainfall interception indicate a direct relationship between interception loss and total basal area (all trees 0.6 inch $d . b . h$. and over). Net rainfall under timber stands containing 35.44, 53.12, and 83.75 square feet basal area per 1/4-acre plot was measured for 23 storms varying from less than 0.01 inch to 1.626 inches in the summer of 1953. These measurements show that 11.87 percent of the rainfall was intercepted by the 35.44 square foot plot, 24.96 percent by the 53.12 square foot plot, and 36.51 percent by the 83.75 square foot plot.

(1967) FOREST INFLUENCES RESEARCH, UPPER RIO GRANDE RESEARCH CENTER.

(b) Laboratory project.

(c) Mr. E. J. Dortignac, In Charge, Upper Rio Grande Research Center, University of New Mexico, T-10, Albuquerque, New Mexico.

(d) Applied research.

(e) The evaluation of reseeded rangelands for infiltration, soil stabilization and soil productivity in woodland and sagebrush types of North Central New Mexico. Rocky Mountain infiltrometer was used to measure infiltration and erosion rates from reseeded and adjacent native rangelands under grazing and nonuse. Measurement of selected vegetation and soil factors included in this study.

(f) Field study completed. Conducted during the summers of 1952 and 1953.

(g) In process of analysis.

(1968) FOREST INFLUENCES RESEARCH, UPPER RIO GRANDE RESEARCH CENTER.

(b) Laboratory project.

(c) Mr. E. J. Dortignac, In Charge, Upper Rio Grande Research Center, University of New Mexico, T-10, Albuquerque, New Mexico.

(d) Applied research.

(e) Study of range and watershed conditions and trends in North Central New Mexico. Rocky Mountain infiltrometer is used to measure infiltration and erosion rates from about 50 fenced-in enclosures installed on native rangelands in 1939 and 1940 and from adjacent open range. Detailed soil and vegetation measurements are taken at each infiltrometer plot location. In addition, re-examination and quantitative measurement of vegetation are taken inside and outside the enclosure for comparison with measured vegetation conditions in $1939-40$.

(f) Field study started in 1953.

(g) Work Plan, May, 1953.

(1969) FOREST INFLUENCES RESEARCH, UPPER RIO GRANDE RESEARCH CENTER.

(b) Cooperative study with Bureau of Land Management, U. S. Geological Survey, and Agricultural Research Service.

(c) Mr. E. J. Dortignac, In Charge, Upper Rio Grande Research Center, University of New Mexico, T-10, Albuquerque, New Mexico.

(d) Applied research. 
(e) Range-watershed evaluation of small San Iuis watersheds in Rio Puerco. Three watersheds, ranging from 370 to 735 acres, are located adjacent to one another about 8 miles north of San Luis (Dominguez) and west of the Rio Puerco. Waterflow and sediment are measured by inflow into small reservoirs formed by dams. Precipitation and vegetation measurements are taken currently. After an adequate calibration period, two watersheds will be treated and the other grazed at the present intensity to serve as a climatic control for evaluating fluctuations in climate. Watershed treatments will be concerned with grazing control, revegetation, and water retardation measures.

(h) Annual Report of the Southwestern Forest and Range Experiment Station.

(1970) FOREST INFLUENCES RESEARCH, UPPER COLORADO RIVER RESEARCH CENTER.

(b) Laboratory project.

(c) Mr. George T. Turner, Acting Research Center Leader, Upper Colorado River Research Center, Delta, Colo.

(d) Field investigation; applied research.

(e) Object is to determine and classify the field conditions under which control of oak-brush should or should not be attempted as a means of increasing grazing capacity or improving watershed conditions.

Study is being conducted in western Colorado where dense stands of oak-brush limit forage production and present problems in range and watershed management.

Physical and biological factors are being investigated to determine present and potential site productivity, erosion hazards, and other factors.

(1971) FOREST INFLUENCES RESEARCH, UPPER COLORADO RIVER RESEARCH CENTER.

(b) Laboratory project, cooperative with Bureau of Land Management, Bureau of Reclamation, and Geological Survey.

(c) Mr. George T. Turner, Acting Research Center Leader, Upper Colorado River Research Center, Delta, Colo.

(d) Experimental, applied research.

(e) To determine the effect of exclusion of livestock grazing on erosion and runoff from semidesert lands in western Colorado, eastern Utah, and southern woming.

Study area is located in the Badger Wash drainage 30 miles west of Grand Junction, Colorado, at an elevation of 4,500 feet. It is characterized by steep to rolling topography, a sparse cover of salt-desert shrub vegetation, and soils derived principally fror Mancos shale. Although average annual precipitation is less than 10 inches, cloud-burst storms result in extensive runoff and erosion. Cattle and sheep graze the area during winter months. Eight experimental watersheds are included in the study, ranging from 20 to 100 acres in size. Four watersheds are being fenced to exclude livestock for a perio of 20 years, and four will contime to be grazed. An earth dam at the mouth of each watershed will collect runoff and sediment.

Results of treatment are being evaluated by infiltration-erosion tests and sampling of ground cover, in addition to measurement of runoff and sediment.

U. S. DEPARTMENT OF AGRICULTURE, FOREST SERVICE, Southeastern Forest Experiment Station.

(380) FOREST INELUENCES INVESTIGATION - WATER RESEARCH AND WATERSHED MANAGENENT RESEARCH.

(b) Laboratory project.

(c) Mr. E. L. Demmon, Director, Southeastern Forest Experiment Station U. S. Forest Service, P. O. Box 2570, Asheville, N. C.

(d) General and complete investigation of forest influences in southeastern United States. Includes fundamental hydrologic research and applied research in water resource and watershed management.

(e) To determine the effect of vegetation on the phases of the hydrologic cycle. To find ou: the effect of land use and land management practices on water yield and water quality. To develop standards and methods of watershed management so as to derive the greatest benefit from the land and water resources in the southeastern United States. 
Most of the actual research experiments and hydrologic data collection is carried out on the 5600-acre Coweeta Hydrologic Laboratory which is located in the zone of maximum precipitation in the eastern Umited States (Nantahala Range of the Southern Appalachian Mountains). Whin this experimental area are approximately 35 individual watersheds whose streamflow is being continuously gaged and which are either being treated experimentally or being used as control checks. In addition to the streamflow gaging, there are 13 recording and 80 non-recording (standard) rain gages, 21 recording and 19 nonrecording ground water wells, 8 recording hygrothermographs, 2 recording anemometers, and one evaporation pan. Water samples for quality analysis are collected on a weekly and storm period basis from selected experimental watersheds.

The Calhoun Experimental Forest near Union, South Carolina, has been established and is doing basic research on how piedmont soils influence water resources and plant growth. Studies include measurement of infiltration, daily changes in field moisture, and runoff from several small watersheds.

Research projects include determination of effects of (1) permanent complete removal of all major vegetation; (2) temporary complete removal of all major vegetation; (3) removal of riparian vegetation; (4) removal of laurel and rhododendron shrub vegetation; (5) local logging practices; (6) mountain agriculture; (7) woodland grazing; (8) forest fires on water yield and quality; (9) improved techniques for removing wood products and retaining high quality water values on mountain watersheds.

(g) Land use studies on woodland grazing and mountain farming have shown changes in soil due to trampling are reflected in infiltration, permeability total porosity, increases in storm peaks, surface drainage characteristics, changes in time of watershed concentration during storm periods and stream turbidities.

Data analyzed this year increased our knowledge for controlling water yields. A LOacre coppice forest watershed 11 years after clear cutting shows diminishing streamflow as the trees grow older and as transpiration increases. The laurel and rhododendron understory on a 70-acre watershed was cut and increases in water yield for the first 2 years after cutting was 3.6 inches. Exploratory studies indicate that the use of sulphur dioxide gas to defoliate trees during drought periods is a rapid, economical, and efficient method of increasing water yields.

The average annual percent of precipitation intercepted by Southern Appalachian Forest canopies varies from 11 to 17 percent. This is the equivalent of 8 to 12 inches of rainfall anmully, depending on the number and type of storm.

Piedmont studies are showing how various plant species influence restoration of fertility and water storage capacities to eroded soils.

(h) "Interception of rainfall in a young loblolly pine plantation." M. D. Hoover, Southeastern Forest Experiment Station Paper 21, 13 pp. Jamuary, 1953.

"Soil moisture under a young loblolly pine plantation." M. D. Hoover, David F. Olson, Jr., and Geoffrey E. Greene, Soil Science Proceedings, Vol. 17, No. 2, pp 147-150, Apri1, 1953.

"Soil temperatures in the South Carolina Piedmont." Geoffrey E. Greene. Southeastern Forest Experiment Station Paper No. 29, 16 pp, September, 1953.

\section{U. S. DEPARTMENT OF THE ARMY, CORPS OF ENGINEERS, Beach Erosion Board.}

Inquiries concerning Projects Nos. 181, 184, 399, 660,661, 663, 970, 972, 973,975, 977, 1460, 1461, 1724 to 1727, incl., 1972 and 1973, should be addressed to the President, Beach Erosion Board, 5201 Iittle Falls Road, N. W. Washington 16, D. C.

(181) EQUILIBRTUM PROFILE OF BEACHES.

(h) Report completed; to be published.

(184) STUDY OF MODEL SCALE EFFECTS.

(f) Suspended until completion of Project 399; thereafter further testing scheduled. 
(b) Laboratory project.

(d) Experimental; design.

(e) To design and construct a wave tank for the study of the effect of waves 6 feet high and 300 feet long. Various types of wave generating mechanisms, the power required by the generator to form the waves, and the action of the waves on a beach which is placed at an angle to the axis of the tank have been studied in a 1:12 scale model. The large wave tank is completed and is 635 feet long, 15 feet wide, and 20 feet deep. Generation of the waves is to be accomplished by a pusher-type wave generator.

(f) Design and specifications for the wave generator are in progress; component parts are being procured. Completion is scheduled for late summer of 1954 .

(660) OBSERVED WAVE CHARACTERISTICS.

(b) Laboratory project; additional research by New York Uni versity.

(d) Field investigation; basic research.

(e) To secure a more thorough knowledge of the characteristics of ocean waves. A number of electrical recording wave gages have been installed in coastal waters and the se records are analysed for significant height and period. Additional gages are being installed.

(h) "Description and operating instructions for wave gage WH-I", Bulletin, Beach Erosion Board, October, 1952.

(661) REPORTS ON BEACH PROCESSES BASED ON EXISTING MISSION, ANAHEIM, AND SANTA MONICA BAY FIELD DATA.

(f) Field work completed.

(h) "Accuracy of hydrographic surveying in and near the surf zone." T. Saville, Jr. and J. M. Caldwell, Proc. 3rd Conference on Coastal Engineering, 1953.

"Accuracy of hydrographic surveying in and near the surf zone." T. Saville, Jr. and J. M. Caldwell, Beach Erosion Board Technical Memorandum No. 32, March, 1953.

"Development and field tests of a sampler for suspended sediment in wave action." G. M. Watts, Beach Erosion Board Technical Memorandum No. 34, March, 1953.

"Field investigation of suspended sediment in the surf zone." G. M. Watts, paper presented at 4 th Conference on Coastal Engineering, Chicago, Illinois, October, 1953. Further reports in preparation.

(663) SAND MOVEMENT AND WAVE STUDY, IONG BRANCH, NEW JERSEY.

(b) Laboratory project.

(d) Field investigation; basic research.

(e) To determine if sand placed in deep water will be moved onto the beach by wave action. Six hundred thousand cubic yards of sand have been placed in 38 feet of water at Long Branch, N. J. Movement of sand is being studied by frequent hydrographic surveys. Whe intensity and direction is being recorded for comparison with any sand movement. An effort is being made to measure the amount of sand moving along the bottom and the amount thrown into suspension by the waves.

(f) Reactivated to determine disposition of dumped sand after 3 years (October, 1949 to October, 1952).

(h) Supplemental report publi shed Jamuary, 1954.

(970) STUDY OF THE EFFECTS OF JETTY CONSTRUCTION AT MISSION BAY, CALIFORNIA, ON THE MOVEMENT OF IITTORAL DRIFT.

(b) Laboratory project.

(d) Field investigation; basic research.

(e) To observe the effects of construction of the two jetties at Mission Bay, California upon the littoral drift of sand past the inlet with a view of determining the changes in regime associated with jetty construction. Movement of the beach material is to be correlated with natural forces.

(f) Field work completed. Analysis of data continuing. 
(972) STRUCTURAL DESIGN OF SHORE STRUCTURES.

(b) Laboratory project.

(d) Experimental; basic research.

(e) To aid in the preparation of a handbook on the design of shore structures. Field and model tests on the wave pressures caused by breaking waves which act on structures will be made in order to fill such gaps in our present knowledge of these forces not covered by other current investigations.

(f) Laboratory pressure measuring tests completed.

(g) Measurements have been made of the shock pressure of breaking waves on a vertical structure (maximum wave height about 7 inches). Whe pressures of more than 18 psi were measured. The high pressures last for a very short time. The time-pressure integral was also measured, the highest being about 0.02 psi-seconds. Froudian model scale relations indicated that the time-pressure integral should vary with three-halves power of the scale of the wave.

(h) "Shock pressure of breaking waves", Culberton W. Ross, paper presented at Lth Coastal Engineering Conference, Chicago, Illinois, October, 1953.

(973) CONSTRUCTION OF COAST MODEL BASIN.

(b) Laboratory project.

(d) Experimental; basic research.

(e) To study beach problems involving waves, littoral currents and tides. The basin is 300 feet long, 150 feet wide and 3 feet deep.

(g) The basin has been completed; ten portable wave machines have been constructed and are undergoing acceptance tests; the tide system is under construction.

(975) METHODS OF BY-PASSING SAND PAST INLETS.

(b) Laboratory project.

(d) Field investigation; applied research.

(e) To study methods and requirements for pumping sand past inlets and to determine the applicability of the methods in stabilization of beaches adjacent to inlets. A component of this study is the correlation of effectiveness of South Lake Worth Inlet, Florida, By-Passing Plant with rate of drift reaching plant. Data were coliected $(3 / 6 / 52$ to $6 / 10 / 52)$ which included daily recorded wave heights and periods, daily observed littoral currents, measured volume of material pumped at by-passing plant, and sand samples.

(g) Preliminary analysis of a portion of the collected data indicates that a relationship between wave energy and material pumped by the by-passing plant can be developed for the period that the data were obtained.

(h) "By-passing littoral drift at coastal inlets". R. O. Eaton and G. M. Whatts, paper presented at ASCE meeting, Miami, Florida, June, 1953.

"A study of sand movement at South Lake Worth Inlet, Florida". G. M. Watts, Beach Erosion Board Technical Memorandum No. 42, Oct. 1953.

(977) DEVELOPMENT OF WAVE HEIGHT AND WAVE DIRECTION GAGES.

(b) Laboratory project.

(d) Experimental; development.

(e) To develop wave height and wave direction gages for use in securing accurate records of wave characteristics. Eight wave gages of the step-resistance surface mounted type and pressure bottom mounted type are now in operation and equipped to operate on a 7-day unattended basis. Laboratory development of a wave direction gage which utilizes two wave height gages operating concurrently is continuing. Further laboratory study of a wave direction gage is being made by utilizing a sensitive pressure cell in conjunction with the Raleigh Disc principle. Additional development of recording parallel wire resistance and capacitance gages for laboratory use has been made to obtain constant linear calibration characteristics.

(1460) MEASUREMENT OF DEEP WATER OCEAN WAVES WITH AN AIRBORNE WAVE RECORDER.

(b) Laboratory project. 
(d) Experimental; basic research.

(e) To assess the reliability of present wave forecasting procedures and formulae for wave transformation in shallow water. In cooperation with the Navy, the Beach Erosion Board established a shore-based recorder off Martha's Vineyard and fabricated a wave gage for use off the Nantucket Iightship by the Navy Hydrographic office. Simultaneous records at these two stations together with those from a Navy plane equipped with an airborne wave recorder were planned. The Navy failed to assign the plane at the selected time and only the lightship and shore records were obtained. The data thus obtained are being analyzed.

(f) Completed.

(h) "A comparison of observed and hindcast wave characteristics off the southern coast of New England". R. F. Dearduff, Beach Erosion Board Bulletin, Vol. 7, No. 4, Oct. 1953.

(I461) IOSS OF WE ENERGY BY BOTTOM FRICTION AND PERCOLATION IN A PERMEABLE BOTTOM.

(f) Completed.

(h) "Laboratory study of wave energy losses by bottom friction and percolation". R. P. Savage, Beach Erosion Board Technical Memorandum No. 31, Feb. 1953.

(1724) STUDY OF THE PARALLEL ITNE METHOD FOR DETECTING AND MEASURING WAVE TRAINS.

(b) Laboratory project.

(d) Experimental; development.

(e) To evaluate the parallel line method for observing and measuring wave trains, and study possible means of improving the method and extending its application. A large number of photographs of wave trains are being examined with the parallel line method for identifying and measuring wave trains for use in water depth determinations. Multiple wave systems generated in the Coast Model Basin (Project 973) will be utilized to check the method.

\section{(1725) STUDY OF EFFECT OF TIDAL FLUCTUATIONS ON WAVE-PRODUCED BEACH PROFIIES.}

(b) Laboratory project.

(d) Experimental; basic research.

(e) To determine the effect, on a wave-produced beach profile, of introducing tidal fluctuations during the period the beach is being formed. Tests are being conducted in a concrete wave tank, 88 by 14 by 4 feet. Constant period waves are being generated against four types of sand beaches and periodic tidal fluctuations introduced into the system. These results will be compared with the data in Projects 181 and 1459 .

(f) Completed.

(h) Report in preparation.

(1726) CORRELATION OF WAVES AND ALONGSHORE CURRENTS.

(b) Laboratory project.

(d) Field investigation; basic research.

(e) To establish a correlation between incident wave characteristics and the resulting littoral currents. Measurements of wave height, period, and angularity of approach were made at selected beaches coincident with measurements of alongshore current velocities and hydrographic changes.

(h) Report in preparation.

(1727) STATISTICAL WAVE DATA FOR GREAT LAKES, ATLANTIC, AND PACIFIC COASTS.

(b) Laboratory project.

(d) Applied research; development.

(e) To compile statistical wave data, by hindcasting from weather maps, into a form suitable for engineering usage. The present study includes five stations on Lake Michigan, four on Lake Erie, three on Lake Ontario, four on North Atlantic, four on North Pacific which data are being obtained and compiled for all stations.

(f) Temporarily suspended on completion of North Atlantic report.

(h) "Wave and lake level statistics for Lakes Michigan, Erie and Ontario." T. Saville, Jr., Beach Erosion Board Technical Memor andums Nos. 36, 37, 38 (respectively), March, 1953. "Hindcast wave statistics for the Great Lakes." T. Saville, Jr., paper presented at the Lth Conference on Coastal Engineering, Chicago, Ill., Oct. 1953. 
(b) Laboratory project.

(d) Experimental; applied research.

(e) To study the action of Tsunami waves over shore areas, with particular application to Hilo Harbor, Hawail.

(g) Significant correlation between wave steepness and man-up has been found.

(h) An interim report completed in Nov. 1953.

1973) EFFECTS OF SOUNDING METHODS ON INDICATED NAVIGATIONAL DEPTHS.

(b) North Atlantic Division of the Corps of Engineers.

(d) Experimental; basic research.

(e) Experimental sounding leads of various shapes will be fabricated and tests will be undertaken to compare these leads with sounding leads currently being employed. The laboratory tests will be conducted with an objective of selecting or devising a more suitable size, shape, and weight of sounding lead which would indicate the elevation of bottom material of minimum consistency which has detrimental effects on navigation.

S. DEPARTMENT OF THE ARMY, CORPS OF ENGINEERS, Bonneville Hydraulic Laboratory.

Inquiries concerning Projects Nos. 1198, 1462, 1464, 1465, 1466, 1728, 1729, 1974 to 1976, incl., should be addressed to the District Engineer, Portland District, Corps of Engineers, 628 Pittock Block, Portland 5, Oregon.

1198) MODEL STUDY OF FRICTION LOSSES IN CORRUGATED METAL PIPE. (CW-828).

(b) Office, Chief of Engineers, U. S. Army, Washington, D. C.

(d) Experimental; applied research.

(e) Tests are being conducted to determine values of Manning's "n" for cormgated metal pipe of $3-, 5-$, and 7-foot diameters with velocities of 1 to 16 fps. Similar tests are also being made with the inverts of the 5 - and 7-foot pipes paved with asphaltic compound; the paving covering one-fourch and one-half the circumference of the 5-foot pipe and one-fourth the circumference of the 7 -foot pipe. Additional data consisting of velocity distribution at various sections of the pipe and pressure distribution along the corrugations are being obtained.

(g) Results to date indicate that the " $n$ " values vary between: $0.0236,0.0245$, and 0.0234 for Reynolds Numbers of $300,000,900,000$, and 4,000,000, respectively, for the 3-foot pipe; $0.0238,0.0243$, and 0.0240 for Reynolds Numbers of $1,000,000,2,000,000$, and $3,500,000$ for the 5 -foot pipe; and 0.0211 and 0.0207 for Reynolds Numbers of $1,500,000$, and $4,000,000$ for the 5-foot pipe with one-quarter paved invert.

(h) Four preliminary or memorandum reports have been issued on results of tests of 3- and 5-foot pipes.

462) GENERAL MODEL STUDY OF THE DALLES DAM, COLUMBIA RIVER, THE DALLES, OREGON.

(b) Department of the Army, Corps of Engineers, Portland District, Portland, Oregon.

(d) Experimental; for design.

(e) A 1:80-scale undistorted fixed bed model reproduces $2.7 \mathrm{miles}$ of the Columbia River at the dam site. The original layout consisted of a circular arc 30-bay spillway, a 22unit powerhouse, an 86 - by 675 -foot navigation lock, a rockfill nonoverflow section, and facilities for passing fish over the dam. Maximum head is 90 feet. Revised layout has a straight 23-bay spillway. Purposes are to study the structures alignment and flow conditions affecting navigation, power generation, cofferdam placement, and fish passage. 
(g) Four major layout plans were tested and the most economical plan that effected satisfactory hydraulic conditions was selected. Tests indicated ability to reduce spillway from 30 to 23 bays, and reduce forebay excavation by 30 feet. Data relative to watersurface elevations and velocities in the tailrace, powerhouse efficiency as affected by oblique approach flow, and the effects of excess fill placed in the forebay have been obtained.

(h) Memorandum reports issued on all tests completed to date. Final report being prepared.

(1464) MODEL STUDY OF ROCK FILL, THE DALLES DAM, COLUMBIA RIVER, THE DALLES, OREGON.

(b) Department of the Army, Corps of Engineers, Portland District, Portland, Oregon.

(d) Experimental; for design.

(e) A 1:40-scale model of the 600-foot wide by 200-foot high rockfill nonoverflow section of The Dalles Dam including portions of the river channel upstream and downstream therefrom is being constructed to provide information relative to rock sizes and placement procedure necessary to construct the fill during river discharges up to $300,000 \mathrm{cf}$ :

(f) Model under construction.

(1465) MODEL STUDY OF THE DAILES DAM SPILLWAY, COLUMBIA RIVER, THE DALIES, OREGON.

(b) Department of the Army, Corps of Engineers, Portland District, Portland, Oregon.

(d) Experimental; for design.

(e) Three bays of the spillway are reproduced to a scale of 1:36 to study the hydraulic characteristics of the spillway crest, piers, gates, stilling basin and baffle piers.

(g) The increased crest efficiency indicated by the model, in conjunction with a crest shape designed for 75 percent of maximum head, permitted a reduction in the number of spillwa. bays from 30 to 23. The stilling basin was shortened 50 feet to a total length of 170 feet, and one row of baffle piers, of the Bluestone type, was eliminated. The capacity of the stilling basin would not be materially reduced by erosion of the shelf located downstream from the basin.

(h) Memorandum reports issued on results of all tests to date. Final report being prepared

(1L66) MODEL STUDY OF THE DALLES DAM NAVIGATION LOCK, COLUMBIA RIVER, THE DALIES, OREGON.

(b) Department of the Army, Corps of Engineers, Portland District, Portland, Oregon.

(d) Experimental; for design.

(e) A 1:25-scale model of the 86 -by 675-foot lock chamber including its culvert systems an portions of the upstream and downstream approach channels is reproduced. Maximum lift is 90 feet. Studies are being made of various types of filling and emptying systems to determine the most advantageous from the standpoints of rate of operations, degree of turbulence, and economy. The several proposed plans include lateral culverts within th lock chamber combined with several locations of intake ports, longitudinal culverts, an outlet works.

(g) Designs of intake works and downstream approach channel have been selected. Latest design of lateral culvert filling system produces maximum hawser forces of 6 tons with filling time of 13.6 minutes, which can be reduced to 12.3 minutes by opening upstream lock tainter gate to supplement filling.

(h) Memorandum reports have been issued on results of all tests to date. Final report bein prepared.

(1728) MODEL STUDY OF THE DALLES DAM FISHLADDERS, COLUMBIA RIVER, THE DALIES, OREGON.

(b) Department of the Army, Corps of Engineers, Portland District, Portland, Oregon.

(d) Experimental; for design.

(e) The 1:8-scale model reproduced a straight portion of a fishladder containing ten stilli pools. Tests were made to study flow conditions with ladder slopes of 1 on 16 and 1 on 20 and to determine the most efficacious orifice sizes for ladder widths of 24 and 30 feet.

(f) Inactive.

(g) Results indicated insignificant differences in flow conditions between $I$ on $I 6$ and $I$ on 20 slopes. Orifices 21 by 23 in. and 25 by 26 in. have been selected for the 24 - and 30-foot ladders, respectively.

(h) Memorandum reports have been issued on results of all tests. Final report being prepar 
1729) MODEL STUDY OF THE DALLES DAM POWERHOUSE INTAKE, COLUMBIA RIVER, THE DALLES, OREGON.

(b) Department of the Arrny, Corps of Engineers, Portland District, Portland, Oregon.

(d) Experimental; for design.

(e) The 1:25-scale model contains a test unit consisting of intake and scroll case, two adjacent units with intakes only, and a semi-circular forebay in which flow can be introduced from any desired direction. To determine the effect of the direction of approach flow on velocity distribution in the intake, discharge distribution through the scroll case, and head loss.

(f) Tests completed.

(g) Results indicate that oblique approach flows, at an angle of $15^{\circ}$ from the powerhouse axis, have little effect on the efficiency of the unit, as indicated by head loss and flow distribution in the intake and scroll case, when trash racks are installed on the noses of the piers to function as guide vanes.

(h) Memorandum reports have been issued on results of all tests. Final report being prepared.

1974) MODEL STUDY OF THE DALLES POWERHOUSE FISHWAY DIFFUSER, COLUMBIA RIVER, THE DALLES, ORECON.

(b) Department of the Army, Corps of Engineers, Portland District, Portland, Oregon.

(d) Experimental; for design.

(e) To determine means of baffling auxilliary flow, in diffusion chambers, to obtain uniform distribution into the fish collection channel by means of a $1: 8$-scale model of one diffusion chamber and a portion of the collection channel.

(f) Tests completed.

(g) Vertical strip baffles placed downstream from the regulating valve produced satisfactory flow distribution.

(h) Memorandum reports have been issued on results of all tests. Final report being prepared.

(1975) MODEL STUDY OF THE DALLES POWERHOUSE SKELETON UNIT, COLUMBIA RIVER, THE DALIES, OREGON.

(b) Department of the Army, Corps of Engineers, Portland District, Portland, Oregon.

(d) Experimental; for design.

(e) To design for adequate discharge capacity and to determine pressures and velocities on exposed rock surfaces in eight skeleton powerhouse units that will be used for diversion during construction of a rock-fill nonoverflow section. A 1:25-scale model reproduces one skeleton unit.

(g) The required size of the draft tube openings and the areas requiring protection from high velocities were determined.

(h) Memorandum reports have been issued on completed tests. Final report being prepared.

(1976) MODEL STUDY OF BONNEVILIE DAM STILIING BASIN, COLUNBIA RIVER, BONNEVILIE, OREGON.

(b) Department of the Army, Corps of Engineers, Portland District, Portland, Oregon.

(d) Experimental; for design.

(e) A 1:36-scale model reproduces three bays of the spillway and stilling basin for the purpose of studying the need of maintaining the stilling basin baffle piers.

(f) Inactive.

(g) Results indicate that baffle piers are required to prevent erosion of bed material downstream from the stilling basin.

(h) One memorandum report has been issued.

10. S. DEPARTMENT OF THE ARMY, CORPS OF ENGINEERS, Jacksonville District.

(1731) WA VES AND WIND TIDES IN INLAND WATERS, LAKE OKEECHOBEE, FIORIDA.

(b) Department of the Army, Office of the Chief of Engineers. 
(c) District Engineer, Jacksonville District, Corps of Engineers, P. 0. Box 4970, Jacksonville, Florida. Colonel H. W. Schull, Jr.

(d) Analytical and applied research; for design.

(e) Fleld gaging and office analysis of data on wind, waves, wind tides, and meteorological factors involved in relationships for determining levee freeboard and slope protection for inland waters.

(g) Formulas and analysis procedures have been developed for set-up computations, verifying wind tides observed in hurricanes and lower wind incidents. Whe-height estimating pro. cedures have been tentatively established for shallow water, high-speed wind conditions, hater-surface shear stress analyses have been completed for natural conditions of water roughness and high-speed winds, as related to wind-tide action.

(h) Hurricane data, Project Bulletins 2, Aug. 26-27, 1949; No. 3, Sept. 21-22, 1948; No. 4, Sept. 16-18, 1947; No. 5, Oct. 17-18, 1950; No. 6, Sept. 15-16, 1945, Aug. 1, 1952.

J. S. DEPAPTMENT OF THE ARMY, CORPS OF ENGTNEERS, LOS Angeles District.

Inquiries concerning Projects Nos.980, 1203, 1204, and 1732 should be addressed to the District Engineer, Los Angeles District, Corps of Engineers, P. 0. Box 17277, Foy Station, Los Angeles 17, California.

(980) MODEL STUDY OF WHITTIER NARROWS FLOOD-CONTROL BASIN.

(b) Laboratory project.

(d) Experimental for design.

(e) Earth dam with gated outlets and spillway. Three models are being used: A 1:24-scale model of the outlet works for tests on the operation of the four $30 \mathrm{ft}$. by $19 \mathrm{ft}$. radia: sluice gates with maximum head of $50 \mathrm{ft.;}$ a 1:42-scale model of a half plan of the spillway for tests on the operation of the nine $50 \mathrm{ft}$. by $29 \mathrm{ft}$. tainter gates with maximum head of $34 \mathrm{ft}$; a 1:60-scale general model of the flood-control basin for tests on the over-all operation of the project.

(g) In the 1:24-scale model, calibration tests were made to determine the discharge characteristics of the radial sluice gates.

(1203) MODEL SIUDY OF LOS ANGELES RIVER CHANNEL IMPROVEMENT, RIO HONDO TO PACIFIC OCEAN.

(b) Laboratory project.

(d) Experimental for design.

(e) In the reach from Rio Hondo to Spring Street (44,500 ft.) the improvement proposed is a paved trapezoidal channel with $300-\mathrm{ft}$. base and 1 on $21 / 4$ side slopes. Normal velocit: would be supercritical ( $25 \mathrm{ft} / \mathrm{sec}$ ) but numerous bridges would produce Class "B" flow ani attendant hydraulic jumps upstream of the bridges. From Spring Street to Pacific Ocean (17,600 ft.) the channel will be trapezoidal with a base width varying between $530 \mathrm{ft}$. and $470 \mathrm{ft}$., the 1 on 2 side slopes will be pared, the bottom unpaved, and the velocity subcritical (12 ft/sec). The design discharge is $140,000 \mathrm{cfs}$ in the first reach and 146,000 cfs in the second reach. A 1:50-scale model will be used to study flow conditions at confluences, at bridges, and at the junction of the pared and unpared channels. The model tests will be accomplished in stages.

(g) Tests were made to determine flow conditions at the Compton Creek confluence for variou: combinations of discharge.

(1204) AIRFIEID SURFACE DRAINAGE INVESTIGATION.

(f) Cormpleted.

(h) Report in preparation.

(1732) MODEL STUDY OF SPILLWAY AND OUTLET WORKS FOR SAN ANTONIO DAM.

(b) Laboratory project.

(d) Experimental for design. 
(e) Earth dam with maximum height of 160 feet and length of 3850 feet. The outlet works designed for a maximum discharge of 10,000 cfs will be at right abutment and will consist of an intake with 3 gated openings 5 feet 8 inches by 10 feet high converging into a circular conduit 14.5 feet in diameter and 621 feet long. The spillway designed to pass 54,000 efs will be in right abutment and will consist of a concrete ogee 200 feet long and a conerete side channel and chute 1075 feet long which will terminate in a flip bucket at stream bed. Three models are being used to study various designs: a 1:20-scale model of the outlet works made of transparent plastic; a 1:36-scale model of the ogee and side channel of the spillway; and a 1:48-scale general model of the spillway.

(f) Tests on $1: 36$-scale spillway model are completed.

(g) In the 1:48-scale model, tests were made to study the operation of the flip bucket at the end of the spillway chute.

EPARTMENT OF THE ARMY, CORPS OF ENGINEERS, ST. PAUL DISTRICT.

In cooperation with St. Anthony Falls Hydraulics Laboratory.

Inquiries concerming Projects Nos. 194, 412, 985, 1206, and 1977, should be addressed to the District Engineer, Corps of Engineers, St. Paul District, $1217 \mathrm{U}$. S. Post Office and Custom House, St. Paul 1, Minn.

(194) A STUDY OF METHODS USED IN THE MEASUREMENT AND ANALYSIS OF SEDTMENT LOADS IN STREAMS.

(b) Federal Inter-Agency River Basin Committee, Subcomittee on Sedimentation.

(d) Experimental; applied research and development.

(e) Plans and specifications for point and depth-integrating suspended sediment samplers and laboratory apparatus have been prepared. Sampler designs include a light-weight depth sampler (4 Ib) operated by hand, medium=weight depth sampler (62 Ib), point sampler (100 lb), and heavy point sampler (300 Ib) for use in deep, swift streams. Designs for a suspended sediment sample splitter, bottom withdrawal tube, bed material sampler (100 lb), and visual accurulation tube apparatus for recording the sedimentation size distribution of sand particles have also been prepared.

(g) Suspended sediment samplers and size analyzers were manufactured in quantities sufficient to satisfy current requirements of Federal agencies. The supply of equipment for sampling and analyzing fluvial sediments, not commercially available to Federal agencies, is a continuing activity. Field testing of the visual accumulation tube method of determining particle-size gradations of fluvial sediments in the sand size range has been initiated.

(h) "Accuracy of sediment size analyses made by the bottom withdrawal tube method." Report No. 10. April, 1953.

(412) ST. ANTHONY FALIS IOCKS.

(b) St. Paul District, Corps of Engineers.

(d) Experimental; for design.

(e) The complete hydraulic systems of the upper lock and the lower lock are being studied in 1:22.4 models. The lower lock is to have a single culvert and chamber laterals, and the upper lock a culvert in each wall and a system of chamber laterals alternating from the two culverts. The two locks will have a total lift of 75 feet.

(f) Suspended.

(g) A slow period of opening the culvert valves was used to reduce vortex action at the intake manifolds of the upper lock. The hydraulic system has sufficient capacity in lock filling to make a slow valve operation feasible.

(985) FILIING AND EMPTYING SYSTEMS FOR HIGH-LIFT LOCKS.

(b) Office, Chief of Engineers, Department of the Army, hashington 25, D. C.

(d) Experimental; applied research. 
(e) To develop adequate criteria for the design of filling and emptying systems for highlift locks. Tests will be conducted in prototype locks, in model locks for definite projects, and in a general lock model simulating a maximum lift of 150 feet.

(g) The general lock model was used to study a mono-culvert bottom lateral hydraulic system. The effect of depth of water in the lock on the formation of surge waves was investigate for one filling system. Maximum surge waves in the lock were reduced 40 percent by twospeed valve opening. Coefficients of contraction and discharge for a Tainter valve and pressures on the valve and in the culvert were measured.

(1206) CONDUTT GATE STRUCTURES AND TRANSTTIONS.

(b) Office, Chief of Engineers, Department of the Arny, Washington, D. C.

(d) Experimental; applied research.

(e) A general model study is being made to establish gate operating procedures for multiple gate conduits and design criteria for conduit transitions downstream from single and multiple control gates. The model includes a complete outlet conduit with upper pool reservoir, multiple control gates in conduit intake, and a stilling basin.

(f) Testing completed.

(g) Spiral or undulating flow was found to originate at the gate and transition sections. The degree of disturbance varied with the type of conduit boundary, being most severe with circular conduits. Guide vanes located on the conduit, walls downstream from the intake transition, reduced spiral or turbulent flow resulting from the operation of one gate alone in multiple gate intake structure.

(h) Report in preparation.

(1977) MODEL STUDY FOR GREENUP AND MARKLLAND LOCKS, OHIO RIVER.

(b) Huntington and Louisville Districts, Corps of Engineers.

(d) Experimental; for design.

(e) The hydraulic systems of the two locks which are of similar design are being tested in a 3 to 100 scale model. The proposed locks will be 110 feet wide and 1,280 feet long with lifts of 32 and 35 feet, respectively. The filling and emptying systems are combined in two culverts, one in each wall, with lateral culvert diffusers in the lock floor and flared outlets discharging into the river below the dam.

(g) The transverse hawser pull by a barge tow was reduced 75 percent by placing protruding port extensions on the lateral culvert diffusers. The longitudinal hawser pull by large barge tows was reduced considerably by confining the inflow from both culverts to the middle third of the lock length. Hawser pull of small and large barge tows was in general less when the inflow from one wall culvert was introduced in the upper half of the lock and inflow from the other culvert, in the downstream half of the lock.

U. S. DEPARTMENT OF THE ARMY, CORPS OF ENGINEERS, Whaterways Experiment Station.

Inquiries concerning Projects Nos. 211, 218, 226, 230, 236, 257, 419, 425, 673, 674, 678 $682,683,986,987,989,992$ to 995 , incl., 998 to 1002, incl., 1004, 1207, 1209 to 1212 incl., 1467 to 1475 , incl., 1735 to 1741 , incl., and 1978 to 1988, incl., should be addressed to the Director, Waterways Experiment Station, Corps of Engineers, P. 0. Box 631, Vicksburg, Mississippi.

(211) MODEL STUDIES OF OUTLET WORKS, SPILLWAY AND STILIING BASIN, GARRISON DAM, MISSOURI RIVER, NORTH DAKOTA.

(b) The District Engineer, Garrison District, Corps of Engineers, Bismarck, N. D.

(f) Testing completed.

(h) Final report in preparation. 
(b) Office of the Chief of Engineers, Department of the Army, Washington, D. C.

(d) Experimental; applied research.

(e) Scale models are being used for a general study of the hydraulic characteristics of entrance curves for (1) rectangular conduits in which the entrance is flared in four directions, and (2) a gated tunnel having a rectangular entrance with floor at same elevation as approach chamel (entrance flared in three directions). Tests involve determination of pressures and discharge coefficients.

(g) Tests to date indicate that, for a gradual reduction in the pressure gradient through the conduit entrance and a minimum size entrance, the entrance curve should be shaped to the elliptical curve of $\mathrm{X}^{2} / \mathrm{D}^{2}+\mathrm{Y}^{2} /(1 / 3 D)^{2}=1$, where $\mathrm{D}$ is the dimension of the conduit in the direction concerned.

(h) Report of tests with conduit flared in four directions in preparation.

\section{6) POTAMOLOGY INVESTIGATIONS.}

(b) The President, Mississippi River Commission, Corps of Engineers, Vicksburg, Miss.

(d) Experimental and field investigations; applied research.

(e) These investigations, to determine the governing principles for the design and over-all planning of river improvements and bank stabilization, consisted of model studies conducted at the Waterways Experiment Station and field studies made at selected sites along the Mississippi River. The purposes of the model studies were to: (I) provide means of predicting future channel changes in meandering of the Mississippi River and the need for bank protection, (2) study revetment stability, (3) study and develop methods of channel stabilization by means other than the use of revetment, and (4) develop and test plans for improvement of specific troublesome reaches of the Mississippi River. The field investigations consisted of (I) soil surveys to determine the nature, characteristics, and physical properties of the banks of the Mississippi River to permit recognition of soil factors affecting bank stability, (2) hydrographic and hydraulic surveys to provide information in specific revetted reaches of the river to permit recogmition of hydraulic and hydrographic factors affecting revetment stability, and (3) turbulence surveys to determine the magnitude and extent of the forces of turbulence engendered at the boundary layer of the Mississippi River and the effects of these forces on revetment stability to permit adequate and economical revetment design.

(f) Model tests and field investigations completed.

(g) A model-operating technique was developed that can be used to forecast with reliable accuracy the future courses of regimen changes in any troublesome reach of the Mississippi River. In addition, a model-operating technique was evolved that permits investigation of various bank-stabilization features. The primary findings of the soils studies indicate that the massive failures occurring in the banks of the Lower Mississippi River are liquefaction failures. Hydraulic studies indicated that the interstices in the articulated concrete mat of conventional design permit a flow of sand sufficient to produce extensive underlying pockets and sinking of the revetment.

(h) Final report on hydrographic and hydraulic field investigations in preparation.

(230) MODEL STUDY OF FLOOD CONTROI, CUMBERIAND, MARYLAND.

(b) The District Engineer, whington District, Corps of Engineers, Washington, D. C.

(f) Testing completed.

(h) Final report in preparation.

\section{(236) MISSISSIPPI BASIN MODEL.}

(b) Office of the Chief of Engineers, Department of the Army, hashington, D. C.

(d) Experimental; for design.

(e) Plans provide for a model study of the Mississippi River Basin including the Mississippi, Ohio, Missourl, White, Arkansas, and Red Rivers, and their principal tributaries. Completed construction consists of the Upper Mississippi River from Hannibal, Mo., to Tiptonville, Tenn.; the Missouri River from Sioux City, Iowa, to the mouth; the Arkansas River from Blackburn Dam Site, Okla., to Pine Bluff, Ark.; the Ohio River from Golconda, IIl., to the mouth; and the Cumberland River from Old Hickory Dam, Tenn., to the mouth. The topography of the streams and floodplains are reproduced to, a horizontal scale of $1: 2000$ and vertical scale of $1: 100$. The model was designed to aid in the development of coordinated basinwide plans for flood control and operation of flood-control structures. 
(g) Tests of flood-routing methods to aid in perfecting flood predictions and reservoir operation, and tests to check the grades and to determine the effects of project levees to assist in planning flood protection and other levee studies were conducted during the past year.

(h) "Verification of Van Buren-to-Pine Bluff Reach, Arkansas River and Tributaries, Spring 1941 and 1943 Floods." Mississippi Basin Model Report No. 14-2, Nov. 1952. (Available on loan.)

(257) MODEL STUDY OF STABILITY OF RUBBLE-MOUND BREAKWATERS.

(b) The Chief, Bureau of Yards and Docks, Department of the Navy, Whington, D. C.

(f) Completed.

(h) "Stability of rubble-mound breakwaters; Hydraulic model investigation." Waterways Experiment Station Technical Memoranaum No. 2-365, June, 1953. (Available for loan.)

(419) SLIDE GATE TESTS, NORFORK DAM, ARKANSAS.

(b) The District Engineer, Iittle Rock District, Corps of Engineers, Iittle Rock, Arkansas.

(f) Testing completed.

(h) Results will be published as an appendix to Waterways Experiment Station Technical Memorandum No. 2-280, "Slide gate tests, Norfork Dam, North Fork River, Arkansas," dated June, 1949.

(425) COMPREHENSIVE MODEL STUDY, DELAWARE RIVER, PENNSYLVANIA.

(b) The District Engineer, Philadelphia District, Corps of Engineers, Philadelphia, Pa.

(d) Experimental; for design.

(e) To develop and test plans for reduction of shoaling in several ranges of the navigation channel, the entire Delaware River estuary from the Atlantic Ocean to Trenton is reproduced in the model which is of the fixed-bed, silt-injection type, with scale ratios of 1:1000 horizontally, and 1:100 vertically. Tides and tidal currents are reproduced by automatic tide-control machines. Observed prototype salinities are reproduced in the Delaware Bay portion of the model, and provisions made for the injection of silt, and for measuring silt deposits.

(f) Active.

(g) Tests to determine effects of tide range, fresh-water discharge, disposal of industrial and municipal wastes, and other possible contributing factors on salinity concentrations throughout the Delaware Estuary were in progress.

\section{(673) GENERAL SPILIWAY MODEI TESTS.}

(b) Office of the Chief of Engineers, Department of the Arry, Washington, D. C.

(d) Experimental; applied research.

(e) Tests on a 1:40 model are used to study hydraulic characteristics of the standard spillway shape with heads up to $1-1 / 3$ times the design head of the crest, including the effect of crest piers and gates, elevation of downstream floor of spillway, and downstream slope of spillway. Tests are also being made to establish general rules for design of rollertype energy dissipators. The drop from spillway crest to bucket is varied to study the effect of nappe thickness. Tests to study pressures on a flat apron-type energy dissipator were undertaken.

(g) Tests to obtain discharge and pressure data for various approach elevation conditions indicated that with height of weir equal to or greater than the head, coefficient and pressure data were in the same range for the same crest shape. The spillway discharge per net foot of width is not materially affected by the use of crest piers or by variation in the shape of these piers. Thickening of the spillway nappe permitted established roller action to contime at lower tailwater depths than noted with the thin spillway jet. Pressures on a flat apron-type energy dissipator approximated the water-surface elevation above the apron.

(h) Advance Report No. 1, General Spillway Investigation, CW 801, "Spillway crest data with and without piers," dated August, 1949.

Advance Report No. 2, General Spillway Investigation, CW 801, "Spillway crest data with varied depths of approach," dated June, 1950. A consolidated report of the above advance reports, together with results obtained by varying the spillway slope and exit area elevation below the spillway, is in preparation. 
(674) MODEL STUDIES OF FORI RANDALL DAM, MISSOURI RIVER, SOUTH DAKOTA.

(b) The District Engineer, Omaha District, Corps of Engineers, Omaha, Nebraska.

(f) Testing completed.

(h) Final report in preparation.

(678) CHARLESTON HARBOR MODEL STUDY.

(b) The District Engineer, Charleston District, Corps of Engineers, Charleston, South Carolina.

(f) Testing completed.

(h) Final report in preparation.

(682) HYDRAULIC CAPACTTY OF MEANDERING CHANNEIS IN STRAIGHT FLOODWAY.

(b) Office of the Chief of Engineers, Department of the Army,

(f) Testing completed.

(h) Final report in preparation.

(683) MODEL STUDIES OF FIOW CONDITIONS IN PUMPING PIANT SUMP AND SURGES IN SETERS.

(b) The District Engineer, Louisville District, Corps of Engineers, Louisville, Ky.

(f) Testing completed.

(h) Final report in preparation.

(986) MODEL TESTS OF CHEATHAM DAM, COMBERIAND RIVER, TEMNESSEE.

(b) The District Engineer, Nashville District, Corps of Engineers, Nashville, Tenn.

(d) Experimental; for design.

(e) A 1:12 model of one wicket of the emergency dam for the lock was tested to determine the relative force required to raise a wicket under various operating conditions and to determine the optimum angle for the face of the wicket, the guard sill, and the strut. A 1:36 model of a portion of spillway crest and bucket was used to determine the most advantageous shape for the submergible tainter gate; the forces acting on the gate; and flow conditions for various tailwater elevations. In addition, the submergible tainter gate developed in the 1:36 model was tested in a 1:10 model to determine its operating characteristics at the larger scale. Tests to determine the location and height of end sill for use with a partially submergible tainter gate also were conducted.

(f) Testing completed.

(g) Uplift forces acting on the upstream emergency dam were eliminated by use of a wicket gate with a curved upstream face. A design has been developed for the submergible tainter gate that eliminates the tendency of the gate to oscillate under certain operating conditions. Results obtained on the 1:10-scale model verified those previously obtained on the 1:36-scale model. Optimum stilling basin dimensions were determined for flow over and under a partially submergible tainter gate.

(h) nUpstream emergency dam, Cheatham Loci, Cumberland River, Tennessee; hydraulic model investigation," haterways Experiment Station Technical Memorandum No. 2-358, April, 1953. (Available for loan.)

Report on model studies of spillway and submergible tainter gate in preparation.

(987) MODEL STUDY OF CHANNEL IMPROVEMENTS, FARM CREEK, ILLTNOIS.

(b) The District Engineer, Chicago District, Corps of Engineers, Chicago, Illinois.

(f) Completed.

(h) "Channel improvements, Farm Creek, Illinois; hydraulic model investigation." Waterways Experiment Station Technical Memorandum No. 2-355, Feb. 1953. (Available for loan.)

(989) MODEL STUDY OF MISSISSIPPI RIVER, VICINITY OF GREENVILIE BRIDGE, GREENVILIE, MISSISSIPPI.

(b) The District Engineer, Vicksburg District, Corps of Engineers, Vicksburg, Mississippi.

(f) Completed.

(h) "Plans for improvement of navigation conditions at Greenville Bridge, Mississippi River; model investigation." Whterways Experiment Station Technical Memorandum No. 2-365, June, 1953. (Available for loan.) 
(992) MODEL STUDIES OF PINE FLAT DAM, KINGS RIVER, CALTFORNIA.

(b) The District Engineer, Sacramento District, Corps of Engineers, Sacramento, Califormia.

(d) Experimental; for design.

(e) Four models were involved in the study of the Pine Flat spillway: (1) a 1:60 comprehensive model; (2) a 1:40 section model of the spillway crest; (3) a $1: 18$ model of a conduit outlet portal in the lower tier of conduits; and (4) a 1:18 model of one of the conduits in the upper tier. Special attention was given in the tests to the hydraulic characteristics of the crest, flow from the conduits, and to the effectiveness of the flip bucket in deflecting the water away from the toe of the dam. Pressures on the crest and discharge coefficients were thoroughly investigated because the crest was designed to fit the lower nappe for a head only 75 per cent as great as the maximum head expected. A deflector block was used in the downstream end of each conduit in the lower tier to spread the discharge onto the surface of the tailwater.

(f) Testing completed.

(g) Negative pressures on the crest were not excessive for any discharge condition. The adequacy of the 50-foot-radius flip bucket to deflect flow was confirmed. Alterations to the alignment of the upper tier of sluices and to the outlet portal of the lower tier of sluices improved flow conditions.

(h) Final report in preparation.

(993) CAVITATION RESEAKCH.

(b) Office of the Chief of Engineers, Department of the Army, Washington, D. C.

(d) Experimental; applied research.

(e) Cavitation characteristics of such elements as baffle piers, steps in stilling basins, gate slots, and offset joints are being studied on models installed in a vacuum tank and in a variable pressure water tunnel. Models tested to date have been generally of three types: (1) offsets away from flow; (2) V-notch construction joints; and (3) gate slots. Reviews of existing literature also are under way to evaluate the many variables which affect cavitation results.

(g) Results of tests indicate that the point of incipient cavitation varies with the scale of the model when cavitation results from vortex or eddy type flow. When cavitation exists at a zone of separation the variation in the point of incipient cavitation as a function of model scale is reduced.

(994) EFFECTS OF MODEL DISTORTION.

(b) Office of the Chief of Engineers, Department of the Army, Washington, D. C.

(d) Experimental; applied research.

(e) A general study is being made to determine the effects of model distortion on velocity distribution and other hydraulic conditions. A series of tests has been completed in a triangular flume having an adjustable central angle and adjustable slope. Additional studies are in planning stage.

(g) The initial results are being analyzed for incorporation in a report.

(995) STMULATION OF AIR ENTRAINMENT IN MODELS INVOLVING HIGH VELOCITY FIOW.

(b) Office of the Chief of Engineers, Department of the Army, Thashington, D. C.

(d) Experimental; applied research.

(e) This investigation comprises a series of studies to determine: (1) the spread of the boundary layer in accelerating flow; (2) the effect of air entrainment on stilling basin performance; and (3) the relationship between air demand in a model and prototype sluice.

(f) Suspended.

(g) Results of boundary layer studies conducted at the University of Iowa on a contract basis permit the prediction of boundary layer development in accelerating flow such as that encountered in flow over a spillway.

(998) STUDY OF WAVE FORCE ON BREAKINTERS.

(b) Office of the Chief of Engineers, Department of the Army, Washington, D. C. 
(d) Experimental; applied research.

(e) A general investigation of wave phenomena and resulting forces is being conducted in a wave tank to develop formulas, supported by experimental data, from which wave pressures on impervious surfaces, vertical and inclined, can be determined.

(g) Suitable pressure measuring and recording apparatus have been obtained.

(999) STABIIITY OF RUBBLE-MOUND BREAKNATERS.

(b) Office of the Chief of Engineers, Department of the Army, Whington, D. C.

(d) Experimental; applied research.

(e) Rubble-mound structures are studied in a wave tank to determine size of cap rock and slope of mound necessary to withstand action of waves and to develop formulas, supported by experimental data, from which the action of waves on rubble structures can be determined. Test data will be presented in dimensionless form, therefore no model scale, as such, is being utilized.

(g) The Iribarren formula for design of mbble breakwaters is being used as a basis for correlating the results of these tests. Coefficients $\left(\mathrm{K}^{\prime}\right)$ have been determined for use with Iribarren formula for rubble breakwaters with no overtopping for seaside slopes from $I$ on $1-1 / 4$ to $I$ on 4 and $d / L$ ratios from 0.10 to 0.50 . It was found that $K^{\prime}$ varied considerably with slope $(\alpha)$ but very little with the $d / I$ ratio. Average values of $K^{\prime}$ for different slopes are as follows:

\begin{tabular}{ll} 
Side Slope & $\mathrm{K}$ \\
\hline 1 on $1-1 / 4$ & 0.003 \\
1 on $1-1 / 2$ & 0.008 \\
1 on 2 & 0.017 \\
1 on $2-1 / 2$ & 0.028 \\
1 on 3 & 0.036 \\
1 on 4 & 0.033
\end{tabular}

A few tests have been conducted in which tetrapods were used instead of rubble. Results of these tests are incomplete, but indicate that tetrapods are considerably more efficient on a volume basis than rubble.

(1000) ROUGHNESS STA NDARDS FOR HYDRAUIIC MODELS.

(b) Office of the Chief of Engineers, Department of the Army, Washington, D. C.

(d) Experimental; applied research.

(e) A general study is being conducted to evaluate resistance of definite types of roughness in terms of Manning's " $n$ " and other parameters, so that much of the trial-and-error process of adjusting the surface roughness of river models can be eliminated. Tests have been performed in three rectangular flumes and a triangular flume.

(h) "Roughness standards for hydraulic models, Report No. 1: Study of finite boundary roughness in rectangular flumes." haterways Experiment Station Technical Memorandum No. 2364, June, 1953. (Available on loan.)

(1001) SCALE EFFECTS ON SPILIWAY DISCHARGE COEFFICIENS.

(b) Office of the Chief of Engineers, Department of the Army, Washington, D. C.

(d) Experimental; applied research.

(e) Tests were conducted on ogee and sharp-crested weirs to permit comparison of spillway discharge coefficients obtained from models of different scales. Tests to determine effect of variation of viscosity from a high of 220 centipoises to about 3 centipoises also were completed.

(g) Tests to determine effect of surface tension on discharge coefficients of spillways revealed no appreciable effect in small-scale spillway models. Analysis of viscosity data has not progressed sufficiently to permit conclusions.

(1002) SCALE EFFECTS IN HARBOR MODELS.

(b) Office of the Chief of Engineers, Department of the Army, Whington, D. C. 
(d) Experimental; applied research.

(e) Tests will be conducted to determine effects of various model scales and distortion on wave characteristics in a harbor.

(f) Suspended.

(1004) INSTRUMENTATION.

(b) Office of the Chief of Engineers, Department of the Army, Whington, D. C.

(d) Experimental; development.

(e) Various types of instruments for use in hydraulic models are being developed to make such measurements as those of wave heights, dynamic fluid pressures, and gate vibration and downpull. Development of an improved tidal reproducing apparatus is in progress.

(1207) MODEL STUDY OF PENSTOCK INTAKE AND SLUICE COASTER GATES.

(b) Office of the Chief of Engineers, Department of the Army, Whington, D. C.

(d) Experimental; applied research.

(e) A general study of relative merits of various penstock intake and sluice coaster gate lip shapes, seals and recesses is being conducted. The investigation includes determination of downpull effects of changes in gate-lip shape, length and shape of seals, size and shape of the recess in the face of the dam, and need for an air vent in the entrance. The 1:20 model of the sluice coaster gate is being tested in combination with a typical sluice which includes a slide gate, standard entrance curves conforming to the elliptical equation $\left(x^{2} / D^{2}\right)+\left(y^{2} /(D / 3)^{2}\right)=1$, and a removable constriction at downstream end of sluice.

(g) Tests of the sluice coaster gate with various slide gate openings and sluice exit conditions revealed greatest downpull forces at coaster gate openings of 2 to 4 feet. The slide gate and air vent were then moved upstream $15 \mathrm{ft}$ and tested to determine the ef fect, if any, of location on the over-all performance of the coaster gate. Moving the slide gate 15 feet closer to the intake was found to have little or no effect on the over-all performance of the sluice gate.

(1209) MODEL STUDY OF BELTON DAM, LEON RIVER, TEXAS.

(b) The District Engineer, Fort Worth District, Corps of Engineers, Fort Worth, Texas.

(f) Completed.

(h) "Spillway for Belton Dam, Leon River, Texas; Hydraulic model investigation." haterways Experiment Station Technical Memor andum No.2-363, April, 1953. (Available for loan.)

(1210) MODEL STUDY OF GRAYS HARBOR, WASHINGTON.

(b) The District'Engineer, Seattle District, Corps of Engineers, Seattle, hishington.

(d) Experimental; for design.

(e) The fixed-bed model, scales 1:800 horizontally and 1:80 vertically, reproduced the Pacific Ocean area adjacent to the harbor entrance and the tidal portion of the harbor and Chehalis River. This model was used to develop a comprehensive plan to protect the existing south jetty from the undermining effects of tidal currents, and to protect Point Chehalis from erosion by current and wave action. Upon completion of this part of the investigation a portion of the model was converted to a movable-bed type to determine scour and shoal tendencies of the selected plan. Plans for reduction of shoaling in the 30-foot-deep navigation channel were also studied.

(f) Inactive.

(1211) MODEL STUDIES OF HOOSIC RIVER, ADAMS AND NORTH ADAMS, MASSACHUSETTS.

(b) The District Engineer, New York District, Corps of Engineers, New York, New York.

(d) Experimental; for design. 
(e) Two models were used to verify the hydraulic design for improvement of certain sections of the North and South Branches of Hoosic River in North Adams, Massachusetts, and of the main channel in Adams, Massachusetts, and to determine whether changes should be made for safety, increased efficiency, or economy. The flow in the major portion of these channels will be below critical depth. In Phase 1 of the study a 1:30 model reproduced the lower sections of the North and South Branches and about 1300 feet of the main stream below the confluence of the North and South Branches. In Phase 2 North Branch was extended to include the control weir at the upstream limit of the improvement works for North Adarns. A l:20 model reproduced a section of the main channel beginning in Adams approximately 8 miles above that reproduced in the 1:30 model. About 1200 feet of Tophet Brook, which joins the Hoosic River, was also reproduced.

(f) Tests on Phase 1 of the 1:20 model of the main channel in Adams, Massachusetts, and of Phase 1 on the 1:30 model of the North and South Branches of Hoosic River in North Adams, Massachusetts, have been completed. Tests on the initial plan of improvement of phase 2 on the 1:30 model also have been completed. Additional tests are contemplated for phase 2 of the Adams model.

(g) The stilling basin as designed for the North Adams section was found unsatisfactory and a basin was developed that produced the desired flow conditions. Design of the curves and superelevation for the bends in Phase 2 of the North Adams model were demonstrated to be satisfactory. The design and location of the stilling basin in the main channel at Adams were verified. Flow conditions at the junction of Tophet Brook and the culvert flume feeding into the brook were greatly improved and the turbulence existing in the Hoosic River below the mouth of Tophet Brook was eliminated.

(1212) MODEL STUDIES OF OUTLET WORKS, OAHE DAM, MISSOURI RIVER, SOUTH DAKOTA.

(b) The District Engineer, Omaha District, Corps of Engineers, Omaha, Nebraska.

(d) Experimental; for design.

(e) Two models are being used for complete investigation of the outlet works proposed for Oahe Dam. A 1:60 model, reproducing the downstream portion of six 18.5-foot-diameter outlet tunnels, the stilling basin, and 2300 feet of the discharge and pilot channels, is being used to investigate the performance of the outlet works and to effect revisions demonstrated to be desirable. A $1: 25$ model of the upstream portion of one of the tunnels, the control structure located in the center of the embankment, and a short length of the tunnel downstream is being used to: (1) check piezometric pressures at various points in the intake structure and transition, particularly pressure variations in the bulkhead slot area; (2) determine the effect of curvature on flow conditions in the upstream tunnel and critical areas downstream therefrom; (3) check piezometric pressures at various points in the gate chamber of the control shaft and the upstream and downstream transitions, with particular attention to pressures near the gate slots; (4) study the forces acting on the service gate and effects of such forces on gate operation; and (5) measure air demand characteristics.

(g) A single stage stilling basin was developed on the 1:60 model which performed satisfactorily. However, foundation problems encountered in the field made it desirable to consider use of a double stage stilling basin located at a higher elevation. The model tests indicated the length of the primary basin and the secondary basin could be reduced from the lengths proposed. The height and length of the dividing piers separating each conduit also could be reduced.

(1467) ANALYSIS OF HYDRAULIC EXPERIMENTAL DATA (MODEL AND PROTOTYPE) AND DEVELOPMENT OF DESIGN CRITERIA.

(b) Office of the Chief of Engineers, Department of the Army, Whinington, D. C.

(d) Experimental and field investigations; for design.

(e) A general study to develop, analyze, and disseminate to Corps of Engineers establishments design criteria for hydraulic structures to insure adequate hydraulic capacity, economy of construction and safe and satisfactory operation. Criteria are developed from model tests and prototype observations relating to the design of spillways, outlet works and gates and valves. Program also includes hydraulic design criteria for navigation structures, flood-control channels and natural waterways.

(g) Hydraulic design charts relating to air demand in outlet works, spillways, and gates and valves have been completed. 
(1458) VAIDIVIA RIVER MODEL STUDY, CORRAL BAY, CHILE.

(b) Government of Chile, South America.

(d) Experimental; for design.

(e) Model study is to determine whether training works or other remedial measures will make possible the maintenance of a channel at least 6 meters deep over the entrance bar from the Port of Corral to the Valdivia River mouth, and to determine the effect such structures might have on present depths and widths of Corral Harbor. The movable-bed model, with scale ratios of 1:400 horizontally and 1:80 vertically, reproduces Corral Bay upstream from Point San Carlos and the lower 3 miles of both the Valdivia and Tornagalenes Rivers.

(f) Testing completed.

(g) A plan consisting of a 7,900-foot-long training dike, beginning at Mancua Island and extending toward deep water in Corral Bay, would provide a navigation channel of at least 2l-foot depth across the outer bar. The training wall should be accompanied by a dike 1000 feet long at Point Niebla to prevent shoaling of the entrance channel by the littoral transport of sand in Corral Bay.

(h) Final report in preparation.

(IL59) MODEL STUDY OF FIOOD-CONTROL PROJECT, ALLENTOWN, PENNSYLVANIA.

(b) The District Engineer, Philadelphia District, Corps of Engineers, Philadelphia, Pennsylvania.

(d) Experimental; for design.

(e) The proposed local improvement plan at Allentown was studied to discover and correct any undesirable features of the plan. The fixed-bed model, scales of 1:150 horizontally and 1:50 vertically, reproduces 3 miles of Lehigh River and I mile each of Little Lehigh Cre and Jordan Creek.

(f) Testing completed.

(g) Modifications in alignment and location of the closure and training dikes, and in the amount and location of dredging as outlined in the original proposed improvement plan were developed.

(h) Final report in preparation.

(1470) NIAGARA RIVER AND FALIS MODEL STUDY.

(b) The District Engineer, Buffalo District, Corps of Engineers, Buffalo, New York.

(d) Experimental; for design.

(e) Use of the Niagara River for power development and other purposes is controlled by treaty between the United States and Canada which includes a specific allotment of the waters for preservation of the scenic beauty of the Falls. Proposed redevelopment of the Niagara River for power includes large increases in diversion and redistribution of flow in the cascades to preserve the beauty of the Falls. A fixed-bed model was used to determine the effects of the proposed redevelopment and remedial works required for efficient power diversion and maintenance of adequate river flows. All features of Niagara River from Lake Erie to below the Falls were reproduced to scales of 1:360 horizontally and $1: 60$ vertically.

(f) Testing completed.

(g) The location and length of control structure at the head of the cascades necessary to control natural elevations in Grass Island pool were determined. The design of remedial works near the crest of the Horsehoe Falls, with a view toward obtaining the desired distribution of flow under flow conditions provided by recent treaty, has been accomplished.

(h) Final report in preparation.

\section{(1471) HYDRAULIC MODEL STUDY OF SAVAGE RIVER DAM SPILLWAY.}

(b) The District Engineer, Washington District, Corps of Engineers, Washington, D. C.

(d) Experimental; for design.

(e) Model tests of the side-channel spillway were conducted on a $1: 36$ model to determine the discharge rating curve and other hydraulic characteristics of the spillway at heads greater than that for which the spillway was originally designed because the spillway design flood for this dam has been increased.

(f) Testing completed. 
(g) The increase in head on the spillway did not result in dangerous pressure conditions.

(h) Final report in preparation.

(1472) MODEL STUDY OF WAVE ACTION, INDIANA HARBOR, INDIANA.

(b) Youngstown Sheet and Tube Company, and Inland Steel Company, Indiana Harbor works, East Chicago, Indiana.

(d) Experimental; for design.

(e) A l:150 fixed-bed model of Indiana Harbor and sufficient area of Lake Michigan to permit reproduction of waves from north-northwest to southeast is being used. Effects of proposed harbor structures on wave action conditions in the entrance channel and in the harbor are being studied.

(山73) MODEL STUDIES OF FOLSOM DAM, AMERICAN RIVER, CALIFORNIA.

(b) The District Engineer, Sacramento District, Corps of Engineers, Sacramento, Califormia.

(f) Completed.

(h) "Spillway for Folsom Dam, American River, California; Hydraulic model investigation." Waterways Experiment Station Technical Memorandum No.2-369, August, 1953. (Available on loan.)

(1474) OPERATING FORCES OF MITER-TYPE LOCK GATES.

(b) Office of the Chief of Engineers, Department of the Army, Washington, D. C.

(d) Experimental; applied research.

(e) A general study to collect basic data on operating forces of miter-type lock gates and to determine the effect of various elements upon the se forces is being conducted in a 1:20 model. A lock chamber $110 \mathrm{ft}$ wide is reproduced with provisions for varying the length up to $500 \mathrm{ft}$ on each side of the gate. Forces required for operation of miter gates will be measured for variations of the following elements: gate leaves, speeds and accelerations of operation, submerged depths, recess shapes, bottom clearances, chamber lengths, and nonsynchronous operation of gate leaves. Variations in the type linkage driving the gate also will be investigated.

(g) Tests indicate that with the Ohio River type linkage the peak torque occurs as the gates enter or leave the mitered position. Nonsynchronous operation of the gates resulted in a slight decrease in torque on the leading leaf and a lesser effect on the lagging leaf, as compared with synchronous operation. An increase in the speed of operation or depth of submergence increases the peak torque. Bottom clearances had little effect on torque values. With the modified Ohio River type linkage the peak torque occurs near the mitered position as was noted with the standard Ohio River linkage. The peak torque of the modified type linkage is somewhat less than that of the Ohio type linkage but the average torque is higher and better distributed. Addition of skin plates on the downstream face of the lock gates with the modified type linkage resulted in a slight decrease in torque. Tests with the Panama type linkage indicated that the high initial torque at the recess position was greatly reduced and distributed more evenly throughout the operating cycle.

(h) Advance Report No. 1, "Operating forces on miter-type lock gates" CW 300, June, 1950. Advance Report No. 2, "Operating forces on miter-type lock gates" CW 300, June, 1951.

(1475) SIPHON ACTION AT PUIPING PIANIS.

(b) Office of the Chief of Engineers, Department of the Army, Washington, D. C.

(d) Experimental; applied research.

(e) A general study is being made of the operating characteristics of siphons operated in connection with pumping plants. The test apparatus consists of 6 -inch-diameter plastic tubing with a lift of 30 feet. The effect of various head-tailwater relationships on priming characteristics, the air demand required to break the siphonic action, and the effect of constriction or reduction in area of the discharge leg of the siphon are to be determined. Investigations also will concern: (1) effect of deflector blocks in the crown of the siphon; (2) effect of vents in the riverward leg to decrease the time of priming; (3) effect of length and slope of riverward leg; and (4) effect of tailwater elevation.

(g) Comparison of results of tests with data procured from field observations on other size siphons indicates that data from the 6-inch tubing can be extrapolated to other sizes with a reasonable degree of accuracy. 
(1735) MODEL STUDY OF WAVE RUN-UP ON SHORE STRUCTURES.

(b) The Resident Member, Beach Erosion Board, Corps of Engineers, Washington, D. C.

(d) Experimental; for design.

(e) Tests are being conducted in a wave flume, using a scale of $1: 17$, to investigate the relationship between water level, wave height, wave period and beach slope and wave mun-up on selected types of shore structures used to prevent erosion caused by wave action.

(g) Tests have shown that the volume of overtopping water and height of wave run-up vary with both wave height and length. The variation is discontinuous. The volume of overtopping water and height of wave run-up vary in cycles from minimum to maximum and increase as wave height and wave length increase.

(1736) MODEL STUDY OF EFFECTS OF INLETS ON ADJACENT BEACHES.

(b) The Resident Member, Beach Erosion Board, Corps of Engineers, Washington, D. C.

(d) Experimental; applied research.

(e) To determine the effects of natural or artificial inlets on adjacent beaches for various conditions of waves, tides, rate of littoral drift, and other factors, tests are being made in a basin simulating an ocean and a lagoon separated by a barrier beach of sand that can be breached to reproduce the desired inlet.

(1737) MODEL STUDY OF CHAIN OF ROCKS PROJECT, MISSISSIPPI RIVER.

(b) The District Engineer, St. Louis District, Corps of Engineers, St. Louis, Missouri.

(d) Experimental; for design.

(e) The Chain of Rocks reach, a 7-mile-long series of rock ledges, is the principal cause of navigational difficulties in the 15 miles between the mouth of the Missouri River and the city of St. Louis. An improvement plan, involving a long canal from the vicinity of the mouth of the Missouri with a navigation lock at is downstream end, was studied in a combination movable-bed fixed-bed type model with scales of 1:400 horizontally and 1:100 vertically. Means were investigated of reducing the silting in the lower approach channel to the canal and of removing and preventing the rebuilding of a bar across the downstream canal entrance.

(f) Testing completed.

(g) Water-surface profiles for bankfull flow and for the crest of the 1947 flood were satisfactorily reproduced in the model, and the qualitative reproduction of silting that occurred in the lower approach channel of the canal during and after the $1947 \mathrm{flood}$ was accomplished. Fixed-bed tests indicated that silting in the downstream entrance to the canal would obtain with each of three proposed alignments of spoil area on Cabaret Island. Efforts to flush out this deposited material by operation of the vertical-lift lock gates at stages of 20 feet and lower on the St. Louis gage were not successful. Flood heights, using the 1947 crest, were not raised appreciably with any of the spoil-area alignments. The design of remedial works to materially decrease shoaling at the lower entrance to the Chain of Rocks canal was accomplished in movablebed tests.

(h) Final report in preparation.

(1738) MODEL STUDY OF GREENUP IOCKS AND DAM, OHIO RIVER.

(b) The District Engineer, Huntington District, Corps of Engineers, Huntington, West Virginia.

(d) Experimental; for design.

(e) A l:120 model of the nonnavigable-type dam and twin parallel locks was used to determine the best arrangements of locks and appurtenant walls, to study approach conditions under various flows and methods of operation of control gates, and to demonstrate to navigation interests the acceptability of the proposed design from a navigation standpoint.

(f) Testing completed.

(g) Results indicate that approach conditions would be better with the main lock on the river side, with modifications in the dimensions of the lock walls, and with ports in the upper guard wall.

(h) Final report in preparation. 
(1739) MODEL STUDIES OF MARKIAND IOCKS AND DAM, OHIO RIVER.

(b) The District Engineer, Louisville District, Corps of Engineers, Louisville, Kentucky.

(d) Experimental; for design.

(e) A comprehensive 1:120 model of the nonnavigable-type dam and twin parallel locks, and a 1:25 section model of the spillway and stilling basin constructed to: (1) determine the best arrangements of locks and appurtenant walls; (2) study approach conditions under various flows and methods of operation of control gates; (3) demonstrate to navigation interests the acceptability of the proposed design from a navigation standpoint; (4) investigate the design of the spillway and stilling basin structures.

(f) Testing completed.

(g) Satisfactory arrangement of lock walls, method of operation of lock gates, location for Stevens Creek diversion channel outlet, and design of spillway and stilling basin were developed.

(h) Final report in preparation.

(1740) MODEL STUDY OF OUTLET STILLING BASIN, TUTTLE CREEK DAM, BIG BLUE RIVER, KANSAS.

(b) The District Engineer, Kansas City District, Corps of Engineers, Kansas City, Missouri.

(d) Experimental; for design.

(e) A 1:25 model was used to check the adequacy of design and effect improvements in flow in the outlet stilling basin with both partial and full operation of the two gate-controlled conduits. Special attention was given to: (1) vibration tendencies of the vertical slide gates used to control flow at the upstream end of the conduits, and (2) necessity for outlet transitions at the junction of the conduit and stilling basin.

(f) Testing completed.

(g) The model tests indicated the possibility of shortening by 50 feet the dividing wall between the twin stilling basins, and raising the elevation of the stilling basins 5 feet. Use of outlet transitions at the ends of the conduits did not appear to improve flow conditions in the stilling basins and were considered unnecessary.

(h) Final report in preparation.

(17LI) MODEL STUDY OF SPILLWAY, GAVINS POINT DAM, MISSOURI RIVER, SOUTH DAKOTA.

(b) The District Engineer, Omaha District, Corps of Engineers, Omaha, Nebraska.

(d) Experimental; for design.

(e) A 1:50 model was used to investigate the hydraulic performance of the spillway; to verify elevation and length of stilling basin required for the proper formation of the hydraulic jump; to determine the adequacy of the wall heights for the chute and stilling basin; and to observe the over-all hydraulic performance of the stmucture.

(f) Testing completed.

(g) Flow conditions in the spillway approach area and discharge characteristics were improved by placing an embankment in the area upstream of the left abutment. Stillingbasin tests indicated that satisfactory energy dissipation was obtained in the stilling basin as originally designed.

(h) Final report in preparation.

(1978) MODEL STUDY OF STILLING BASIN, NEW CUMBERLAND IOCKS AND DAM, OHIO RIVER, PENNSYLVANIA.

(b) The District Engineer, Pittsburgh District, Corps of Engineers, Pittsburgh, Pennsylvania.

(c) Experimental; for design.

(e) A $1: 36$ section model is being used to study the hydraulic characteristics of the spillway stilling basin as designed, and to determine what changes are desirable particularly with respect to the elevation of the stilling basin and the type and spacing of baffle piers and end sill.

(f) Testing completed.

(g) An adequate basin was developed and considerable saving in construction cost effected by reducing the basin length 15 feet and rearranging the location of the baffle piers.

(h) Final report in preparation. 
(1979) MODEL STUDY OF STILLING BASIN, BULI SHOALS DAM, WHITE RIVER, ARKANSAS.

(b) The District Engineer, Little Rock District, Corps of Engineers, Iittle Rock, Arkansas.

(d) Experimental; for design.

(e) The spillway was constructed with a stepped-type stilling basin designed to spread the jets issuing from the conduits. After a period of operation the steps were damaged by cavitation. A l:I2 model is being used to develop a satisfactory method of repairing the basin for conduit discharges; a 1:50 model is to be used to check the performance of the modified design basin with spillway discharges.

(f) Active.

(g) Negative pressures and resulting cavitation tendencies in the stilling basin have been eliminated by filling in the steps of the original basin to form a long sloping floor. Tests have demonstrated that spreading of the conduit jets can be accomplished by increasing the end sill height from 4 feet to 10 feet and installing a single row of 8foot-high baffle blocks about 50 feet upstream from the end sill.

(1980) MODEI STUDY OF STILIING BASIN, TABLE ROCK DAM, WHITE RIVER, MISSOURI.

(b) The District Engineer, Iittle Rock District, Corps of Engineers, Little Rock, Arkansas.

(d) Experimental; for design.

(e) A 1:50 section model of the stilling basin will be used to determine the adequacy of the basin for spillway flow, and a 1:12 model of the stilling basin will be used for tests of the basin under conduit flow.

(f) Tests temporarily suspended while test facilities are being used for study of Bull Shoals Dam stilling basin.

(1981) MODEL STUDIES OF SPILITAY FLIP BUCKET AND CONDUIT OUTLET PORTAL, HARTWELI DAM, SAVANNAH RIVER, GEORGIA.

(b) The District Engineer, Savannah District, Corps of Engineers, Savannah, Georgia.

(d) Experimental; for design.

(e) A I:45-section model is being used to develop a feasible and economical design for the spillway flip bucket and the training wall between the flip bucket and powerhouse. A 1:20 model of the conduit outlet portal is being investigated to assure satisfactory spreading of the jet, pressures, and discharge.

(g) A spillway flip bucket of 30-foot radius and 30-degree lip discharge angle was developed as the most economical design consistent with satisfactory performance. A 5-degree deflector wall was placed between the powerhouse and the dam in order to divert the spillway jet from the powerhouse and tailrace. A design has been developed for the sluice outlet portal which uses a reverse slope in the floor and flared side walls to accomplish spreading of the jet.

(1982) MODEL STUDY OF CONTROL STRUCTURE AT MOUTH OF OID RIVER, IOUISIANA.

(b) The President, Mississippi River Commission, Corps of Engineers, Vicksburg, Mississippi.

(d) Experimental; for design.

(e) The old River control structure will control flow into old River, which links the Mississippi and Atchafalaya Rivers, so that Mississippi River flows will be divided between the lower reaches of the Mississippi and Atchafalaya. Tests are being made on a 1:35 model to investigate the over-all performance of the proposed stmucture with special attention to discharge coefficients, flow conditions at the abutments, and the effectiveness of the stilling basin.

(g) Tests to date indicate that improved flow conditions can be obtained by realignment of the upstream and downstream training walls. Also it was demonstrated that the horizonta] stilling basin could be raised from elevation $-12.0 \mathrm{msl}$ to elevation $-5.0 \mathrm{msl}$.

(1983) MODEL STUDY OF SEDTMENT DIVERSION AT THE MOUTH OF OID RIVER, IOUISIANA.

(b) The President, Mississippi River Commission, Corps of Engineers, Vicksburg, Mississippi. (d) Experimental; for design. 
(e) A 10-mile reach of the Mississippi River upstream of the mouth of old River is reproduced in a fixed-bed model to scale ratios of 1:400 horizontally and 1:100 vertically. Tests are being made to determine a suitable location for a control structure that will permit the same percentage of sediment to enter the Atchafalaya River as now enters that stream through Old River, should Old River be closed with a lock and dam.

(f) Testing completed.

(g) Tests indicated that the proposed location for the control structure would be satisfactory insofar as sediment diversion is concerned and that the relative positions of the low-sill and high-sill sections of the structure should be reversed to improve flow conditions during higher stages. Satisfactory modifications in the alignment and dimensions of the approach channel were developed.

(h) Final report in preparation.

(1984) MODEL STUDY OF CONTROL GATE FOR TUNNEL NO. 4, FORT PECK DAM, MISSOURI RIVER, MONTANA.

(b) The District Engineer, Fort Peck District, Fort Peck, Montana, and the District Engineer, Garrison District, Corps of Engineers, Bismarck, South Dakota.

(c) Experimental; for design.

(e) Tests to study methods of eliminating cavitation on the port liner and vibration of the cylinder gate in the main control shaft of tunnel No. 4 will be conducted on a 1:25model. Discharge capacities, pressures, air demand, and gate vibration will be determined for the existing cylinder gate installation, a vertical lift gate installation, and a tainter gate installation.

(g) In construction phase.

(1985) DEVELOPMENT OF TURBULENCE METER.

(b) Office of the Chief of Engineers, Department of the Army, Washington, D. C.

(d) Experimental; development.

(e) The investigation is being conducted to develop instruments that will: (a) indicate the speed and direction of fluid currents at great depths and moderate velocities; (b) indicate the speed and direction of currents at shallow depths and high velocities; (c) receive signals from (a) or (b) and separate them into (l) instantaneous velocity and direction; (2) mean velocity and direction, and (3) the root-mean-square deviations from the mean.

(f) Suspended pending a review of the status of the developmental work on each phase.

(1986) MODEL STUDY OF SALINITY PHENOMENA UNDER INFLUENCE OF TIDES.

(b) Committee on Tidal Hydraulics, Corps of Engineers (Correspondence should be addressed to Mr. C. F. W cker, Chairman, Committee on Tidal Hydraulics, Philadelphia District, Corps of Engineers, Philadelphia, $\mathrm{Pa}$. ).

(d) Experimental; applied research.

(e) To determine the effects of salinity and related phenomena on the vertical distribution of currents and shoaling characteristics in estuaries, tests are being made in a lucite flume 327 feet long, 1.5 feet deep, and 0.75 foot wide. One end of the flume is connected to a 25-foot-square tidal basin in which any desired tide may be produced and in which the salinity may be controlled. The opposite end is connected to a fresh-water source.

(1987) MODEL REPRODUCTION OF PROTOTYPE EROSION BELOW STILIING BASINS.

(b) Office of the Chief of Engineers, Department of the Army, Washington, D. C.

(d) Experimental; applied research.

(e) Initially, the investigation will be conducted on a model of a selected dam with provisions for studying sands of different sizes in the channel below the stilling basin. Later, models with two or more different linear scales will be constructed to verify findings using various suitable bed materials.

(g) Preliminary design and layout in preparation. 
(1988) WATER TEMPERATURE EFFECTS ON BED FORMS AND ROUGHNESS.

(b) Office of the Chief of Engineers, Department of the Army, Washington, D. C.

(d) Experimental; applied research.

(e) Existing laboratory flumes, in which water temperatures can be varied to simulate normally experienced summer and winter temperatures, will be used for investigating the effects of water temperature on bed forms and bed roughness of various types of bed materials.

(g) Preliminary design and layout in preparation.

U. S. DEPARTMENT OF COMMERCE, BUREAU OF PUBLIC ROADS.

(568) SCOUR AT BRIDGE PIERS AND ABUTMENTS.

Cooperative with Iowa Institute of Hydraulic Research. See page 43.

(1101) MOVEMENT OF SEDTMENT IN HIGHWAY DRAINAGE SYSTEMS.

Cooperative with Iowa Institute of Hydraulic Research. See page 44.

(1383) MODEL STUDIES OF TAPERED INLETS FOR BOX CULVERTS ON STEEP GRADES.

Cooperative with Oregon State College. See page 70.

(1590) FREQUENCY STUDY OF HYDROLOGIC DATA.

Cooperative with University of Illinois. See page 40.

(1597) A STUDY OF THE EFFICIENCY OF SAND TRAPS.

Cooperative with Iowa Institute of Hydraulic Research. See page 46.

(1654) MODEL INVESTIGATION OF FISH LADDERS IN BOX CULVERTS.

Cooperative with Oregon State College. See page 70.

(1925) EFFECT OF INLET DESIGN ON CULVERT CAPACITY.

Cooperative with St. Anthony Falls Hydraulic Laboratory. See page 79.

(1945) ESTIMATING RAINFALI INTENSITY FROM TOPOGRAPHIC PARAMETERS.

Cooperative with Stanford University. See page 84.

U. S. DEPARTMENT OF COMMERCE, NATIONAL BUREAU OF STANDARDS, Fluid Mechanics Section.

Inquiries concerning Projects Nos. 159, 160, 1217, 1477 to 1480, inc1., 1482, 1742, 1989 and 1990, should be addressed to the Chief, Fluid Mechanics Section, National Bureau of Standards, washington 25, D. C.

(159) MODEL LALS FOR DENSITY CURRENTS.

(b) Waterways Experiment Station, Corps of Engineers, Department of the Army.

(d) Theoretical and experimental; basic and applied research. 
(e) To determine model laws for models involving the motion of stratified liquids. The two major problems are ( 1 ) the motion of a heavy liquid initially confined in a "lock" when released into a long channel containing a stationary lighter liquid, and (2) the motion of a heavy liquid from a "sea" into a long channel with either still or flowing lighter liquid.

(160) EFFECT OF STORM WINDS ON LAKE LEVELS.

(b) Laboratory project.

(d) Theoretical and experimental; basic research.

(e) To determine frictional forces of wind on lake surfaces and the resulting set-up.

(685) ORIFICE METERS.

(b) Cooperative with American Gas Association, American Society of Mechanical Engineers, and Bureau of Ships, Department of the Navy.

(c) Mr. Howard Bean, National Bureau of Standards, Washington 25, D. C.

(d) Experimental; applied research.

(e) To obtain information on installation requirements of orifices, flow nozzles, and venturi tubes with special reference to (1) using shorter meter runs than now recommended; (2) the effects of globe and plug valves preceding an orifice, and (3) possible development of a field method of evaluating pipe roughness.

(f) Completed.

(h) Final report in press. (Available American Gas Association, 400 Lexington Avenue, New York 18, N. Y.)

(1217) OPEN CHANNELS WITH UNIFORMIY DISTRIBUTED FLOW.

(b) Laboratory project.

(d) Experimental; basic and applied research.

(e) To determine surface curves, velocity distribution, and friction laws for channels in which the inflow is uniformly distributed along the length of the channel.

(1477) TURBULENT EXPANSION OF JTTS IN WATER.

(b) Office of Naval Research, Department of the Navy.

(d) Experimental and theoretical; basic research.

(e) To determine experimentally the nature of turbulent expansion of jets in water with relation to Reynolds number, using jets of hot water, salt water, etc.

(1478) WIND WAVES.

(b) Office of Naval Research, Department of the Navy.

(d) Experimental and theoretical; basic research.

(e) Includes mathematical and experimental studies of (1) wind tides (set-up), (2) growth of wind waves, and (3) surface traction of wi nd on wavy surfaces.

(h) Paper in preparation.

(1479) ENERGY DISSIPATION IN STANDING WAVES.

(b) Office of Naval Research, Department of the Navy.

(d) Experimental and theoretical; basic research.

(e) To determine significance of viscous boundary layer effects in wave phenomena.

( 1480$)$ POSITIVE WAVES IN DRY CHANNELS.

(b) Office of Naval Research, Department of the Navy.

(d) Experimental and theoretical; basic research.

(e) To determine mathematically velocity and form of waves taking friction into account. To analyze the tip of the wave mathematically, and to determine form of wave experimentally as function of time and roughness. 
(1482) INITIAL VELOCITY DISTRIBUTIONS IN SALT WATER WEDGE.

(b) Laboratory project.

(d) Experimental; basic research.

(e) To determine velocities and particle trajectories during initial motion when a gate separating two bodies of liquids of different densities is suddenly opened.

(1742) MECHANISM OF TURBULENCE.

(b) Office of Scientific Research, Air Research and Development Board.

(d) Experimental.

(e) To determine whether reproducible fundamental flow pattern occurring at initiation of turbulence can be demonstrated.

(1989) STABILTTY OF THE INTERFACE BETWEEN TWO PARALLEL STREAMS OF IMMISCIBLE FLUID OF DIFFERENT DENSTTIES.

(b) Office of Naval Research, Department of Navy.

(d) Theoretical.

(e) To determine the stability criterion of the free laminar boundary layer between two parallel streams of different densities.

(1990) INTERNAL PROGRESSIVE WAVES.

(b) Office of Naval Research.

(d) Theoretical and experimental.

(e) To determine laws of propagation and dissipation of internal progressive waves.

(h) "Characteristics of internal solitary waves." G. H. Keulegan, National Bureau of Standards Journal of Research, RP2442, Sept. 1953.

U. S. DEPARTMENT OF COMMERE, WEATHER BUREAU.

Inquiries concerning Projects Nos. 1010 to 1015, incl., 1743 to 1753 incl., and 1991 to 1994, incl., should be addressed to Mr. William E. Hiatt, Hydrologic Services Division, U. S. Weather Bureau, Washington 25, D. C.

(1010) ELECTRONIC FLOOD ROUTING ANALOGUE.

(b) Laboratory project.

(d) Field investigation; applied research.

(e) A basic circuit for an electronic analogue computer to solve flood wave problems has been developed and its application to the solution of local streamflow problems is being studied at the following River Forecast Centers: Cincinnati, Ohio; Knoxville, Tenn.; St. Louis, Mo.; Kansas City, Mo.; Tulsa, Okla.; Portland, Oregon; Harrisburg, and Pittsburgh, $\mathrm{Pa}$.

(h) "Electronic streamflow routing, Jpper Mississippi River," Phillip Light. Presented at American Geophysical Union Meeting, Minneapolis, Aug. 1953.

(1011) SHORT RANGE SNOW-MELT FORECASTING.

(b) Laboratory project.

(d) Field investigation; applied research.

(e) To develop relations between streamflow resulting from melting snow and appropriate meteorological parameters using a statistical approach.

(g) A reasonably adequate procedure has been established and is being refined and tested.

(1012) AUTOMATIC RADIO REPORTING RAIN GAGE.

(b) Laboratory project. 
(d) Field investigation; applied research.

(e) A simple telemetering device has been constmucted for use with a standard recording rain gage. Limited field tests indicate satisfactory performance. Other telemetering units are also being tested.

1013) PRESSURE-ACTUATED RIVER GAGE.

(b) Laboratory project.

(d) Field investigation; development.

(e) To develop a more economical remote, recording gage.

(g) Satisfactorily tested for accuracy in laboratory. Experiments continuing on telemetering system for remoting.

(1014) UTILIZATION OF SOIL MOISTURE DATA IN FORECASTING STREAMFIOW.

(b) Laboratory project.

(d) Field investigation.

(e) Standard electrical resistance soil moisture and temperature equipment has been installed in selected areas. After sufficient data has been obtained, statistical tests will be made to determine whether such data can be used to improve forecasts of munof from rainfall.

(1015) MEASUREMENT OF EVAPORATION.

(b) Laboratory project.

(d) Theoretical and field investigation; applied research.

(e) Studies are directed toward the derivations of reliable procedures for estimating evaporation from reservoirs (existing and proposed) and land surfaces, utilizing readily available meteorological data and pan evaporation observations.

(g) Test of methods and techniques at Lake Hefner, Okla., completed; and similar project being conducted at Lake Mead. Both are cooperative projects involving Bureau of Reclamation, Navy, Geological Survey as well as weather Bureau. Another such study is being started at Felt Lake, on contract with Stanford University. Evaporation pan comparative studies also being made at Silver Hill, Maryland.

(h) "Water-loss investigations: Vol. 1 - Lake Hefner studies technical report, "Geological Survey Circ. 229, 1952.

(1743) DEVELOPMENT OF IMPROVED RIVER FORECASTING METHODS.

(b) The Leland Stanford Jr. University, Stanford, Calif.

(d) Experimental; applied research.

(e) Investigate various methods of modifying the Electronic Streamflow Routing Analogue for use in river basins where the Muskingum Storage Equation does not give satisfactory results. Also, investigate relationship between observed soil moisture data and selected meteorological observations.

(g) A theoretical analogue circuit for the more complex routings has been developed; also a tentative relationship between antecedent precipitation and soil moisture in the upper $20 \mathrm{cms}$.

(1744) DEVELOPMENT OF RIVER FORECASTING METHODS.

(b) River Forecast Centers for Ohio River Basin, Cincinnati; Susquehanna and Delaware River Basins, Harrisburg, Pa.; Lower Missouri River Basin, Kansas City, Mo.; Tennessee River Basin, Knoxville, Tenn.; Columbia River Basin, Portland, Ore.; Middle and Upper Miss. River Basin, St. Louis, Mo.; and Arkansas River Basin, Tulsa, Okla.

(d) Experimental; applied research.

(e) To develop modern river forecast procedures for all ranges of flow for various streams of each basin. Procedures include (a) rainfall-munoff relations involving consideration of the physics of soil moisture, vegetative reception, transpiration, evaporation and geological features of the basins; (b) snow melt forecasting relation involving consideration of the physics of snow and heat transfer; (c) unit hydrographs; (d) streamflow routing procedures; based upon adaptations of basic hydraulic principles. 
(g) Forecasting procedures have been developed for key points; refinement of these procedures and derelopment for other basins are underway.

(h) "The celerity of very large flood waves in the Arkansas Basin." Charles D. Hopkins, Jr., Trans. Amer. Geophys. Union, Vol. 34, No. 4, pp 594-596, Aug. 1953.

"Flood forecasting on the Ohio River directly from rainfall." Roy E. Lundquist and Robert I. Fulk, to be published in Bull. Amer. Met. Soc.

"U. S. Weather Bureau snow cover observation program." Keith Butson, presented at iestern Snow Conference, Boise, April, 1953.

(1745) WATER SUPPLY FORECASTS FOR WESTERN UNTTED STATES.

(b) Wrk being conducted in field offices for River Forecast Center, Portland, Oreg.; Water Supply Forecast Unit, Salt Lake City, Utah; and River Forecast Center, Kansas City, Mo.

(d) Experimental; applied research.

(e) To develop precipitation-runoff relations for water supply forecasting utilizing statistical methods to correlate precipitation during the winter with runoff during the melting season.

(g) Water Supply Forecasts are prepared for over 300 points in the western United States. These forecasts of water year flow are released in Monthly Water Supply Forecast Bulletins January through May. This research program is of a continuing nature designed to improve and extend the present forecasting service.

(h) "The use of precipitation and snow survey data in water supply forecasting." Anthony J. Polos, presented at hestern Snow Conference, Boise, April, 1953.

(1746) FIOOD REPORT - MISSOURI AND UPPER MISS. RIVER BASINS - APRIL, 1952.

(b) Laboratory.

(d) Compilation and publication of hydrologic data.

(e) It is proposed to present in a special report all hydrologic and meteorological data associated with the occurrence of this disaster.

(h) IFloods of April, 1952 - Upper Mississippi, Missouri, Red River of the North." weather Bureau Tech. Paper No. 23, to be published early 1954 .

(1747) PROBABLE MAXIMUM FLOOD-PRODUCING CONDITIONS FOR THE SNAKE RIVER ABOVE HELIS CANYON DAM SITE.

(b) Conducted for Bureau of Reclamation.

(d) Applied research.

(e) Involves investigations of the optimum conditions for the probable maximum flood for the Snake River Basin above Hells Canyon Dam Site and four sub-basins, the Big Lost, Bmineau, Payette, and Powder river basins. These investigations include determination of the probable maximum rainstorm and its seasonal variation, the maximum amount of water stored in the basin in the form of snow, and the maximum amounts of heat available during the spring and early summer for melting the snow.

(f) Completed.

(h) "Critical meteorological conditions for design floods in the Snake River Basin." Cooperative Studies Report No. 11, Coop. Studies Section, Hydrologic Services Div., U. S. weather Bureau, Feb. 1953.

(1748) CENTRAL VALIEY PROJECT.

(b) Bureau of Reclamation.

(d) Applied research.

(e) Involves the development of a generalized procedure for quickly estimating the probable maximum precipitation over areas from 10 to l,000 sq. mi. on the west slopes of the Sierra Nevada from the Feather River Basin to the San Joaquin.

(g) Relation established for Western Sierra slopes above 1,000-ft. elevation; work continuing on relation for valley floor.

(1749) NEST COAST RAINFALI INTENSTTY-FREQUENCY PROJECT.

(b) Corps of Engineers. 
(d) Applied research.

(e) Involves determination of I-hour rainfall amounts expected to be equalled or exceeded once in 2, 5, and 10 years. Also includes derivation of relationships between the 1hour intensities and those for 5, 10, 15, 30, 120, and 240 mimutes.

(g) Project now extended eastward to 105th meridian.

(h) "Rainfall intensities for local drainage design in the United States for durations of 5 to 240 minutes and 2, 5, and 10-year return periods - Part I: West of the 115th meridian." Weather Bureau Tech. Paper No. 23, August, 1953.

(1750) CRITICAL METEOROLOGICAL ANALYSIS OF MAJOR STORMS.

(b) Corps of Engineers, Department of the Army.

(d) Basic research.

(e) Detailed hour-by-hour analysis of all meteorological data available during major rainstorms.

(f) Continuing.

(h) "An extraordinary rainfall centered at Hallett, Oklahoma." George A. Iott, Monthly Weather Review, Vol. 81, No. 1, Jamuary, 1953.

"The unparalleled thrall, Texas rainstorm." George A. Lott, Monthly weather Review, Vol. 81, No. 7, July, 1953.

(1751) MAXIMUM STATION PRECIPITATION.

(b) Corps of Engineers, Department of the Army, and Bureau of Reclamation.

(d) Analysis of diata.

(e) Tabulations of maximum recorded 1,2, 3, 6, 12, and 24-hour precipitation, for automatic recording rain gage stations, by states.

(g) Project continuing for additional states.

(h) Weather Bureau Technical Paper No. 15, Part IV: Maryland, Delaware, District of Columbia, Part V: New Jersey, Part VI: New England and Part VII: South Carolina, all in process of publication.

(1752) SEASONAI VARIATION OF STANDARD PROJECT STORM.

(b) Corps of Engineers, Department of the Army.

(d) Applied research for design purposes.

(e) An attempt to present a seasonal variation of storm rainfall amounts over areas of 200 and 1,000 square miles which will give approximately uniform degree of design safety for all areas east of the 105th meridian.

(f) Completed.

(h) Hydrometeorological Report No. 29. Hydrometeorological Section, Hydrologic Services Division, U. S. Weather Bureau, March, 1953.

(1753) SURVEY OF HURRICANES.

(b) Corps of Engineers, Department of the Army.

(d) Applied research.

(e) Climatological analysis of 50 years of hurricanes affecting United States to establish frequencies of winds and pressures required as engineering design data.

(h) "Fifty Years of Hurricanes." Vance A. Myers and Iillian K. Rubin, weatherwise, Vol. 6, No. 4, August, 1953.

(1991) TOPOGRAPHIC ADJUSTMENT OF MEAN PRECIPITATION, MOGOLION RIM AREA.

(b) Laboratory project.

(d) Field investigation, applied research.

(e) To develop relations between topographic parameters and seasonal precipitation in this area for refinement and extension of seasonal and annual isohyetal pattern.

(f) Completed.

(g) Maps of average Oct-Apr., May-Sept., and annual precipitation developed for Arizona and New Mexico north of the Gila River. 
(h) "The analysis of precipitation data," Whlliam E. Hiatt, The Physical and Economic Foundation of Natural Resources, Vol. IV: Subsurface facilities of Whater Management and Patterns of Supply - Type Area Studies, Interior and Insular Affairs Committee, House of Representatives, U. S. Congress, 1953.

(1992) CONTINUOUS RAIN GAGE CHART.

(b) Laboratory project.

(d) Experimental; operation.

(e) To substitute recording chart between rollers instead of on drum to avoid superposition of traces.

\section{(1993) PRESSURE JUMP ITNES.}

(b) Laboratory project supported in part by U. S. A. F. Geophysical Research Directorate.

(c) Dr. Morris Tepper, Scientific Services Division, U. S. Weather Bureau, Washington, D. C.

(d) Theoretical and field investigation; basic and applied research.

(e) Investigate the properties of and the mechanisms producing pressure jump lines in the atmosphere. These lines, identified by means of discontinuities in microbarograms, have been found to be correlated very strongly with severe local storms. The study is based on (1) observational data collected from a special field program and (2) theoretical models in which the pressure jump line is interpreted as a gravity wave propagating on an inversion surface between stratified atmospheric layers.

(h) Basic theory in "Application of the Hydraulic Analogy to Certain Atmospheric Flow Problems." M. Tepper, USWB Research Paper No. 35, October, 1952. Report covering analysis of field network data jor 1951 will be published early in 1954.

(1994) SHORT PERIOD FLUCTUATIONS IN GREAT LAKE WATER IEVELS.

(b) Laboratory project.

(c) Mr. D. Lee Harris, Scientific Services Division, U. S. Weather Bureau, Washington 25, D. C.

(d) Theoretical and field investigation: basic and applied research.

(e) The contimous records of lake leveI gages belonging to the U. S. Lake Survey and several other organizations for the year 1950 and a few other periods have been examined to learm the properties of the seiche-like phenomena observed on the Great Lakes. A theoretical model which appears to explain the observations has been derived. This work was undertaken to investigate the possibility of forecasting the floods which are due to the oscillations of the lakes.

(g) It appears that the east-west oscillation of Lake Erie may be forecastable. It does not appear that useful forecasts can be prepared for the other lakes at this time. However, the analysis of the problem may be of some value in harbor engineering.

U. S. DEPARTMENT OF THE INTERIOR, GEOLOGICAL SURVEY.

(194) A STUDY OF METHODS USED IN THE MEASUREMENT AND ANALYSIS OF SEDTMENT IOADS IN STREAMS.

(b) Cooperative. See Project 194, page 121.

(439) EFFECT OF REFORESTATION ON STREAM FIOW.

(b) Cooperative with state of New York.

(c) Mr. A. W. Harrington, U. S. Geological Survey, Albany, N. Y.

(d) Field investigation; basic research.

(e) To study effect on stream flow of growing trees on abandoned farm land. Observations of stream flow, precipitation, ground-water levels, and evaporation at three small reforested drainage basins and adjacent controls were begun in $1935^{\circ}$ 
(445) SMALI RESERVOIRS IN ARID REGIONS.

(b) Laboratory project.

(c) Mr.H. V. Peterson, U. S. Geological Survey, Salt Lake City, Utah.

(d) Field investigation; applied research.

(e) To determine runoff, evaporation, seepage, and sedimentation in arid regions. Readings are being obtained on staff gages installed on a number of representative stock-watering reservoirs in western states.

(h) Progress reports on file.

(690) DISCHARGE THROUGH MUITIPLE OPENINGS.

(b) Laboratory project.

(c) Prof. C. E. Kindsvater, U. S. Geological Survey, Atlanta, Ga.

(d) Field investigation; applied research.

(e) Crest-stage gages are installed on upstream and downstream sides of all openings of selected bridge and valley crossings, so that study can be made of the drop through each opening and of the transverse water-surface profiles. Current-meter measurements " made during the floods will be used to study relationships of discharge through each opening to the total di scharge, the drop, and the conveyance.

(691) COMPUTING PEAK DISCHARGES BY INDIRECT METHODS.

(b) Laboratory project.

(c) Mr. Tate Dalrymple, U. S. Geological Survey, Washington 25, D. C.

(d) Field investigation; applied research.

(e) Establishment of maximum stage gages on slope-reaches or suitable contracted openings, computing flood discharges and comparing with measured discharge; to test slope-area method of computing flood discharge and to verify roughness coefficients.

(1219) ELECTRICAL IOGGING INSTRUMENTS FOR GROUND-WATER WELLS.

(b) Cooperative with State of Maryland.

(c) Mr.R. R. Bennett, U. S. Geological Survey, Baltimore, Md.

(d) Development.

(e) Development of geophysical unit for obtaining resistivity curves of electrical log, fluid velocity, conductivity, caliper, and temperature for deep well surveying - all combined in a single unit and mounted in station wagons.

(1220) RELATION OF GROUND WATER TO STREAM FLOW.

(b) Labor atory project.

(c) Mr. S. L. Schoff, U. S. Geological Survey, Washington 25, D. C.

(d) Field investigation.

(e) Network of 23 observation wells in basin of Pond Creek, Okla., begun in March, 1948. Whater level data are to be correlated with low-water stream flow.

(1221) STEADY STATE ELECTRIC FLOW NET MODELS.

(b) Cooperative with State of Maryland.

(c) Mr. R. R. Bennett, U. S. Geological Survey, washington 25, D. C.

(d) Experimental.

(e) Preparation of electrical flow net models using coloidal carbon. Boundary conditions simulate those commonly found in nature. Object is to catalogue various types of nets for future reference.

(1222) INFIITRATION AND EVAPO-TRANSPIRATION STUDY.

(b) Cooperative with State of Maryland.

(c) Mr. W. C. Rasmussen, U. S. Geological Survey, Washington 25, D. C.

(d) Field investigation.

(e) Weekly measurement of wells, rain gages, soil moisture, runoff and pond storage in two drainage basins near Sali sbury, Md., to measure all factors in hydrologic cycle to determine infiltration, evapo-transpiration and specific yield. 
(f) Field work completed.

(h) Report in preparation.

\section{(1223) EVALUATION OF HYDROLOGIC CYCLE.}

(b) Cooperative with State of Virginia.

(c) Mr. D. S. Wallace, U. S. Geological Survey, Charlottesville, Va.

(d) Field investigation.

(e) Establishment of gaging station and network of observation wells on headwaters of Hudson Creek, Louisa Co., Va., for correlation of water levels and stream flow.

(I225) STORM WATER INFILTRATION IN GROUND-WATER BECHARGE BASINS.

(b) Cooperative with Nassau County, N. Y.

(c) Mr. A. W. Harrington, U. S. Geological Survey, Mineola, I. I.

(d) Field investigation.

(e) Observations are made of precipitation, evaporation, ground-water levels and storm water inflow into artificial recharge basins, to determine rate of infiltration and amount of storm water available for ground-water recharge when collected in recharge basins, and to evaluate effectiveness of these basins.

(1227) STOCK-WATER RESERVOIR STUDIES.

(b) Cooperative with Bureau of Reclamation.

(c) Mr. R. C. Culler, U. S. Geological Survey, Salt Lake City, Utah.

(d) Field investigation.

(e) Development of techniques for determination of effects of stock-water reservoirs on water supply. Detailed surveys made of number, capacity and performance of reservoirs in the Cheyenne River Basin in hyoming, will be analyzed to determine evaporation, transpiration, and seepage losses and their effect on flow of Cheyenne River.

(1229) GLACIER RUNOFF.

(b) Laboratory project.

(c) Mr. C. S. Heidel, U. S. Geological Survey, Helena, Mont.

(d) Field investigation.

(e) Study of recession and accretion of Grinnel Glacier, Mont. Glacier mapped anmally for some years, storage rain gage and stream gaging station installed in 1949.

(h) Annual reports of surveys available.

(1230) EFFECT OF IOGGING ON STREAM FIOW.

(b) Cities of Tacoma and Seattle.

(c) Mr. F. M. Veatch, U. S. Geological Survey, Tacoma, Wash.

(d) Field investigation.

(e) Operation of seven gaging stations on small streams in areas where logging operations are scheduled in several years. There are control basins where no timber will be cut.

(1231) CATHODIC PROTECTION OF BURIED PIPE AGAINST CORROSION.

(b) Cooperative with State of Pennsylvania and State of Louisiana.

(c) Mr. Max Noecker, U. S. Geological Survey, Pittsburgh, Pa., and Mr. R. P. Smith, U. S. Geological Survey, Jonesboro, La.

(d) Field investigation.

(e) Magnesium anodes are to be installed at several gaging stations where corrosion of pipe wells or intake pipes has required frequent replacement. Anodes and pipes are to be inspected anmally to determine rate of loss of magnesium and to observe extent of corrosion.

(1233) MAGNITUDE AND FREQUENCY OF FLOODS.

(b) Cooperative with several state agencies. 
(c) Mr. Tate Dalrymple, U. S. Geological Survey, Washington 25, D. C.

(d) Applied research.

(e) Analyses of flood records to determine magnitude and frequency of flood discharge at gaging stations, and at supplementary network of crest-stage gages on small streams, to determine techniques for establishing flood discharges on ungaged streams.

(h) Reports published for Georgia, Iowa, Minnesota, Western Washington, Ohio, westerm Pennsylvania, Alabama, Louisiana, and Illinois.

(1235) SEDIMENT CARRIED AS BED IOAD.

(b) Laboratory project.

(c) Mr. P. C. Benedict, U. S. Geological Survey, Lincoln, Neb.

(d) Field investigations; theoretical studies.

(e) Determination of the amount of sediment moving as bed load at three stations, evaluation of the several bed-load formulas, and basic studies of bed-load movement.

(1485) EROSION AND DEPOSITION OF SEDIMENT.

(b) Laboratory project.

(c) Mr. P. C. Benedict, Lincoln, Neb.

(d) Field surveys; applied research.

(e) Studies of the effects of climate, soil types, geology, topography, and land use in rates of erosion.

(1487) FIOW THROUGH CONTRACTED OPENINGS.

(b) Laboratory project.

(c) Prof. C. E. Kindsvater, U. S. Geological Survey, Atlanta, Ga.

(d) Experimental; applied research.

(e) To obtain data on model and prototype on flow through contracted openings.

(h) Results published as Geological Survey Circular 284.

(1488) ROUGHNESS COEFFICIENTS OF SAND BED STREAMS.

(b) Laboratory project.

(c) Mr. C. E. Ellsworth, U. S. Geological Survey, Austin, Texas, and Mr. D. D. Lewis, U. S. Geological Survey, Lincoln, Neb.

(d) Field survey; applied research.

(e) To determine channel coefficients for use in computing peak discharges by indirect methods in sand bed streams, extent of scour and fill.

(1755) CHARACTERISTICS OF SAND CHANNEL STREAMS.

(b) Laboratory project.

(c) Mr. Tate Dalrymple, U. S. Geological Survey, Washington, D. C.

(d) Field investigation; applied research.

(e) The research is conducted at a 1,900 foot reach. The following factors are being investigated: variation of value of " $\mathrm{n}$ " with stage; accuracy and reliability of highwater marks recovered after a rise; accuracy of slope of water surface determined by present procedures; extent of scour and fill; reliability with which scoured depths can be determined by subsequent prodding; definition of the patterm of scour and fill during floods; shapes of vertical velocity curves; and quantity of suspended sediment in transport.

(1756) WATER LOSS FROM LAKE MEAD.

(b) Cooperative with Bureau of Reclamation.

(c) Mr. G. E. Harbeck, U. S. Geological Survey, Denver, Colo.

(d) Field investigation.

(e) Evaporation from Lake Mead is being determined using mass-transfer and energy budget techniques. The Cummings radiation integrator is being used to determine the areal variability in solar and atmospheric radiation.

(f) Field work completed.

(h) Final report in preparation. 


\section{(1757) EVAPOTRANSPIRATION INVESTIGATION.}

(b) Cooperative with Bureau of Reclamation, Division of Hydrology.

(c) Mr. G. E. Harbeck, U. S. Geological Survey, Denver, Colo.

(d) Field investigation at site near Bruning, Nebr.

(e) Tests are to be made by mass-transfer and energy budget techniques of evapotranspiration from grass land, with comparison with water-budget control.

\section{(1758) RELATION OF GROUND WATER TO STREAMFLOW.}

(b) Laboratory project.

(d) Field investigation; applied research.

(e) Study of hydrologic cycle in small drainage basins, in Massachusetts, Virginia, New Jersey, Connecticut, North Carolina, Loui siana, Oklahoma, New York and Tennessee to determine the relationships between ground-water levels, runoff, evapotranspiration, and the geology.

\section{(1759) INFILTRATION STUDIES.}

(b) Laboratory project.

(c) Mr. Irwin Remson, Seabrook, N. J.

(d) Field investigation; applied research.

(e) Study of the movement of percolating waters between the land surface and the water table, and water-budget studies in connection with the waste disposal project at seabrook Farms.

(f) In progress.

(h) Provisional reports on file.

(1761) DIRECT MEASUREMENT OF GROUND-WATER RECHARGE.

(b) Laboratory project.

(c) Mr. Wallace de Laguna, Brookhaven National Laboratory, N. Y.

(d) Experimental; field research.

(e) To observe the annual cycle of recharge to the water table and to measure the amount of recharge. A new type of lysimeter has been developed, to maintain ground water in lysimeter at same level as that in surrounding aquifer.

(1763) THE RIVER CHANNEL; BRANDYWINE CREEK, PENNSYLVANIA.

(b) Laboratory project.

(c) Mr. M. G. Whlman, U. S. Geological Survey, Washington 25, D. C.

(d) Field investigation; applied research.

(e) The applicability of previously described principles of hydraulic geometry to a small stream. Intensive study of some hydraulic and geologic variables on a watershed of 312 square miles. Includes measurements of water surface slope and computations of Manning' "n". Attempt to relate roughness to coarse bed material.

(h) Report in preparation.

(1764) CONBINED PHYSIOGRAPHIC AND HYDRAULIC STUDIES.

(b) Laboratory project.

(c) Mr. Iuna B. Leopold, J. S. Geological Survey, Shishington 25, D. C.

(d) Field and office research.

(e) Longitudinal profiles of natural channels, relation to bed material, geologic history, and hydraulic characteristics. Problems in meanders and flood plain construction.

\section{(1765) SONAR INVESTIGATIONS (EQUIPMENT DEVELOPMENT).}

(b) Laboratory project.

(c) Dr. A. N. Sayre, U. S. Geological Survey, Washington, D. C.

(d) Development; theoretical laboratory.

(e) To adopt the sonar principle of the fathometer as nethod of delineating under-water sedi ments of moderate thickness (several hundred feet) and depth to underlying bedrock. De. velopment work is presently in progress to modify and simplify the procedures of interpretation and use of the sonar technique for geophysical investigations on land. 
(1995) COMPARATIVE STUDY OF SOIL MOISTURE ERUIPMENT.

(b) Laboratory project.

(c) Mr. Irwin Remson, U. S. Geological Survey, Trenton, N. J.

(d) Field investigation; applied research.

(e) A comparative study of all commercially available instruments for measuring soll moisture; possible design of new instruments.

(g) Laboratory and field calibrations in progress.

(1996) INFILTRATION AND EVAPOTRANSPIRATION STUDY.

(b) Laboratory project.

(c) Mr. Irwin Remson, U. S. Geological Survey, Trenton, N. J.

(d) Field investigation; applied research.

(e) To determine interrelation of the various factors involved in the hydrologic cycle with special emphasis on the magnitude of evapotranspiration.

(g) Observation networks established, periodic measurements begun.

(1997) EFFECT OF FOREST MANAGEMENT ON WATER YIELD.

(b) Cooperative with State of New Jersey.

(c) Mr. H. C. Barksdale, U. S. Geological Survey, Trenton, N. J.

(d) Field investigation.

(e) Study of effects caused by forest management practices on interception, infiltration capacity, evapotranspiration, and yield of water-bearing sands in New Jersey Pine Barrens area.

(g) Instrumentation in process of installation.

(1998) DEVELOPMENT OF INSTRUMENTS AND TECHNIQUES FOR SUBSURFACE EXPLORATION OF GROUND WATER.

(b) Cooperative with State of Arizona.

(c) Mr.H. E. Skibitzke, U. S. Geological Survey, Tucson, Arizona.

(d) Applied research.

(e) To adapt instruments and techniques for solving problems of the occurrence of water in alluvial fill; including electrical resistivity methods, electric logging and deep well current meters.

(1999) PERFORMANCE OF RECHARGE POND.

(b) Cooperative with Bureau of Reclamation.

(c) Mr. H. A. Waite, U. S. Geological Survey, Salt Lake City, Utah.

(d) Field investigation.

(e) Studies of factors controlling rates of infiltration in an abandoned gravel pit used as a recharge pond.

(2000) GHYBEN-HERZBERG LENS.

(b) Laboratory project.

(c) Mr. Dan A. Davis, U. S. Geological Survey, Honolulu, T. H.

(d) Field investigation.

(e) Study of ground-water body in marine islands, to determine the relationship of fresh water storage to the geology of the island, rainfall, head, tidal fluctuations, leakage, and draft.

(2001) HYDROLOGIC INVESTIGATION, LTTTLE MIAMI RIVER.

(b) Cooperative with State of Ohio.

(c) Mr. William C. Walton, U. S. Geological Survey, Columbus, Ohio.

(d) Field investigation.

(e) Detailed studies of ground-water levels in various types of glacial deposits to determine effects on ground-water storage of various land use and stream improvement practices.

(g) Instmuments and observation wells installed. 
U. S. DEPARTMENT OF THE INTERIOR, BUREAU OF RECLAMATION.

Inquiries concerning Projects Nos. 463, 705, 1022, 1236, 1240, 1241, 1243 to 1246, incl. $1252,1254,1255,1261,1262,1264,1266,1494$ to 1496, inc1., 1498, 1499, 1501, 1502, 1766 to 1769, incl., 1771 to 1777, incl., and 2002 to 2017, incl., should be addressed to the Chief Engineer, Bureau of Reclamation, Denver Federal Center, Denver, Colo.

(463) DAVIS DAM SPILLWAY.

(b) Laboratory project.

(d) Experimental; for design.

(e) A 1:72 model was used in the investigation of roller buckets, sloping aprons, and stilling basins to determine the most effective and economical design of the spillway, the possible retrogression of streambed in the future being taken into consideration. The model was used to test diversion scheme for construction purposes. An air model was use to test bellmouth shapes for low-level outlets.

(f) Completed.

(g) Type and proportions of spillway stilling device were determined; rectangular-type still ing basin proved most feasible for the receding tail water which could be expected.

(h) Report preparation suspended.

(705) HUNGRY HORSE DAM SPILIWAY.

(f) Completed.

(h) "Hydraulic model studies of Hungry Horse Dam Spillway." G. I. Beichley, Report No. Hyd. -355 . (Available on loan.)

(1022) KEYHOLE DAM OUTLET WORKS.

(f) Completed.

(h) "Hydraulic model studies of the outlet works, Keyhole Dam--Belle Fourche Unit, Wyoming-Missouri River Basin Project." W. E. Whgner, Report No. Hyd.-338. (Available on loan.)

(1236) WILIOW CREEK DAM EMERGENCY SPILLWAY.

(f) Completed.

(h) Report in preparation.

(1240) SOLDIER CANYON OUTLET WORKS.

(f) Completed.

(h) "Hydraulic model studies of the Soldier Canyon Dam outlet works--Colorado-Big Thompson Project." T. J. Rhone, Report No. Hyd.-334.

(12LI) WELITON-MOHAWK CANAL STRUCTURES.

(f) Completed.

(h) "Hydraulic model studies of outlet control structure, culvert under dike and wash overchute at station 938+00--Wellton-Mohawk Division, Gila Project, Arizona." W. E. Wagner, Report No. Hyd. -359 .

(1243) RECTANGULAR SEMIBELLMOUTH ENTRANCE STUDIES.

(f) Completed.

(h) Report in preparation.

(1244) WILLOW CREEK DAM SPILLWAY AND OUTLET WORKS.

(f) Completed.

(h) Report in preparation. 
.245) DISCHARGE MEASURTNG SYSTEM FOR ALVA B. ADAMS TUNNEL.

(b) Laboratory project.

(d) Experimental; for operation and field tests on completed stmucture.

(e) A 1:10 scale hydraulic model of the tunnel near the entrance portal was built for the purpose of developing a satisfactory discharge measuring system.

(f) Field test will continue. Model studies completed.

(g) A curved weir was developed and calibrated. It provided an accurate means of measuring the discharge and had a low energy loss at the maximum discharge. Flow conditions immediately downstream of the gates were greatly improved. Field tests showed measuring device to be accurate and satisfactory.

(h) Model studies for the development of a discharge measuring system at the west portal of Alva B. Adams Tunnel--Colorado-Big Thompson project, Colo." E. J. Rusho, Report No. Hyd. -364 .

\section{5) CACHUMA DAM SPILLWAY.}

(f) Completed.

(h) "Hydraulic laboratory studies of Cachuma Dam Spillway." W. E. Wagner, Report No. Hyd.-380.

252) CAVITATION-FEE OPERATION OF REGULATING GATES.

(b) Laboratory project.

(d) Experimental; for design.

(e) A general study to (1) develop design criteria for cavitation-free operation of regulating gates in closed conduit irrigation distribution systems, and (2) to determine the number of pipe diameters of rubber-lined steel pipe required to protect a concrete pipe irrigation line from cavitation pitting from a partially opened leaf-type valve.

(g) A method of computing the required back pressure to prevent cavitation was obtained by use of parameters which were affected by a flow pattern change due to cavitation and wich indicated system efficiency.

(h) 'Determination of the operational characteristics of valves for use in water distribution systems requiring pressures up to 125 feet of water Contra Costa Distribution System-Central Valley Project, Calif." J. C. Schuster, Report No. Hyd.-337. (Abstract available on loan.)

254) VIBRATION--KEECHELUS DAM OUTLET WORKS TOWER.

(f) Completed.

(h) "Hydraulic model studies of Keechelus Dam outlet works--Yakima Project Washington." J. C. Schuster, Report No. Hyd. -342 .

255) PALTSADES DAM RECTANGULAR REGULATING GATES.

(b) Laboratory project.

(d) Experimental; for design.

(e) A 1:19 model was used to develop a rectangular, downstream seal, regulating slide gate suitable for use at heads up to 240 feet and capable of discharging a smooth, even stream into closed or open conduit or on a spillway. Particular attention was directed to the gate slots using a 1:2 scale sectional model. The tests were extended to study the effect of an emergency gate of identical design placed immediately upstream from the regulating gate. Other tests will be made to determine the operating characteristics of the gate when discharging under water.

(g) A practical gate was developed which discharged the desired smooth stream at a discharge coefficient of 0.95 when full open. A slot design was obtained which, when the gate discharges into the atmosphere at a 240 head, produces pressures no lower than mims 1 foot of water. The emergency gate operated satisfactorily when used for the control except at gate settings of 97 to 100 percent open where air must be admitted to relieve 10; pressures.

(h) Report in preparation. 
(I2́́1) REPUBLIC DIVERSION DAM, HEADWORKS AND SLUICEWAY STRUCTURES.

(f) Completed.

(h) "Hydraulic model studies of Republic Diversion Dam--headworks and sluiceway structures O. S. Hanson and E. J. Carlson, Report No. Hyd. -315 .

(1252) SHEEP CREEK DIVERSION SEDIMENTATION BASIN.

(b) Laboratory project.

(d) Experimental; for design.

(e) Tests on a 1:9 model of a sedimentation basin are being conducted to determine the moc fications required to improve the efficiency of the basin. Tests will also be made or prototype structure to determine additional data on model-prototype relationships for movable bed models.

(f) Suspended.

(1254) VORTEX TUBE.

(b) Laboratory project.

(d) Experimental; for design.

(e) A program of general testing is being made to obtain additional information for desigi criteria for a vortex tube desanding apparatus. A horizontal vane with a gradually e: panding cross section is used to increase the velocity over the vortex tube in order 1 obtain better action in canals having low water velocities.

(f) Discontimed.

(g) Effectiveness of vortex tube was increased.

(h) Work accomplished on this project reported in "Hydraulic model studies of Republic Diversion Dam, headworks and sluiceway structures." O. S. Hanson and E. J. Carlson, Report No. Hyd. -315 .

(1494) GLEN ANNE SPILIWAY.

(f) Completed.

(h) "Hydraulic model studies of Glen Anne Dam Spillway and Stilling Basin--Cachuma Projec Califormia." P. F. Enger, Report No. Hyd. -360 .

(1495) YELIOWIAII DAM SPIILWAY AND OUTLET WORKS.

(b) Laboratory project.

(d) Experimental; for design.

(e) A 1:54 scale model of all discharge facilities and surrounding area was used to deter mine feasibility of entire lay-out, develop a low-cost tunnel spillway and energydissipating device, check the proposed powerhouse outlet works lay-out, and determine inter-related discharge effects in river. A 1:28 scale model of the outlet works was used to develop a low-cost efficient stilling basin.

(i) Completed.

(g) Feasibility has been determined. Tunnel size was reduced, combination stilling basin and ski-jump bucket was developed, approach to spillway improved, outlet works and po house lay-out improved, and an economical but efficient stilling basin developed.

(h) Report in preparation.

(14,95) HYDRAULIC LABORATORY PROCEDURES.

(b) Laboratory project.

(d) Record of experience; applied research.

(e) A mamal for instruction purposes in theory and procedure for Hydraulic Laboratory personnel.

(f) Completed.

(g) Bureau monograph has been published.

(h) "Hydraulic laboratory practice." Engineering Monograph No. 18, U. S. Dept. of the Interior, Bureau of Reclamation. 
1988) IEIR STANDS--IRRIGATION WATER DISTRIBUTION SYSTEM.

(f) Completed.

(h) Report in preparation.

1,99) CANAL TURNOUT -METER LOCATION.

(f) Completed.

(h) Report in preparation.

1501) STABLE CHANNEL STUDIES--SCOUR ON CURVES.

(b) Laboratory project.

(d) Experimental; for design.

(e) A program of general testing is being made to obtain information which will correlate extent of scour with degree of curvature in canals.

(f) Suspended.

1502) STABLE CHANNEL STUDIES--TRACTIVE FORCES REQUIRED TO MOVE MATERIALS.

(b) Laboratory project.

(d) Experimental; for design.

(e) A program of general testing is being made to determine critical tractive forces required to move given sizes of materials when they are found in normal mixtures. These tests are to be performed in conjunction with tests to determine extent of scour on curves in canals.

1766) HYDRAULIC AND SOIL TESTS ON PROPOSED CANAL IINING MATERIAL FOR MADERA DISTRIBUTION SYSTEMS.

(b) Laboratory project.

(d) Experimental; for design.

(e) A model study of the action of a proposed earth lining material, under the action of flowing water, was made. Various velocities were used in the testing program. To study the possibilities of creating a more stable channel, several types of sand-gravel blankets were tested.

(g) The material was found suitable for canal embankment but unsuitable for canal lining. The use of a sand-gravel blanket over the soil increased the stability of the section.

(h) Report in preparation.

1767) MILBURN DIVERSION DAM, HEADWORKS AND SLUICEWAY STRUCTURES.

(b) Laboratory project.

(d) Experimental; for design.

(e) Tests on a 1:16 scale model of the headworks and spillway structures are to be made to determine and improve the sediment-excluding characteristics of the stmacture.

1768) BARTLEY DIVERSION DAM, HEADTORKS AND SLUICETAY STRUCTURES.

(b) Laboratory project.

(d) Experimental; for design.

(e) Tests on a 1:7 scale model of the headwork and sluiceway structures were made to improve the sediment-excluding characteristics of the sluiceway.

(g) Guided flow immediately upstream from the headworks and sluiceway obtained by installing curved parallel guide walls proved most effective for reducing bed-load sediment passing the headworks.

(h) Report in preparation.

1759) TEIR TURNOUT.

(b) Laboratory project.

(d) Experimental; for design. 
(e) To develop a weir turnout, with emphasis on minimum structure dimensions, that will gia smooth head-on-weir water surface when the turnout is discharging (1) 5 cfs at 6-foot head and (2) 2 cfs at 1-foot head.

(f) Completed.

(h) Report in preparation.

(1771) TURNOUT AND METERING STRUCTURE--SAN DIEGO AQUEDUCT.

(b) Laboratory project.

(d) Experimental; for design.

(e) Studies were made of the flow distribution, the operating characteristics, and the losses incurred in the proposed turnout and metering structure to be added to the aque duct when the second barrel is added.

(g) The flow distribution and operating characteristics were satisfactory. Minor changes were required to reduce the head losses to the required low values.

(h) "Hydraulic model studies of the San Jacinto-San Vincente turnout and metering structur San Diego Aqueduct Project, Califormia." W. P. Simmons, Jr., Report No. Hyd.-365.

(1772) FLOAT -OPERATED REGULATING VALVES.

(b) Laboratory project.

(d) Experimental; for design.

(e) Tests are being made to determine the operating characteristics at relatively high hea of several standard commercial valve designs.

(f) Completed.

(h) Report classified as Administrative Confidential for use within the Bureau of Reclamation for information of its design and construction staff only.

(1773) WEBSTER DAM SPILLWAY.

(b) Laboratory project.

(d) Experimental; for design.

(e) A 1:54 model will be used to investigate the hydraulic performance of the spillway str ture including: checking the entrance flow conditions; calibrating the free crest and crest with partial gate openings; checking the spreading characteristics of flows thro the long chute; checking the stilling basin for elevation, length, etc.; and checking water surface profiles along training walls.

(f) Completed.

(h) Report in preparation.

(1774) KIRWIN DAM SPILIWAY AND STILIING BASTN.

(b) Laboratory project.

(d) Experimental; for design.

(e) A 1:48 model used to test the approach conditions, coefficient of discharge, flow distribution on concrete apron and the efficiency of the stilling basin.

(g) Approach conditions improved. Training walls realigned to secure better flow distribu tion in the stilling basin. Spur-type wing walls were added below the stilling basin prevent erosion.

(h) Report in preparation.

(1775) HIGH-HEAD TURNOUT WITH REGULATING VALVE AND TMPELLER-TYPE FLOW METER.

(b) Laboratory project.

(d) Experimental; for design.

(e) To develop an energy dissipator downstream from the regulating valve that will create a uniform flow distribution at the outlet of a vertical pipe with a propeller-type flo meter.

(f) Completed.

(h) Report in preparation. 
776) ADAMINABY TUNNEL JUNCTION SHAFT AND CYLINDER GATE.

(b) Snowy Mountains Hydroelectric Authority, Australia.

(d) Experimental; for design.

(e) Hydraulic model studies are being made of an 18-foot-diameter vertical shaft approximately 300 feet deep which supplies excess water from a river to a 14 mile long, 2l-foot diameter tunnel connecting a storage and power reservoir. Whter from the river flowing through the vertical shaft is controlled by a proposed 21 -foot-diameter cylinder gate at the junction of the shaft and tunnel. Two models are used (1) a 1:21.6 model of the inlet and a section of the vertical shaft and (2) a 1:18 model of the cylinder gate.

(g) Controlling the shaft pressure with the cylinder gate will prevent air entrainment.

777) SIPHON SPILLWAY STUDIES.

(b) Laboratory project.

(d) Experimental; for design.

(e) A program of model-prototype testing of siphon spillways is being made to evaluate various entrance and exit conditions, effectiveness of regulating air supply on priming, the influence of crest radii on priming qualities, adjustable crests, pressure and velocity distributions, and the failure of some prototype installations to operate in the manner for which they were designed.

2002) INVESTIGATION OF HYDRAULIC CHARACTERTSTICS OF VERTICAL STILLTNG WELIS.

(b) Laboratory project.

(d) Experimental; applied research.

(e) Unwatering certain structures which contain water under high pressure and supplying irrigation water from high pressure conduits to earth ditches present problems of energy dissipation. Investigations of several particular structures and operation of a completed field structure have established the feasibility of the stilling-well. Area, depth, and shape of well for various discharges and entrance velocities will be obtained in a generalized form.

(g) Data now available have been analyzed, indicating that design criteria can be established for the circular well.

?003) STUDY OF HYDRAULIC JUMP AND BUCKET ENERGY DISSIPATORS.

(b) Laboratory project.

(d) Experimental; applied research.

(e) Many stilling devices are used in dams and irrigation works. Four general types are considered in this program (1) stilling basins with horizontal floors (with or without baffle piers and sills), (2) basins with sloping floors (no baffle piers), (3) short stilling basins for canal chutes, drops, river crossings, and wasteways, and (4) bucket dissipators.

(g) Data available indicates that extensive generalization for design application may be possible.

:004) STANDARDIZATION OF DESIGN OF SMALI CANAL STRUCTURES.

(b) Laboratory project.

(d) Experimental; applied research.

(e) Canal systems contain numerous and many kinds of small structures such as drops, turnouts, overchutes, wasteways, culverts, and bifurcation works. Many of these incorporate dissipating devices which are quite different from the conventional types. The velocity of flow is low compared to larger structures. This research will standardize designs to a large extent.

005) CAVITATION EROSION OF ROUGHENED SURFACES.

(b) Laboratory project.

(d) Experimental; applied research. 
(e) Irregularities in surface of concrete water passages can be a source of cavitation. The purpose of this project is to explore into a method of determining the cavitation potential of various types and degrees of roughened surfaces.

(g) A successful test apparatus has been designed and built, and an interpretation method evolved, from which any specific surface can be evaluated.

(2006) CAMINO CONDUTT TURNOUT AND METERING STRUCTURES.

(b) Laboratory project.

(d) Experimental; for design.

(e) A l:L scale model was used to determine the head loss through the proposed turnout structures for Stations $105+85$ and $253+50$, and to develop suitable baffles and basins to handle and measure the flow which may be diverted through a gate or over an elevatec skiming weir.

(g) The losses through the structures were low enough to permit passage of the desired flo with the heads available. Economical baffles and basins were developed which produced relatively tranquil flow at the measuring weirs.

(h) Report being prepared.

(2007) SLY PARK DAM OUTLET WORKS.

(b) Laboratory project.

(d) Experimental; for design.

(e) A $1: 5.75$ scale model was used to study the bifurcation of the outlet conduit, the two regulating slide gates, the flow distributor and energy dissipator, and the inlet of $t$ Camino Conduit which carries the water to iis destination.

(g) The outlet works adequately handles the required flows, and the initially proposed dis tributor baffles can be omitted from the structure.

(h) Report being prepared.

(2008) SLY PARK DAM SPILLWAY.

(b) Laboratory project.

(d) Experimental; for design.

(e) A 1:36 scale model was used to study the flow conditions in and the capacity of a doub side channel spillway and the direction of flow in the approach chanmel.

(f) Model studies completed and report issued.

(g) A material reduction in excavation of the preliminary approach channel was possible an some improvement of flow conditions in the channel was realized. The capacity of the crest was adequate for handling the design floods.

(h) "Sly Park Dam Spillway hydraulic model stuaies--Sly Park Unit--American River Divi sion Central valley Project, California." I. V. hillson, Hydraulic Laboratory Report No. Hyd. -370 .

(2009) NIMBUS DAM SYILLWAY.

(b) Laboratory project.

(d) Experimental; for design.

(e) A $1: 35$ sectional model of a concrete diversion dam which will operate submerged at the higher flows; the primary purpose of the study was to determine a satisfactory stillir basin.

(f) Completed.

(g) An unusually short basin, utilizing chute blocks, baffle piers, and a dentated sill proved effective for all flow conditions. Data on submerged flow coefficient were als obtained.

(h) Report being prepared.

(2010) BOULDER SUPPLY CANAL.

(b) Laboratory project.

(d) Experimental; for design. 
(e) A 1:10 model of a section of canal in which the main flow of the canal is supplemented by inflow from storm drainage. Skimming weirs downstream from the inlets discharge the excess flow orer the opposite side of the canal.

(f) Completed.

(g) The scheme was found to be a feasible method for transporting storm water across a canal.

(h) Report being prepared.

2012) PIIOT FISH SCREEN STRUCIURE--DELTA-MENDOTA CANAL.

(b) Laboratory project.

(d) Experimental; for alterations to structure in field.

(e) As the flow was increased to practically twice that for which the structure was designed, it was necessary to make certain changes in the fish screen structure and widen the canal. A 1:15 scale model served to determine the most economical canal section and a 1:10 sectional model is being utilized to determine changes at the screen structure.

(f) Testing in progress.

(g) It was found that several inexpensive revisions to the existing structure and canal will enable the capacity to be doubled.

2012) PARSHALI FLUME SETTING--DRY CREEK TURNOUT, MADERA CANAL.

(b) Laboratory project.

(d) Experimental; for design.

(e) A 1:10 scale model to determine the adequacy of a proposal to add a water-measuring device to an existing irrigation turnout.

(f) Completed.

(g) Two proposed designs were tested and both provided excellent flow conditions in the measuring device.

(h) "Hydraulic model studies on the proposed water-measuring device at Dry Creek Turnout, lateral 24.2--Madera Canal, Central Valley Project, California." T. J. Rhone, Report No. Hyd. -378 .

2013) MAIN UNLINED CANAL, KENNEWICK DIVISION, YAKIMA PROJECT--PROTECTIVE COVER MATERIAL.

(b) Laboratory project.

(d) Experimental; for design.

(e) Full scale tests on a section of canal bank on 2:1 slope were conducted in a 2-foot flume in which waves were created of various heights and frequencies. Tests were conducted on talus and gravel materials to determine the most adequate protective blanket against wave action and leaching of silt base material through the protective blanket.

(g) Placing protective corer material in two layers screened on one screen gives meh better protection than one single graded layer. Material that did not satisfy filter criteria gave good protection against leaching from wave action when placed in two layers.

2014) CODING DEVICE FOR RADIO-REPORTING RAIN GAGE.

(b) Region 2, Bureau of Reclamation, Sacramento, California.

(d) Field investigation; development.

(e) A consistently accurate, dependable, low power DC coding device for radio telemetering from remote rain gage stations was needed for control of releases from Shasta Reservoir. A coding system which transmits intelligence by patterned pulse signals from a photoelectric cell to the screen of a cathode-ray tube has been developed. Measurement is read directly from the cathode-ray screen.

(f) Completed. Possible future refinements.

(g) Six installations have been made. Final results will be analyzed after the 1953-54 season.

(h) Report in preparation.

2015) DEVELOPMENT OF A LOW VEIOCITY CURRENT MEI'ER.

(b) Laboratory project; field performance tests.

(d) Experimental; for development and field studies. 
(e) To develop a recording current meter capable of operating unattended for periods up to I4 days; to operate under tidal influence and the attendant reversing direction of flow without physical rotation of the meter; to develop electronic circuits capable of converting impulses received from the meter to a direct recording of velocity versus time; to evaluate various bearings in attempts to measure velocities down to 0.1 foot per second or lower, and up to 5.0 feet per second.

(g) Two meters have been built and given field tests. Several bearing designs and materials have been used. Investigations are contimuing in an effort to improve wearing qualitie: Calibration tests show the latest meter will operate satisfactorily from 0.12 foot per second to over 5 feet per second.

(2015) STUDIES OF AIR DEMAND OF GATES AND VALVES IN CONDUITS.

(b) Laboratory project.

(d) Experimental; applied research.

(e) This project is being made to determine the size of air vents to prevent adverse effect. of vibration and cavitation erosion from "in line" gates and valves. Small amount of model testing is contemplated to provide data for comparison with results of field test:

(2017) INVESTIGATION OF METHODS FOR MEASURING DISCHARGE IN IARGE CONDUTTS.

(b) Laboratory project.

(d) Experimental; applied research.

(e) This series of studies includes the investigation of application of the salt velocity, chemical dilution, and pressure variation methods, as well as other methods of measurement of discharge in large conduits. The studies are directed toward the determination of the accuracy of various methods to permit selection of the proper method for given requirements. The investigations include laboratory tests, analytical studies, and library research.

(g) The laboratory studies have been confined to the salt velocity method so far. Development of salt injection equipment has been completed and electrode studies are now in progress.

U. S. DEPARTMENT OF THE NATY, DAVID TAYLOR MODEL BASIN.

Inquiries concerning Projects Nos. 467, 470, 709 to 711, incl., 1268, 1503, 1505 to 1507, incl., 1510 to 1512, incl., 1514, 1516, 1517, 1521, 1522, 1778 to 1786, incl., 1788 to 1791, incl., and 2018 to 2020, incl., should be addressed to The Commanding Officer and Director, David Taylor Model Basin, Washington 7, D. C.

(467) DEVELOPMENT OF A HOT-IITE INSTRUNENT FOR TURBULENCE MEASUREMENTS IN WATER.

(b) Bureau of Ships, David Taylor Model Basin.

(d) Flow instrumentation.

(e) Development of the hot-wire technique for measuring turbulent velocity components in water.

(g) Dynamic calibration techniques and the use of coated wires are being investigated.

(h) "Progress report on research in frictional resistance." TMB Report 726, Sept. 1950 which includes:

"Recent progress in hot-wire measurements of turbulence." M. S. Macovsky and W. I. Stracke.

Model basin turbulence." M. S. Macovsky and J. P. Breslin.

(470) ELECTROLYTIC TANK STUDIES.

(b) Bureau of Ordnance; David Taylor Model Basin.

(d) Potential flow research.

(e) Investigations using the method of electrical analogy to obtain pressure measurements 0 and about various bodies in a fluid. 
(g) An electrolytic tank has been developed for obtaining the pressure distribution about cylindrical bodies. A single probe method is used to obtain potential differences on the body and a double probe method is used for obtaining the potential differences in the surrounding field.

Refinement of instrumentation and techniques has made possible the determination of pressure coefficients at a body surface with an accuracy of better than 0.4 percent of the stagnation pressure.

Plans are underway for adapting the present tank to other problems in potential flow.

(h) "An electrolytic tank developed for obtaining velocity and pressure distributions about hydrodynamic forms." A. Borden, G. L. Shelton Jr., and W. E. Ball, Jr., TMB Report 82L, April 1953.

"Whall corrections for two and three dimensional bodies in a rectangular electrolytic tank." A. Borden, TMB Report 864, (in preparation).

709) THEORY OF WAVE RESISTANCE.

(b) Bureau of Ships; David Taylor Model Basin.

(d) Hydrodynamic research.

(e) A mathematical study of the theory of wave resistance for the purpose of establishing methods for extending the theory to the analysis of ship resistance. Studies will include the general theory of waves in liquids and will encompass a review of existing theory and comparisons with existing experimental data.

(g) A synopsis has been written on the application of theory to the calculations of wave resistance. Calculations were made to obtain general information about wave resistance of submerged bodies of revolution. The forms considered are ellipsoids, Rankine ovoids, and a simple family of streamlined bodies. A report of this work is to be published.

(h) "Investigation of wave effects produced by a thin body - TMB model 4125." G. P. heinblum, J. J. Kendrick and M. A. Todd, TMB Report 8LL, Nov. 1952.

"The forces and moments on a body moving in an arbitrary potential stream." W. $E$. Cummins, TMB Report 780, June 1953.

"A systematic evaluation of Michell's integral." G. P. Weinblum, TMB Report 886, (in preparation).

710) RESEARCH ON MAIN INJECTION SCOOPS AND OVERBOARD DISCHARGES.

(b) Cooperative with Bureau of Ships.

(d) Epplied research; for design.

(e) Investigations to determine the characteristics of a broad series of injection scoops and discharges to provide design data for use in design of future high-speed ships.

(g) An analysis has been made to determine the important parameters and develop a means of mathematically describing the geometry of several series of injection scoops. A contract has been awarded to the Newport News Shipbuilding and Drydock Company for the conduct of an extensive experimental study to determine the effect of changes in scoop geometry on efficiency. Three different families of scoop shapes are to be tested.

\section{1) CAVITATION RESEARCH.}

(b) Bureau of Ships; David Taylor Model Basin.

(d) Hydrodynamic research.

(e) Research on the mechanism and effects of cavitation phenomena including the physics and analytical description of steady-state cavities in real and ideal fluids and investigations of the inception of cavitation, the growth and collapse processes of transient cavities, and the effects of cavitation on the forces on underwater bodies.

(g) A linearized theory has been developed for steady, two-dimensional cavity flows about slender bodies. The theory is being applied to the case of lifting surfaces.

(h) "Steady, two-dimensional cavity flows about slender bodies." M. P. Tulin, TMB Report 834, May 1953.

"A brief survey of progress on the mechanics of cavitation." P. Eisenberg, TMB Report 842 , June 1953.

"Discussions and author's closure for a brief survey of progress on the mechanics of cavitation." P. Eisenberg, TMB Report 842A, June 1953. 


\section{(1268) STUDIES OF THE INTERACTION OF APPENDAGES AND BODIES.}

(b) Bureau of Ships; David Taylor Model Basin.

(d) Hydrodynamics of submerged bodies.

(e) An investigation of potential flow and boundary layer phenomena associated with appendage-body combinations in order to determine the nature of interference effects. The generation of lift and moments by fins in non-uniform flows is being studied. A theoretical and experimental investigation is being made in order to determine the mutual interference effects of appendages and bodies. In addition an experimental investigation is being carried out in order to determine the effects of non-uniform flows on the lift and moments of a low aspect ratio fin.

(g) A theoretical investigation is being made.

\section{(1503) BOUNDARY LAYER TRANSITION STUDY.}

(b) Cooperative with Bureau of Ships.

(d) Basic research.

(e) A study of methods for stimulating predictable turbulent boundary layers to improve the reliability of model tests for resistance prediction. Tests are to be made with flat plates, ship models and bodies of revolution and will include investigations of the effects of size arrangement of stimulators and the effect of pressure gradient.

(g) Theoretical studies have directed attention toward intemal roughness stimulators. Design criteria are being developed by means of qualitative boundary layer measurements on flat plates using pin type stimulators.

(1505) EFFECT OF TRANSVERSE CURVATURE ON FRICTIONAL RESIST ANCE.

(b) Bureau of Ships; David Taylor Model Basin.

(d) Frictional resistance research.

(e) Studies to determine the effect of transverse cirvature on the frictional resistance to motion of a body through a liquid. Shear stress measurements and velocity profiles wil be obtained at 10-foot intervals along a 150-foot length of towed cylinder. Results wi: be extended to determine flat plate resistance without surface and edge effects normall: present.

(g) A theoretical analysis of the laminar flow case fur slender cylinders has been made to determine significant parameters and the expected magnitude of the curvature effect. Equipment for the experimental phase has been designed and is under construction.

(h) "Progress report on research in frictional resistance." TMB Report 726, Sept. 1950, which includes

"Effect of transverse curvature on frictional resistance." Wm. M. Ellsworth.

"The laminar flow about very slender cylinders in axial motion, including the effect of pressure gradients and unsteady motions." R. D. Cooper and M. P. Tulin, TMB Report 838 April 1953.

\section{(1506) STIMULATION OF TURBULENCE ON SHIP MODELS.}

(b) Cooperative with Bureau of Ships.

(d) Basic research.

(e) Development of a suitable technique for stimulating a turbulent boundary layer over the entire length of any ship model. Empirical studies will be conducted to evaluate the relative effectiveness of turbulence rods, trip wires, sand roughness and isolated stud Their relative effectiveness will be judged by studying the model resistance curve and the character of the boundary layer flow as determined by dye-method, chemicals, and ho wire survey of the model wetted surface.

(g) The work of the previous year was devoted to the study of the stimulating effect of studs. The evaluation of studs is still continuing. A report is under preparation which covers turbulence stimulation tests on BSRA Model and an evaluation of the effectiveness of the various stimulators. 
1507) SERIES 57 - RESISTANCE OF VARIOUS HULL FORMS.

(b) Bureau of Ships; Maritime Commission, David Taylor Model Basin.

(d) Experimental testing.

(e) The dependance of resistance upon the coefficients of hull form for a practical range of single-screw ship forms is to be determined.

(f) Discontinued.

(g) A method of generating a systematic series of forms has been accomplished. Further research into the basic parent form was instituted in order to obtain near optimum parents. As a result the contours for Series 50 were developed.

1510) GENERAL SEAWORTHINESS.

(b) Bureau of Ships; David Taylor Model Basin.

(d) Hydrodynamic research.

(e) Dtudies to provide information leading to the design of more seakindly ships to meet operational requirements in rough seas. This includes tests to determine optimum shape of hull and erections for maximum speed in a seaway, the applicability of model seaworthiness tests to the prediction of full-scale performance, and the wave damping of basic ship forms. Theoretical studies will include a determination of the effect of pitch and heave on ahead motion, the interference effects between ocean waves and the ships own wave train, and other influences which tend to reduce ship speed.

(g) A program of tests in regular waves of two different size models of the same ship has been completed. The analysis of the data is expected to indicate the reliability of extrapolating model results on ship motions to full scale.

1511) SERIES SEAWORTHINESS.

(b) Office of Naval Research; David Taylor Model Basin.

(d) Experimental testing.

(e) Investigations to determine the effect of various hull form parameters on reduction of speed, ship motions, and dryness of decks for ships operating in waves.

A standard series 60 model with block coefficient 0.50 is to be the parent model for the series of hull forms. Studies will include the effect of: ( 1 ) bow sections, $-U, V$, and bulb; (2) bow flare; (3) free board; (4) plumb stern; (5) raked stern; and (6) stern sections, - U, $\nabla$, raised counter. Tests will be made in the 140-foot model basin using 5-foot models at several speed and wave conditions.

(g) Basic model has been built and tests were started January 1954.

512) EF FECTIVENESS OF BIIGE KEELS.

(b) Bureau of Ships; David Taylor Model Basin.

(d) Experimental testing.

(e) Measurements of the amplitudes of roll versus rolling moment and frequency at or near resonance for a ship model with and without bilge keels; the increase in resistance of a model due to rolling and roll-induced yawing; and the lift, drag, and torque developed by fins. Data will be used in amiving at criteria for the design of fin stabilizers.

(g) Roll tests have been made in the basin on a ship model with and without bilge keels. Also, wind tunnel measurements have been made to determine the effect of variation in fin stabilizers on lift, drag, and torque characteristics.

(h) "Model tests of the effect of sweep hydrofoils on ships bilge keels." C. G. Moody, Report 888, (in press).

51) MANEUVERING CHARACTERISTICS OF' SINGLE-SCREW VESSELS.

(b) Bureau of Ships, David Taylor Model Basin.

(d) Experimental testing.

(e) Measurements of side forces on propeller, rudder, and hull of a single-screw ship model during successive phases of starting, stopping, and backing maneuvers.

(f) Inactive.

(g) A test program has been formulated. A side-force dynamometer has been designed and construction nearly completed. 
(1515) STUDIES OF RESISTANCE PREDICTION METHODS.

(b) Cooperative with Bureau of Ships.

(d) Theoretical research.

(e) The theoretical possibility of separating the viscous and wave drag for surface flows by means of wake surveys, has been demonstrated. Experiments are to be performed on ship models to verify the practical possibility of using this method to improve resistance predictions.

(g) Instrumentation for the wake survey, including pitot rakes and traversing mechanisms with associate manometric system, is under construction.

\section{(1517) MINIATURE MODEL BASIN.}

(b) Bureau of Ships; David Taylor Model Basin.

(d) Facility development.

(e) In order to obtain data on the drag, side force, and vortex configurations of vibrating cylinders a special model basin facility was required. This facility consists of a miniature model basin with small towing carriage whereby cylinders may be towed over a range of speeds while oscillating with controllable amplitude and frequency. Measurements of the attendent forces are made by means of strain gage apparatus and vortex. configurations may be studied by means of special photographic techniques.

(g) The miniature model basin and associate equipment have been constructed and preliminary tests have been made on a 1 and 2-inch diameter circular cylinder.

(1521) 36-INCH VARIABLE PRESSURE WATER TUNNEL.

(b) Bureau of Ships; David Taylor Model Basin.

(d) New facility.

(e) Design and construction of a 36-inch variable pressure water-tunnel for investigation of propulsion, cavitation, and noise characteristics of propellers as well as tests on sub-surface bodies. Interchangeable test sections of open and closed jet type will be provided. The maximum design speed is $85 \mathrm{fps}$.

(g) Architectural and engineering work has been completed. Construction is expected to start this year.

(1522) WAVEMAKER STUDIES.

(b) Bureau of Ships; David Taylor Model Basin.

(d) Hydrodynamic research and facility development.

(e) Theoretical and experimental studies of surface wave generators to develop criteria for the design and construction of a large-scale wavemaker installation. A program of research on wave absorbers is also underway. Prerequi site to this latter investigation i the development of practical means for evaluating the effectiveness of a given absorber

(g) A small pilot model of a pneumatic wavemaker has been developed and successfully operat Improvement has been made in the means of controlling amplitude and frequency of gener. ated waves. A much larger pneumatic wavemaker has been installed in the 140 -foot mode: basin, and has been in regular operation generating waves for ship model tests. A 51foot wide pneumatic wavemaker for the deep water basin is now in the final stages of design. A method of making measurements and determining wave absorption characteristic therefrom has been developed analytically. The accuracy with which wave height can be determined has been improved by the development of an electronic wave-height recorder which operates on a change of capacitance principle.

(1778) HYDRODYNAMIC NOISE.

(b) Bureau of Ships; David Taylor Model Basin.

(d) Hydrodynamic research.

(e) Investigations of the characteristics of underwater noise associated with various hydr dynamic phenomena such as cavitation, bubble oscillation, turbulence and splashing.

(g) Measurements of the noise radiated by a turbulent jet have been made and compared to existing theory. Studies have been made of noise produced by cavitation, splashing, a: oscillating air bubbles. 
(h) "Free field measurements of sound radiated by sub-sonic air jets." R. Lee, TMB 868, Dec. 1953.

1779) TURBULENT BOUNDARY LAYERS.

(b) Bureau of Ships; David Taylor Model Basin.

(d) Frictional resistance research.

(e) A theoretical and experimental investigation of the velocity profiles and surface shearing stresses in turbulent boundary layers. An analysis of boundary layers on bodies of revolution has been made. Experiments on a body of revolution and on two-dimensional flows in a low turbulence wind tunnel are to be made.

(h) "The calculation of the viscous drag of bodies of revolution." P. S. Granville, TMB Report 849, July, 1953.

(1780) BUBBLE FLOW STUDIES.

(b) Bureau of Ships; David Taylor Model Basin.

(d) Hydrodynamic research.

(e) Studies of bubble drag and virtual mass, and the kinematic behavior of bubbles as a function of size, pressure gradient, density, viscosity and surface tension of the media.

(g) Experiments were made to determine the shape and drag of individual air bubbles rising freely in various liquids. Theoretical analyses are being made to determine the effect of varying pressure gradients on the motion of bubbles in a fluid.

(h) "An experimental investigation of the drag and shape of air bubbles rising in various Iiquids." W. I. Haberman and Rose K. Morton, TMB Report 802, Sept. 1953.

"An experimental study of bubbles moving in liquids." W. L. Haberman and Rose $K$. Morton, A.S.C.E. Proc. Separate 387, Jan. 1954.

(1781) ROTATING-ARM AND MANEUVERING BASIN.

(b) Cooperative with Bureau of Ships.

(d) New facility.

(e) Design and construction of a circular basin of 260-foot diameter with a rotating arm whose radius can be varied from 18 to 120 feet. To be used for towing tests of surface and sub-surface models. Also, design and construction of a maneuvering basin 350 feet long and 230 feet wide, equipped with traveling bridge and towing carriages, and wavemakers for the purpose of making maneuvering tests on ship models.

(g) Functional specifications for the facility have been prepared.

1782) SHIP MOTIONS.

(b) Bureau of Ships; David Taylor Model Basin.

(d) Basic research.

(e) Determination of ship motions in a regular seaway when coupling exists between heave and pitch. The work is to be based on the linear theory and is a contimuation of work on uncoupled motion. It is intended to extend the applicability of the linear theory to a larger number of vessels of various type.

1783) MATHEMATICAL SHIP IINES.

(b) Cooperative with Bureau of Ships.

(d) Theoretical research.

(e) Development of a suitable method for the mathematical determination of ship lines which can be applied to a wide variety of ship forms especially to those of modern design.

(g) A preliminary study has been made which indicates that a solution should be sought through mathematical fairing by waterlines (Benson) instead of by sections (Taylor).

1784) RESEARCH ON UNSTEADY FLOW PROBLEMS - UNSTEADY EFFECTS ON STABILITY DERTVATIVES.

(b) Bureau of Ships; David Taylor Model Basin.

(d) Theoretical and experimental. 
(e) Studies of the effect of oscillation frequency and amplitude, speed of advance and geom. etry on the stability derivatives of an oscillating body in a fluid.

(g) The effect of the various parameters has been studied with a spheroid of 7 to $I$ finenes: ratio. It was shown that unsteady effects may be of importance especially when combinec with non-linearity.

(h) "Unsteady and amplitude effects on the moment derivatives of a prolate spheroid." $V$. $G$. Szebehely and 0. C. Niederer, TMB Report 828, Dec. 1953.

"Oscillatary motion of a spheroid." $\nabla$. G. Szebehely. To be presented at the Second U. S. National Congress of Applied Mechanics.

(1785) RESEARCH ON UNSTEADY FLOW PROBLEMS - GENERAL THEORY.

(b) Bureau of Ships; David Taylor Model Basin.

(d) Theoretical research.

(e) A generalized theoretical study of the field of time-dependent hydrodynamic phenomena.

(g) Flows with d'Alembert type unsteadiness, unsteady jet problems, decay of vorticity, d'hlembert flows, Gerstner's waves, potential waves, have been studied. It was shown that the dimensionless parameter which describes the unsteadiness of general fluid motion reduces to the conventional Strouhal number (or dimensionless frequency ratio) for oscillatory flows under certain conditions.

(h) "A measure of unsteadiness of time dependent flows." V. G. Szebehely. Third Midwester Conference on Fluid Mechanics, Proceedings, Page 221-231, 1953.

\section{(1786) SLAMMING OF SHIPS.}

(b) Bureau of Ships; David Taylor Model Basin.

(d) Experimental and theoretical.

(e) Computations and measurements of the maximum pressure and impact forces on the bottoms of slamming ships for the purpose of developing design criteria to effect their reduction.

(g) Studies with ship models were made to determine hydrodynamic impact forces on ships. Regular and confused seas were studied to determine conditions favorable for slamming.

(h) "Slamming due to pure pitchings motion." M. A. Todd, TMB Report 883, to be published.

\section{(1788) WAX TECHNIQUES.}

(b) Laboratcry project.

(d) Experimental testing.

(e) Development of a wax composition and manufacturing techniques for the manufacture of ship models up to 30 feet on waterline length.

(g) Numerous blends of natural and synthetic waxes have been investigated. Of the blends tested a successful compound has been developed for the manufacture of 20-foot models. Work is underway to develop a wax blend which will permit the construction of 30-foot models. A satisfactory manufacturing technique has been developed.

(h) Report in preparation.

\section{(1789) PRESSURE DISTRIBUTION ON SHIP MODEIS.}

(b) Bureau of Ships; David Taylor Model Basin.

(d) Frictional resistance research.

(e) Measurements of pressure distribution and resistance with photographs of wave profiles and flow lines for a series of ship models. Data are to be used for the design of turbulent boundary layer stimulators and the improvement of resistance prediction technique.

(g) Piezometer orifices have been installed over the surface of a wax model of a merchant ship. A special multiple-tube, circular manometer has been designed and built for use in obtaining a large number of simultaneous pressure measurements. Preliminary experiments have been conducted on the above wax mudel. Consistent data were obtained for the piezometers mounted in the side of the model, but the lack of consistency for those on the bottom indicate the need for improving the measuring technique. 
(1790) PROPELLER THEORY, ARBITRARY DISTRIBUTION OF CIRCULATION.

(b) Cooperative with Bureau of Ships.

(d) Theoretical; applied research.

(e) Studies of moderately loaded propellers with a finite number of blades and an arbitrary distribution of circulation. The theory is based on the velocity potential of helical vortices with numerical representation of the velocity field by means of "induction factors." Application of basic theory to contra-rotating propellers.

(g) Problems have been solved both for a free-ruming and for a wake-adapted propeller.

(h) Moderately loaded propellers with a finite mumber of blades and an arbitrary distribution of circulation." H. W. Lerbs, Soc. of Nav. Architects and Marine Engineers, 50, 73 to $123,1952$.

(1791) PROPELIER THEORY, OPTIMUM DISTRIEUTION OF CIRCUIATION.

(b) Cooperative with Bureau of Ships.

(d) Theoretical; applied research.

(e) Study to determine the optimum distribution of circulation for a moderately loaded propeller which operates in a radially varying wake. Studies have been carried out to determine whether or not the assumption of an axi-symmetrical inflow is sufficiently realistic.

(g) The loss of energy which arises from a peripheral non-uniformity of the inflow is small and may be neglected.

(h) "The loss of energy of a propeller in a locally varying wake field." H. W. Lerbs, TMB report 862.

(2018) SERIES 60-RESISTANCE OF VARIOUS REIATED HULL FORMS.

(b) Bureau of Ships; Maritime Commission; David Taylor Model Basin.

(d) Experimental testing.

(e) The dependance of resistance upon the coefficients of hull form for a practical range of single-screw ship forms is to be determined. The history of the project, the scope of the proposed series is given in ( $h$ ) for Series 57. The resistance results of the original series 57 models were somewhat disappointing and therefore careful thought was given to the problem of improving the original parents. As a result, new parent forms have been drawn out, together with necessary contours and models run for resistance. The new family was designated number Series 60.

(g) It is believed that the new Series 60 contours now are such as to justify their use as a starting point for future research in a number of fields. Suggestions as to such systematic research were made in the earlier paper, and include the evaluation of the effect of LCB position, $L / B$ and $B / H$ ratios etc.

(h) "Some further experiments on single-screw merchant ship forms-series 60." F. H. Todd, Nov. 1953. Paper presented to Society of Naval Architects and Marine Engineers.

\section{(2019) PROPELLER EXCITED VIBRATION.}

(b) David Taylor Model Basin and Society of Naval Architects and Marine Engineers.

(d) Experimental; basic research.

(e) Investigation, measurement and prediction of propeller excited vibratory forces on ship models.

(g) Development of the instrumentation and testing technique for single screw vessels has been completed. An investigation of the principal main hull, propeller and rudder parameters is being conducted in order to determine the effect of such parameters on the vibratory force.

(h) Report is in preparation.

'2020) SHIP MOTIONS.

(b) Bureau of Ships; David Taylor Model Basin.

(d) Basic research.

(e) Determination of ship motions in a confused seaway. The work is based on the linear theory and assumes motions to be uncoupled. The seaway and the resulting motions are described statistically. 
(f) Completed.

(g) The motions are described in terms of an energy spectrum from which certain predictions of motions can be made.

(h) "On the motions of ships in confused seas." M. St. Denis and w. Pierson, Transactions by S.N.A.M.E. 1953.

U. S. DEPARTMENT OF THE NAVY, NAVAI BOILER AND TURBINE IABORATORY.

Inquiries concerning Projects Nos. 1523 and 1524 should be addressed to Mr. James W. Murdock, Instrument Division, U. '. Naval Boiler and Turbine Laboratory, Philadelphia Naval Base, Philadelphia 12, Pa.

(1523) HIGH PRECISION POWER INSTRUMENTS (I-II).

(b) Bureau of Ships and Office of Naval Research, Department of the Navy.

(d) Experimental; applied research.

(e) For improvement of fluid flow measurement. (1) Tests underway to determine influence of approach conditions on orifice meters. Various fittings placed 6 to 60 pipe diameters before orifices. (2) Determination of expansion effects of steam, particularly in low superheat regions; involves introduction of low superheat steam through proper approaches to orifices having beta ratios of 0.30 to 0.87 .

(g) Results indicate that (1) length of straight pipe required before orifice meter is reducible to less than $50 \%$ of that presently stipulated without appreciably affecting accuracy of measurement; (2) expansion factors for steam are in general agreement with those now specified except at low superheats where empirical equations must be modified

(h) "Progress on globe valve series."

Test I-II Interim Report No. 4, 26 Nov. 1951.

"Experimental evaluation of expansion factors for steam." J. W. Murdock and C. J. Folt: Trans. ASME Vol. 75, No. 5, pp 953 to 959, July, 1953.

(1524) DETERINATION OF HYDRAULIC CHARACTERISTICS OF SHIP PIPING SYSTEM COMPONENTS (I-25).

(b) Bureau of Ships, Department of the Navy.

(d) Field investigation; design.

(e) Study of design arrangement for accurate prediction of pressures in copper-nickel pipin systems. (1) Runs conducted to determine friction factors of 2-1/2", 4", 6" IPS cuNi tubing. (2) $\mathrm{K}$ factors for $125 \mathrm{psi}$ Navy and commercial valves, tees, and ells.

(g) (1) Friction factors agree with ASVE (Moody's factors). (2) K values with special Navy fittings are lower than with standard equipment.

(h) "Pressure drop determination of component parts of piping systems - 2-1/2", 4", and 6" IPS." Test I-25 Interim Report No. 35. (Summary Interim Reports I to 34, inclusive). Bureau of Ships, Department of the Navy. July 13, 1953.

U. S. DEPARTMENT OF THE NAVY, NAVAI ENGINEERING EXPERIMENT STATION.

Inquiries concerning Projects Nos. 472, 1525 and 1528, should be addressed to Commandin Officer and Director, Naval Engineering Experiment Station, Bureau of Ships, Department of the Navy, Washington 25, D. C.

(472) SEA WATER CORROSION AND EROSION STUDIES CONDENSER TUBES, PIPING AND VALVES.

(b) Bureau of Ships.

(d) Experimental; applied research. 
(e) During the past year tests have been continued on a series of condenser tube alloys. Some 30 condenser tube alloys have been or are currently under test in natural sea water at a velocity of $10 \mathrm{ft} / \mathrm{sec}$. The materials have included copper-nickel alloys of the 7030 and 90-10 types with various iron contents, aluminum alloy, aluminum brass, regular and modified aluminum bronzes, Admiralty metal, modified "G" bronze, Hastelloy "C", titanium, and various stainless steels. New condensers containing tubes of nickel and nickel-base alloys are available for test. Arrangements have been made to construct two other condensers for test at $20 \mathrm{ft} / \mathrm{sec}$. The tubing will be copper-nickel and duplexed tubes lined with titanium and Hastelloy "C". Report 4A(2)966845 of 31 JuIy, 1951 was the last progress report relating to this subject.

Piping systems consisting of pipes up to $3^{\prime \prime}$ IPS of three modifications of 70-30 coppernickel alloy were put under test in sea water at $15 \mathrm{ft} / \mathrm{sec}$. in 1948. At present, only representative sections of these systems continue under test. These sections are to be operated for sufficient time to afford life comparison of the alloys. Previous work had shown that corrosion-erosion attack was dependent on the materials of construction and the degree of water turbulence as influenced by design. The most severe corrosion damage occurred immediately downstream of valves, fittings and branch connections. Tests of 90-10 copper-nickel alloy piping, with various iron contents, have been under test since March, 1950. The 90-10 alloy has performed very satisfactorily, and the alloy has been included in tubing Specification MIL-T-15420A (Ships) Amendment -1 of 15 July, 1952.

Piping made of two aluminum bronze alloys and one aluminum brass alloy have been under test at $15 \mathrm{ft} / \mathrm{sec}$. since December, 1952. Materials are currently being obtained to install an all-titanium piping system, including titanium valves and fittings. This system is to be tested in sea water at $20 \mathrm{ft} / \mathrm{sec}$.

A three-year comparison test of black and galvanized wrought iron and black steel pipe in sea water has been completed. A report is in process of being printed.

A number of alloys, considered less strategic than monel metal, are being tested for application in stems of salt water valves. Corrosion data were obtained for laboratory specimens and on actual valves tested to obtain comparative performance of stem, seat and disc materials. Stem thread wear in steam and salt water was also included. The work is continuing at present.

Experiment $s$ have been completed on the sea water corrosion-erosion characteristics of one design of jacket water cooler. The following points were evaluated: cooler material, head design as related to tube impingement, tube bundle design as related to crevices, effect of tinning the tubes, effect of cathodic protection with magnesium and various grades of zinc, means to measure anode efficiency, and the effects of inadequate screening of debris. Another design of cooler is now under test. The various pumps used to supply sea water to the above tests are being observed to determine weaknesses in design and materials. Seal rings have given the most trouble to date, and titanium rings are being evaluated in an effort to improve this situation.

(h) "Progress report on experimental 90-10 copper-nickel alloy salt water piping system." EES Report 0L0037-BL (in press).

"Investigation of trim materials for bronze globe valves." EES Report 040037-B2 of 18 June, 1953.

(1525) NOISE ATTENUATION TESTS OF FLEXIBLE PIPE COUPLINGS.

(b) Bureau of Ships.

(d) Investigative.

(e) Investigation of the noise propagation, resistance to vibration, and burst strength characteristics of flexible pipe couplings suitable for isolating naval machinery, particularly submarine auxiliary machinery, is contimuing. All sizes of various types of flexible pipe couplings have been investigated up to $5 "$ maximum pipe size. Various configurations of pipe couplings have been investigated under static and flow conditions at pressures up to $500 \mathrm{psi}$.

Modifications to make our apparatus suitable for 1000 psi static conditions have been completed. New apparatus suitable for making flow tests at pressures up to 3000 psi are now underway.

(g) From the investigation, a commercially available rubber hose has been found to provide the greatest noise isolation, both with commercially available fittings and fittings developed as a result of the investigation. Significant flow characteristics of various types of valves have been determined. Even at low pressures and comparatively low velocities, there are significant differences in turbulent noises caused by various valve constructions and restricted valve openings. 
(h) "Preliminary measurements of sound and vibration-reducing characteristics of five flexibl pipe couplings." EES Report C-3590-1, 21 April, 1950.

"Noise-reduction characteristics of flexible pipe couplings in piping systems." EES Reports C-3590-2, 5(4)0.56735 and 050074.

(1528) HYRAULIC PUMPS AND POIER TRANSMISSION.

(b) Bureau of Ships.

(d) Investigative.

(e) All pumps that are commercially available that would be suitable for hydraulic submarine power transmission have been investigated, and it has been determined that the quietest unit standardized measurement systems for evaluating pumps have been developed and is a pump of the screw type. A method has been developed that would be suitable for manufacturers and shipyards in making structureborme noise inrestigations of all types of hydraulic pumps. The apparatus is now being modified to cover capacities from 6 to 50 gallons per minute and speed ranges between 450 and 3,500 rpm. Maximu pressures at which the pumps will be investigated will be 3000 psi.

(g) All commercially available pumps suitable for the service have been investigated. New de signs made by Delaval and haterbury Tool Co. that resulted from the investigation are nor being noise tested on existing apparatus. When these tests are completed, the apparatus will be modified and the pumps will be re-evaluated at higher speed and discharge pressur

(h) Various letter reports have been submitted to the Bureau of Ships (Code 522) covering all the pumps tested.

U. S. DEPARTMENT OF THE NATY, NAVAL ORDNANCE TEST STATION.

Inquiries concerning Projects Nos. 1531, 2021 and 2022, should be addressed to the Commander, U.S. Naval Ordnance Test Station, Pasadena Annex, 3202 East Foothill Blvd., Pasadena 8, Calif., Attn: Code P807.

(1531) MECHANISM OF CAVTTATION.

(b) Laboratory project.

(d) Experimental and theoretical; basic research.

(e) Theoretical calculations on the effective nucleus size for bubble growth are being considered. The rates of growth of vapor bubbles in various superheated liquids are being obtained in order to have a more detailed check on the theoretical calculations of Plesse and Zwick on growth rates.

(g) The rates of growth of vapor bubbles in carbon tetrachloride, benzene, methyl alcohol, and ethyl alcohol have been obtained and show good agreement with the theoretical calculations of Plesset and Zwick. A report will be prepared describing this work.

(h) "The rate of growth of vapor bubbles in superheated water." Paul Dergarabedian, Journal of Applied Mechanics, 1953 (paper No. 53-SA-10).

(2021) EXPLORATORY, ANALYTICAI INVESTIGATION OF ROTATIONAL, NONVISCOUS FLOW.

(b) Laboratory project.

(d) Theoretical; basic research.

(e) The differences arising in the hydrodynamic characteristics of bodies when situated in rotational (but nonviscous), rather than in irrotational flow fields are being investigated.

(g) Project is getting underway.

(2022) BOUNDARY IAYER STUDIES.

(b) Laboratory project.

(d) Theoretical; basic research.

(e) Analytic study of the turbulent boundary layer problem.

(g) Project is getting underway. 
U. S. DEPARTMENT OF THE NAVY, OFFICE OF NAVAL RESEARCH.

For sponsored projects see the following:

Project

(15) Studies of cavitation phenomena

(279) Flow in rotating channels

(803) Dynamics of cavitation bubbles

(804) The effect of physical characteristics of liquid on the inception of cavitation

(1300) Basic water entry study

(1301) Hydrodynamics of free-boundary flows

(1548) Special problems in hydrodynamics

(1817) Scale effects in cavitating flow

(47) Gravity waves and related phenomenon

(822) Diffusion of heat, vapor, and momentum

(1838) Behavior of model ship hulls in an oblique sea

(62) Hydraulic structures

(290) Hydraulics of short outlets in bodies of dams

(1324) Losses in two-dimensional junctions.

(1850) A laboratory study of beach profiles and beach stability

(1335) Mathematical theory of waves

(69) Relation of sediment characteristics to bed erosion

(72) Electrical analogy of three-dimensional flow

(79) Cavitation

(81) Mathematical analysis of pressure distribution

(851) A constant-temperature hot-wire anemometer for the measurement of turbulence in air

(854) Boundary-layer development on smooth and rough surfaces

(1107) Transportation of sediment as suspended and total load

(1344) Calculation of free-streamline flows

(577) Characteristics of solitary waves

(578) Turbulence measurements with a pitot tube-pressure cell combination

(579) Investigation of fluid friction in unsteady motion

(1355) Cavitation inception for steady motion

(880) Recovery factors and heat-transfer coefficients for air flowing at supersonic velocities in a tube

(1359) Effect of heating on transition of water boundary layers

(1374) Shear flow in bends

(1616) Efficiency of diffusion of droplet laden air stream

(1885) Flow of air containing suspended water sprays in pipes

(1886) Sampling of water content of spray-laden air stream

(1888) Theory of laminar flow in the entry of a pipe

(1889) Total pressure measurements in a stream containing entrained water particles

(1640) Stability of towed ships

(1387) Study of tip vortex cavitation

(1388) Turbulent boundary layers

(100) Air entraiment research

(104) Flow diversion research

(924) Free-jet water tunnel studies

(1930) Bottom currents and sand motion

(1931) Deep-sea instrument station

(1932) High-speed, maximum-depth cable depressors

(1933) Ocean swell resonating system

(1934) Free-instrument design

(1935) Beach and nearshore processes

(1936) Gravity waves and related phenomena

(895) The compilation of resistance and propulsion data

(340) Planing surfaces

(113) An investigation of ship resistance using statistical methods

44

45 
(1949) A study of laminar flow phenomena utilizing a doubly refractive liquid

(1477) Turbulent expansion of jets in water

( 178$)$ 佔识 waves

(1479) Energy dissipation in standing waves

(1480) Positive waves in dry channels

(1511) Series seaworthiness

(1523) High precision power instruments (I-II)

TENNESSEE VALLEY AUTHORITY, Hydraulic Data Branch.

Inquiries concerning all TVA Projects should be addressed to Mr. Albert S. Fry, Hydraulic Data Branch, Tennessee Valley Authority, Knoxville, Tennessee.

Unless otherwise noted, work is being done for Tennessee Valley Authority, Hydraulic Laboratory Section.

(728) SOUTH HOLSTON AND WATAUGA DAMS, SPILIWAY MODEL STUDIES.

(d) Experimental; for design.

(e) Tests on 1:100 and 1:51 models were made to develop a morning-glory spillway to handle flood overflows.

(f) Model studies completed.

(g) Proper location of piers on crest were determined, and a deflector in the vertical shaft to deflect flow to outside of bend at bottom was developed.

(h) Report in preparation.

(730) SOUTH HOLSTON DAM, SPILLWAY OUTIET MODEL STUDIES.

(d) Experimental; for design.

(e) Tests on a 1:51 model were made to develop an outlet structure to dissipate the energy from the moming-glory spillway and the Howell-Bunger valve sluiceway without damage to the tunnel or outlet structures.

(f) Model studies completed.

(h) Report in preparation.

(731) SOUTH HOLSTON DAM, SURGE TANK MODEL STUDY.

(d) Experimental; for design.

(e) A 1:50 model of the penstock and surge chamber was used to determine (1) the orifice size and characteristic shape to produce favorable pressure and water surface elevation change for the best governor operation; (2) the maximum and minimum water surface elevations to be expected in the surge chamber; and (3) the operational characteristics or the selectec design.

(f) Model studies completed.

(g) 项 th the proper orifice between the riser and the surge chamber as satisfactory results can be obtained as with the differential riser type of surge tank.

(h) Report in preparation.

(732) WATAUGA DAM, BED IOAD STUDY.

(d) Experimental; for design.

(e) A fixed-bed 1:70 model of the river near the powerhouse was tested to determine whether bed load moved by the spillway discharge would be deposited in the powerhouse tailrace, and, if so, how it could be prevented.

(f) Model studies completed.

(g) A small wall located along the upstream edge of the tailrace channel was found sufficient to keep the bed load from depositing in the draft tubes and the tailrace.

(h) Report in preparation. 


\section{(736) APALACHIA DAM, SPILLTWAY RATING.}

(d) Experimental; operation.

(e) Model tests, checked by field measurements, are to be used in determining the discharge ratings for all anticipated operating conditions. Discharge tables for operating purposes will be prepared.

(f) Model studies completed.

(738) CHEROKEE DAM, SPILLWAY RATING.

(d) Experimental; operation.

(e) Model tests, checked by field measurements, are to be used in determining the spillway discharge ratings for all anticipated operating conditions. Discharge tables for operating purposes will be prepared.

(f) Model studies completed.

(739) CHEROKEE DAM, SLUICE RATING.

(d) Field investigation; operation.

(e) Measurement of discharges and differential pressures in the sluices, supplemented by model test data, hill be used to establish the discharge ratings for the eight sluices. Tables of discharge for any gate opening at any headwater elevation within the operating range are to be prepared.

(741) DOUGLAS DAM, SPILLWAY RATING.

(d) Experimental; operation.

(e) Model tests, checked by field measurements, are to be used in determining the spillway discharge ratings for all anticipated operating conditions. Discharge tables for operating purposes will be prepared.

(f) Model studies completed.

(742) DOUGLAS DAM, SLUICE RATING.

(d) Field investigation; operating.

(e) Measurement of discharges and differential pressures in the sluices, supplemented by model test data, will be used to establish the discharge ratings for the eight sluices. Tables of discharge for any gate opening at any headwater elevation within the operating range are to be prepared.

(745) FONTANA DAM, SLUICE RATING.

(d) Field investigation; operation.

(e) Model tests, checked by field measurements, are to be used in determining the discharge ratings for all anticipated operating conditions. Discharge tables for operating purposes will be prepared.

(f) Model studies completed.

(746) FORT LOUDOUN DAM, SPILLWAY RATING.

(d) Experimental and field investigation; operation.

(e) Model tests, checked by field measurements, are to be used in detemining the discharge ratings for all anticipated operating conditions. Discharge tables for operating purposes will be prepared.

(f) Model studies completed.

(758) CHEROKEE DAM, PROTOTYPE CHECK TESTS.

(d) Field investigation; applied research.

(e) Periodic checks and observations will be made on the various hydraulic appurtenances to determine the operating characteristics of the structures and the effect of operation on the structures. 
(g) Measurement of pressures in the sluice barrel have been obtained and will be compared with pressures obtained in model tests. The apron and sluice barrels were inspected in 1953 to determine the effect of intermittent operation during the past 11 years.

(759) DOUGLAS DAM, PROTOTYPE CHECK TESTS.

(d) Field investigation; applied research.

(e) Periodic checks and observations will be made on the various hydraulic appurtenances to determine the operating characteristics of the stmuctures and the effect of operation on the structures.

(g) Measurement of pressures in the sluice barrel have been obtained and will be compared with pressures obtained in model tests. The apron and sluice barrels were inspected in 1953 to determine the effect of intermittent operation during the past 10 years.

(760) FONTANA DAM, PROTOTYPE CHECK TESTS.

(d) Field investigation; applied research.

(e) Plaster surface impressions of carefully located sections are taken after each extended period of tunnel operation to obtain evidence of damage. Entire tunnel is examined for erosion, cavitation damage, or structural failure.

(g) Inspections made in Sept. 1946, Oct. 1949, and May, 1950.

(761) KENTUCKY DAM, PROTOTYPE CHECK TESTS.

(d) Field investigation; applied research.

(e) Measurements are made of lateral pressures on the face of the spillway piers and on the submerged baffle piers on the spillway apron to be compared with the results of the model tests.

(g) Field measurements of crest and baffle block pressures were made in 1946 and 1950.

(762) SOUTH HOLSTON DAM, SURGE TANK PROTOTYPE CHECK TESTS.

(d) Field investigation; applied research.

(e) The prototype installation was equipped to allow testing in a manner similar to that used in the model studies which established the design. A check on the model accuracy can thus be obtained.

(g) Initial tests made in Feb. 1950.

(763) HIWASSEE DAM, PROTOTYPE CHECK TESTS.

(d) Field investigation; applied research.

(e) Measurements of pressure in sluices are being obtained for comparison with pressures measured in model tests.

(g) Field measurements of sluice pressures were made in 1943.

(1038) HALES BAR DAM, SPILITIAY APPROACH STUDIES.

(d) Experimental; for design.

(e) Tests are made on a 1:65 model to determine effect of the remains of cofferdam structures upstream of the spillway on the spillway discharge and to determine amount of the obstructions which should be removed.

(f) Model tests completed.

(h) Report in preparation.

(1273) HALES BAR DAM, MISCELLANEOUS STRUCTURES STUDIES.

(d) Experimental; for design.

(e) Tests were made on a 1:65 model to determine location of trash boom and head-water gage intake for a new powerhouse.

(h) Report in preparation. 
(1274) BOONE DAM, SPILLWAY MODEL STUDIES.

(d) Experimental; for design.

(e) Tests are made on a 1:50 model to determine proper dimensions for bucket-type spillway and associated training walls.

(g) The tests proved that for certain anticipated operating conditions for the bucket-type spillway can be advantageously used.

(h) Report in preparation.

(1277) WATAUGA DAM, PROTOTYFE CHECK TESTS.

(d) Field investigation; applied research.

(e) Outlet tunnel surfaces are inspected after completion and after extended periods of operation to determine erosion, cavitation damage, or structural failure.

(g) Initial inspection in Dec. 1949.

(1283) STEAM PLANT AIR POLLUTION STUDIES.

(d) Field investigation; design and operation.

(e) To obtain information for use in studies of air pollution and its control. Measurements of air temperatures, wind velocities and directions, and atmospheric sulphur dioxide are being obtained at Johnsonville, Shawnee, and hilows Creek Steam Plant areas. Air temperature, wind velocities, and wind directions are being measured at Colbert, Kingston, Gallatin and John Sevier Steam Plant areas.

(1534) FORT PATRICK HENRY DAM, SPILLWAY MODEL STUDIES.

(d) Experimental; for design.

(e) Tests are being conducted on a $1: 50$ scale and a $1: 112.5$ scale model to determine the apron design, training well dimensions, and other related data.

(g) An apron using a single row of rectangular baffle blocks was developed on the 1:50 scale model. This apron was then used in the $1: 112.5$ scale model and the necessary appurtenant structures developed. Of main interest in the developed design was the lack of training walls. Studies to determine the effect of vegetative growth on the island areas below the spillway showed which areas must be kept free of growth and which may be allowed to grow up.

(h) Report in preparation.

(1535) DEVELOPMENT OF ERODIBLE BED MATERIAL FOR USE IN MODEL TESTING.

(d) Experimental; developmental.

(e) An erodible material that will start to move at model velocities comparable to the anticipated velocity at which the prototype material will erode is needed when erosion tests are to be made for areas in which steep banks or cliffs exist. Experiments are under way to develop such a material.

(g) Iimited success has been achieved. Experiments are continuing.

(1536) VHF RADIO GAGES FOR REPORTING RAINFALL AND RIVER STAGES.

(d) Experimental; development.

(e) Standard FM tone modulated 169 - 172 Mc. radio equipment has been modified to transmit pulsed signals produced in a specially designed electro-mechanical converter unit (keyer). This keyer can be directly operated for river stage measurement by the conventional float system. By use of an electrical servo system, rainfall caught in a standard weighing type gage can be transmitted to the keyer unit. Standard VHF radio station transmitterreceiver units have been modifled for use as automatic repeater units. A printing type recorder operated by a standard VHF, FM receiver suitably modified, records and prints all transmitted signals on a 5 inch tape. All transmitting units are supplied with at least 3 days emergency power in case of $\mathrm{AC}$ power failure. Suitable signals indicate when any gage is on emergency power.

(g) Four receiving systems which include 7 stream gages, 2 rainfall gages, 5 repeater stations, and 4 receivers have been installed and operated up to one year very satisfactorily. Installation is continuing. 
(1794) WATTS BAR LOCK PROTOTYPE TESTS.

(d) Fleld investigation; applied research.

(e) The prototype installation was equipped with piezometers to allow checking of culvert and port pressures and discharges. The culverts and ports were designed from model studies. Thus, measurement on the prototype would provide model-prototype verification data.

(f) Complete field tests were conducted in May, 1952.

(h) Reduction of data is being completed.

(1795) HALES BAR DAM, PROPOSED LOCK LOCATION STUDIES.

(d) Experimental; for design.

(e) To determine the most expeditious location for the proposed 110 by 600 foot lock, tests are being made on a $1: 65$ scale model. Effect of changes is determined by measurement of bow and stern forces on model tows and by measurement of wave heights in the navigation channel.

(f) Tests on downstream conditions are completed with tests yet to be made on upstream conditions.

(g) The study showed that any of the proposed locations were satisfactory and that only the minimum length of lower guide wall was required.

(h) Report in preparation.

(1796) KINGSTON STEAM PLANT, CONDENSER WATER INIAKE TEMPERATURE STUDIES.

(d) Theoretical and field investigation; design.

(e) The condenser water intakes and outlets draw water from and discharge into watts Bar Reservoir (Tennessee River). During the warmer portions of the year this reservoir becomes stratified and the inflowing waters pass through the reservoir as density currents. By means of theoretical considerations and field observations, the proper location and shapes for the intakes and outlets are to be determined and the probable intake temperature calculated.

(g) Six-point recording temperature gages were installed on the Tennessee, Clinch, and Emory Rivers and data obtained during the period of stratification in 1953. Velocity and temperature profile measurements were made at eight sections in the Clinch and $E_{m o r y}$ Rivers for periods of steady flow to define thermal density underflow.

(h) "Significant effects of density currents in TVA's integrated reservoir and river systems. Albert S. Fry, Milo A. Churchill, and Rex A. Elder, Proceedings, Minn. International Hydraulic Convention, 1953.

(1797) GALIATIN STEAM PLANI, CONDENSER WATER INTAKE TEMPERATURE STUDY.

(d) Theoretical and field investigation; design.

(e) The condenser water intakes and outlets are to draw water from and discharge into the proposed Old Hickory Reservoir (Cumberland River). The entire setup is to be analyzed to determine the type of flow conditions to be expected in the reservoir; the temperatures to be expected at the inlets; and the best design for the inlets and outlet structures.

(g) Single-point temperature recorders were installed at six stations which can be used in connection with turbine intake temperature recorders to determine temperature increases between points on the Cumberland River for various conditions. Data are being collected and evaluated. A 1:60 model of the intake is being planned to provide data for design of the intake chamel to provide minimum disturbance of flow.

(1800) WIDOWS CREEK STEAM PLANT - DIRECTIONAL DUST COLLECTORS.

(d) Field investigation; design and operation.

(e) To obtain information on the sources of dust in the steam plant area, three direction dust collectors were designed and installed. The collected material is analyzed for amount of catch and mineral constituents.

(f) Suspended. Replaced by non-directional collectors. 
(2023) PERSIMON CREEK DAM, SPILLWAY RATING.

(b) U. S. Forest Service.

(d) Experimental; operation.

(e) Tests on a 1:30 model of an arched dam to determine free discharge spillway rating.

(f) Completed and rating curves issued.

(2024) BOONE DAM, SLUICE RATING.

(d) Field investigation; operation.

(e) Measurement of discharges and differential pressures in the sluice will be used to establish the discharge rating.

(g) Field tests have been made and tables of discharge for any gate opening at any headwater elevation within the operating range have been issued.

(2025) DISCHARGE COEFFICIENTS FOR SPILLWAYS OF TVA DAMS.

(d) Experimental; applied research.

(e) Model tests for spillway crest shapes used by TVA are correlated and compared for gates and free discharge for submerged and unsubmerged flow.

(g) Discharge coefficients for standard crest and certain irregular crest shapes can be predicted from the dimensionaless plots.

(h) "Coefficients for spillways at TVA Dams" presented by Kenneth W. Kirkpatrick at ASCE Annual Meeting, New York, Oct. 1953 to be published as an ASCE Proceedings Separate.

(2026) WHEELER DAM, SPILLWAY RATING.

(d) Experimental; operation.

(e) A $1: 34.35$ model of 6 spillway bays was used to determine free discharge and gated discharge rating curves for all anticipated operating conditions.

(g) Discharge tables issued.

(2027) NOTTELY AND CHATUGE DAMS, HOWELL-BUNGER VALVE MODEL STUDY.

(d) Experimental; design.

(e) The 78-inch Howell-Bunger valve is to be used as a bypass valve discharging from the turbine scroll case into the tailrace channel. A l:2L scale model was used to study the jet distribution and the structures necessary to protect the tailrace channel.

(g) The discharge jet was heavier on one side due to spiral flow in the scroll case. Only minor changes were required to the draft tube roof to prevent erosion of the tailrace channel. The tailwater effectively contai ned the jet within bank limits. Memorandum reports have been prepared.

(h) Discussion of "Characteristics of fixed dispersion cone valves." Rex A. Elder and Gale B. Dougherty, page 943, Trans. ASCE, Vol. 118, 1953.

(2028) JOHN SEVIER STEAM PLANT, INTAKE DAM.

(d) Experimental; design.

(e) A 1:50 scale model was used to study the energy dissipating characteristics and the erosion tendencies of the cascade-type water diversion dam.

(g) The model studies showed that an end sill 4 feet high, instead of 2 feet, provided excellent operation. These studies also showed that this simple apron was effective in front of the gates, which eliminated a more elaborate and expensive apron.

(h) A memorandum report was prepared.

(2029) APAIACHIA POWER TUNNEL, PROTOTYPE CHECK TESTS.

(d) Field investigation; operation.

(e) Periodic inspections of the power tunnel will be made to determine change in subsurface roughness. Field test measurements will be made to determine the change in friction and roughness coefficients.

(g) The tunnel was inspected in 1953 after 10 years of continuous operation. Field pressure measurements are to be made to determine the change in friction coefficients as compared to those obtained as reported in project 757 in Hydraulic Research in the United States, Vol. 14, May, 1950. 
(2030) BOONE DAM, SPILLWAY RATING.

(d) Experimental; operation.

(e) Model tests, checked by field measurements, are to be used in determining the spillway discharge ratings for all anticipated operating conditions. Discharge tables for operating purposes will be prepared.

(f) Model studies completed.

(2031) FORT PATRICK HENRY DAM, SPILLWAY RATING.

(d) Experimental; operation.

(e) Model tests, checked by field measurements, are to be used in determining the spillway discharge ratings for all anticipated operating conditions. Discharge tables for operating purposes will be prepared.

(f) Model studies completed.

Hydraulic Investigations Section.

(764) DETERMINATION OF SEDIMENT CARRIED IN SUSPENSION BY TENNESSEE RIVER AND TRIBUTARIES.

(d) Field investigation; basic research.

(e) To provide data for estimating effective life of storage reservoirs, and loss of soil from the land. Samples of water were collected periodically at stream gaging stations in the watershed, analyzed to determine the sediment content, and correlated with river discharge to determine the suspended sediment load at each station.

(h) Report in preparation.

(765) EVAPORATION IN THE TENNESSEE BASIN.

(d) Field investigation; applied research.

(e) To provide data for estimating reservoir losses and derive a general rule, applicable to the Basin, permitting computation of evaporation from pans at six locations in Basin together with standard meteorological readings.

(g) No serious leakage conditions have been found.

(h) Preliminary report prepared for internal use.

\section{(767) RESERVOIR RIM INVESTIGATIONS.}

(d) Field investigation; basic research.

(e) To determine the leakage, through rims of new reservoirs, and to check conditions for other reservoirs. Ground-water levels are observed and post-impoundage levels compared with pre-impoundage records; stream flow from rim areas is measured to determine whether any increase has occurred after creation of a reservoir.

(g) Preliminary report prepared for internal use. No serious leakage conditions have been found.

\section{(768) PRECIPITATION IN TENNESSEE RIVER BASIN.}

(d) Field investigation; basic research.

(e) A comprehensive study of rainfall and other weather phenomena for purposes of water dispatching and improvements in water control; storm studies as related to maximum preci itation, rainfall-runoff, spillway design and operation, etc.

(h) Monthly bulletin, "Precipitation in Tennessee River Basin." Also anmal summary.

(769) RESERVOIR AND STREAM TEMPERATURES.

(d) Field investigation; basic research.

(e) Study of water utilization and water movement as concerns industrial plant locations and stream pollution. Variations in temperature from surface to bottom in reservoirs throug out the year are determined by soundings, and by contimous recording gages in natural streams. 
(771) GALIERY DRAINAGE IN LARGE DAMS.

(d) Field investigation; design.

(e) Weirs are placed in main galleries and drainage measured as check on tightness and stability.

(h) Reports prepared anmally for internal use.

(778) EFFECT OF ALTITUDE UPON RAINFALI.

(f) Completed.

(h) "Some precipitation--altitude studies of the Tennessee Valley Authority." James Smallshaw, Trans. Amer. Geophys. Union, Aug. 1953.

(783) WHITE AND RICHLAND CREEKS--DETERMTNATION OF ROUGHNESS COEFFICIENT.

(d) Field investigation; basic research.

(e) Determinations being made in several river reaches of known di scharge to extend knowledge of relation between roughness coeffizient and physical characteristics of rivers.

(785) SEDIMENTATION OF EXISTING RESERVOIRS.

(d) Field investigation; basic research.

(e) Selected ranges in reservoirs are probed and sounded, volumetric samples are collected and analyzed, quantity and distribution of sediment are computed to determine deposition by stream, probable life of reservoir, effect of sediment storage on navigation channels and sedimentation of downstream reservoirs, and probable sedimentation in future reservoirs.

(786) WATER TRAVEL IN NATURAL STREAMS.

(d) Field investigations; applied research.

(e) Sanitary and chemical changes in water during passage downstream are determined. A given mass of water is identified by electrical conductivity or chemical titration.

(787) MOVEMENT OF WATER THROUGH IARGE RESERVOIRS.

(d) Field investigation; applied research.

(e) Because of slow water travel, samples are collected by traverse through lake.

(g) Wentering a reservoir does not intermix with the rest of the reservoir, but remains as a density current as a result of the difference in temperature between the inflowing water and that in the reservoir. During certain seasons of the year, in watts Bar Reservoir the cold water released from Norris Reservoir passes upstream along the bottom of the Emory River arm of the former reservoir.

(1284) RESERVOIR SEDIMENT DENSTTY SAMPLER.

(b) Cooperative with Federal Inter-Agency River Basin Committee, Subcomittee on Sedimentation.

(d) Experimental; applied research, design, operation, development.

(e) Laboratory testing of the device for making in-place density measurements of deposited reservoir sediment was contimued. Tests showed that strontium 90 was not a suitable source. Thallium 204 appeared to have possibilities and further experimentation is planned.

Hydrology Section.

(777) RUNOFF-EROSION INVESTIGATIONS ON SMALI WATERSHEDS.

(d) Field investigation; basic and applied research.

(e) To evaluate hydrologically existing or changed land-use practices or management. Data are obtained on rainfall, munoff, and soil loss, and in some instances include groundwater levels and soil moisture. 
(779) MAXIMUM POSSIBIE PRECIPITATION IN TENNESSEE VALLEY.

(b) Cooperative with U. S. Weather Bureau.

(d) Theoretical; applied research.

(e) Hydrometeorological analysis of large storms with upward adjustments of controlling factors to maximum limits as applied to the Tennessee Valley and subdivisions.

(g) Results to be published as one of current series of hydrometeorological reports by the U. S. Weather Bureau and cooperating agencies.

(780) MONTHLY EVALUATION OF GROUND-TATER STORAGE.

(d) Theoretical; operation.

(e) By analysis of current records of stream discharge, the volumes of runoff in groundwater and channel storage are determined for use in operation of multi-purpose reservoirs.

(g) Results reported monthly within the organization.

Procedures Development Section.

(1801) RAIN GAGE IOCATION STUDIES--SOUTH CHICKAMAUGA CREEK WATERSHED.

(d) Field investigation; applied research.

(e) A study to learn the most applicable location and necessary density of rain gages to obtain an accurate record, particularly for river forecasting purposes, in a basin having mumerous parallel ridges, and to compare several methods of computing average rainfall and of estimating runoff. Three recording and 11 nonrecording rain gages, in addition to 4 existing nonrecording gages, were established in the South Chickamauga Creek watershed, which has a drainage area of 428 square miles.

(g) Daily observations began December 1, 1952. Two recording and 8 nonrecording gages are being discontimed December 1, 1953.

(h) Results reported monthly within the organization.

(2032) DEVELOPMENT OF RIVER FORECASTING METHODS.

(d) Experimental; applied research.

(e) Studies to develop improvements to river forecast procedures with particular application to streams and local inflows into reservoirs operated by the TVA. Procedures include

(1) rainfall-munoff relations involving the effect of soil moisture, evapo-transpiration and interception losses, geological features of the watersheds, and seasons; (2) unit surface-water and ground-water hydrographs; (3) streamflow routing procedures; (4) coordinated studies with an established unit of the U. S. Weather Bureau for determination of natural flows at pertinent river points. 
UNIVERSITY OF BRITISH COLUMBIA, Hydraulics Laboratory.

Inquiries concerning Projects Nos. 1044, 2033 to 2038 incl., should be addressed to Prof. Edward S. Pretious, Department of Civil Engineering, University of British Columbia, Vancouver, Canada.

(1044) FRASER RIVER MODEL.

(b) Cooperative with the Department of Public Works of Canada.

(d) Experimental; to assist in problems of river regulation and control.

(e) An outdoor erodible-bed tidal river model to study methods for improving and maintaining the navigable channels of the lower Fraser River estuary. Hnrizontal scale 1:600, vertical scale 1:70. The model represents the tide water area of the lower Fraser River from the Strait of Georgia to Sumas, and includes Pitt River and Pitt Lake. Natural tides and river discharges can be simulated in the model. Sand injection, automatically controlled is a function of river discharge. Instantaneous water surface slopes can be obtained by automatic electrically recording point gauges.

(h) Progress and technical reports submitted periodically.

(2033) VANCOUVER HARBOUR MODEL.

(b) Cooperative with the National Research Council of Canada.

(d) Experimental; to determine the hydraulic effects of dredging the First Narrows in Burrard Inlet.

(e) An outdoor fixed-bed model to investigate the effect on tides and current patterns in Vancouver Harbour and current velocities in Second Narrows due to dredging the First Narrows. Pilot model of First Narrows being constructed initially, with horizontal scale 1:400, vertical scale 1:100, to determine required roughness for this distortion.

(h) Progress and techrical reports submitted periodically.

(2034) OKANAGAN FLOOD CONTROL DROP STRUCTURES.

(b) Cooperative with the Dominion Department of Fisheries.

(d) Laboratory experimental project to determine designs suitable for salmon migration.

(e) Wooden models built and tested in steel and glass flume. Scale 1:25 using ore half of the structure which is symmetrical about the center line, and scale 1:10 of a central portion of structure. Tests conducted to find the best method of control with provision for fishway structures. Modifications in bucket design as an alternative to fishway structures.

(f) Completed.

(h) Report in preparation by sponsor.

(2035) OKANAGAN FLOOD CONTROL DROP STRUCTURES.

(b) Cooperative with the Department of Public Works, Province of British Columbia.

(d) Laboratory experimental project to investigate the hydraulics of bucket designs, using multiple notches and single converging openings as alternative methods of control.

(e) Wooden 1:20-scale model built and tested in steel and glass flume. Large scale made possible by testing one half of structure which is symmetrical about center line.

(f) Completed.

(2036) PUMP TESTS.

(b) Cooperative with the Bingham Pump Company Itd.

(d) Laboratory tests to determine operating characteristics of industrial pumps.

(e) Acceptance tests made on two types of oil refinery pumps using the laboratory D. C. Cradled Dynamometer and weighing tanks.

(f) Completed.

(2037) FISHWAY FOR SETON CREEK DAM (B. C. ELECTRIC CO. ITD.).

(b) Cooperative with the International Pacific Salmon Fisheries Commission. 
(d) Laboratory experimental project to determine best design of fishway to function with adjacent siuiceway in dam. Modifications in the design of the tail-bay necessary for suitable approach conditions.

(e) Woden l:10 scale-model built and tested in large concrete flume. Fishway, adjacent sluiceway, one siphon spillway and portion of tail-bay used in tests.

(f) Completed.

(h) Report in preparation by sponsor.

(2038) SETON CREEK DAM AND APPURTENANCES (B. C. ELECTRIC CO. ITD.).

(b) Cooperative with the British Columbia International Engineering Company Ltd.

(d) Laboratory experimental project to test proposed design and hydraulics of tail-bay.

(e) Woden 1:24-scale-model built and tested in large concrete flume. Model will include fishway, sluiceway, tainter gate, 5 siphon spillways. Since the main purpose of the model is to check the design of the tail-bay, only the outlet legs of the siphons will be simulated. The siphons will then be operated to pass the required discharge.

\section{MCGILI UNIVERSITY.}

(2039) IOSSES AT BENDS IN STEEL PIPING CARRYING WATER-BORNE SUSPENSION OF WOOD-PULP.

(b) Laboratory project.

(c) Prof. V. W. G. W. Ison, Dept. of Civil Engineering, McGill University, Montreal 2, Canada.

(d) Experimental.

(f) Completed for 4 -inch diameter pipe.

(h) Report in preparation.

(20LO) SUPER-CRITICAL FLOW IN CURVED CHANNEL.

(b) Laboratory project; for graduate thesis.

(c) Prof. C. Craig, Dept. of Civil Engineering, McGill Universitj, Montreal 2, Canada.

(d) Experimental.

(f) Completed.

(h) Report in preparation.

ÉCOLE POLYTECHNIQUE DE MONTREAL, Hydraulics Laboratory.

Inquiries concerming Projects Nos. 266, 268, and 1803 should be addressed to Prof. Raymond Boucher, École Polytechnique, Montreal 18, Canada.

(266) HYDRAULIC MODEL STUDIES OF DIFFERENT SPILLWAY PROFILES.

(b) Laboratory project.

(d) Experimental; applied research.

(e) To establish a comparison between the discharge capacities of different spillway designs. Studies are made on concrete models of existing and recommended spillway profiles. Pressure distribution on spillway faces and coefficients of discharge are determined for various heads up to the designed head. The effect of gate piers of various design is also investigated. Eight different profiles have been studied, including two modifications of the Creager profile upstream of crest line.

(f) Suspended.

(268) CALIBRATION TESTS OF A SHARP-CRESTED PARABOLIC WEIR.

(b) Laboratory project. 
(d) Experimental; applied research.

(e) To obtain the head-discharge curves and head-discharge coefficient curves for a sharpcrested parabolic weir (2l-inch maximum width by 18-inch maximum height) having a capacity of $3 \mathrm{cfs}$. The influence of viscosity is also being investigated. This weir is to be used in a flume for model testing and open channel studies.

(f) Nearly completed.

(79I) NEW METHOD OF UTIIIZING THE WATER HAMMER FOR THE DETECTION OF LEAKS IN PIPES.

(f) Discontinued.

(1803) MODEL STUDY OF LAC BETSY LOGWAY.

(f) Completed.

(g) Report in preparation.

NATIONAL RESEARCH COUNCIL, Division of Mechanical Engineering.

Inquiries concerning Projects Nos. 1806, and 2041 to 2043, incl., should be addressed to the Director, Division of Mechanical Engineering, National Research Council, Montreal Road, Ottawa, Canada.

(1806) ST. IAWRENCE RIVER MODEL - PRESCOTT-CARDINAL REACH.

(b) Laboratory project.

(d) Experimental; for design and operation.

(e) A I:500 by 1:50 scale model of the St. Lawrence River between the towns of Prescott and Cardinal has been constructed to study the effect of engineering works to be made in connection with the proposed seaway. The first phase of the project has been completed.

(g) The gauge relationship was successfully verified with the prototype by adding roughness in the form of screens made from expanded metal. Because it is desired to investigate problems for which the model was not designed, a new model of reduced distortion is required. A design having scales of $1: 250$ by $1: 50$ is being studied.

(20LI) ST. LAWRENCE MODEL - CORNWALL REACH.

(b) Laboratory project.

(d) Experimental; for design and operation.

(e) A 1:500 by $1: 100$ scale model of five miles of the St. Lawrence River near Cornwall is being designed in order to study the design of engineering works for the proposed seaway. Preliminary designs being made and construction methods being studied.

(20L2) LOCK MODEL.

(b) Department of Transport.

(d) Experimental; for design.

(e) A 1:30 scale model, now under construction, of an 800-foot navigation lock will be used to study lock filling systems and procecures.

(2043) FILLING PORTS FOR I.OCK.

(b) Department of Transport.

(d) Experimental; for design.

(e) A l:I5 scale model of three lock filling ports and a section of the supply conduit have been constructed to obtain design data. The filling ports, which are also used for emptying the lock, will be tested with the flow in both directions. The models and measuring equipment are being arranged for testing. 
QUEEN'S UNIVERSTTY, Hydraulics Laboratory.

Inquiries concerning Projects Nos. 1807 and 2044, should be addressed to Prof. R. J. Kennedy, Dept. of Civil Engineering, Queen's Umiversity, Kingston, Ontario, Canada.

(1807) STUDY OF CUBE-TIPPED PITOT TUBE.

(b) Laboratory project.

(d) Expe rimental; basic research.

(e) To develop methods of measuring flow in pipes by means of a cube-tipped pitot tube.

(2044) ECONOMICAL CONSTRUCTION OF SAFE PULPWOOD HOLDING GROUNDS.

(b) Pulp and Paper Research Institute of Canada Ltd., 3420 Uni versity Street, Montreal, Quebec, Canada.

(d) Applied research; experimental field and laboratory investigation.

(e) Field and laboratory model investigation of forces acting on various types of pulpwood holding grounds is in progress.

UNIVERSTTY OF TORONTO, Department of Mechanical Engineering.

Inquiries concerming Projects Nos. 1295, 2045 and 2048, incl., should be addressed to Prof. G. Ross Lord, University of Toronto, Toronto 5, Canada.

(1295) THE DESIGN OF EXPANDERS FOR PIPE EXITS.

(b) Laboratory project.

(d) Experimental; applied research and masters thesis.

(e) This is a resumption of earlier work with the purpose of developing efficient expansion devices to be placed at the end of pipes discharging into tanks or experimental channels.

(20L5) MODEL STUDY OF BEARSPAW SPILLWAY.

(b) Montreal Engineering Company Limited.

(d) Experimental; for design.

(e) Tests were conducted on a 1:80 scale model for the purpose of designing a stilling basin below the spillway.

(f) Completed.

(h) Reported to sponsor.

(20L6) MODEL STUDY OF ICE PROBLEMS CONNECTED ILTH A SMALL DAM.

(b) Ontario Department of Planning and Development.

(d) Experimental; design.

(e) The study is for the purpose of ascertaining the best method of holding ice above the dam and discharging it in quantities which will not cause jams downstream.

(2047) THE INFLUENCE OF SCALE ON THE DETERMINATION OF SPILLWAY DISCHARGE CHARACTERISTICS FROM MODELS.

(b) Laboratory project.

(c) Prof. I. E. Jones, Uni versity of Toronto, Toronto 5, Canada.

(d) Experimental; applied research and masters thesis.

(20L8) SYSTEMATIC REVIEW OF SPILLWAY MODEL RESULTS.

(b) Laboratory project.

(c) Prof. L. E. Jones, University of Toronto, Toronto 5, Canada.

(d) An analytical stuay.

(e) The results of a number of years of research on model spillways is being studied with a view to systematizing discharge characteristics for spillways having various pier spacin and proportions. 
ccelerated motion

disks (813)........................ 12 spheres $(1104) \ldots \ldots \ldots \ldots \ldots \ldots \ldots \ldots . . . . . . . . . .45$ (1923)......................... 78

ir entrainment

flumes $(100) \ldots . . . \ldots \ldots \ldots . . . . . . . . .79$

models $(995) \ldots \ldots \ldots \ldots \ldots \ldots \ldots \ldots \ldots . . \ldots \ldots$

pipes $(1303) \ldots \ldots \ldots \ldots \ldots \ldots \ldots \ldots \ldots . . \ldots \ldots$

turbines $(1305) \ldots \ldots \ldots \ldots \ldots \ldots \ldots \ldots . . \ldots \ldots$

weirs $(1869) \ldots \ldots \ldots \ldots \ldots \ldots \ldots . . . \ldots \ldots 47$

ir pollution (1283) .................. 171

irfield drainage

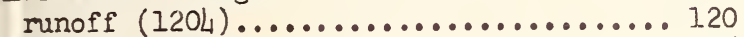

iirfoils, cascades (1118).............. 55

airship, hydrodynamic coefficient (1408).. 86

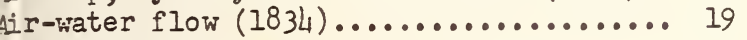

ir-water mixtures

measurement of pressure in (1889) ...... 58

sampling techniques $(1886) \ldots \ldots . . . \ldots .58$

Ipparatus

channels, rotating (279)............. 3

coast model basin (973).............. 115

cyclone, Iiquid-liquid (IILI)......... 69

" " solid $(905)(906) \ldots . . . .68$

flood forecasting (1010).............. 138

permeameter, wall effect (II72)....... 78

photo-electric, sediment (1331)....... 31

polariscope, design (1546)............ 2

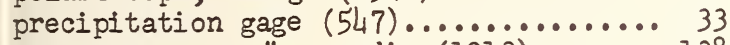

" "radio (1012)....... 138

pressure recorder $(791) \ldots \ldots \ldots \ldots \ldots \ldots . . . . .179$

propeller measuring $(1411)(1412) \ldots . . .887$

rotating arm $(1781) \ldots \ldots \ldots \ldots . . . . . . . .161$

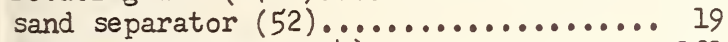

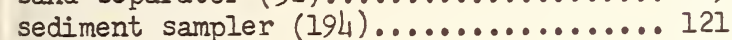

ship models (1788) ................. 162

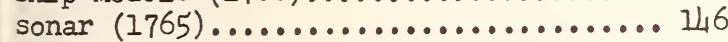

stream gage (1013) ................. 139

tank, electrolytic (470)............. 156

tilting design (1336).............. 37

water tunnel (79) ................. 42

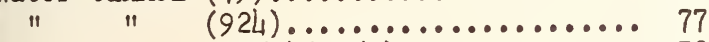

" $"$ (1150)(1151)........... 72

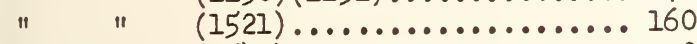

$" \quad " \quad(1547) \ldots \ldots \ldots \ldots \ldots \ldots \ldots \ldots 2_{2}$

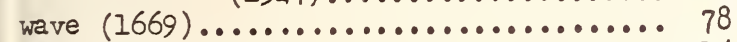

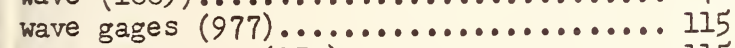

wave generator (973) ............... 115

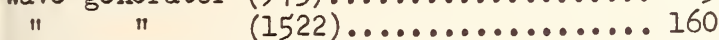

wave recorder, airborne (1460)........ 115

wave tank (399)................... 114

wind tunnel (1152)................. 73

3ackwater

constricted channels (1332)........... 31

$"$ " $\quad(1853) \ldots \ldots \ldots \ldots . . \ldots 32$

Baffle piers

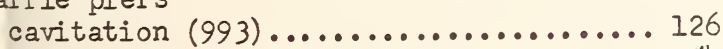

drag $(1611) \ldots \ldots \ldots \ldots \ldots \ldots \ldots \ldots . \ldots \ldots . \ldots \ldots$

Barges

resistance $(585)$

62
Beaches

by-passing sand, inlets (975)........ 115

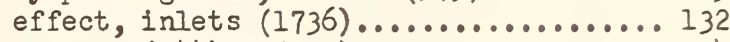

" , jetties (970)..................114

equilibrium profile $(181) \ldots \ldots \ldots \ldots \ldots 113$

model laws $(184) \ldots \ldots \ldots \ldots \ldots \ldots \ldots \ldots \ldots \ldots$

structures, design (972)............. 115

tidal effects $(1725) \ldots \ldots \ldots \ldots \ldots \ldots$

wave action (47)................... 10

$n \quad " \quad(529) \ldots \ldots \ldots \ldots \ldots \ldots \ldots \ldots \ldots \ldots 12$

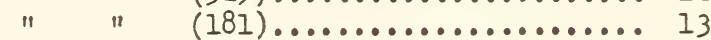

$" n(660)(661) \ldots \ldots \ldots \ldots \ldots \ldots . \ldots \ldots$

" $"$ (1609)...................... 54

" $"$ (1631).................663 63

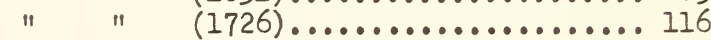

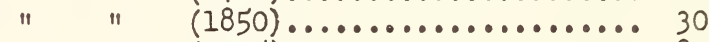

" $"$ (1935).................. 81

Bends (see Pipes, bends)

open channeI $(1304) \ldots . . . \ldots \ldots . . . \ldots 13$

Bibliographies

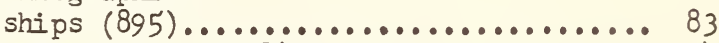

Boundary flow $(1301) \ldots \ldots \ldots \ldots \ldots \ldots \ldots \ldots$

Boundary layer

conduits (290)..................... 27

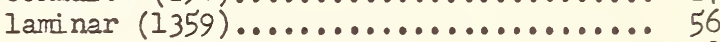

$(1503) \ldots \ldots \ldots \ldots \ldots \ldots \ldots \ldots \ldots \ldots \ldots . \ldots \ldots$

(1888) ........................ 58

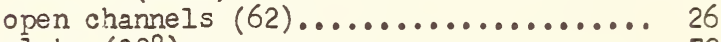

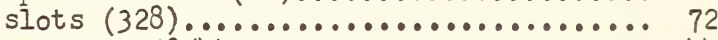

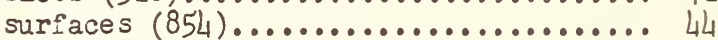

turbulent $(627) \ldots \ldots \ldots \ldots \ldots \ldots \ldots . . . \ldots . . . . .64$

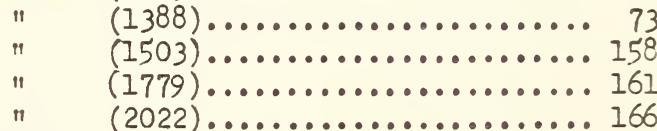

Breakwaters

pervious and impervious (998)......... 126 rubble-mound (257)................. 124

" $"$ (999)...................... 127

wave diffraction $(47) \ldots \ldots \ldots \ldots . . . . . .10$

Bridge piers

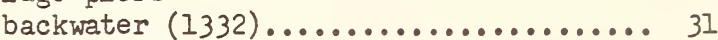

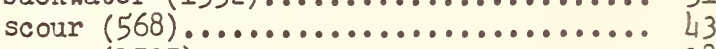

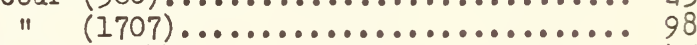

theory $(1344) \ldots \ldots \ldots \ldots \ldots \ldots \ldots . \ldots \ldots$

Bubbles

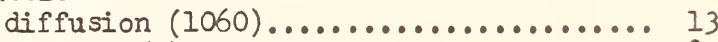

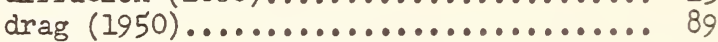

drag and shape $(1780) \ldots \ldots \ldots \ldots \ldots . . . \ldots 16$

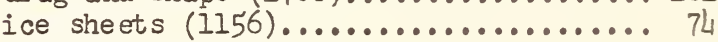

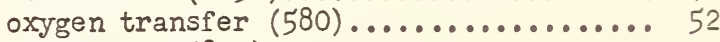

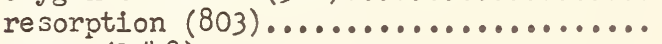

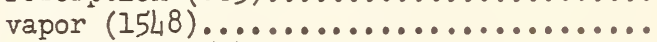

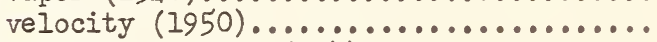

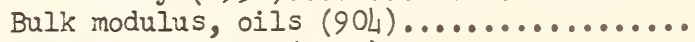

Cable depressors $(1932) \ldots . . . . . . . . . .$.

Canals

density currents $(\mathcal{L} 82) \ldots \ldots \ldots \ldots \ldots$ irrigation

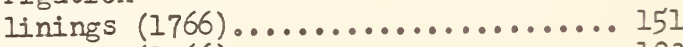

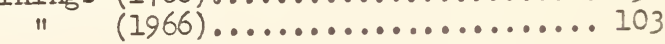


Canals

irrigation

linings (1966)...................151

seepage $(820) \ldots \ldots \ldots \ldots \ldots \ldots \ldots \ldots \ldots . . . .21$

(1091)................... 34

(1859)..................... 34

model study $(1595) \ldots \ldots \ldots \ldots \ldots \ldots \ldots \ldots . . .46$

(2010)................... 155

navigation, silting $(i 737) \ldots \ldots \ldots \ldots \ldots . \ldots 132$

scour on curves (1501)................151

structures $(2004) \ldots \ldots \ldots \ldots \ldots \ldots \ldots . . . .153$

Capillary potential (1576)............. 28

Cavitation

baffle piers (993)................. 126

basic research

Calif. Inst. of Tech. (15) $\ldots \ldots \ldots \ldots \ldots\}_{n}^{3}$

David Taylor Model Basin (711)....... 157

Iowa State University (79) .......... 42

" " (81).......... 43

Mass. Inst. of Tech. (579).......... 52

Northwestern Univ. (326)........... 68

Penna. State College (1386).......... 73

haterways Experiment Station (993).... 126

boundary mi salignment $(90) \ldots . . . . . . .50$

bubbles

air nuclei $(804) \ldots \ldots \ldots \ldots \ldots \ldots \ldots \ldots . . . \ldots \ldots$

cavity flow (1301)................

conduit contractions $(72) \ldots \ldots \ldots \ldots \ldots, 42$

damage from $(1815) \ldots \ldots \ldots \ldots \ldots \ldots \ldots \ldots . . .4$

dynamics of $(803) \ldots \ldots \ldots \ldots \ldots \ldots \ldots . . . \ldots 3$

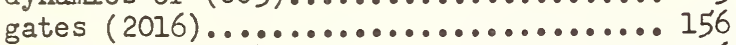

gate slots $(993) \ldots \ldots \ldots \ldots \ldots \ldots \ldots \ldots . . \ldots 126$

inception $(1355) \ldots \ldots \ldots \ldots \ldots \ldots \ldots \ldots . . . . .53$

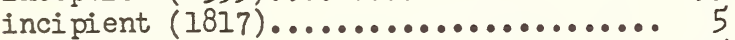

intake $(674) \ldots \ldots \ldots \ldots \ldots \ldots \ldots . \ldots \ldots . \ldots . \ldots 125$

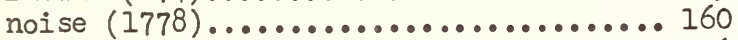

offset joints $(993) \ldots \ldots \ldots \ldots \ldots \ldots \ldots . . .126$

pi pe bends (993).................... 126

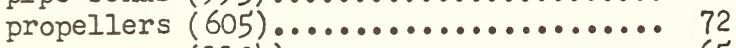

$(1134) \ldots \ldots \ldots \ldots \ldots \ldots \ldots \ldots, 65$

(1531) ...................... 166

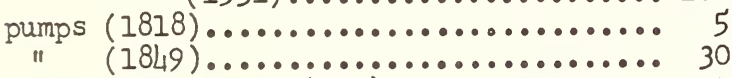

rotating channels (279).............. 3

rough surfaces $(2005) \ldots \ldots \ldots \ldots \ldots \ldots \ldots . . .153$

scale effects (1817)................ 5

sluice gates (79).................... 42

stilling basin steps $(993) \ldots \ldots \ldots \ldots \ldots 126$

tip vortex (1387)................. 73

turbines

models (1133).................... 65

propeller (271)................. 1

unsteady motion $(579) \ldots \ldots \ldots \ldots \ldots \ldots \ldots . \ldots \ldots 2$

valves $(2015) \ldots \ldots \ldots \ldots \ldots \ldots \ldots \ldots \ldots \ldots . \ldots 156$

water tunnel $(79) \ldots \ldots \ldots \ldots \ldots \ldots \ldots . . . . . .42$

Cavities

$(1671) \ldots \ldots \ldots \ldots \ldots \ldots \ldots, 78$

shape (1386).......................

Channel improvement

flood control

Allentom, $\mathrm{Pa}$. (1469).
Cumberland, Md. (230)............... 123

F arm Creek, Ill. (987)............. 125

Hoosic River, Mass. (1211).......... 128

Los Angeles River (1203)............ 120

Middle Miss. River (236) ............ 123

navigation

Charleston Harbor, S. C. (678)........ 125

Delaware River, $\mathrm{Pa}$. (425)............ 124

Fraser River (1044)............... 177

Miss. River, N. J. (989)............ 125

Valdivia River, Chile (1468)......... 130 power development (1470).............. 130 Channels (see Open channels)

alluvial (1313)................... 23

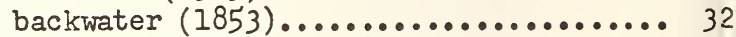

boundary roughness ( 1854$) \ldots \ldots \ldots \ldots \ldots . . .32$

conservation linings (152)(153) ........ 102

constricted flow $(1855) \ldots \ldots \ldots \ldots \ldots \ldots . . . . .32$

converging, diverging (1558)........... 19

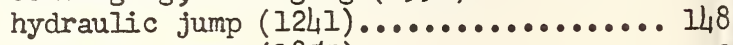

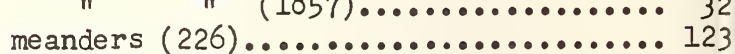

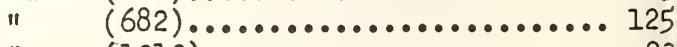

" (1313)................... 23

overfall $(1571) \ldots \ldots \ldots \ldots \ldots \ldots \ldots \ldots \ldots . . \ldots 26$

regime theory of (1839)............... 26

rotating flow (279)................. 3

super-critical flow $(2040) \ldots . . \ldots \ldots \ldots . . .178$

transition (1321)................. 26

trapezoidal (682).................. 125

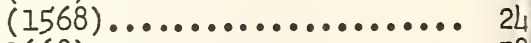

trinagular $(1668) \ldots \ldots \ldots \ldots \ldots \ldots \ldots \ldots . . . \ldots 78$

uniform flow (1924)................ 79

velocity distribution $(1304) \ldots \ldots \ldots \ldots . . .13$

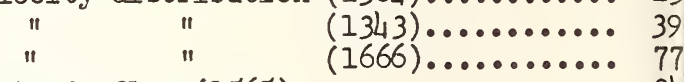

unsteady flow (1565)................ 24

Circulation, condenser water

Schuylkill River (1712)............. 100

Cofferdams

Dalles Dam, Ore. (1462)............ 117

Conduits

boundary layer (290)................ 27

discharge measurements $(2017) \ldots \ldots \ldots \ldots . .156$

entrances $(1833) \ldots \ldots \ldots \ldots \ldots \ldots \ldots . . . .19$

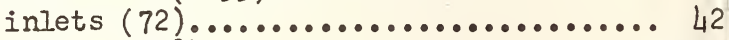

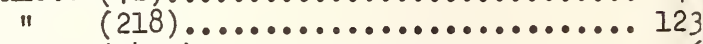

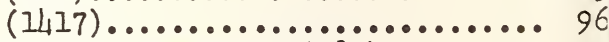

separation at expansions $(289) \ldots \ldots \ldots . .27$

varied flow (1698).................. 96

Constant volume tanks-air (1894)........ 59

Corrosion

basic research (1341)............. 37

condenser tubes $(472) \ldots \ldots \ldots \ldots \ldots \ldots . .164$

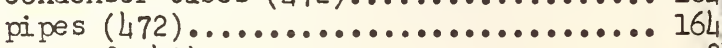

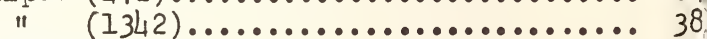

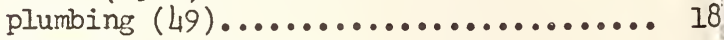

Culveris

discharge characteristics (1856)....... 32

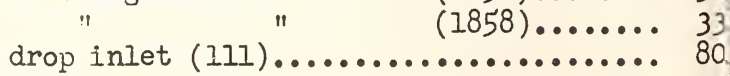


IIverts

entrance losses (1383).............. 70

inlet conditions $(1952) \ldots \ldots \ldots \ldots . . . . . .69$

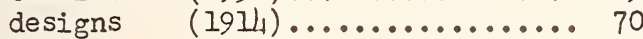

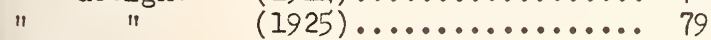

rinders

lift coefficients (1905)............. 62

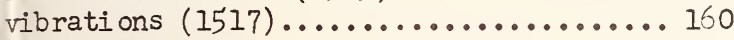
uns

gallery drainage (771) .............. 175

ice holding (2045)................... 180

ep-sea instrument station (1931)....... 81 insity currents

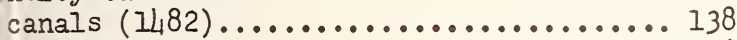
model laws $(159) \ldots \ldots \ldots \ldots \ldots \ldots \ldots \ldots \ldots \ldots$ reservoir

cold water $(1796)(1797) \ldots . . . . . . . .172$

sedimentation $(307) \ldots \ldots \ldots \ldots \ldots \ldots \ldots \ldots$

suspended sediment $(805) \ldots \ldots \ldots \ldots . . . . .3$

salt water intrusion

Delaware River (525)................ 124 stability of interface (1989) .......... 138 tidal estuaries (1986)............... 135 ffusers

varied (1901)

ffusion

gases (1566) (1616)

heat (822).

particles in sks

accelerated motion (813)............ 12

stillation, sea water $(1554) \ldots \ldots \ldots . . . .15$ -version channels, model studies (1976)... 119 aft tubes

efficiency

$"$

(1708)

(1851)

(1870)

ag

accelerated spheres (1923)

ainage

Coachella Valley, Calif. (26)..........

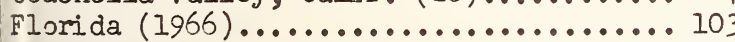

galleries, dams $(771) \ldots \ldots \ldots \ldots \ldots \ldots . . \ldots 175$

irrigated lands $(1302) \ldots \ldots \ldots \ldots \ldots \ldots . . . \ldots$

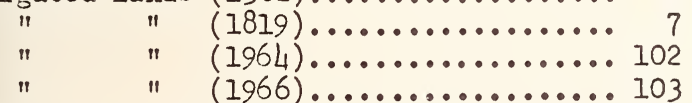

ain tile, disposal fields (1957)........ 95

$"$, junction losses (1929)........ 79

op structures $(1075) \ldots \ldots \ldots \ldots . \ldots \ldots . . \ldots 22$

1st collectors $(1800) \ldots \ldots \ldots \ldots \ldots \ldots . \ldots \ldots 172$

ist separators, cyclone (1884)......... 57

ldies, effect of boundary geometry (i875). 48

ectric analogy

three-dimensi onal (72) ............. 42

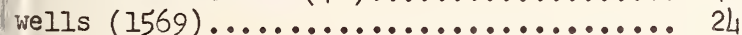

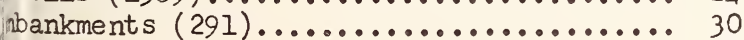

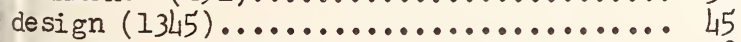

protection of $(1922) \ldots \ldots \ldots \ldots \ldots \ldots \ldots$

atry, water

airplanes $(14,05)$
Erosion research

canal, ditch linings (1966).......... 103

" " " (2013)............155

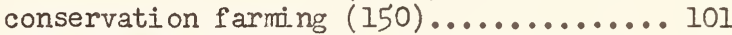

effect sediment characteristics (69).... 42 effect vegetation (261)............... 102

" $"$ ( 175$) \ldots \ldots \ldots \ldots \ldots \ldots 110$

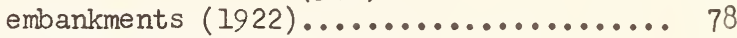

forest influences $(380) \ldots \ldots \ldots \ldots \ldots 12$

" $" \quad(657) \ldots \ldots \ldots \ldots \ldots \ldots . \ldots 110$

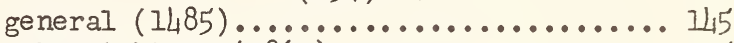

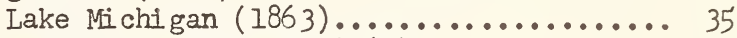

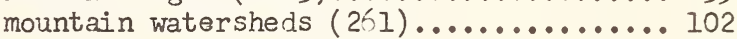

$(376) \ldots \ldots \ldots \ldots \ldots \ldots$

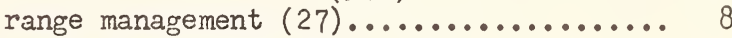

semi-desert vegetation $(657) \ldots \ldots \ldots \ldots . . . .110$

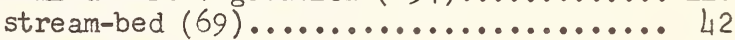

Evaporation

arid regions $(445) \ldots \ldots \ldots \ldots . . . \ldots . . . \ldots 143$ effect of reforestation (439)........... IL2 evapo-transpiration (1222)..............143

$(1996) \ldots \ldots \ldots \ldots \ldots \ldots$

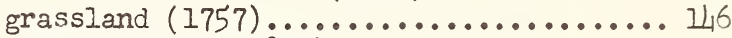

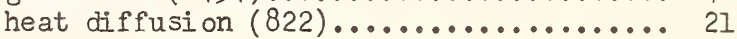

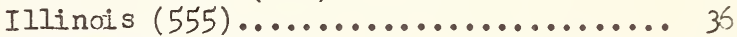

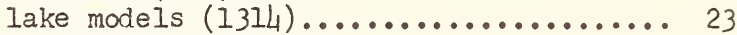

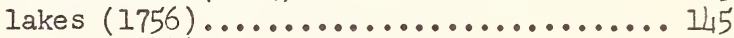

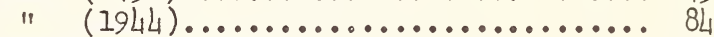

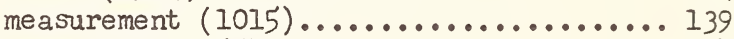

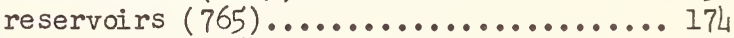

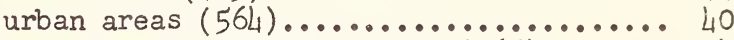
watersheds, Tennessee Basin (765)...... 171

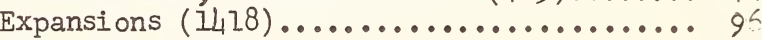

Filters $(1577) \ldots \ldots \ldots \ldots \ldots . \ldots \ldots . . \ldots \ldots$

Fish

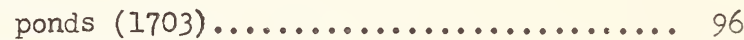

Fish ladders

culverts $(1554) \ldots \ldots \ldots \ldots . \ldots \ldots . . . \ldots 70$

dams

Dalles Dam, Ore. (1462) ........... 117

(1728) ............... 118

Fish screen, Delta-Mendota Canal (2011).... 155 Fishways model study (1974)............ 119

Flood control

(2037) ............... 177

basin, whittier Narrows (980) .......... 120

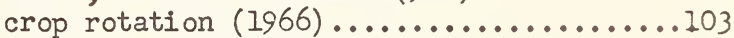

crop structures (2034) (2035) .......... 177

Hogback Dam (1961)................. 100 rivers

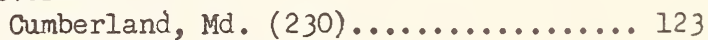

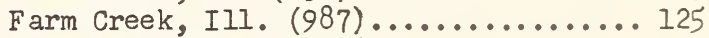

Mississippi Basin (236)............. 123

Flood discharge

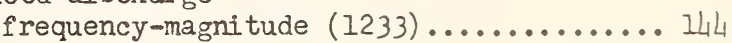

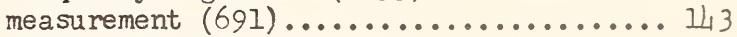

Miss. and Mo. Rivers, 1952 (1746)....... 140

probable maximum $(1747) \ldots \ldots . . . . . . .140$

Flow controller

coefficient of discharge (1844)..........

Flow between flat plates (1890)...........

86 Flow routing $(1943) \ldots \ldots \ldots \ldots \ldots \ldots . \ldots . \ldots . \ldots$ 
Flow, rotational nonviscous (2021)....... 166

Flow, supercritical (I8LO)............ 27

", surface curves (1840)........... 27

Flur dization $(1138) \ldots \ldots \ldots \ldots \ldots \ldots \ldots .66$

Fluidized solids, flow of (1882)........ 57

Fluids, physical properties (1340)...... 37

Flumes

air entrainment $(100) \ldots \ldots \ldots \ldots \ldots . \ldots 76$

tilting design (1336)............. 37

Frost in ground (1187)............... 109

Gas-liquid

distribution, porous media (1830)...... 18

Gas-liquid, flow (1829)............... 17

Gates

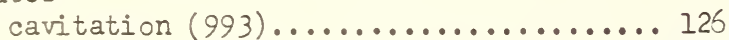

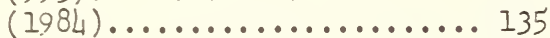

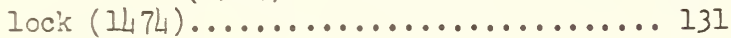

operation $(1206) \ldots \ldots \ldots \ldots \ldots \ldots \ldots \ldots . . .122$

(1252)................ 而9

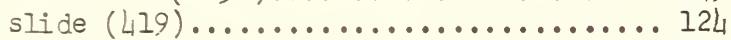

" (1255)...................... I49

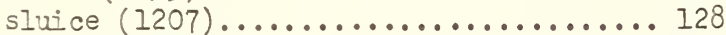

tainter $(980) \ldots \ldots \ldots \ldots \ldots \ldots \ldots \ldots \ldots . \ldots \ldots$

" (1598).......................45

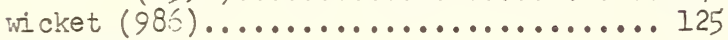

Ground water

artificial recharge (559)............ 39

(1965)............... 103

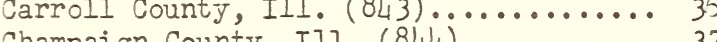

Champaign County, IIl. (844)......... 37

Chicago area (1335)................ 39

Coachella Valley, Calif. (25)......... 7

compilation of theories, formulas (1866) 39

East St. Louis area (561)............. 36

effect forests $(656) \ldots \ldots \ldots \ldots \ldots \ldots \ldots . \ldots 108$

" " (1997)...............147

electric flow net (1221).............143

fluctuations (821)................. 19

fresh water storage $(2000) \ldots \ldots \ldots \ldots$..... I4 7

frost (1574)..................... 28

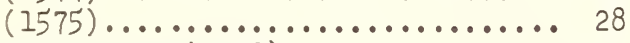

hydrologic cycle (1092)................ 37

hydrologic investigation (2001)....... 153

instruments, adaptation (1998)......... I4 7

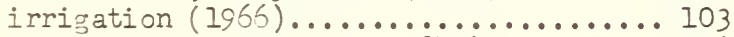

Jo Daviess County, Ill. (843)........ 35

Peoria area, Ill. (560)............... 39

Ralston Creek, Iowa (66).............. LI

Rapid Creek, Iowa (68)............... 41

ref orestation $(439) \ldots \ldots \ldots \ldots \ldots \ldots . \ldots 142$

reservoirs $(757) \ldots \ldots \ldots \ldots \ldots \ldots \ldots . \ldots \ldots 174$

Stephanson County, III. (843)........ 35

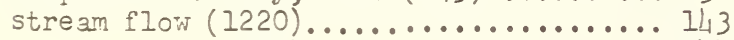

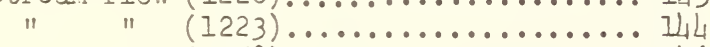

" $" \quad(1758) \ldots \ldots \ldots \ldots \ldots \ldots \ldots$ 146

Tennessee Valley (777).............. 175

" $"(780) \ldots \ldots \ldots \ldots \ldots . . . \ldots 175$

variable flow $(845) \ldots \ldots \ldots \ldots \ldots . . . \ldots 39$

Guide vanes $(104) \ldots . . . \ldots \ldots . . . . . . .76$

Harbor improvement

Charleston, S. C. (678)............ 125
Harbor improvement

Grays Harbor, Nash. (1210)........... 12!

Indiana Harbor, Ind. (1472).......... 13:

Harbor models

scale effects (1002)................ 12

Vancouver (2033)................... 17

Heat transfer

cooling towers (1059)

general research (822)

supersonic flow ( 880 )

unsteady phenomena (1594)

Hi ghway drainage

culverts (III)

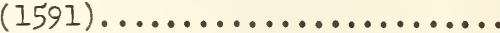

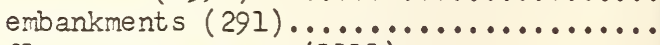

flow gage, sewers (IIII).............

sediment in sewers (IIOI).

Hydraulic control system

valves $(1897)(1898)$...

Hydraulic history (1102)

$$
\text { " jumps ( } 1572)
$$

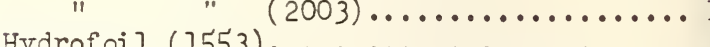

Hydrofoils, cavitating flow (i8ii)

, study of (1816)..............

Hydrologic studies, Florida (1965)........ Ic Hydrology

frequency studies ( 1590 )

Ice, frazil ( 1158$) \ldots . . . . .30$.

Infiltration

effect vegetation (376).

farms (1759).

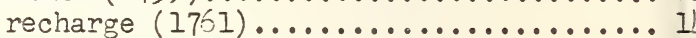

$"$ basins $(1225) \ldots \ldots \ldots \ldots \ldots \ldots$.

soil $(25) \ldots$

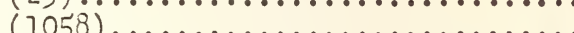

(1222)

" (1996)...

Inlets

conduits (72)

culverts (III)

dams (2028)

gutters $(855)$

theory (1344).

Instruments

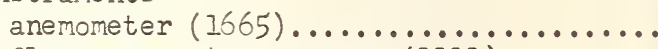

flow gage, storm sewers (IIII).........

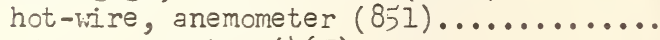
" ", meter (457)

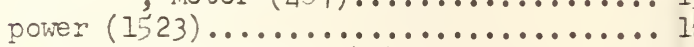
precipitation gage (547).

pressure cells (100L)................. I pressure fluctuation (1307)

radio rain gage (1012)................ I

" " $"(1536) \ldots \ldots \ldots \ldots \ldots \ldots 1$

rain gage, continuous (1992).......... I

rain gage, coding derice (2014)........ I 
Meters (see Nozzles, Orifice meters, Venturis) hot-wire (851)................... 44 irrigation $(24) \ldots \ldots \ldots \ldots \ldots \ldots \ldots \ldots . . . .6$ open channei (1589).................. 40 precipitation gages (547)............ 33 turbulence $(578) \ldots \ldots \ldots \ldots \ldots \ldots \ldots \ldots \ldots \ldots$ velocity, electro-magnetic (46)........ 10 Model distortion (994).............. 126 Model laws

air entrainment (995).............. 126 beaches (184).......................113 density currents (159).............. 136 scale effects

harbors (1002)................... 127

spillways (1001).................. 127

small models $(593) \ldots . . \ldots \ldots \ldots \ldots \ldots . . .67$

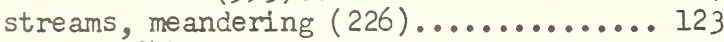

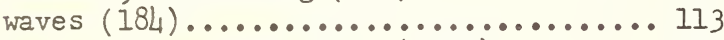
Model roughness standards $(1000) \ldots . . . . .127$ Model verification

pressure measurement

penstocks, South Holstor Dam (76?) .... 170 sluices, Cherokee Dam (758)......... 169 " , Douglas Dam (759)........... 170 , Hiwassee Dam (763)......... 170

rowing tank (1848)................. 30 spillway piers and baffles

Kentucky Dam (761)............... 170 prototype confirmation (1467)......... 129 Models, bed material (1535)............ 171

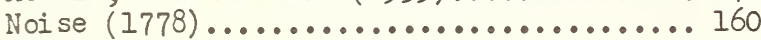
Nozzles

calibration (1843).................. 29

fire $(1697) \ldots \ldots \ldots \ldots \ldots \ldots \ldots . . \ldots . \ldots 96$

installation effects $(685) \ldots \ldots \ldots \ldots . . . .137$

low Reynolds number (1327)........... 29

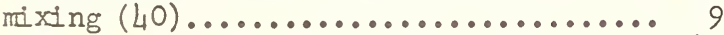

pressure distribution (72)........... 42

roughness $(1328) \ldots \ldots \ldots \ldots \ldots \ldots \ldots . . . . .29$

Open channels (see Channels)

air entrainment $(100) \ldots \ldots \ldots \ldots \ldots \ldots . \ldots 76$

backwater (1332)................... 31

(1853).................. 32

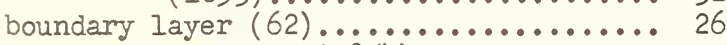

boundary roughness $(1854) \ldots \ldots \ldots \ldots \ldots . . \ldots 32$

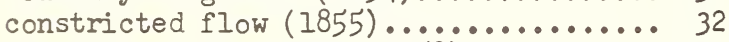

converging, diverging (1558)........... 19

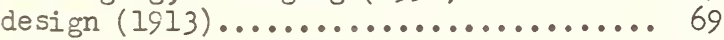

flow past slots $(328) \ldots \ldots \ldots \ldots \ldots \ldots . . \ldots 72$

hydraulic jump $(1857) \ldots \ldots \ldots \ldots \ldots \ldots . . . .632$

meanders $(1313) \ldots \ldots \ldots \ldots \ldots \ldots \ldots \ldots . \ldots . \ldots 23$

overfall (1571).................. 26

steep slope $(100) \ldots \ldots \ldots \ldots \ldots \ldots \ldots . . . .676$

supercritical flow

air entrainment $(100) \ldots \ldots \ldots \ldots \ldots$ transitions (1321)..................

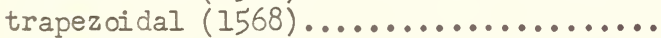

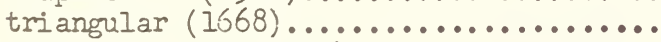
uniform inflow $(1217) \ldots \ldots \ldots \ldots \ldots \ldots \ldots$ " " (1924)............... 79 unsteady flow $(1565) \ldots \ldots \ldots \ldots . . . .24$
Open channels (see Channels)

velocity distribution (1304)........... 1

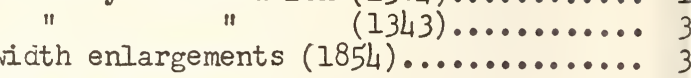

orifice meters

installation effects (585)............ 137

"

rounded entrances $(1887) \ldots \ldots \ldots \ldots \ldots$....... 58

orifices

vortex flow (1181)................ gr

Outlets

pipe, cantilevered (1168)............ 8c

short, in dams $(290) \ldots \ldots \ldots \ldots \ldots \ldots . . \ldots 2$

outlet works

dams

Garrison, N. D. (211)............. 12

Keechelus (1254)..................14

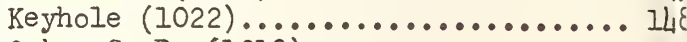

Oahe, S. D. (1212)................ 135,

Rio Hondo, Calif. (980)............. 126

San Antonio (1732)................ 12

Sly Park (2007)................... 15L

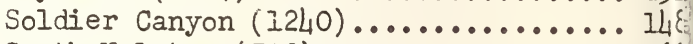

South Holston (730)................ 16

伍llow Creek (1236)(1244)........... I I k

Yellowtail (1495) .................. 15 ( spillway tunnels

South Holston Dam (730).............16 vibration $(1254) \ldots \ldots \ldots \ldots \ldots \ldots . . . \ldots 145$

Penstocks

flow studies (1959).................. 10

South Holston Dam $(762) \ldots \ldots \ldots \ldots \ldots . . .17$

Percolation studies

San Joaquin Valley, Calif. (1966)...... 10

Pipe fittings

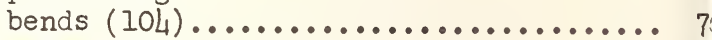

bends, elbows (1602)............... 5c

1 , separation (289)............... 2

$"$, shear flow (1374)............... 5

cavitation (993).................... 12

guide vanes $(104) \ldots \ldots \ldots \ldots \ldots \ldots \ldots$. 76

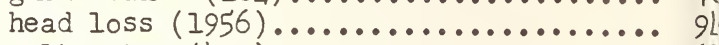

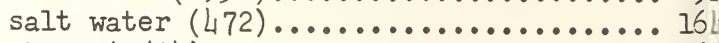

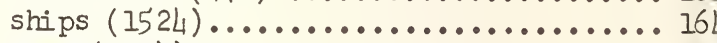

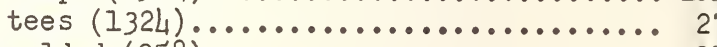

welded $(958) \ldots \ldots \ldots \ldots \ldots \ldots \ldots \ldots \ldots$,

Pipes

artificial roughness (1704)............ 94

cavitation (993) ...................... 126

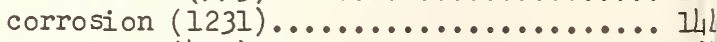

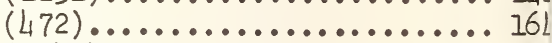

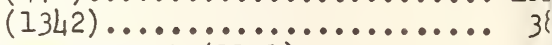

discharge measurement (1191).......... 9.

entrance sections $(290) \ldots \ldots \ldots \ldots \ldots \ldots$........

" $"$ " (627).............. 81

(1888)............ 58

expansions, outlets $(1295) \ldots \ldots \ldots \ldots \ldots .18 \mathrm{c}$ flexible (1192)................... 9;

flow of mixtures

liquid-gas $(1551) \ldots \ldots \ldots \ldots \ldots \ldots$. It 
Pipes

flow of mixtures

liquid-solid (2039)............... 178

solid-gas (40)................... 9

two-phase, two-component (LI)........ 10

friction

alumi num $(950) \ldots \ldots \ldots \ldots \ldots \ldots \ldots . . . . .63$

concrete $(24) \ldots \ldots \ldots \ldots \ldots \ldots \ldots \ldots \ldots, 6$

corrugated (1198).................. 117

high pressure (956).............. 97

roughness $(944) \ldots \ldots \ldots \ldots \ldots \ldots \ldots . . .69$

salt water $(472) \ldots \ldots \ldots \ldots \ldots \ldots \ldots . . . \ldots \ldots$

heat transfer $(40) \ldots \ldots \ldots \ldots \ldots \ldots \ldots \ldots$. 9

" " $(880) \ldots \ldots \ldots \ldots \ldots \ldots \ldots . . . . .55$

leakage (791) ....................... 179

losses at bends (2039).............. 178

manifold ports (II7I) ............. 84

networks $(1683) \ldots \ldots \ldots \ldots \ldots \ldots \ldots \ldots . \ldots . \ldots$

(1689) ...................... 94

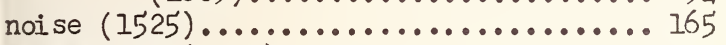

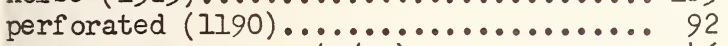

pressure at outlet (1593)........... 46

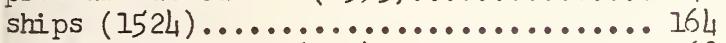

surge suppressors $(127) \ldots \ldots \ldots \ldots \ldots \ldots 68$

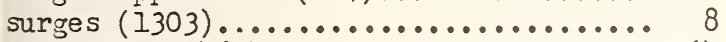

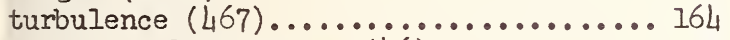

velocity fluctuations $(46) \ldots \ldots \ldots \ldots . . .10$

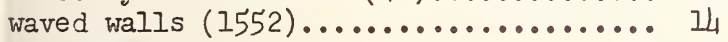

Pitot tubes

calibration (1942)............... 83

development $(43) \ldots \ldots \ldots \ldots \ldots \ldots \ldots \ldots . . . .10$

" (1807).................. 180

Plates, rough $(854) \ldots \ldots \ldots \ldots \ldots \ldots \ldots . \ldots \ldots$

Plumbing

backflow prevention (49) ............ 18

corrosion (49).................... 18

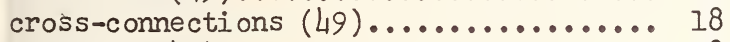

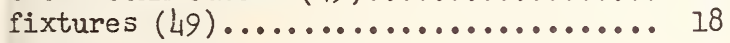

Pneumatic control systems

design (1896)..................... 60

perf ormance $(1899) \ldots \ldots \ldots \ldots \ldots \ldots . . . \ldots 60$

valves $(1897)(1898) \ldots \ldots \ldots \ldots \ldots \ldots . . . .660$

Pneumatic valves

characteristics of $(1900) \ldots . . . \ldots . .61$

Porous media, flow

basic research (1555)(1556)(1557)...... 16

fluidized, systems $(1635) \ldots \ldots \ldots \ldots \ldots 66$

multi-phase (282)................ 12

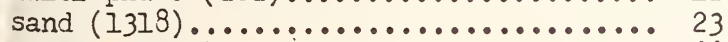

spheres $(590) \ldots \ldots \ldots \ldots \ldots \ldots \ldots \ldots \ldots \ldots . \ldots \ldots 6 . \ldots \ldots$

turbulence $(557) \ldots \ldots \ldots \ldots \ldots \ldots \ldots \ldots \ldots \ldots \ldots \ldots$

(1864).................. 38

two-phase media (39)............... 9

(1555) ................... 15

Porous media, unsteady flow $(1826) \ldots \ldots . . .17$

Pressure control systems (1893)......... 59

Pressure distribution $(1694) \ldots \ldots \ldots \ldots . . .69$

basic research $(79) \ldots \ldots \ldots \ldots \ldots \ldots \ldots . \ldots \ldots 2$

" " (81)................. 43

by electric analogy $(72) \ldots \ldots \ldots \ldots \ldots 42$

" $"$ " $(470) \ldots \ldots \ldots \ldots \ldots . \ldots . \ldots . \ldots 156$
Pressure distribution

entrances (1243)..................148

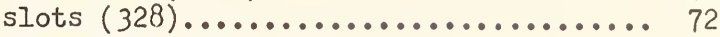

submerged bodies (16).............. 3

Pressure measurement

$(579) \ldots \ldots \ldots \ldots \ldots \ldots, 52$

electric analogy (72)............. 42

" $"$ " (470)................ 156

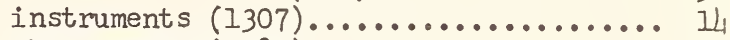

ship models (1789).................. 162

sluices

Cherokee Dam (758).................169

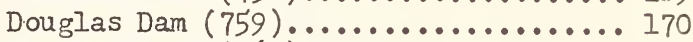

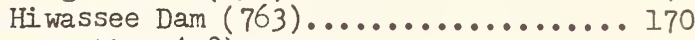

wave action (38).................. 9

Pressure reducing header $(1694) \ldots . . . .$. ... 95

Propellers

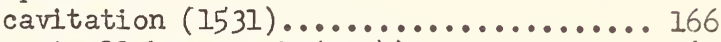

controllable pitch (1904).............6 6I

electro-magnetic analogy $(920) \ldots \ldots \ldots . .672$

measuring apparatus (1L1]).......... 87

symmetric wakes (921).............. 72

the ory $(1790)(1791) \ldots \ldots \ldots \ldots \ldots \ldots \ldots \ldots . \ldots 163$

undulatory $(1813) \ldots \ldots \ldots \ldots \ldots \ldots . . . \ldots$. 1

Prototype check tests

penstocks (762)................... 170

sluices $(758) \ldots \ldots \ldots \ldots \ldots \ldots \ldots . . \ldots \ldots . . . \ldots 159$

(759) ......................... 170

spillways $(761) \ldots \ldots \ldots \ldots \ldots \ldots \ldots \ldots \ldots$

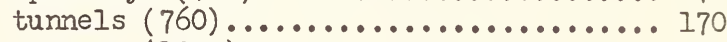

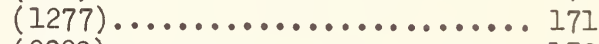

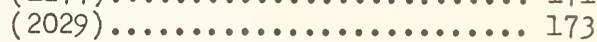

Pulpwood holding grounds $(2044) \ldots \ldots \ldots \ldots 180$

Pumping plant, sewers (683),.............. 125

Pumps

cavitation $(1849) \ldots \ldots \ldots \ldots \ldots \ldots . . . . . .30$

power transmission (1528)............ 166

regenerative turbines (1883) .......... 57

research $(1548) \ldots \ldots \ldots \ldots \ldots \ldots \ldots \ldots \ldots$

(1818).................. 5

suction, $\operatorname{air}(810) \ldots \ldots \ldots \ldots \ldots \ldots \ldots . \ldots \ldots$

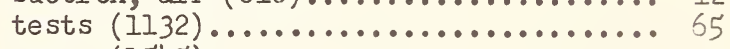

" $(1545) \ldots \ldots \ldots \ldots \ldots \ldots \ldots \ldots \ldots \ldots \ldots \ldots$

(1612)......................... 54

$(1813) \ldots \ldots \ldots \ldots \ldots \ldots \ldots \ldots \ldots \ldots \ldots \ldots$ I

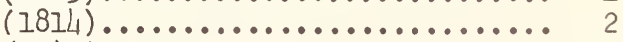

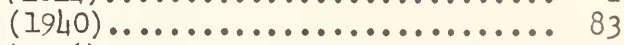

(2036)........................ 77

thrust bearing loading (1821).......... 16

turbine type $(1952) \ldots \ldots \ldots \ldots \ldots . \ldots 100$

Rainfall

altitude effect $(778) \ldots \ldots \ldots \ldots \ldots \ldots \ldots$

" $"$ " (1958)................... 95

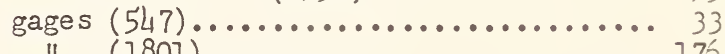

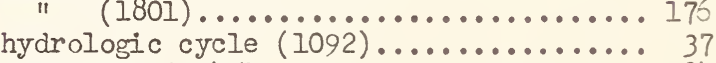

intensity $(1945) \ldots \ldots \ldots \ldots \ldots \ldots . . . \ldots . . .64$

maximum $(779) \ldots \ldots \ldots \ldots \ldots \ldots \ldots \ldots \ldots \ldots \ldots \ldots \ldots$

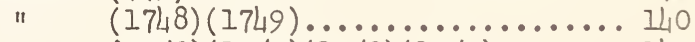

" (1750)(1751)(1752)(1753)....... 141

radar research $(553) \ldots \ldots \ldots \ldots \ldots . . . . .36$ 
Rainfall

rainfall-runoff $(68) \ldots \ldots \ldots \ldots \ldots \ldots . .41$

$(564) \ldots \ldots \ldots \ldots \ldots \ldots, 40$

(768) ............... 174

(777)............... 175

(856).............. 49

(918)............. 70

(1078).............. 27

records (1636)...................6 67 research, Southern California (261).... 106 Tennessee River Basin (768).......... 174 (778)........... 175 (779) ............ 176

topography effect (1991).............. I I I Range management practices (27)......... 8 Reservoirs

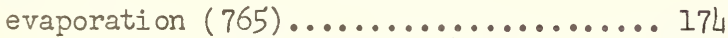
" aird regions $(445) \ldots \ldots \ldots$. 143

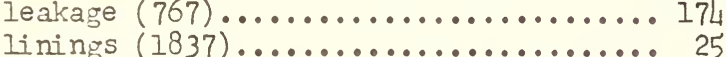
sedimentation (307)................ 51 $(1284) \ldots \ldots \ldots \ldots \ldots \ldots \ldots \ldots \ldots \ldots$

seepage $(445) \ldots \ldots \ldots \ldots \ldots \ldots \ldots \ldots . . . \ldots 143$ silting

arid regions $(445) \ldots \ldots \ldots \ldots \ldots \ldots 143$

Illinois (552)................... 35

Safe Harbor (1157)................ 74

stock water $(1227) \ldots \ldots \ldots \ldots \ldots \ldots . . .144$ temperature gaging (769)............ 174 Tennessee River $(764) \ldots \ldots \ldots \ldots \ldots \ldots . . . .174$ " $"$ " $(785) \ldots \ldots \ldots \ldots \ldots \ldots \ldots . \ldots 175$

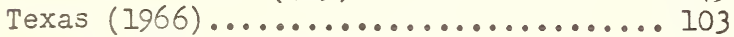
water supply, Illinois (551)......... 35

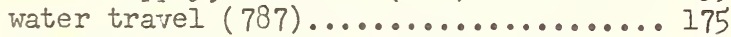
Resonating system, ocean swell (1933).... 81 Revetments

stream control meandering (226)....... 123

River control structures

Old River, La. (1982)(1983)........... 134 Rockfill

model tests (1464)................118 Roughness

artificial

open channels (1854)............. 32

standards, models (1000)........... 127

surfaces, drag (854)............. 44 effect of water temperature (1985)..... 136 Runoff

arid regions $(445) \ldots \ldots \ldots \ldots \ldots \ldots$. 43 denudation effects $(23) \ldots \ldots \ldots \ldots \ldots .66$ (27) ............ 8 effect of forest $(376)(377) \ldots \ldots \ldots \ldots . .110$ " " " (656)................. 108 effect of soil moisture (1909)........ 64 forecasting

rainfall (1693)................. 95

snow surveys $(120) \ldots \ldots \ldots \ldots . . . . .99$

snow melt $(1692) \ldots \ldots \ldots \ldots \ldots \ldots \ldots . . . .696$

soil moisture $(1014) \ldots \ldots \ldots \ldots \ldots . . .139$

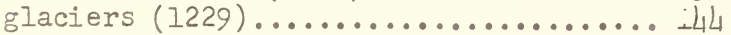
hydrologic cycle (1092)............ 37
Runoff

rainfall-runoff $(554) \ldots \ldots \ldots \ldots \ldots . \ldots 40$

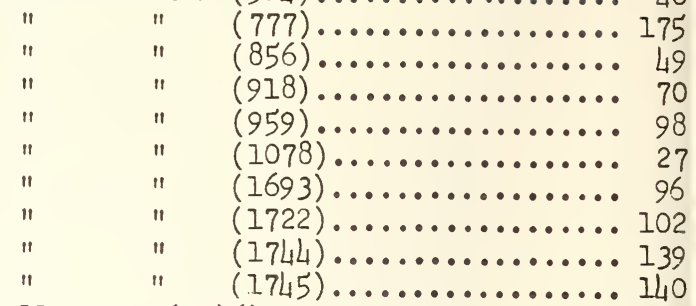

small areas $(1946) \ldots . . . \ldots \ldots \ldots . . . . .68$

small watersheds $(1908) \ldots \ldots \ldots \ldots \ldots .66 .64$

urban areas $(564) \ldots \ldots \ldots \ldots \ldots \ldots \ldots . . . . . .640$

" $"$ (856)....................... 49

watersheds

Illinois (551).................... 35

Laf ayette, Ind. (1966)................ 103

Ohio and Great Plains (1966).......... 103

Pennsylvania (656)................ 108

Ralston Creek, Iowa (66)........... LI

Rapid Creek, Iowa (68).............. 41

Tennessee River Valley $(777) \ldots . . \ldots . .175$

" " " (780)......... 176

Utah (1862).................... 34

" (1966).........................103

Salt water intrusion

control of (1831).................. 18

Delaware River (425)................ I24

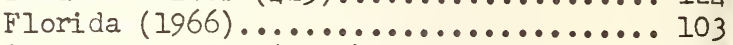

irrigated lands (1302)............... 8

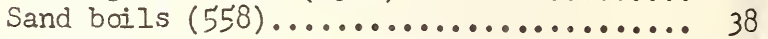

Sand classification methods $(52) \ldots \ldots \ldots$.... 19

Sand mixtures, permeability (556)........ 38

Sand transport

influence of waves and currents (1935).. 81

Sand traps, design (53).............. 20

" , efficiency (1597).......... 46

bridge piers (568)................4 43

" " (1707)................. 98

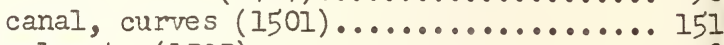

culverts $(1707) \ldots . . \ldots \ldots \ldots \ldots . . . . . .99$ dams

Ft. Randall, S. D. (674)........... 125 stilling basins $(823) \ldots \ldots \ldots \ldots \ldots \ldots . .21$ Seaplane hulls (1567)............... 24

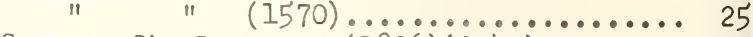

Seaway, St. Lawrence (1806)(2041)........ 179 Sediment

analysis methods $(302) \ldots \ldots \ldots \ldots \ldots . . .43$

bed erosion (69).................... 42 converging, diverging streams (1558).... 19 exclusion $(1261)(1264) \ldots \ldots \ldots \ldots \ldots \ldots . \ldots 150$ reservoir sampler $(1284) \ldots \ldots \ldots \ldots \ldots 175$

Sediment transportation

beaches (529)..................... 12

bed load $(1107) \ldots \ldots \ldots \ldots \ldots \ldots \ldots \ldots \ldots . \ldots \ldots$

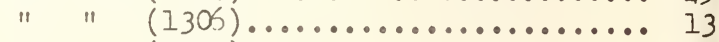

$(1313) \ldots \ldots \ldots \ldots \ldots \ldots \ldots \ldots \ldots \ldots \ldots \ldots$

$(1354) \ldots \ldots \ldots \ldots \ldots \ldots \ldots \ldots \ldots \ldots \ldots$ 
Sediment transportation

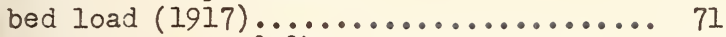

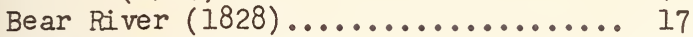

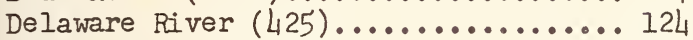

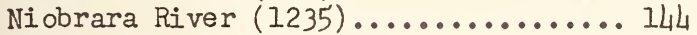

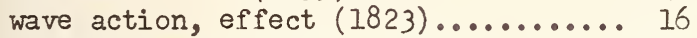

critical tractive force (1502)......... 151

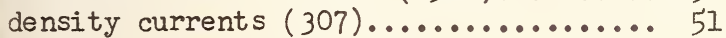

forces on particles (280)............. 11

measurement $(194) \ldots \ldots \ldots \ldots \ldots \ldots \ldots \ldots \ldots$

reservoirs $(1966) \ldots \ldots \ldots \ldots \ldots . \ldots \ldots . . \ldots \ldots$

ripple formation (1165)............. 77

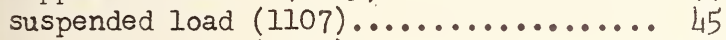

$" \quad "(1313) \ldots \ldots \ldots \ldots \ldots \ldots . . \ldots \ldots$

density currents $(805) \ldots \ldots \ldots \ldots \ldots . \ldots \ldots$

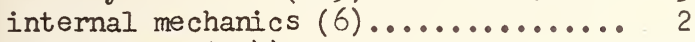

measurement $(194) \ldots \ldots \ldots \ldots \ldots \ldots . . \ldots \ldots 121$

(1966)................... 103

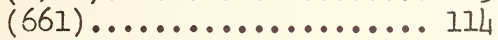

temperature changes (1928)......... 79

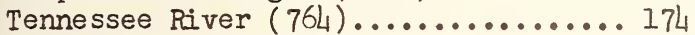

Texas streams $(1966) \ldots \ldots \ldots \ldots . . . \ldots 103$

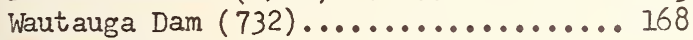

Sedimentation

arid regions $(445) \ldots \ldots \ldots \ldots . \ldots \ldots \ldots$

basins $(1262) \ldots \ldots \ldots \ldots \ldots \ldots . . . \ldots \ldots$

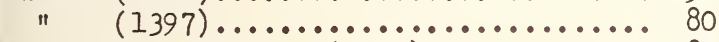

bed 1oad, estuaries (1930)........... 81

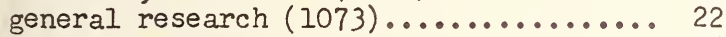

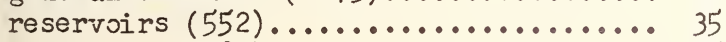

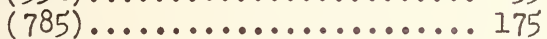

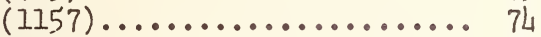

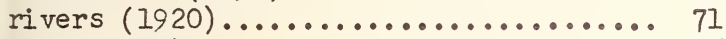

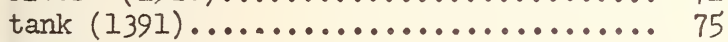

Seepage

canals $(820) \ldots . . . \ldots \ldots \ldots . . . . . . . . .21$

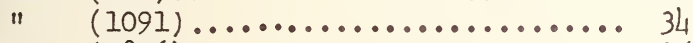

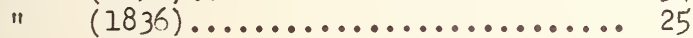

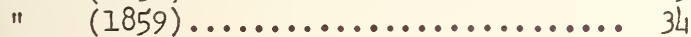

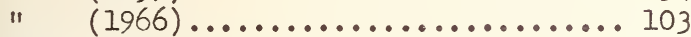

reservoirs $(445) \ldots \ldots \ldots \ldots \ldots \ldots \ldots \ldots . \ldots \ldots \ldots$

soil sediments $(1859) \ldots \ldots \ldots . . . . . . . .34$

Separat ors

liquid-liquid cyclone (1ILI)......... 69 solid " $(905)(906) \ldots \ldots .68$

Servomechanisms, closed-loop (1877)...... 48

Servomotors $(1613) \ldots \ldots \ldots \ldots . \ldots \ldots$

Settling, fall velocity

effect boundaries (298)............. 43

shape $(298) \ldots \ldots \ldots \ldots \ldots \ldots . \ldots \ldots$

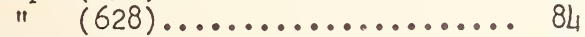

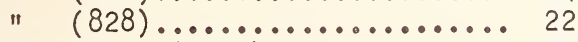

suspensions $(1073) \ldots \ldots \ldots \ldots . \ldots 22$

Sewage

activated sludge process $(580) \ldots \ldots \ldots . . .52$

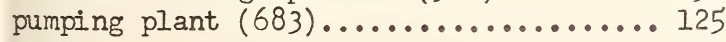

jewers

outfalls $(1700) \ldots \ldots \ldots \ldots . \ldots \ldots$

surges $(683) \ldots \ldots \ldots \ldots \ldots \ldots \ldots \ldots . \ldots \ldots$

Ships

appendage-body interaction (1268) ..... 158
Ships

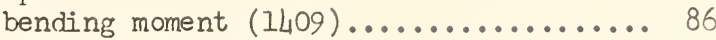

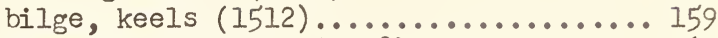

commercial, design (1128).............6 62

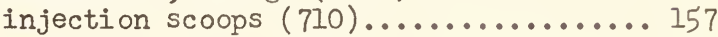

lines $(1783) \ldots \ldots \ldots \ldots . . . . .65$

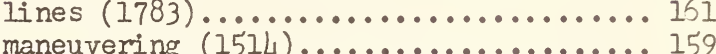
models, turbulence stimulation (1506)... 158

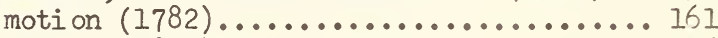

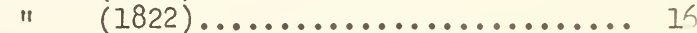

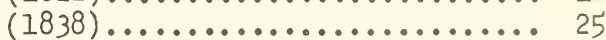

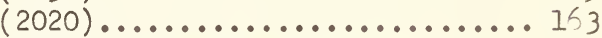

mot or-boats, transom immersion (1127)... 62

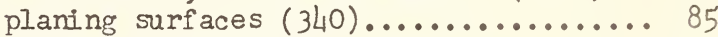

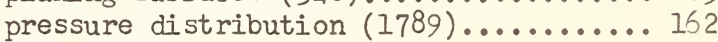

propellers

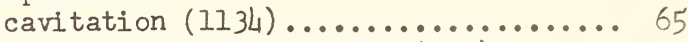

electro-magnetic analogy (920)...... 72

symmetric wakes (921)............... 72

resistance

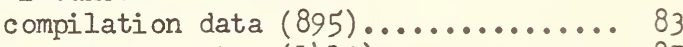

" " (1413)............ 87

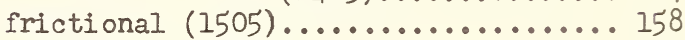

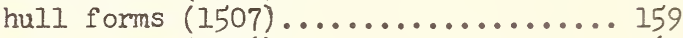

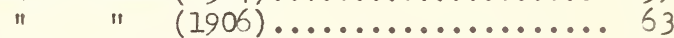

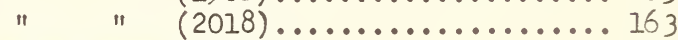

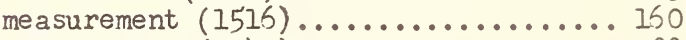

$(1947) \ldots \ldots \ldots \ldots \ldots \ldots . \ldots . \ldots$

models $(901) \ldots \ldots \ldots \ldots \ldots \ldots \ldots . \ldots \ldots . . \ldots \ldots$

prediction $(1516) \ldots \ldots \ldots . \ldots \ldots \ldots$

theory $(709) \ldots \ldots \ldots \ldots \ldots \ldots \ldots . . \ldots \ldots$

wave making $(1680)(1681) \ldots \ldots . \ldots . . . . . . . . .88$

seaworthiness $(1407) \ldots \ldots \ldots \ldots . . \ldots \ldots$

$(1510)(1511) \ldots \ldots \ldots \ldots \ldots \ldots$

self-propeller models (ILIO) (ILII) ..... 87

" "

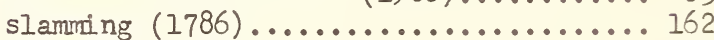

stability $(1907) \ldots \ldots \ldots \ldots \ldots . \ldots \ldots . . \ldots \ldots$

turning characteristics (1948)......... 88

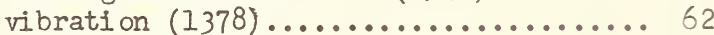

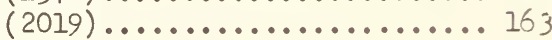

Shore protection, stmuctures (38)....... 9

" " " (529)....... 12

" $"$ " (972)...... 115

Silting

reservoirs

arid regions $(445) \ldots \ldots \ldots \ldots \ldots . . . \ldots . . .143$

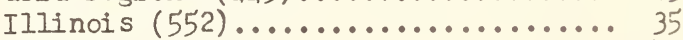

Lake Mead $(445) \ldots . . \ldots \ldots \ldots . . . \ldots 143$

Tennessee Valley $(785) \ldots \ldots \ldots \ldots \ldots$

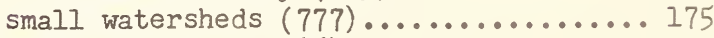

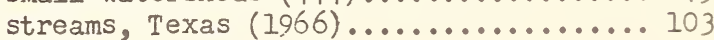

Siphons

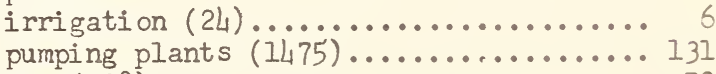

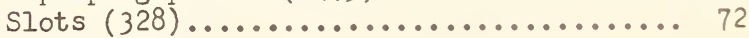

Sluice gates

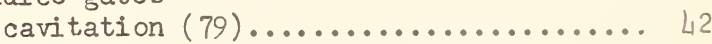

Slui ceways

dams 
Sluiceways

dams

discharge ratings

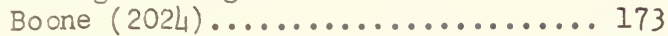

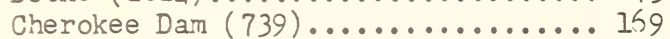

Douglas Dam $(742) \ldots \ldots \ldots \ldots \ldots . . . . .169$

Fontana Dam $(745) \ldots . . . . . .169$

pressure measurement

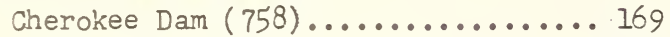

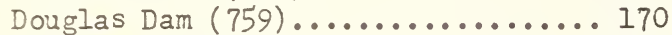

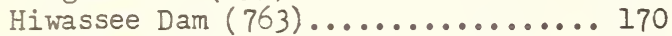

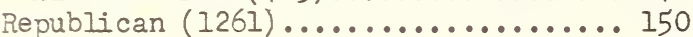

sand, design (53).................... 20 sediment excluding $(1767)(1768) \ldots \ldots . . .151$ Snow, forecast, melting (1011)......... 138 " " " (1420)......... 98

Snow surveys

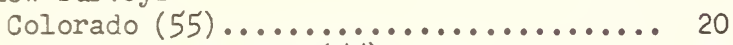

munoff forecasting $(55) \ldots \ldots \ldots . . . . . . .20$

$(1420) \ldots \ldots \ldots \ldots . \ldots . \ldots 98$

(1966) ............... 103

Soil moisture

depletion, evaporation losses (1954).... 93

depletion rates (1953) ............... 92

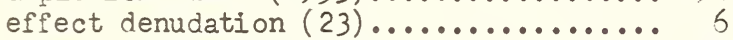

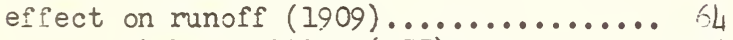

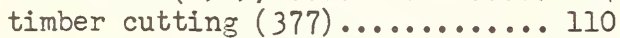

forecasting stream flow (1014)........ 139

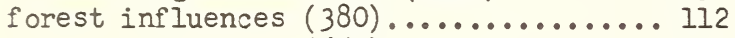

$(657) \ldots \ldots \ldots \ldots \ldots \ldots$

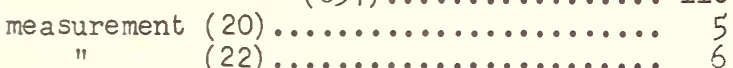

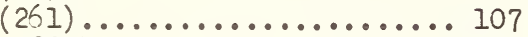

$(1860) \ldots \ldots \ldots \ldots \ldots \ldots \ldots . \ldots \ldots$

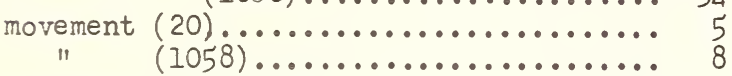

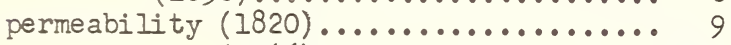

(1966) .................... 103

relation to plants (19)..................... 5

semi-desert vegetation (657) ........... 110

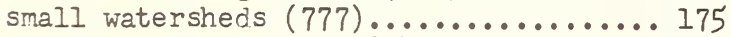

Southern Califormia (261)........... 107

thermodynamics $(22) \ldots \ldots \ldots \ldots \ldots . . \ldots \ldots$

Soil permeability (1966)................ 103

Specific gravity, oils (904)............ 68

Sphere, accelerated motion (1104)....... 45

Spillways

aeration, Pine Flat, Calif. (992) ..... 126

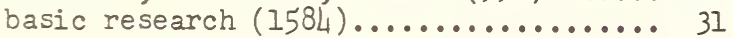

check tests $(761) \ldots \ldots \ldots \ldots \ldots \ldots \ldots$

comparison, profiles (266).............. 178 dams

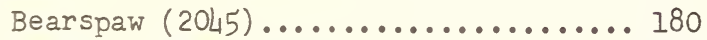

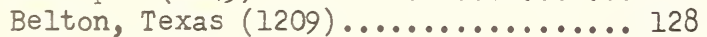

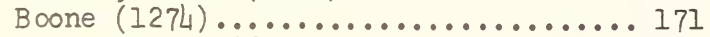

Box Canyon (1663)................ 77

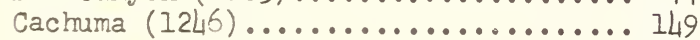

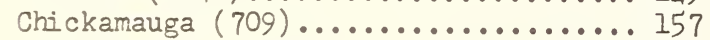

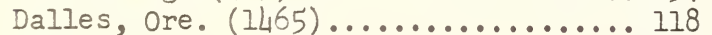

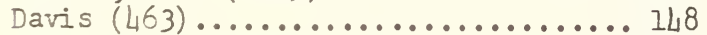

Folsom Dam, Calif. (1473) ............. 131
Spillways

dams

Fort Patrick Henry (1534).......... 171

Ft. Randall, S. D. (674) ............ 125

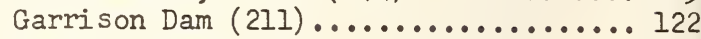

Gavins Point, S. D. (1741).......... 133

Glenn Anne $(1494) \ldots . . \ldots \ldots . . . . . .150$

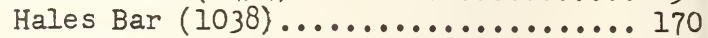

Hartwell, Ga. (1981)............... 134

Hungry Horse $(705) \ldots . . . . . . . . . .148$

Kentucky $(761) \ldots . . \ldots \ldots \ldots . . . . . . .170$

Kerwin $(1774) \ldots \ldots \ldots \ldots \ldots . . \ldots \ldots 152$

Keyhole $(1022) \ldots \ldots \ldots \ldots \ldots \ldots \ldots \ldots . . \ldots \ldots$

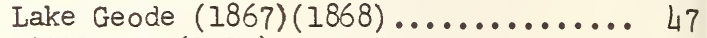

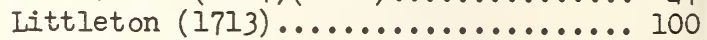

Markland, Ohio River (1739)......... 133

Nimbus (2009) ..................... 154

Persimmon Creek (2023).............. 173

Pine Flat, Calif. (992)............ 126

Rio Hondo, Calif. (980)............ 120

San Antonio (1732) ................ 120

Savage River, Md. (1471)........... 130

Sly Park (2008) ................... 154

South Holston (728)(730) ............. 168

Watauga $(728)(732) \ldots \ldots \ldots \ldots \ldots . . \ldots 168$

hillow Creek (1236) (1244)........... 149

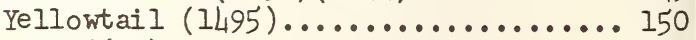

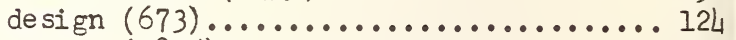

" $\quad(1835) \ldots \ldots \ldots \ldots \ldots \ldots \ldots \ldots . . \ldots \ldots 19$

discharge characteristics $(2048) \ldots . . .180$ discharge ratings, dams

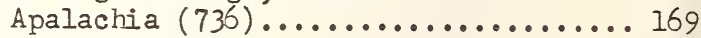

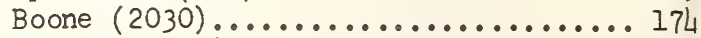

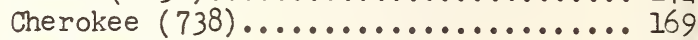

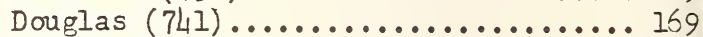

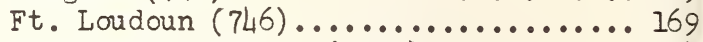

Fort Patrick Henry (2031).......... 174

Tennessee Valley Authority (2025) ..... 173

Wheeler $(2026) \ldots . . . \ldots \ldots . . . . . . .173$

drop, design (1398)............... 80

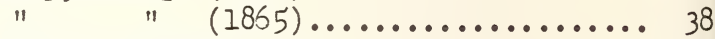

effect tailrace $(732) \ldots \ldots \ldots \ldots \ldots \ldots \ldots$

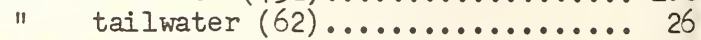

entrance conditions $(1685) \ldots . . . . . . . .99$

flow measurements $(1960) \ldots \ldots \ldots . . \ldots 100$

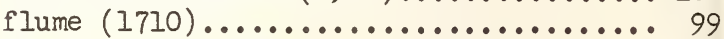
morning-glory dams

Hungry Horse $(705) \ldots \ldots \ldots \ldots . . . \ldots 14$

South Holston (728)................. 168

Watauga $(728) \ldots \ldots \ldots \ldots \ldots . \ldots \ldots . \ldots \ldots$

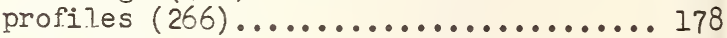

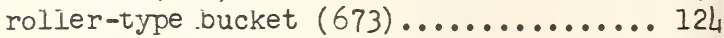

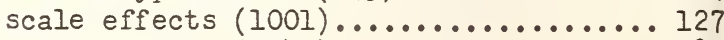

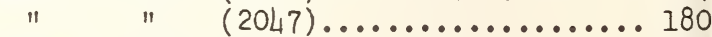

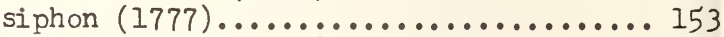

Whittier Narrows (980)................ 120

Spray, drop size (1832)................. 18

Spray, from jets $(1637) \ldots \ldots . \ldots . . . . . .69$

Sprinkling systems

irrigation (1076) ................. 22

jets, distribution $(21) \ldots \ldots \ldots \ldots \ldots . . \ldots . . . . .6$ 
Stability

towed ships (1540)...............669

wave tests $(1136) \ldots \ldots \ldots \ldots \ldots \ldots \ldots . . .65$

" " (1173).................. 85

" $\quad$ (1907)...................66 63

Stall, rotating (1903)..............6 61

Stilling basins

dams

Bonneville (1976)................ 119

Bull Shoals, Ark. (1979)........... 134

Chickamauga $(709) \ldots \ldots \ldots \ldots \ldots \ldots \ldots . . .157$

Davis $(463) \ldots \ldots \ldots \ldots \ldots \ldots \ldots \ldots . \ldots \ldots$

Folsom Dam, Calif. (1473)........... 131

Ft. Randall, S. D. $(674) \ldots \ldots \ldots \ldots . . .125$

Garrison, N. D. (2II) ............... 122

Gavins Point, S. D. (174I) .......... 133

Hungry Horse $(705) \ldots \ldots \ldots \ldots . . . .148$

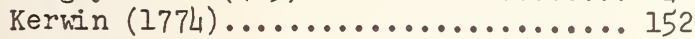

Markland, Ohio River (1739).......... 133

New Cumberland, Ohio River (1978)..... 133

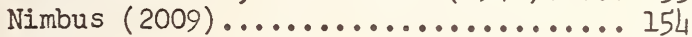

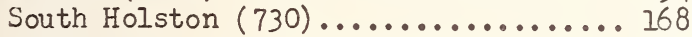

Table Rock, Mo. (1980)............... 134

Tuttle Creek, Kansas (1740)......... 133

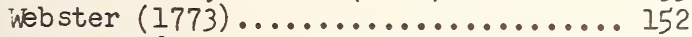

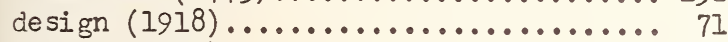

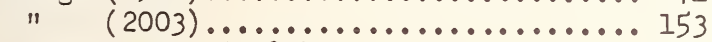

erosion below $(1987) \ldots \ldots \ldots \ldots \ldots \ldots . . . \ldots 135$

scour $(823) \ldots \ldots \ldots \ldots \ldots \ldots \ldots \ldots . \ldots . \ldots . \ldots 21$

Stilling wells

hydraulic characteristics (2002)....... 153

Streamflow forecasts (1743)(1744)....... 139

" " (1745)(1747).......140

" (2032).............. 176

Colorado (55)...................... 20

snow surveys $(55) \ldots \ldots \ldots \ldots \ldots \ldots \ldots . . .20$

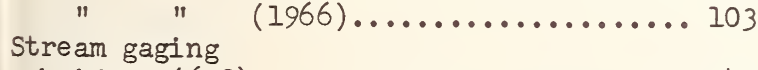

bridges $(690) \ldots . \ldots \ldots \ldots \ldots \ldots \ldots \ldots . \ldots 143$

gage $(1013) \ldots \ldots \ldots \ldots \ldots \ldots \ldots \ldots \ldots \ldots \ldots . \ldots \ldots$

radio gages $(1535) \ldots \ldots \ldots \ldots \ldots \ldots \ldots . . . . .171$

Tennessee Valley $(769) \ldots \ldots \ldots \ldots \ldots . . \ldots 174$

Streams

discharge $(1705) \ldots \ldots \ldots \ldots \ldots \ldots . . . .69$

effect logging (969)................. 109

" $" 1$ (1230)................ 144

erosion control (226).................. 123

research (69).............. 42

forest effects $(439) \ldots \ldots \ldots \ldots \ldots \ldots . . \ldots 142$

meandering $(226) \ldots \ldots \ldots \ldots \ldots \ldots \ldots \ldots \ldots \ldots \ldots \ldots$

peak discharge $(691) \ldots \ldots \ldots \ldots \ldots \ldots . . \ldots 143$

roughness coefficient $(783) \ldots \ldots \ldots \ldots 175$

$(1488) \ldots \ldots \ldots \ldots \ldots \ldots$

(1755)..................... 145

Iowa $(67) \ldots \ldots \ldots \ldots \ldots \ldots \ldots . . . .41$

Texas $(1966) \ldots \ldots \ldots \ldots \ldots \ldots \ldots \ldots \ldots . . . . .103$

water quality $(786) \ldots \ldots \ldots \ldots \ldots \ldots . \ldots 175$

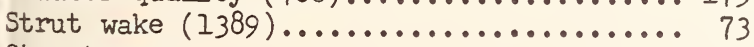

Structures

canal (2004).
Structures

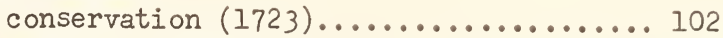

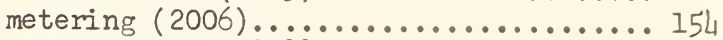

wave forces on $(1881) \ldots \ldots \ldots \ldots \ldots . . \ldots 55$

Submerged bodies

pressure distribution

basic research (16)

$(579) \ldots \ldots \cdots \cdots \cdots \cdots \cdots, 52$

electric analogy $(72) \ldots \ldots \ldots \ldots \ldots, 42$

theoretical analyses (81)........... 43

underwater, inspection of (1921)...... 75

Surges

pipes (1303)...................... 8

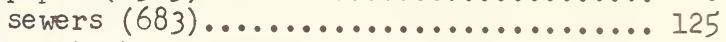

Surge tanks

mechani cal-pneumatic (127)..........6 68

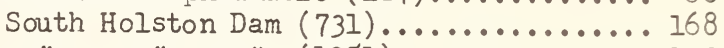

Swirling flow (1951) (1951)............ 170

Tailraces

Seton Creek Dam (2038).............. 178

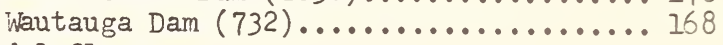

Tidal flow

channels

bottom currents (1930)............ 81

Charlest on Harbor, S. C. (678)........ 125

Delaware River, $\mathrm{Pa} .(425) \ldots \ldots \ldots . . .124$

Torque, converter (1660)............. 75

Towing tank research

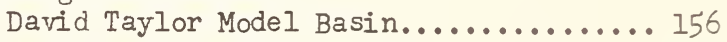

Michigan Uni versity................. 62

Newport News S. and D. D. Co......... 64

Northwestern Uni versity............. 68

Society of Naval Architects........... 83

Stevens Institute of Technology....... 85

Transitions

tumnels $(1206) \ldots \ldots \ldots \ldots \ldots \ldots \ldots \ldots . \ldots 122$

Tunnels

check tests $(760) \ldots \ldots \ldots \ldots \ldots \ldots . \ldots 170$

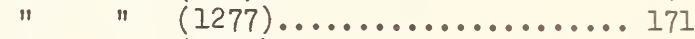

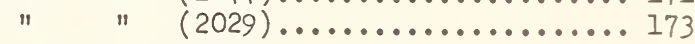

dams

Fontana $(760) \ldots \ldots \ldots \ldots \ldots \ldots \ldots$

measuring system (1245)............. 149

vertical shaft $(1776) \ldots \ldots \ldots \ldots \ldots \ldots . \ldots 153$

Turbines

buckets $(1915) \ldots \ldots \ldots \ldots \ldots \ldots \ldots \ldots . .71$

cavitation (1133).................. 65

" (1939).................... 83

design $(1902) \ldots \ldots \ldots \ldots \ldots \ldots . . . . . .61$

discharge channels (1305)............. 13

impulse

efficiency $(1656) \ldots \ldots \ldots \ldots \ldots \ldots \ldots . \ldots 71$

head effects, tests $(1146) \ldots \ldots \ldots \ldots 70$

model tests $(123) \ldots \ldots \ldots \ldots \ldots \ldots \ldots . . .64$

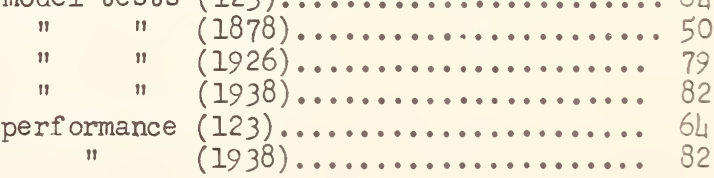


Turbines

propeller

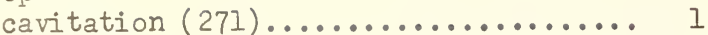

performance $(271) \ldots \ldots \ldots \ldots \ldots \ldots \ldots \ldots$

$(1544) \ldots \ldots \ldots \ldots \ldots \ldots \ldots \ldots$

$(1612) \ldots \ldots \ldots \ldots \ldots \ldots \ldots \ldots \ldots \ldots \ldots \ldots$

vane moments $(896) \ldots \ldots \ldots \ldots . . . . . . . . . .64$

Turbulence

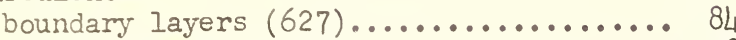

granular media $(557) \ldots \ldots \ldots \ldots \ldots . \ldots \ldots$ measurement

apparatus

$$
(73)
$$

lent

................. 10

hot-wire, $\operatorname{air}(811) \ldots \ldots \ldots \ldots . . \ldots \ldots$

" ", water $(467) \ldots \ldots \ldots \ldots \ldots \ldots . . . . .156$

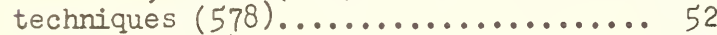

mechanism $(1742) \ldots \ldots \ldots \ldots \ldots \ldots \ldots \ldots \ldots$

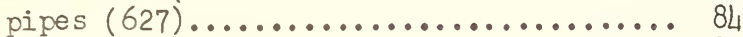

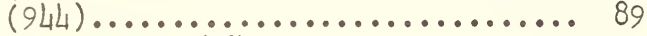

basic research $(46) \ldots \ldots \ldots \ldots \ldots \ldots \ldots \ldots$

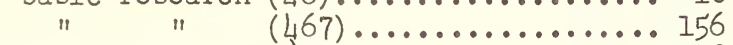

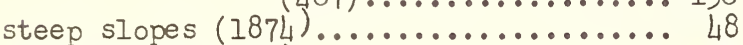

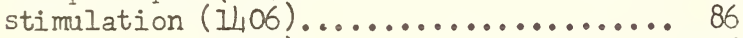

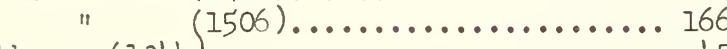

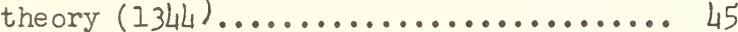

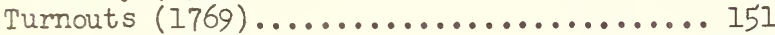

" $(1771)(1775) \ldots \ldots \ldots \ldots \ldots \ldots \ldots \ldots \ldots \ldots \ldots$

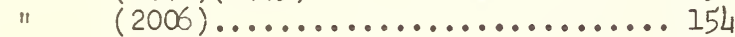

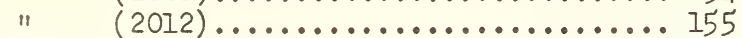

Unsteady flow $(1784) \ldots \ldots \ldots \ldots \ldots \ldots \ldots \ldots$

$" \quad$ " $(1785)(1786) \ldots \ldots \ldots \ldots \ldots \ldots 162$

Valves

butterfly $(1603) \ldots \ldots \ldots \ldots \ldots \ldots \ldots \ldots \ldots \ldots$

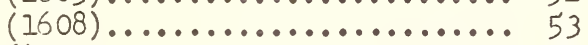

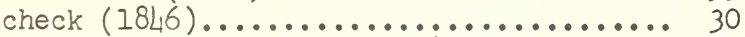

coefficients of discharge (1941)....... 83

dynamic flow forces on $(1895) \ldots . . . . .59$

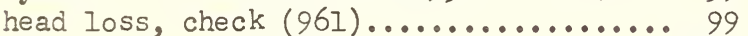

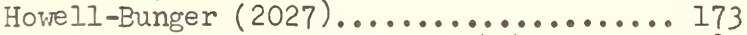

operating characteristics (1941)....... 83

poppet $(1892) \ldots \ldots \ldots \ldots \ldots \ldots . . . \ldots \ldots$

regulating $(1772) \ldots \ldots \ldots \ldots \ldots \ldots \ldots \ldots \ldots$

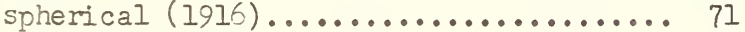

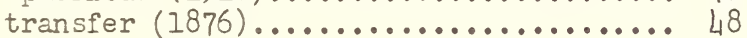

Velocity distribution

air, over ocean waves $(1824) \ldots \ldots \ldots \ldots . . .17$

Velocity measurement

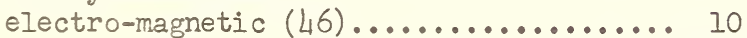

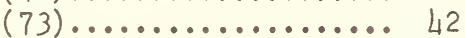

$(467) \ldots \ldots \ldots \ldots \ldots \ldots \ldots$

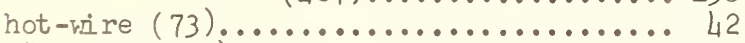

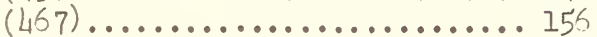

ultrasonics $(1154) \ldots \ldots \ldots \ldots \ldots \ldots . . . \ldots 74$

Ventilation $(1684) \ldots \ldots \ldots . . . . . . . . .90$

Venturi

calibration $(1842)(1843)(1845) \ldots \ldots . . .29$

characteristics $(1841) \ldots \ldots \ldots \ldots . . \ldots . . . . . . .29$

installation effects $(685) \ldots \ldots \ldots \ldots \ldots 137$

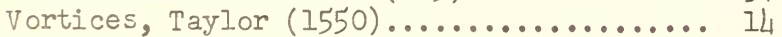

Viscosity

measurement (1927)................. 79

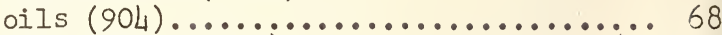

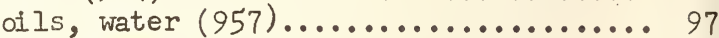

Viscous flow

past spheres (1910)................. 66

through assemblages of spheres (1911)... 67

Vortex rings $(1872) \ldots \ldots \ldots \ldots \ldots \ldots . . \ldots 47$

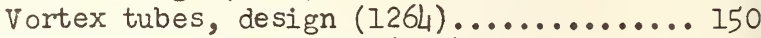

Water channel rotating $(279) \ldots \ldots \ldots \ldots . . . . .3$

Water, consumptive use (1966).............103

Water control facilities, design (1964)... 102

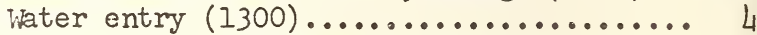

Water hammer

airplanes $(1405) \ldots \ldots \ldots . . . . .86$

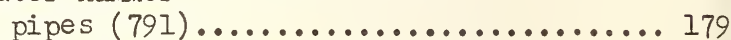

surge suppressors $(127) \ldots \ldots \ldots \ldots \ldots \ldots . \ldots 68$ Water measurement

Irrigation $(23)(24) \ldots \ldots \ldots \ldots \ldots . \ldots . \ldots$

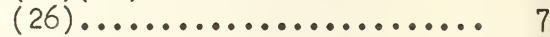

stream flow $(67) \ldots \ldots \ldots \ldots \ldots \ldots . . . . . .41$

Watershed management

Colorado $(1970)(1971) \ldots . . . . . . . . . .112$

Continental Divide (377) ............. 110

New Mexico (1967)(1968)(1969).......... III

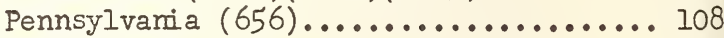

Rocky Mountain Front Range (376)........ 110

Sierra Ancha, Ariz. (657) ............ 110

Southeastern United States (380)....... 112

Southem California (261)............ 106

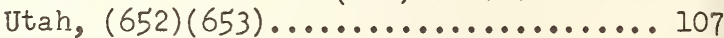

" $(654)(655) \ldots \ldots \ldots \ldots \ldots \ldots . \ldots \ldots \ldots$

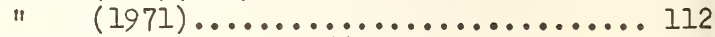

Wayne County, Pa. (966)................. 109

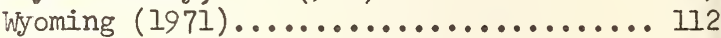

Watershed studies

Blacklands, Texas (150).............. 101

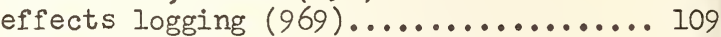

forest influences $(376)(377) \ldots \ldots \ldots \ldots . . . .110$

$" \quad$ " $\quad(380) \ldots \ldots \ldots \ldots \ldots \ldots 112$

$" \quad n \quad(656) \ldots \ldots \ldots \ldots \ldots \ldots 10 \ldots \ldots \ldots$

$" \quad n \quad(657) \ldots \ldots \ldots \ldots \ldots \ldots 110$

$" \quad$ " $\quad(966) \ldots \ldots \ldots \ldots \ldots . \ldots 109$

$"$ " $(1188) \ldots \ldots \ldots \ldots \ldots 109$

frost studies $(1187) \ldots \ldots \ldots \ldots . . . . . . . .109$ hydrologic cycle (1758)(1763)(1764) .... 146

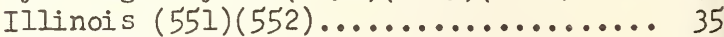

Lafayette, Ind. (1966) .............. 103

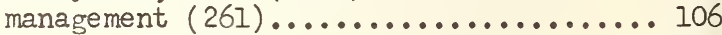

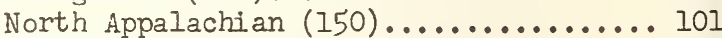

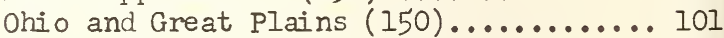

Pine Region, N. J. (1662)............. 76

Ralston Creek, Iowa (66)............... LI

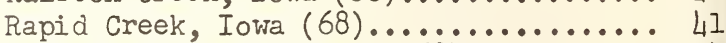

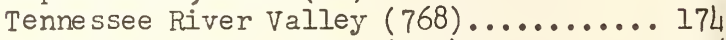

$(780) \ldots \ldots \ldots \ldots 176$

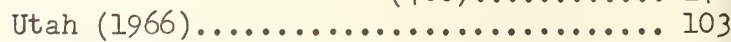

Water tunnel

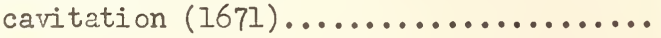


Water tunnel

design

Calif. Inst. of Tech. (15) (16) ...... 3

closed jet $(1672) \ldots \ldots \ldots \ldots \ldots . \ldots \ldots$

Penn. State College (115'1).......... 72

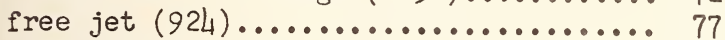

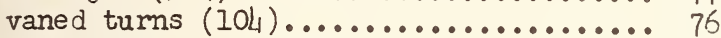

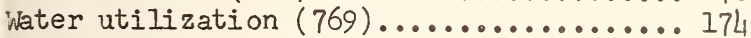

Whe action

beaches (47)...................... 10

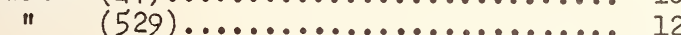

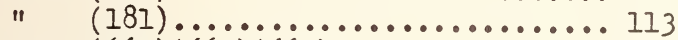

" $(660)(661)(663) \ldots \ldots . . . . . . . .114$

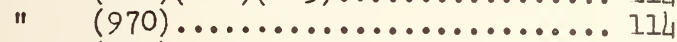

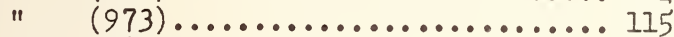

" $(1609) \ldots \ldots \ldots \ldots \ldots \ldots \ldots \ldots . \ldots \ldots \ldots$

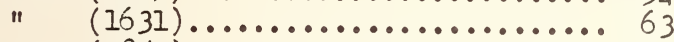

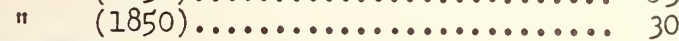

breakwaters

pervious, impervious (998)......... 125 rubble-mound (257)............... 124

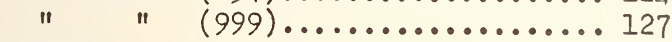

harbors

Indiana Harbor, Ind. (1472)....... 131

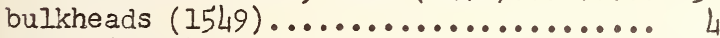

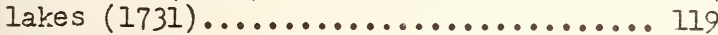
shore protection, tank (399).......... 114

$"$ " " $"$ "works $(38) \ldots \ldots \ldots \ldots . . . .9$

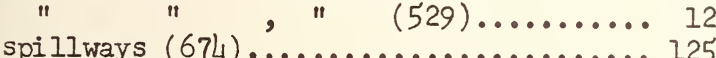

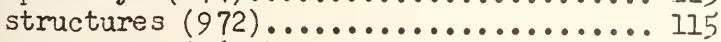

Waves

$(1630) \ldots \ldots \ldots \ldots \ldots \ldots \ldots \ldots$

generation $(1825) \ldots \ldots \ldots \ldots \ldots \ldots \ldots$

gravity $(1936) \ldots \ldots \ldots \ldots \ldots \ldots \ldots . \ldots \ldots . \ldots \ldots$

internal progressive (1990)..............138

measurement $(1724) \ldots \ldots \ldots \ldots \ldots \ldots \ldots \ldots \ldots$

data for coasts $(1727) \ldots \ldots \ldots \ldots . \ldots \ldots 16$

ripples, sediment (1165) ............ 77

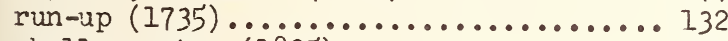

shallow water $(1825) \ldots \ldots \ldots \ldots \ldots \ldots . \ldots \ldots$

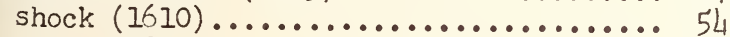

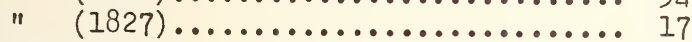

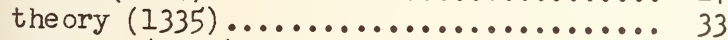

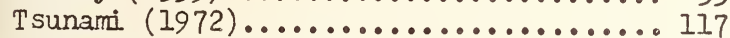

wind generated $(1825) \ldots \ldots \ldots \ldots \ldots \ldots . \ldots \ldots$

ikves, surface

characteristics, observed (560)........ 1.4 contours $(340) \ldots \ldots \ldots \ldots \ldots \ldots . \ldots \ldots . \ldots \ldots$

diffraction $(47) \ldots \ldots \ldots \ldots \ldots . . \ldots \ldots$
Waves, surface

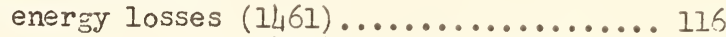

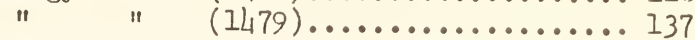

positive, dry channels (U180) ........ 137

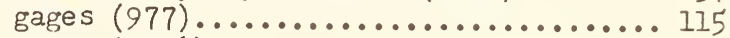

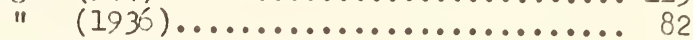

general research $(47) \ldots \ldots \ldots \ldots \ldots \ldots \ldots . . \ldots 10$

generation $(4) \ldots \ldots \ldots \ldots \ldots . \ldots . \ldots . \ldots 63$

$" \quad(35) \ldots \ldots \ldots \ldots \ldots \ldots \ldots \ldots . \ldots \ldots 9 . \ldots \ldots$

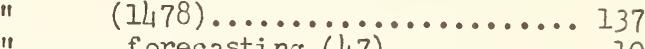

measurement forecasting (47) ......... 10

$(1460) \ldots \ldots \ldots \ldots \ldots \ldots \ldots \ldots \ldots \ldots \ldots$

model laws $(184) \ldots \ldots \ldots \ldots \ldots \ldots \ldots \ldots$

oscillatory $(35) \ldots \ldots \ldots \ldots \ldots \ldots . \ldots \ldots$

" , theory $(47) \ldots \ldots \ldots . . . . . .10$

resistance $(709) \ldots \ldots \ldots \ldots \ldots \ldots . . \ldots \ldots . . \ldots \ldots 157$

shallow water $(35) \ldots \ldots \ldots \ldots . . . . . . . .9$

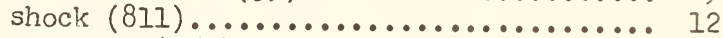

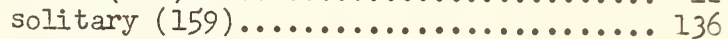

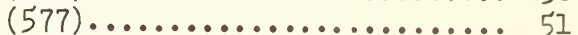

wind-generated $(4) \ldots \ldots \ldots \ldots . \ldots . \ldots . \ldots 63$

Wave tank, design $(399) \ldots \ldots \ldots \ldots \ldots \ldots \ldots$

inells

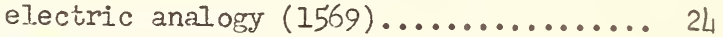
weirs

aerati on demand $(1869) \ldots \ldots \ldots \ldots \ldots$

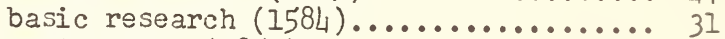

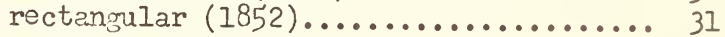

sharp-crested

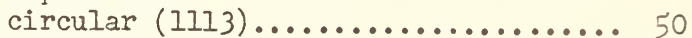

parabolic $(268) \ldots \ldots \ldots \ldots \ldots . \ldots \ldots$

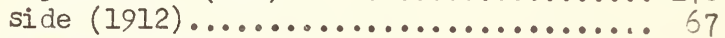

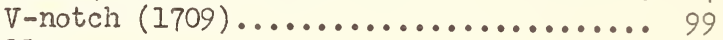

iells

drilling $(24) \ldots . . . \ldots \ldots . . . . . . .6$

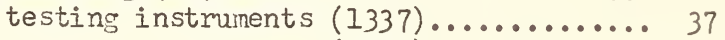

Well screens

(1219) .............. 143

design $(287) \ldots . . . \ldots \ldots . . . . . . . . .20$

turbulence $(557) \ldots \ldots \ldots \ldots \ldots \ldots . \ldots \ldots$ hifind

building forms $(1079) \ldots \ldots \ldots \ldots . \ldots \ldots$

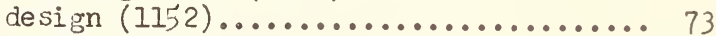

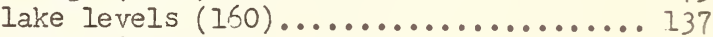

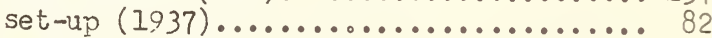

velocity $(1665) \ldots \ldots \ldots \ldots \ldots \ldots \ldots \ldots \ldots$

thind tides

lake $s(1731) \ldots \ldots \ldots \ldots \ldots \ldots \ldots . . \ldots \ldots 19$

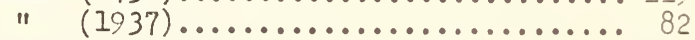

research $(1478) \ldots \ldots \ldots \ldots \ldots \ldots \ldots . \ldots \ldots$ 



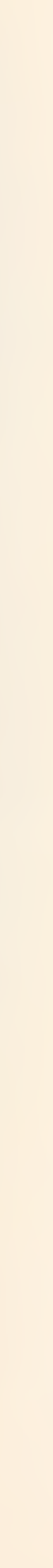



answering a number of questions regarding the adequacy of stack venting of plumbing fixtures for one- and two-story dwellings. Diagrams, tables, and graphs showing the various components of a stack-vented system and provide pressure and trap-seal data.

Order NBS Building Materials and Structures Report 118, Stack Venting of Plumbing Fixtures, 21 pages. Price: 25 cents.

\section{Hydraulic Research in the United States}

Guides to projects conducted by various hydraulic and hydrologic laboratories in the United States and Canada during 1951, 1952, and 1953. Project reports cover work done at 66 private or State laboratories in the United States, 34 Federal laboratories, and five Canadian laboratories. These publications outline individual projects on nearly 200 subjects in the field.

Order:

NBS Miscellaneous Publication 201, Hydraulic Research in the United States, 1951, 190 pages. Price: $\$ 1.25$.

NBS Miscellaneous Publication 205, Hydraulic Research in the United States, 1952, 200 pages. Price: $\$ 1.00$.

NBS Miscellaneous Publication 208, Hydraulic Research in the United States, 1953, 215 pages. Price: $\$ 1.25$.

\section{Correcting for Density and Viscosity of Incompressible Fluids in Float-Type Flowmeters}

Information on the theory of the flow of incompressible fluids through floattype flowmeters developed by the methods of dimensional analysis and experimental verification of the relations thus derived. Procedures are described whereby, after calibration of a metering tube with a few fluids of known physical properties, accurate corrections may be calculated for any fluid whose properties lie within the range embraced by the calibration fluids.

Order NBS Research Paper 2247, Correcting for Density and Viscosity of Incompressible Fluids in Float-Type Flowmeters, 12 pages. Price: 10 cents.

\section{Hydrodynamic Effects of Gales on Lake Erie}

The coefficients of wind stress and sea roughness are derived from research of water levels and wind intensities relating to gales passing over Lake Erie during the past 50 years. Both of these coefficients are found to decrease with increasing wind velocities. A theoretical determination of the wind tides is made and agrees well with the observations.

Order NBS Research Paper 2396, Hydrodynamic Effects of Gales on Lake Erie, 11 pages. Price 15 cents. 
